
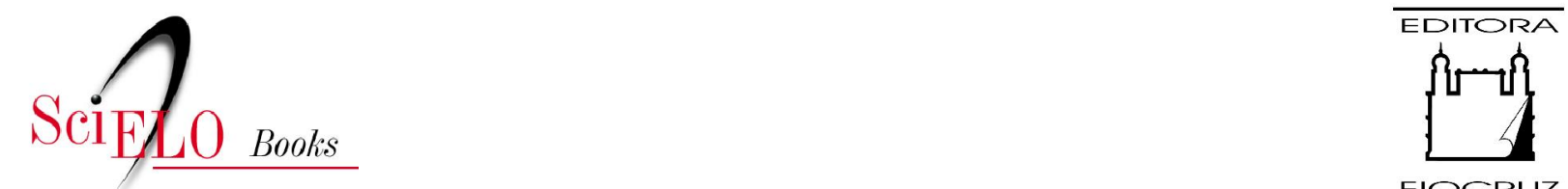

FIOCRUZ

\title{
Análisis estratégico en salud y gestión a través de la escucha
}

\author{
Francisco Javier Uribe Rivera \\ Viviana Martinovich (transl.)
}

\section{SciELO Books / SciELO Livros / SciELO Libros}

RIVERA, FJU. Análisis estratégico en salud y gestión a través de la escucha [online].

MARTINOVICH, V., transl. Rio de Janeiro: Editora FIOCRUZ, 2006, 311 p. ISBN: 978-85-7541542-9. Available from: doi: 10.747/9788575415429. Also available in ePUB from:

http://books.scielo.org/id/gzqf6/epub/rivera-9788575415429.epub.

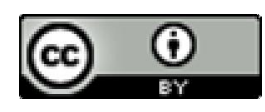

All the contents of this work, except where otherwise noted, is licensed under a Creative Commons Attribution $\underline{4.0 \text { International license. }}$

Todo o conteúdo deste trabalho, exceto quando houver ressalva, é publicado sob a licença Creative Commons Atribição 4.0.

Todo el contenido de esta obra, excepto donde se indique lo contrario, está bajo licencia de la licencia Creative Commons Reconocimento 4.0 . 


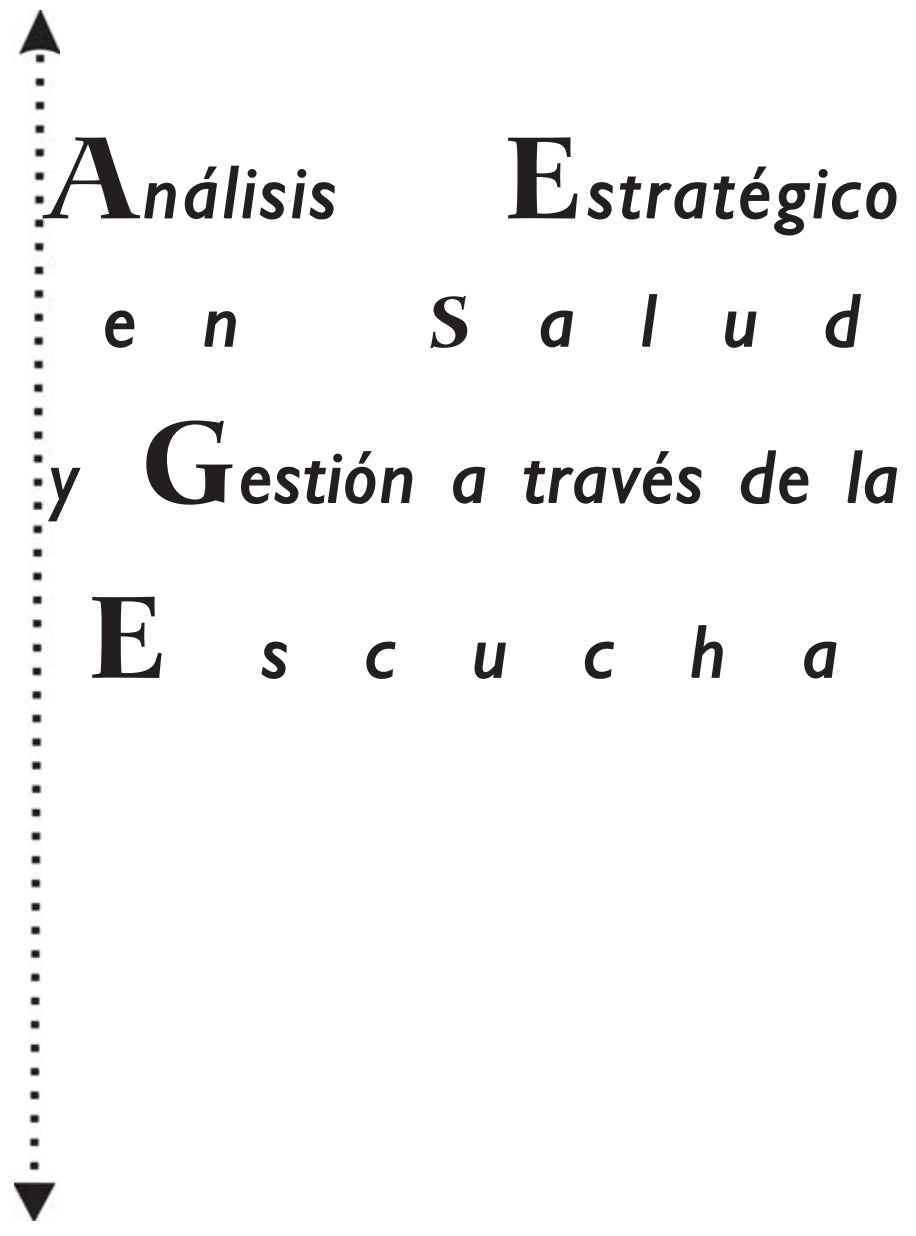




\section{FUNDAÇÃO OSWALDO CRUZ}

Presidente

Paulo Marchiori Buss

Vicepresidente de Enseñanza, Información y Comunicación Maria do Carmo Leal

\section{EDITORA FIOCRUZ}

\section{Directora}

Maria do Carmo Leal

Editor Ejecutivo

João Carlos Canossa Pereira Mendes

Editores Científicos

Nísia Trindade Lima e Ricardo Ventura Santos

Consejo Editorial

Carlos E. A. Coimbra Jr.

Gerson Oliveira Penna

Gilberto Hochman

Lígia Vieira da Silva

Maria Cecília de Souza Minayo

Maria Elizabeth Lopes Moreira

Pedro Lagerblad de Oliveira

Ricardo Lourenço de Oliveira

Comité Consultivo

Carlos Linger

Edmundo Granda

Francisco Javier Mercado

Hugo Mercer

Marcos Cueto

Maria Isabel Rodriguez

Mario Rovere

Oscar Feo

Roberto Brisceño-Leon

Roberto Castro

Saul Franco Agudelo 


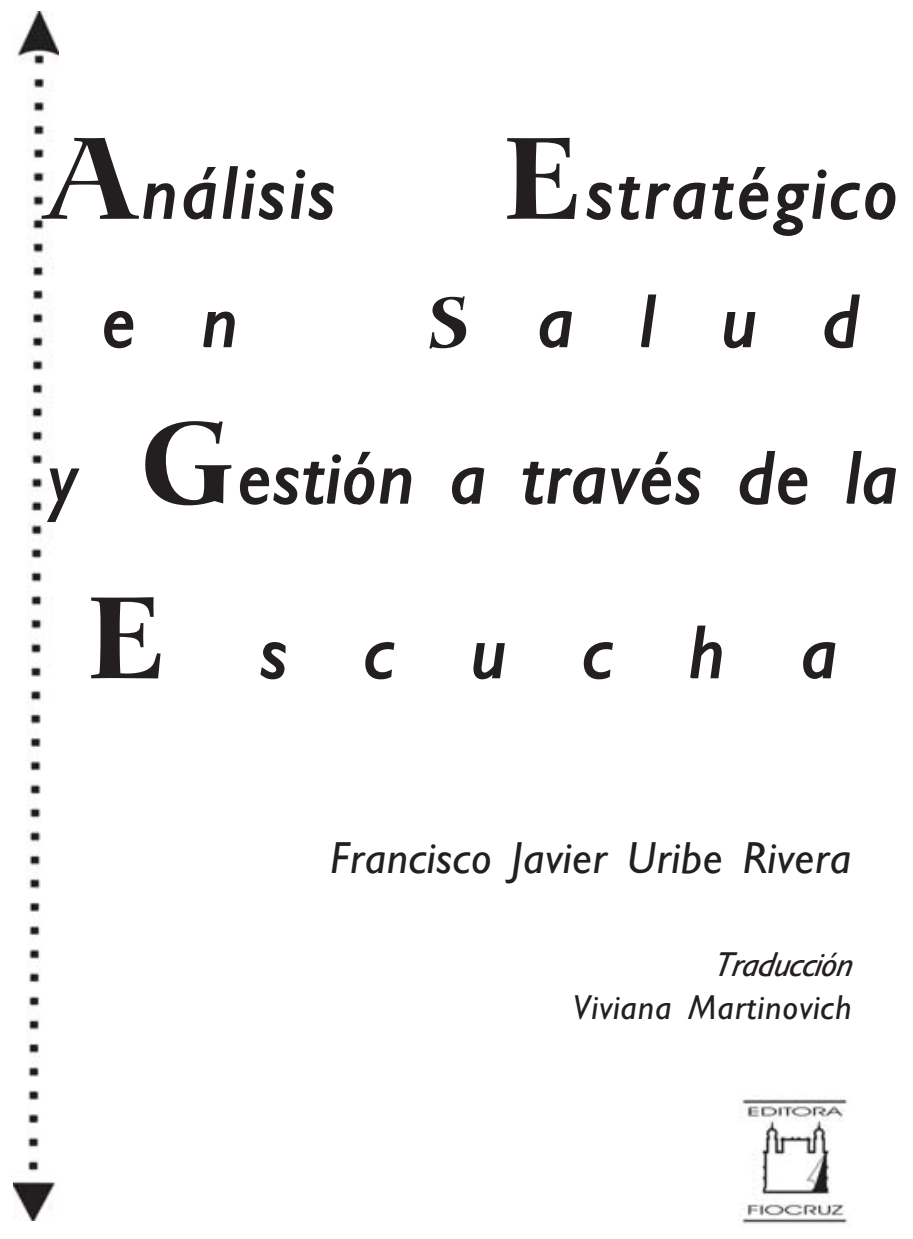


Copyright (C) 2006 del autor

Todos los derechos de esta edición reservados a la

Fundaç̃̃o Oswaldo CRUZ / EdiTora

ISBN: 85-7541-027-X

Portada, Proyecto Gráfico

Carlota Rios y Gordeeff

Daniel Pose Vazquez (versión al espanhol)

Editoración Electrónica

Daniel Pose Varquez,

Traducción

Viviana Martinovich

Revisión

Juan Enrique Ullivarri y Juana Portugal

Catalogación en la fuente

Centro de Informação Científica e Tecnológica

Biblioteca Lincoln de Freitas Filho

U76a Uribe Rivera, Francisco Javier

Análisis estratégico en salud y gestión a través de la escucha./Francisco Javier Uribe Rivera; traducción de Viviana Martinovich. - Rio de Janeiro : Editora Fiocruz, 2006.

310p., tab., graf.

1. Planificación Estratégica. 2. Administración Hospitalar. 3. Planificación en Salud

CDD- 20.ed. - 362.10425

2006

EDITORA FIOCRUZ

Av. Brasil, 4036 - 1o andar - sala 112 - Manguinhos

21040-361 - Rio de Janeiro - RJ

Tels: +55 $213882-9039$ e 3882-9041

Telefax: +55 $213882-9006$

e-mail: editora@fiocruz.br

http://www.fiocruz.br

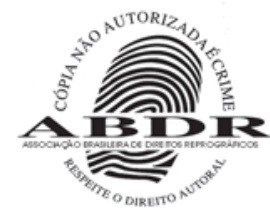




\section{Colaboradores}

Elizabeth Artmann

Asistente social, sanitarista, doctora en Salud Colectiva por la Facudade de Medicina de la Universidade Estadual de Campinas (Unicamp), investigadora adjunta de Salud Pública de la Escola Nacional de Saúde Pública Sergio Arouca de la Fundação Oswaldo Cruz (Ensp/Fiocruz).

\section{Fernando Augusto de Cunha Ramos}

Médico, especialista en Psiquiatría (Ipub/UFRJ), especialista en Gestión Hospitalaria (Ensp/Fiocruz), ex director del Hospital Philippe Pinel (RJ), donde actualmente coordina la Residencia Médica.

\section{Liliane Mendes Penello}

Médica, especialista en Psiquiatría y Psicoterapia Analítica de Grupo, especialista en Gestión Hospitalaria (Ensp/Fiocruz), ex directora del Hospital Philippe Pinel (RJ), trabaja actualmente en el Ministerio de la Salud (Brasil). 



\section{Sumario}

Presentación

I. Planificación y Gestión en Salud: flexibilidad metodológica

y acción comunicativa

Francisco Javier Uribe Rivera

Elizabeth Artmann

2. Análisis Estratégico Hospitalario y Proyecto Asistencial:

la perspectiva de Michel Crémadez y François Grateau

Francisco Javier Uribe Rivera

Elizabeth Artmann

3. Aplicación de la Démarche Stratégique al Hospital Philippe Pinel: pensando en red

Fernando Augusto de Cunha Ramos

Liliane Mendes Penello

Francisco Javier Uribe Rivera

4. Análisis Estratégico y Prospectiva en Salud: el enfoque de Godet y simulaciones de escenarios para el Programa de Salud Familiar (PSF)

Francisco Javier Uribe Rivera

5. Cultura y Liderazgo Comunicativo

Francisco Javier Uribe Rivera

6. Comunicación y Negociación Gerencial

Francisco Javier Uribe Rivera

7. (Inter)subjetividad, Aprendizaje Organizacional y Cambio:

algunas herramientas lúdico-pragmáticas

Francisco Javier Uribe Rivera 



\section{Presentación}

Este libro reúne una serie de trabajos, cuyo hilo conductor representa una propuesta teórico metodológica de gestión, que se traduce en el título: Análisis Estratégico en Salud y Gestión a través de la Escucha. Estos estudios adquieren coherencia con relación al pasado o por oposición al pasado. Representan un desdoblamiento de nuestra tesis de doctorado en Salud Pública, defendida en 1991 en la Escuela Nacional de Salud Pública de la Fundación Oswaldo Cruz (Ensp/Fiocruz), la cual consistió en un contrapunto teórico metodológico entre la Teoría de la Acción Comunicativa de Habermas y la Teoría de la Planificación Estratégica en Salud. En aquel momento, nos motivó el propósito de (des)construir el enfoque de planificación estratégica, a través de un análisis crítico sistemático, fundamentado en la idea de la planificación como una relación interactiva dialógica, superadora de la lógica de la utilidad individual y de la reificación de los otros actores. Sin embargo esa crítica no tuvo como objetivo la negación radical de los métodos conocidos de planificación estratégica, especialmente del enfoque situacional de Matus, sino que fue una ampliación de la perspectiva, en dirección a una mayor flexibilidad metodológica, rescatando la planificación al servicio de la creación de un ambiente de comunicación amplio, de la búsqueda de legitimidad y del consenso en la construcción de las propuestas pertinentes.

Aquella tesis tuvo una intención eminentemente teórica de reflexionar, al interior del campo de la planificación y de la gestión, un nuevo paradigma: el comunicativo. A partir de entonces, conscientes de que la crítica teórica es necesaria, aunque insuficiente en un campo pragmático, surge el propósito de realizar un trabajo propositivo que implique dar un contenido práctico a una propuesta de acción comunicativa en gestión y planificación. Tal propósito no ha sido fácil de realizar, ya que sobreentiende el establecimiento de mediaciones, de puentes, entre el nivel más epistemológico de la gran teoría y la especificidad del terreno de la gerencia. Este esfuerzo implica la búsqueda de autores y de enfoques del campo respectivo, que puedan ser utilizados como factores de articula- 
ción y ser identificados como exponentes de la gestión, como intersubjetividad discursiva y como proceso de desarrollo del aprendizaje, de la solidaridad y de nexos o redes creativas. Esto quiere decir, que no es posible deducir mecánicamente o linealmente de la Acción Comunicativa, una propuesta práctica. Esta solo se configura como una diversidad pragmática de enfoques que pueden ser aproximados a los presupuestos generales de ese paradigma comunicativo.

La docencia sistemática en la posgraduación de la Ensp nos aportó una disciplina de investigación y reflexión que nos permitió tomar autores y enfoques, los cuales pudimos aglutinar dentro de nuestro referencial. Algunos de estos autores y enfoques fueron testados o experimentados junto a los alumnos de esa casa de estudios y son algunas de esas experiencias las que queremos mostrar en este libro. Estos alumnos fueron la condición de posibilidad de algunos capítulos. Pueden ser llamados casi como coautores, en algunos momentos, y les agradecemos. El trabajo de investigación, articulado a la docencia, es lento, acumulativo y demanda tiempo. Es un intento constante por disipar los trazos de oscuridad, inherentes a la experimentación con ideas, en busca de más luminosidad. Esto, sumado a los vaivenes de la vida, explica el lapso de tiempo transcurrido hasta mostrar los resultados de este trabajo en esta publicación y el porqué no alcanzamos completamente nuestro propósito. Vale decir que el trabajo de investigación con ideas es permanente y continuo.

Los autores que fuimos consolidando en ese proceso relativamente sistemático, a veces intuitivo, de aprehensión de las identificaciones discursivas, son principalmente cuatro: Matus, Crémadez, Godet y Senge.

Carlos Matus, gran ideólogo de la planificación latinoamericana, fallecido hace poco tiempo, nos enseñó el arte de pensar más pragmáticamente la planificación, como gerencia descentralizada de problemas abordados creativa e interactivamente, como así también las reglas de cómo pensar estratégicamente una organización. Es el autor que mejor pudimos abarcar y conocer, y el que debe haber dejado más marcas en nuestro imaginario más profundo. No es él, el tema principal de este libro, pero sí le dedicamos las primeras líneas, en el primer capítulo, pues es a partir de las lagunas/posibilidades que identificamos en él, iluminados por la Acción Comunicativa de Habermas, que desarrollamos la investigación de otros autores y perspectivas que pudiesen complementar su abordaje cubriendo los vacíos y posibilidades de comunicación. Su vasta producción es más que suficiente, y nos lleva naturalmente a la búsqueda de nuevos autores que amplíen el perfil de su obra, como parte de nuestro trabajo de investigación. Debemos resaltar que el legado de Matus es un patrimonio inexorable en esta área que es nuestro campo de reflexión y de práctica.

Michel Crémadez, integrante de un equipo francés de gestión estratégica (de Altos Estudios Comerciales), es el segundo autor que conocemos con rela- 
tiva profundidad. A su obra teórico práctica y a sus proliferaciones, dedicamos una parte significativa del libro (dos capítulos). Crémadez, junto con François Grateau (ex director del Centro Hospitalario Regional Universitario de Lille (CHRU), son los responsables del desarrollo de la démarche stratégique en salud, dentro del área hospitalaria. Este enfoque fue traído por nosotros del CHRU de Lille, luego de una pasantía que realizamos como parte de una política de colaboración entre la Ensp/Fiocruz, brasileña, y la Ensp francesa.

El CHRU es un holding hospitalario, de naturaleza pública, que actúa como referencia para todo el norte de Francia y parte de Bélgica. Este enfoque fue adaptado por nosotros a la realidad brasileña, respetando el rigor de los principios y de la metodología originales, y aplicado en varios hospitales públicos de Brasil.

Existen algunas diferencias entre la realidad francesa y la brasileña. En Francia, el sector público forma parte del sistema hospitalario, no así del sistema ambulatorio. En Brasil, el sistema ambulatorio es predominantemente público y en el área hospitalaria existe un predominio del sector privado, aunque el sector público tenga un papel destacado sobretodo en lo que respecta a la alta complejidad y, por otro lado, parte importante del sector privado se encuentra regulado por el sector público, atendiendo la clientela del Sistema Único de Salud, y siendo financiado parcialmente con recursos públicos.

La diferencia más significativa de las realidades de ambos países, es el hecho de que en Francia, existe una oferta hospitalaria más saturada, configurando situaciones más claras de competencia, entendida como sobreposición de actividades y ausencia de coordinación (que se traducen en disputas de recursos y/ o de clientela). En ese contexto, la aplicación de la démarche es claramente más justificable o necesaria. En Brasil, habría menos recursos relativos y en algunos espacios geográficos (no los grandes centros urbanos densamente poblados) identificamos situaciones de monopolio o de pocas estructuras hospitalarias, sin competencia. Estas situaciones dificultarían la aplicación de la démarche como método de coordinación o de regulación de la competencia. Sin embargo, no la invalidan completamente. Simular la competencia en estos casos, es el consejo que se da para aplicar la démarche como perspectiva de análisis que apunta a mejorar los niveles de calidad preexistentes.

Otro elemento del contexto que favorecería la aplicación del enfoque en Francia corresponde a la obligatoriedad normativa de que los hospitales formulen proyectos institucionales para negociar entre sí, regulados bajo la perspectiva de la regionalización (de las agencias regionales de hospitalización creadas a fines de la década del 90 e inicio del año 2000). Sin embargo, el avance recientemente experimentado por Brasil en el diseño de una política de regionalización, que compense los problemas derivados de la municipalización radical 
de la década del '90 (Norma Operacional de Asistencia a la Salud Noas-SUS 01/02. Decreto MS/GM no 373, de 27/01/2002.Brasilia-DF), crea condiciones para la instauración de una lógica de formulación de proyectos como parte del proceso de negociación de redes micro y macro regionales.

Podemos señalar, que a partir de nuestra experiencia de aplicación del enfoque en Brasil, avanzamos significativamente en el dominio del mismo, justamente porque se transformó en una realidad práctica, fomentando nuevos trabajos también académicos.

En este libro, extraemos y presentamos lo que nos parece fundamental de la obra de los autores, haciendo nuestro propio análisis y comentarios. Anexamos un caso elaborado con alumnos del curso de Gestión Hospitalaria de la Ensp, a partir de un ejercicio didáctico de aplicación de la metodología a un hospital de Río de Janeiro; Hospital Philippe Pinel, y la guía de aplicación de esta forma de análisis estratégico. Lo comunicativo de esta propuesta, es su objetivo de transformar situaciones de competencia en colaboración, de generar proyectos integrados y solidarios por servicio que compensen la diferenciación, el postulado organizacional de redes de exploración de transversalidades internas y externas a los hospitales, y a su implementación participativa y dialógica, de abajo hacia arriba, como espacio de comunicación permanente. Es esencial al enfoque, la observación de algunas características culturales de las organizaciones profesionales, como la gran autonomía operacional de los centros asistenciales. Tomando en cuenta la escucha de ese padrón cultural, el enfoque busca el mayor compromiso de los actores de base y la creación de eslabones de unión entre lo estratégico y lo operacional, a través de una comunicación intensiva entre la dirección y los profesionales.

A continuación, el otro autor que perfilamos en el libro es Michel Godet, francés, uno de los autores que trabaja con análisis prospectiva de mayor renombre internacional. La prospectiva y la construcción de escenarios configuran una de las dimensiones más desestructuradas de la Gestión y un campo aún sin ser muy explorado. Esta naturaleza de la Prospectiva no es motivo para evitar el tema. No es posible la gestión y la planificación sin una visión del futuro, de los escenarios futuros. Esta necesidad inexorable define una de las características que diferencian la planificación estratégica de la normativa, como aprendimos con Matus.

La metodología de Godet llama la atención y se impone por su grado de formalización interna y por el hecho de aliar una lógica de análisis cualitativo de los actores sociales con una lógica más matemática de probabilidades de tendencias a partir de un sistema de consulta amplia a especialistas. Este enfoque no es nuevo. Aunque, es permanentemente nuevo el desafío de aplicarlo creativamente con las adaptaciones necesarias al área de salud. Nuestro obje- 
tivo es presentarlo con ese espíritu de innovación y de incremento de alternativas instrumentales.

De este modo, el protocolo de trabajo del autor será objeto de un capítulo particular de acuerdo con nuestra lectura del mismo y contrapuesto a las visiones más cualitativas y simplificadas de técnicas de escenarios. Varios casos trabajados con alumnos en el ámbito del Programa de Salud de la Familia (PSF) serán introducidos con la intención práctica de posibilitar la apropiación de su lógica. El aspecto comunicativo en esta visión de la prospectiva está representado por la intención práctica de reducir la subjetividad inmanente a la lectura del futuro, a través de las numerosas consultas a especialistas y de la exploración de la posibilidad del consenso entre ellos, aunque entre ellos no se establezca una relación dialógica directa. Comunicativo es el espíritu del taller de trabajo participativo de pares y de actores externos, tejiendo acuerdos sobre lo que será esencial en el futuro y sobre sus implicaciones prácticas para el trazado de la acción presente. Comunicativo es el uso que de acuerdo con Senge puede hacerse de la narrativa del futuro como medio de sacar a la superficie los modelos mentales de los actores involucrados en esa narrativa y el diálogo que se puede establecer sobre esos modelos particulares, apuntando a alinear la visión a través de la reflexión crítica de esos materiales.

Peter Senge es el autor que conocimos más recientemente. Nos aportó además el don de la simplicidad. Representando la corriente americana e internacional de la learning organization, este autor nos trae una importante metáfora: la del entendimiento de la organización como una sociedad o intersubjetividad en proceso permanente de aprendizaje. Como sistema que aprende, la organización dependería, para tener éxito, del desarrollo por parte de sus miembros, de las habilidades de reflexión, de interacción, de indagación y de argumentación necesarias para la transferencia de símbolos y capacidades inherentes al mismo aprendizaje. Esta corriente está directamente vinculada a la visión de la organización como proceso lingüístico y de comunicación.

Nuestro objetivo es establecer nexos entre intersubjetividad y gestión desde la perspectiva del aprendizaje y presentar instrumentos y propuestas de aprendizaje organizacional que potencialicen cambios. Esta corriente incorpora temáticas que son más características de una forma de gerenciar, que supone una auscultación cultural permanente y el ejercicio de un liderazgo comunicativo, de apoyo sistemático a la capacidad colectiva de aprendizaje. Está muy cercana a las temáticas que constituyen el objeto de los últimos tres capítulos sobre gestión a través de la escucha: cultura, liderazgo comunicativo y negociación.

El telón de fondo es el concepto de liderazgo como posibilidad intersubjetiva de desarrollo del consenso necesario a la actividad productiva de una organización y a la producción de los cambios que se tornan necesarios. De los autores que 
trabajan el concepto de liderazgo (algunos presentados aquí, especialmente en los capítulos cinco y siete), tomamos la idea básica de que las principales habilidades del mismo, son la visión estratégica que se articula a la capacidad de reflexionar sobre el futuro y a la capacidad de mediar colectivos y subjetividades.

El título del libro, Análisis Estratégico en Salud y Gestión a través de la Escucha, expresa el deseo de ofrecer materiales de análisis y de utilidad práctica que puedan ayudar a incentivar el desarrollo del liderazgo individual y colectivo. Esta publicación representa, a través de su propuesta, el intento de presentar una referencia más para el entrenamiento de habilidades típicas del liderazgo. La gestión a través de la escucha acentúa la necesidad de un liderazgo que se desarrolle a partir de una escucha de la cultura, de un aumento de la capacidad de negociación cooperativa y de un poder de comunicación al servicio, preferentemente, del crecimiento colectivo.

En el primer capítulo, en coautoría con Elizabeth Artmann, actualizamos nuestro muestreo de tendencias en este campo y de los desafíos en términos de investigación para complementar el referencial de la planificación estratégica situacional, de manera a construir un substrato práctico para la gestión comunicativa. Esta discusión es una actualización de un artículo ya publicado en 1999, en la Revista Ciência e Saúde Coletiva, de la Asociación Brasileña de Posgraduación en Salud Colectiva (Abrasco).

El segundo capítulo, también en coautoría con Elizabeth Artmann, presenta la propuesta teórico metodológica de Michel Crémadez, la cual sobresale por el esfuerzo de transformación de una lógica de la planificación estratégica corporativa, en un sistema de gestión estratégica para hospitales del sector público y privado, que contribuya para una evaluación sistemática de la misión en función de una perspectiva que privilegia los usuarios del sistema y la conformación de redes.

El capítulo tres representa el resultado de un ejercicio de aplicación del enfoque del análisis estratégico hospitalario francés, al Hospital Philippe Pinel, cuyo autor principal fue el entonces director del hospital y alumno de la Ensp, Fernando Augusto da Cunha Ramos, del Curso de Gestión Hospitalaria (1997)

En el cuarto capítulo presentamos, discutimos, y aplicamos el modelo de análisis de Godet, y otras aproximaciones al tema de los escenarios de cálculo prospectivo.

Los capítulos cinco, seis y siete representan un conjunto de textos de nuestra autoría cuyo hilo conductor es la gestión a través de la escucha, donde destacamos en cada uno de ellos cuestiones específicas pertinentes al tema.

En el primero de ellos, en el capítulo cinco, presentamos varios enfoques de análisis cultural, incluyendo una discusión sobre la perspectiva de cambio 
cultural, y de análisis del concepto de liderazgo, privilegiando una concepción comunicativa del mismo, que se articula a la posibilidad de cambio cultural.

El sexto capítulo representa un enfoque general de negociación cooperativa -consagrado por autores como Fischer y Ury de la escuela de Negociación de Harvard- donde destacamos la necesidad de la utilización de herramientas de comunicación provenientes de ámbitos variados, como la propia psicología.

En el capítulo siete: (Inter)subjetividad, aprendizaje organizacional y cambio: algunas herramientas lúdico pragmáticas, presentamos las principales corrientes de la metáfora de la organización que aprende, herramientas e instrumentos de trabajo al servicio del desarrollo de un liderazgo comunicativo y del cambio.

Como anexo, presentamos la guía para el análisis estratégico del perfil asistencial de las especialidades médicas, constituida por las matrices, referentes a las diferentes etapas de los respectivos enfoques, los criterios de análisis estratégico, explicitados con las preguntas necesarias para la evaluación de los mismos, y toda la orientación para formular una estrategia y un plan de acción.

Este es un trabajo colectivo. No hay producción a partir de cero. Los principales autores que trabajamos están presentes en el libro y este se propone reunir sus variadas subculturas dentro del universo cultural mayor definido por el alcance del título. La dinámica de la posgraduación de la Ensp y sus múltiples actores también está presente. Traemos la contribución de ex alumnos, especialmente el grupo de Salud Mental del Curso de Gestión Hospitalaria de 1997, coautor del capítulo tres, y de los alumnos de varios grupos de la disciplina de Planificación y Gestión en Salud de la Maestría de Salud Pública de la Ensp, que nos ayudaron a construir los escenarios para el PSF.

Por último, esperamos sinceramente que este libro sea de utilidad para el lector y contribuya a la enseñanza de la gestión en salud y para la gerencia organizacional. 



\title{
Planificación y gestión en salud: flexibilidad metodológica y acción comunicativa
}

\author{
Francisco Javier Uribe Rivera \\ Elizabeth Artmann
}

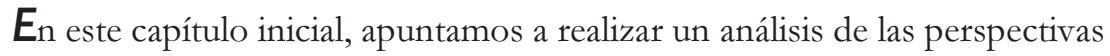
teórico-metodológicas de la planificación/gestión en salud en Brasil. Para tal fin, nos vemos obligados a asumir una perspectiva situacional y a rescatar del conjunto de nuestras reflexiones y lecturas, un hilo conductor: el de las posibilidades de la planificación estratégica, según nuestra matriz cultural, en la constitución de organizaciones solidarias. El término comunicante atribuido a esas organizaciones es tomado de Bartolli (1992) apud Rivera (1996a) y corresponde a organizaciones abiertas, evolutivas, flexibles, con una finalidad explícita y responsabilizante para todos.

En el desarrollo de este discurso, identificamos los aspectos productivos de la propuesta de la planificación estratégica situacional y sus vacíos conceptuales y metodológicos, procurando señalar posibles áreas de complementación, que podrían ser motivo de investigación y de aplicación, con la intención de abrir camino hacia una propuesta más amplia y comunicacional del objeto aludido. De esta manera, intentamos darle un sentido más práctico a la alternativa de la planificación comunicativa, rescatada de una crítica al modelo puramente estratégico. (Artmann, 1993; Rivera, 1995).

En el transcurso del trabajo, procuramos también hacer un muestreo de tendencias en el área de planificación y gestión a nivel nacional e internacional. No tenemos la intención de hacer un análisis profundo sobre estas tendencias, sino hacer algunos comentarios que puedan llevar a cuestionamientos delimitadores de objetos de investigación.

Debe quedar claro a lo largo del trabajo, que situamos la planificación como momento de elaboración- al interior del proceso de gerenciamiento/ gestión de servicios y sistemas. La planificación, de este modo, es entendida como herramienta organizacional, formando parte de un proceso más amplio 
de desarrollo de las organizaciones, que valoriza la conducción de la acción. Las propias posibilidades de la planificación son interpretadas aquí como mediadas/subordinadas a la cultura de las organizaciones.

\section{La Planificación Situacional como Posibilidad Instituyente de una Organización Comunicante}

La planificación fracasa en su intento original de obtención de una regulación global, imperativa, de la sociedad. Como alternativa a la economía de mercado, la planificación realizada por los países socialistas no dejó de ser el modelo de regulación de un actor único, de un actor tecnocrático, que subordinó las relaciones intersubjetivas a una visión de desarrollo basada en el determinismo económico.

Los modelos de planificación global de los que se apropia el sector salud, como el Cendes/OPS, padecen el mismo problema: la incapacidad de totalización desde una perspectiva central de actores e instituciones dispares, con racionalidades distintas. Existe una incapacidad del Estado de representar la diversidad mediante actos formuladores que substituyan la negociación política.

La planificación estratégica en salud surge, a mediados de la década del 70, como la tentativa de reconocimiento de la complejidad, al introducir las ideas de la superioridad de lo político sobre lo económico y de la diversidad de actores-sujetos del acto de planificar. La cuestión de la viabilidad política pasa a ocupar un papel central y la definición de propuestas/compromisos de acción, a depender de una articulación que se abre a una perspectiva policéntrica de análisis.

Tal vez, el gran mérito de la planificación estratégica haya sido sacar a la luz la necesidad del diálogo. Hablar de planificación comunicativa corresponde a una interpretación de la planificación estratégica matusiana, como la posibilidad de una problematización colectiva, capaz de articular sujetos sociales, como la posibilidad de incorporación de una racionalidad sobre la gobernabilidad de situaciones de división y dispersión del poder que enfatiza la negociación política.

Aunque la planificación estratégica no haya planteado con transparencia esa perspectiva -su abordaje del poder como relación entre acumulaciones de recursos movilizados en función del éxito de actores individuales, oculta esa visión-, encontramos aspectos que permiten una interpretación comunicativa. El reconocimiento del acto de planificar como relación interactiva, la adopción de la negociación cooperativa como medio estratégico posible, la valorización de la explicación del otro como parámetro de crítica de la nuestra y posible com- 
plemento y, finalmente, la importancia concedida a la cultura en la elaboración de las reglas institucionales, son elementos que abren camino para una interpretación menos encerrada a una racionalidad puramente de fines.

Se asume la planificación comunicativa, como medio de construcción de organizaciones dialógicas. Un aspecto fundamental de este enfoque es la búsqueda de la integración, de la posibilidad de un proyecto solidario, entendido como desafío gerencial permanente. En esta perspectiva, la elección de los métodos de elaboración o de análisis se subordina a ese objetivo propio del campo de la gestión. Se pueden utilizar varios métodos que crean la posibilidad de flujos de comunicación ampliada y de negociación de compromisos. No existe, por lo tanto, la pretensión de una exclusividad metodológica. El propio método debe confrontarse con la diversidad.

Es importante resaltar que la perspectiva comunicativa, no se reduce a la elección de métodos, sino que abarca el proceso gerencial como un todo, a partir de una racionalidad ampliada, más allá de la racionalidad de fines, considerando el mundo de la vida de los actores involucrados en una postura dialógica que motive la construcción de proyectos que puedan ser asumidos colectivamente como compromisos.

Ayudar a desarrollar una dinámica de dirección que potencialice el diálogo generador de compromisos es, entonces, el hilo conductor de una nueva comprensión de la planificación que no consigue divorciarse más de la gestión. Matus (1994a) entendió muy bien, que la viabilidad del modelo racional de la planificación defendido por él, dependía de determinadas características de las reglas organizacionales, especialmente de las reglas de responsabilidad que sobredeterminarían la calidad de la gestión.

El triángulo de hierro de la Planificación Estratégica Situacional (PES) (Matus, 1994a) es una buena figura que puede ayudar a delimitar los contornos de una organización comunicante o dialógica. Los tres vértices representan los principales subsistemas del sistema de dirección estratégica: la Agenda del Dirigente, que exige concentración en lo que es estratégico, la Gerencia por Operaciones y el sistema de Petición y Rendición de Cuentas. El autor defiende que la baja responsabilidad genera una tendencia en el sentido de la centralización y de la ingobernabilidad. La falta de rendición de cuentas lleva al dirigente a no organizar su agenda priorizando problemas de alto valor relativo. De esta manera, acumula todo tipo de problemas, no delega, generando en consecuencia la ingobernabilidad (falta de poder y autonomía en la toma de decisiones).

Idealmente, se defiende como objetivo la construcción de una organización donde la rendición de cuentas por resultados sea una norma interiorizada culturalmente por los individuos, donde haya desconcentración del poder y delegación permanente (una sabia distribución del poder de procesamiento de 
problemas) y donde predomine un tipo de gestión creativa por operaciones o por objetivos.

Para el autor, la responsabilidad supone una demanda de planificación creativa como un estímulo a la descentralización. Es importante destacar que Matus, junto con Trosa (2001), entiende la responsabilidad vinculada a la posibilidad de control de los procesos de producción técnica y organizativa por parte de quien se ubica como objeto de control. Estos dos autores desmitifican una determinada crítica radical a la gestión por objetivos, de negación de la planificación, al afirmar que, sin objetivos libremente planificados en ambientes comunicativos, no es posible desarrollar la responsabilidad individual. Su importancia puede ser dimensionada en los marcos de los procesos de reforma del sector público, como una postulación del principio de que la responsabilidad, aunque presuponga la descentralización, actúa como freno a una descentralización exagerada, sin controles, generadora de desigualdades y de una mayor fragmentación. Esto se aplica a la crítica hecha al proceso de descentralización del Sistema Único de Salud (SUS) de Brasil, de municipalización autárquica, típica de los años 90, por la propuesta de la Noas (Brasil, 2002), en donde se reivindica más equidad e integralidad. $\mathrm{Al}$ respecto, vale la pena recordar, el énfasis puesto por Matus (1994a; 1994b) en la combinación inteligente entre centralización y descentralización.

Matus plantea que, con la introducción de nuevas prácticas gerenciales será posible viabilizar una alta calidad de gestión. Estas nuevas prácticas gerenciales se confunden con la propuesta de su sistema de dirección estratégica, que además de contar con los subsistemas anteriormente señalados, debe ser apoyada por otros como la planificación estratégica, el sistema de informaciones, etc. La recomendación explícita es, que esa construcción siga el modelo de una reforma organizativa vertical, en el sentido de una reforma radical y selectiva de forma simultánea en todos los sistemas relevantes de la organización, dada la mutua dependencia de todos los subsistemas, en donde cada uno genera demandas hacia los otros.

La sobredeterminación que las reglas de responsabilidad ejercerían sobre toda la dinámica de gestión, refuerza la importancia de la cultura como conjunto de estructuras mentales que subordinarían todas las prácticas de trabajo y las formas organizativas derivadas. La necesidad de impactar ese baluarte definidor de las virtualidades gerenciales, pone la atención en la prioridad de los componentes Teoría y Entrenamiento en cualquier proceso de cambio organizacional. De este modo, el primer paso de una estrategia de reforma administrativa estaría representado, en el modelo matusiano, por el desarrollo de un centro de entrenamiento con el objetivo de promover nuevas prácticas gerenciales y de trabajo. 
Sutilmente, el voluntarismo racionalista de Matus, encuentra un límite en las posibilidades de lidiar con cultura. Aunque reconozca la supremacía de la cultura en relación a los procesos de trabajo, el autor no profundiza su análisis en búsqueda de una propuesta de intervención más eficaz. La cultura impone un elemento de moderación que dificulta el establecimiento de plazos para el cambio organizacional, que se alimenta de la indeterminación del proceso de cambio cultural (Rivera, 1996a; 1998a; Artmann, 1997).

No cuestionamos la propuesta de entrenamiento y la teoría en sí, sino que debemos relativizar su impacto cuando se presenta como medida aislada de actuación sobre estructuras mentales. Para alcanzar ese objetivo, el desarrollo de prácticas educativas permanentes debería ser acompañado de cambios en el sistema de gerencia. El propio Matus señala, que el cambio de las prácticas de trabajo, subordinadas a las estructuras mentales, depende de la introducción de nuevos métodos y sistemas debidamente fundamentados en el entrenamiento. Aunque admita una relación casi lineal de la cultura con las prácticas de trabajo y de estas hacia las formas organizativas, el autor señala la existencia de relaciones inversas, más débiles a corto plazo, pero factibles de tornarse muy fuertes en un mayor período de tiempo (Matus, 1997). Dentro de esta perspectiva, la introducción de nuevas racionalidades gerenciales puede impactar en la cultura a largo plazo. Básicamente, pensamos en la introducción de un sistema de gestión creativa que priorice formas de toma de decisiones y de control colectivas, consensuadas, capaces de estimular la comunicación. La única posibilidad de cambiar la cultura a largo plazo, reside en la capacidad de construcción legitimada de nuevas representaciones que los actores pueden tener en función de su participación en procesos comunicativos de aprendizaje. De cualquier manera, la cultura tendrá que ser considerada como elemento de viabilidad o de modulación de la propuesta de cambio organizacional. En las organizaciones de tipo profesional, según la clasificación de Mintzberg (1989), como es el caso de las organizaciones de salud, no se justifica la introducción de un sistema pesado de gestión estratégica, del tipo superestructural, sino un conjunto de prácticas, que de un modo más informal, contengan la filosofía de la intensificación del espíritu de la gestión por compromisos. La fuerte autonomía profesional en esas organizaciones, como dato cultural, sugiere reforzar el objetivo de ayudar a los profesionales a internalizar el raciocinio estratégico, como parte de un proceso cotidiano de decisión, como alternativa a pesados procesos de formalización de planes realizados en instancias separadas de los centros operadores, de corte tecnoburocrático.

En este sentido, hemos destacado la necesidad de valorización de la reflexión realizada por autores del área de salud pública (Dussault, 1992; Lima, 1994) acerca de los requisitos, en términos de modelo de gestión, planteados a 
través de la observación de las características de las organizaciones profesionales de salud. La complejidad del trabajo en esas organizaciones, la imposibilidad relativa a una padronización mecanicista y la gran distribución del poder, sugieren, junto con otras características, un modelo de gestión negociado, comunicativo, de adaptación mutua. Esto refuerza nuestra perspectiva de organización comunicante.

En esta perspectiva de la organización comunicante, el desarrollo de nuevas racionalidades gerenciales como desafío cultural, supone el ejercicio de un liderazgo para el aprendizaje, y de procesos complejos de establecimiento de redes interactivas de naturaleza dialógica e instrumental.

De Matus (1993) rescatamos principalmente los siguientes elementos: la idea de un sistema de gestión descentralizada por operaciones; el análisis de problemas y de soluciones; como también aspectos del análisis de viabilidad y del diseño estratégico.

Es inherente a un sistema de gestión descentralizada, la definición de objetivos a partir de problemas planteados dentro y fuera de la organización (o macroorganización). La capacidad de procesamiento de estos problemas, entendidos como necesidades declaradas o demandas, define la calidad de la oferta institucional. El arte de gerenciar consiste, para Matus (1994a), en saber distribuir bien los problemas en la organización, de modo que todos los niveles estén siempre lidiando de forma creativa con problemas de alto valor relativo. El modelo organizacional propuesto por este autor es el de una organización reflexiva en todos los niveles, como condición de gobernabilidad.

El carácter totalizador y riguroso de la explicación situacional, facilita la elección de operaciones de carácter transversal u horizontal, que transcienden sectores, departamentos y unidades y, de este modo, la planificación situacional favorece la integración horizontal, bajo la forma de una estructura matricial por proyectos. La horizontalización puede ser entendida aquí, como sinónimo de descentralización y de creatividad, de tratamiento multidisciplinario.

Existe en la PES, un apelo claro en el sentido de la coordinación lateral, como alternativa a un tipo de estructura típicamente jerárquica. Este elemento característico de estructuras descentralizadas y participativas ha sido destacado por el Laboratorio de Planificación del Departamento de Salud Colectiva (Lapa) de la Universidad Estatal de Campinas (Unicamp) como parte de un modelo que pone énfasis en la autonomía de las unidades de producción y la necesidad de órganos de gestión que democraticen la toma de decisiones. En relación a las organizaciones profesionales de salud, defendemos la tesis de equipos de gestión con representantes de las principales profesiones.

La complejidad de la PES, ha sido suavizada a través de propuestas y adaptaciones del método (Artmann, 1993; Cecílio, 1997) que conservan ciertos 
aspectos como la necesidad de una buena descripción del problema como base para una explicación eficaz; la diagramación de las relaciones de causalidad bajo la forma de una red o árbol simple de causalidad; la definición de nudos críticos en base al protocolo ad hoc de la PES y su descripción, con el objeto de colaborar en la definición de un contenido más preciso de las propuestas de intervención (operaciones), vistas como macrounidades de acción que inciden sobre nudos críticos; la definición a través de la operación de la relación recursos/ productos/resultados; un análisis de viabilidad simplificada basada en la motivación de los actores en relación a las operaciones y en la definición de quien controla predominantemente los recursos involucrados en las operaciones; y, finalmente, la necesidad de relacionar genéricamente estrategias de viabilización y construir indicadores de seguimiento del plan.

La adaptación y simplificación del enfoque de la PES ha colaborado a evitar una centralización obsesiva en cuestiones metodológicas, reforzando la idea de que el método es un simple medio al servicio de sujetos.

Algunos problemas o deficiencias del método de la PES ya fueron señalados por nosotros en algunos trabajos. El primero es la inexistencia de una reflexión más profunda sobre cultura como componente de la viabilidad de una intervención planificada; (Artmann, 1993; 1997; Rivera, 1995; 1996a). El segundo problema es la necesidad de un desarrollo específico de la tecnología de negociación cooperativa (Rivera, 1998b)

Una determinada visión de liderazgo que destaca la necesidad de un Estado mayor constituido por el desarrollo de superestructuras de gestión, en detrimento del perfeccionamiento de habilidades da liderazgo centradas en la capacidad de la mediación de las relaciones interpersonales (Rivera, 1996a; 1998a), representa otra deficiencia de la PES. Este cuestionamiento debe ser relativizado teniendo en cuenta la admisión, en los últimos trabajos de Matus (1996), de la posibilidad del ejercicio de un liderazgo basado en la fuerza moral y en el consenso, identificado con el estilo Ghandi de hacer política (poco significativo históricamente).

La cuestión de la validez del método para el delineamiento o precisión de una visión compartida sobre la misión institucional (Artmann et al., 1997) también puede ser considerada un problema.

Otro punto importante de debilidad, es una construcción aún muy simplificada de la prospectiva, donde predomina una relación excesivamente determinista del contexto sobre el plan y donde las relaciones cruzadas entre las variables-claves del escenario no son debidamente registradas o formalizadas; (Rivera, 1998c).

La posibilidad de construcción de un proyecto colectivo a partir de la multiplicidad de racionalidades presentes en organizaciones de salud, representa 
otro problema, como también las dificultades inherentes a la propia complejidad del método.

Estas áreas definen desafíos metodológicos importantes.

La cuestión de la cultura nos lleva a M. Thévenet (1986; 1993), autor francés que destaca la necesidad de un análisis participativo de la cultura que colabore en el discernimiento de aspectos fuertes de la cultura que pueden ser funcionales al cambio. La visión de la cultura como recurso, se plantea pragmáticamente al servicio del objetivo de discernir los aspectos que deberían ser reforzados para enfrentar problemas semejantes. La relación problemas/cultura, como definición desafiadora permanente, presenta a la cultura como condición de viabilidad de las formas de enfrentamiento en los problemas.

El autor propone un grado de análisis cultural, con categorías de información delimitadas y formas de establecer hipótesis culturales. El carácter participativo y sistemático de la investigación cultural colabora con la posibilidad de realización de un sentido profundo inherente a ese análisis, el de ayudar a develar representaciones sociales compartidas, lo cual refuerza núcleos de colaboración y asociación institucionales. La cultura, como conjunto de tradiciones y pre-interpretaciones de situaciones, juega un papel determinante en la organización y su abordaje es sumamente interesante para la comprensión del mundo organizacional. No obstante, basados en Habermas (1987), entendemos que las tradiciones culturales, aunque condicionen fuertemente el funcionamiento de las organizaciones y la acción de los actores, pueden ser cuestionadas a partir del ejercicio de un discurso crítico. Esta cuestión se encuentra abordada en el texto de Artmann (1997).

La PES distingue, en la instancia estratégica, la negociación (conflictiva, mixta y cooperativa) como un medio estratégico posible. La indicación de la necesidad de un tipo de estrategia determinada no es suficiente si no es acompañada de una reflexión más profunda del contenido específico de la negociación. La Escuela de Negociación de Harvard, de Fischer y Ury (1985), ofrece un buen modelo de negociación cooperativa, al estilo ganar-ganar, que se aproxima a un modelo argumentativo. Algunos aspectos importantes de este enfoque son:

- La necesidad de separar la negociación de la esencia del problema del relacionamiento intersubjetivo, que requiere una inversión particular;

- La necesidad de negociar a partir de los intereses, de los preconceptos o motivaciones de las posiciones, y no de las posiciones mismas, procurando diferenciar en posiciones aparentemente opuestas, intereses comunes que pueden ser explorados en términos de área de acuerdo, o distintos intereses, por ende no conflictivos, que pueden ser armonizados;

- La idea de que la negociación es un proceso ideativo, creativo, interdisciplinario, de generación de múltiples opciones de ganancia mutua, lo cual desvirtúa la idea de la negociación como un bloque rígido; 
- La teoría, de que lo fundamental es negociar criterios de validez universal o de mayor legitimación, capaces de delimitar objetivamente la posibilidad de un acuerdo.

El enfoque de negociación de Cómo llegar al Sí (1985) puede y debe ser explorado como complemento necesario a la planificación estratégica y al desarrollo de las habilidades de liderazgo.

El paradigma de la "organización que aprende" de Peter Senge pone especial atención a la cuestión del liderazgo. En "El Nuevo Trabajo del Líder" (Starkey, 1997), el autor se opone a la visión del liderazgo fuerte, carismático, asumiendo el liderazgo como el principal responsable de los procesos de aprendizaje colectivos. Aprender significa incorporar habilidades nuevas, no realizadas, de interacción y de reflexión. Estas habilidades básicas, que suponen un cuestionamiento profundo a los modelos mentales, de los preconceptos y creencias en los participantes organizacionales, pueden ayudar a consolidar una visión compartida capaz de provocar cierta tensión en la organización en un sentido renovador y productivo. No existiría para Senge algo como contenidos universales y específicos de la administración, sino el desafío de crear un liderazgo diseminado, como posibilidad de mediación reflexiva de las relaciones interpersonales y de escucha de la subjetividad (expresada a través de aquello de lo que no se habla que mediatiza negativamente relaciones de aprendizaje poco exitosas). Una parte importante de la propuesta de este autor se refiere a la necesidad de desarrollo de un raciocinio estructural relacionado a la explicación de problemas, buscando causas esenciales de alto poder de potenciación, lo cual lo aproxima a Matus. Otra contribución es la necesidad de trabajar con la técnica de simulación de escenarios como instrumento de aprendizaje. Sobre esto último, Senge sustenta que el aprendizaje de la experiencia es limitado, pues la realidad es compleja, siendo difícil el establecimiento de relaciones claras de causa-efecto entre las decisiones que tomamos hoy y sus consecuencias futuras, dado las distancias eventuales en el tiempo y en el espacio. Este elemento de indeterminación obligaría a intentar aprender del futuro, mediante experiencias de simulación que esencialmente ayudarían a entretejer una visión de futuro organizacional. Para el autor el gran mérito de la prospectiva, es el de posibilitar un diálogo sobre los modelos mentales que fundan las visiones de futuro, que crea posibilidades armonizadoras en lo que atañe a la visión organizacional. Traer "el recuerdo del futuro", corresponde al intento por reforzar una construcción positiva, de la visión que actúe como un polo fuerte de modelado del proyecto institucional, que se tensa creativamente con la experiencia de los problemas de la organización. Existe en Senge, -basado en la experiencia de seguidores de la learning organization-, una nueva comprensión de la planificación como proceso de aprendizaje. Lo fundamental no seria la elaboración de grandes planes estratégicos, sino la difusión o incorporación de un raciocinio estratégico al interior del 
cuerpo organizacional, para ser aplicado en el cotidiano de las decisiones sobre opciones alternativas. Coherente con el pensamiento de Mintzberg, la estrategia sería el resultado, no de un proceso superior destacado en el tiempo y en el espacio, sino de múltiples interacciones entre los agentes organizacionales muñidos de habilidades comunes como, por ejemplo, de análisis de sistemas. Este concepto sería el de estrategia emergente, que desde nuestra perspectiva valoriza la planificación táctico-operacional o el momento táctico-operacional de la planificación.

Una de las preguntas que nos planteamos se relaciona a la contribución de la PES al delineamiento de la misión, de los productos organizacionales. Matus (1994b) afirma que el primer desafío de la organización es la correcta delimitación de sus productos y responsables. La planificación a partir de problemas terminales, planteados por un ámbito externo, por los usuarios de la organización, podría ayudar a realizar este delineamiento. Varios pasos serían necesarios: un relevamiento exhaustivo de los problemas de salud de un área de referencia; priorizarlos en función de criterios sociopolíticos y técnico-sanitarios (epidemiológicos, económicos, de vulnerabilidad, etc.); una explicación adaptada buscando seleccionar nudos críticos, en las diferentes áreas de prestación de servicios posibles, sectorial y extrasectorial (promoción, prevención específica, tratamiento, seguimiento, rehabilitación, etc.) y, finalmente, una distribución de las operaciones/acciones entre las diferentes unidades de servicios de salud del área (en función del grado de complejidad acordado para las mismas) y las unidades extrasectoriales. Se deben respetar algunas particularidades del sector: criterios específicos de priorización; clasificación de las operaciones/acciones en diferentes formas específicas de cuidado/prestación; una planificación ex ante de la complejidad de las unidades operacionales. La priorización de determinados problemas no puede dejar de ser acompañada de un tratamiento extensivo a los problemas menos prioritarios, aunque a un nivel de mantenimiento que implique en un no empeoramiento de la situación de salud. La necesidad de una atención universal en salud lleva a considerar el aspecto de red y aspectos extrasectoriales de los problemas de salud.

La mayor parte de las experiencias que hemos acompañado reflejan una tendencia a trabajar en el ámbito de los problemas intermedios que afligen a una organización, en detrimento de la selección de problemas terminales a nivel de la red local, aunque aquellos también impacten los productos finales. En este caso, la selección de problemas presupondría una misión previamente definida, lo cual refuerza la importancia de prerrequisito de la misma. A veces, la propia falta de claridad sobre la misión aparece como problema (Artmann, Azevedo \& Sá., 1997) Creemos, por ende, que existe en Brasil un capital acumulado en el ámbito de la definición de la oferta, a partir de problemas terminales dentro de 
la corriente de la Vigilancia de la Salud, que ha producido instrumentos propios de programación situacional. Este abordaje no se llama programación situacional impunemente: es bastante extensivo y se apoya en formas de territorialización, en formas de estimación rápida de problemas que encuadran minuciosamente regiones en mapas de riesgo epidemiológico y social, y finalmente, en la dinámica de explicación de problemas y de diseño de acciones.

Esta es, sin duda, una de las áreas de investigación evaluativa más importantes del momento. Pensamos, por ende, que la situación es tan o más compleja en el ámbito del sector hospitalario abarcando también el subsector privado. Este ámbito está caracterizado, en algunos espacios, por situaciones de competencia o de descoordinación (desintegración, duplicación), donde se disputa clientela o recursos. Aquí nos parece útil el enfoque de gestión estratégica hospitalaria de Michel Crémadez: la démarche stratégique (1997).

Ese enfoque supone inicialmente la segmentación o agrupamiento de actividades homogéneas por especialidades. A continuación se realiza el análisis estratégico específico de cada segmento en función de dos dimensiones: el valor de cada segmento, correspondiente a la capacidad de atracción de clientela y al interés del hospital de asignación de recursos, y la posición competitiva del mismo, -función del grado de control en los factores claves de éxito. El valor y la posición de competitividad, se calculan a través de un sistema de notación. A partir de este análisis se construye el portafolio de cada especialidad, que corresponde a la localización de todos los segmentos dentro de una escala constituida por las dos variables o dimensiones anteriores. Este documento sirve de base para la definición de la estrategia, que abarca tres grandes objetivos: segmentos a expandir; segmentos a mantener; segmentos a desactivar, recortar, negociar con la red. Finalmente, se diseña el plan de acción, caracterizado en general, por atacar los puntos débiles del análisis de competitividad y por lidiar con aspectos del valor, cuando es posible.

Este enfoque ha sido aplicado en algunas situaciones hospitalarias y, aunque no hayamos tenido tiempo de evaluar con mayor profundidad estas experiencias, aún recientes, detectamos un relativo éxito en el delineamiento de la misión. A pesar del lenguaje típico de la planificación estratégica corporativa, este instrumento ayuda a negociar formas de integración con la red. Fundamentado en la estrategia de diferenciación o de profundización de las capacidades distintivas, el análisis estratégico de Crémadez permite transformar la competencia frontal en colaboración. Es, finalmente, un espacio de comunicación que fortalece la autonomía en los centros operativos y que ayuda a promover cambios culturales a través de la difusión del pensamiento estratégico a nivel de esos centros.

Una confrontación PES/ démarche acerca de las posibilidades de la utilización de ambas, en el caso de la formulación de la misión, es un tema de investigación 
que estimulamos. Nos parece que ambos enfoques pueden contribuir mucho más que la Calidad Total, que más allá de sus apelaciones, en el sentido de las Jornadas de Misión no exhibiría enfoques metodológicos tan estructurados.

La cuestión de la prospectiva ha sido embrionariamente desarrollada por nosotros, a la luz de Godet (Rivera, 1998c), con la intención de solucionar problemas no resueltos por la PES. Dos técnicas nos llaman la atención del enfoque de Godet: el análisis estructural, que es una simulación del poder de influencia recíproca (dos a dos) de las variables inicialmente relacionadas para construir el escenario del sistema seleccionado, y la matriz de los impactos cruzados, centrada en las principales tendencias o hipótesis de comportamiento de las variables. La primera permite reducir el número de variables, o seleccionar las más importantes (de mayor poder de determinación), y la segunda posibilita analizar en qué medida una hipótesis de comportamiento de una variable, influencia las hipótesis de comportamiento de las otras. Podemos decir que estos dos instrumentos son de gran valor en la construcción de escenarios.

Afirmada en la consulta de especialistas para reducir la subjetividad, en el análisis del juego en los actores y en un software basado en cálculo de probabilidades de escenarios, el abordaje de Godet corresponde a lo más avanzado en el campo de la prospectiva más formalizada.

No se puede olvidar, por ende, que se puede traducir el mismo abordaje formalizado en un enfoque más cualitativo y simple, que rescata las dos técnicas anteriormente mencionadas. La simplificación de la técnica, puesta al servicio de la discusión de los modelos mentales de los participantes de la simulación, en los moldes de la propuesta de Senge, parece pertinente.

\section{Panorama de los Enfoques Gerenciales en el Mundo}

De la multiplicidad de enfoques existentes, comentaremos sintéticamente, cuatro corrientes que nos parecen significativas: La Gestión de la Calidad Total (CT), la Reingeniería, la Planificación Estratégica Corporativa y la Learning Organization.

Sobre la CT, ya hemos realizado comentarios en artículo ad hoc (Rivera, 1996b). Con un discurso estimulante de centralización en el cliente y de reconocimiento de las relaciones de confianza proveedor-cliente como garantía de calidad, la CT parece no haber estructurado instrumentos y técnicas que le proporcionen la superioridad metodológica sobre otras corrientes, principalmente sobre los diferentes enfoques estratégicos. A pesar de contar con instrumentos de utilidad para la detección y explicación de problemas (en ambientes partici- 
pativos), la CT no desarrolló enfoques propios de análisis de actores y de prospectiva. Esto, sumado a toda una tradición histórica de preocupación estadística por la reducción de variedad y con la padronización productiva, tiende a transformarla en una corriente normativa con matices humanitarios. Recientemente evolucionó, a partir de una lectura menos racionalizadora de la obra de Deming, hacia un discurso que sustenta la alternativa de un Liderazgo Comunicativo en contraposición a la Administración por Objetivos y para la incorporación de elementos de la Administración Estratégica, principalmente el concepto de factores clave de éxito. Sin un cuerpo teórico-metodológico propio y adaptado a los avances de la época, la CT persiste como un remanente del pasado que se alimenta de todos y pretende ser el gran refugio de todos.

La Reingeniería, vista equivocadamente por adeptos a la CT como su continuación, entra en el mercado como una moda de pocas recetas, algunas extremadamente válidas, sin embargo de efectos secundarios imprevisibles. La compactación de procesos es una de ellas. La crítica a la fragmentación exagerada del trabajo y la defensa de la creación de equipos de trabajo son factores que colaboran para una mayor creatividad y diversificación, para una mayor innovación. Menos padronizadora que la CT, la Reingeniería sucumbe por el peso del autoritarismo, por la pretensión de provocar rupturas organizacionales, por los motivos ocultos de explotación y destitución de la fuerza de trabajo, secundarios al intento de integración de tareas y de simplificación de los múltiples controles anteriores. En el campo de la planificación, una lectura productiva de la Reingeniería, aliada al enfoque lingüístico de las organizaciones de Flores (1993), puede ser verificada en Matus (1994b) y aporta algunas contribuciones importantes.

La Planificación Corporativa Americana, representada por ejemplo por Michael Porter (1980; 1986), de la Escuela de Negocios de Harvard, muestra un gran dinamismo en el ámbito de las grandes corporaciones americanas y japonesas. Apoyada en la segmentación estratégica de las empresas y en un tipo de análisis estratégico de las posibilidades mercadológicas de esos segmentos, este enfoque ha sido útil para la definición de estrategias que permitan ventajas comparativas. Esta corriente se vale de varios portafolios de actividades, uno de los cuales es el portafolio mercado/posición competitivo, que ha sido adaptado creativamente por Crémadez para su aplicación en hospitales y en el sector público. Aún caben dudas en cuanto a la aplicación del modelo empresarial original, a la lógica del sector social.

Ya se han comentado aspectos de la Learning Organization en relación al liderazgo. El paradigma de la organización que aprende, tomado de la V Disciplina de Senge (1998), se constituye de técnicas e instrumentos que apuntan a despertar habilidades de aprendizaje. La cuestión sería aprender a aprender, a 
través de la incorporación de habilidades de reflexión, de indagación, de argumentación, de colocación auténtica. Estas capacidades se refieren a cinco disciplinas: el aprendizaje en equipo; el trabajo con modelos mentales; el dominio de sí mismo; la visión compartida; el pensamiento sistémico. Un aspecto crítico de esta corriente correspondería al uso propuesto por Senge, de la idea de arquetipos sistémicos o de regularidades de comportamiento para efectos de aprendizaje. Con este intento Senge reduce los comportamientos globales posibles de las empresas económicas a unos pocos modelos cuya capacidad de dar cuenta de la diversidad puede ser cuestionable.

\section{La Planificación de Salud en Brasil}

Mehry (1995) hace una buena clasificación del estado del arte en un artículo conocido. Desde nuestro punto de vista, los cuatro modelos referidos pueden perfectamente convivir en un flujo de mucha alimentación. De su diversidad situacional de puntos de vista es posible aprehender aspectos que pueden ser complementarios, aunque las divergencias apunten, a veces, hacia la construcción de diferentes tipos de modelos asistenciales.

La corriente de la Vigilancia de la Salud se destaca por la búsqueda de operacionalización práctica de conceptos de la planificación situacional dentro del contexto de la construcción de la idea de distrito sanitario como proceso social de cambio de las prácticas sanitarias, en el sentido de la eficiencia y eficacia sociales, equidad y democratización. Este proceso se manifiesta a nivel local, donde se establecen las relaciones entre instituciones de salud, ancladas en el paradigma de la promoción de la salud, bajo la regulación de una autoridad sanitaria local y la sociedad o grupos sociales, con la diversidad de problemas que se expresan en la singularidad de cada territorio. Este, además de territoriosuelo, se constituye en territorio económico, político, ideológico, cultural y epidemiológico.

Este enfoque reúne un conjunto de técnicas de diferentes campos: de la planificación urbano-espacial, de la epidemiología, de la planificación estratégica en salud y de la gestión. Nutre un concepto alternativo a la vieja salud pública, que se destaca por la tentativa de crear horizontalidades entre los viejos programas sanitarios a través de la planificación a partir de problemas, basado en la concepción matusiana, en contraposición al enfoque por programas.

Al proporcionar una visión más socioambiental del binomio salud-enfermedad, este enfoque abriría camino hacia una perspectiva de intersectorialidad y de promoción de la salud, contribuyendo de este modo a una recreación de los 
modelos asistenciales, a partir de nuevas prácticas sanitarias, las cuales se constituyen en conjuntos de procesos de trabajo, articulados en operaciones, que imponen una estrategia de acción sobre los nudos críticos de los problemas y sus efectos en un territorio determinado.

Dos prácticas sanitarias contradictorias coexisten en el Distrito Sanitario. La primera se refiere a la Vigilancia de la Salud, direccionada hacia problemas de enfrentamiento continuo, seleccionados por el alto impacto en las condiciones de vida de los grupos poblacionales de las microáreas. La segunda, la Atención a la Demanda, volcada hacia la intervención puntual, ocasional, sobre los efectos de los problemas a nivel individual, auto-percibidos, que es considerada estratégica para la legitimidad social del proyecto y para la captación de informaciones para la Vigilancia de la Salud, la cual, se pretende que sea la práctica hegemónica.

Un problema de este enfoque podría estar representado por la ausencia de una propuesta que de cuenta de las particularidades del ámbito hospitalario.

La corriente de la Programación en Salud de la Universidad de San Pablo (USP) propone la construcción de un sistema de salud programado en términos de sus actividades a partir de la Epidemiología Social. Apunta a reducir una lógica de atención espontánea, de mercado. Se afirma en un tipo de construcción micropolítica de nuevas prácticas asistenciales, referentes a equipos de salud integral (en varios campos de la atención). Busca promover nuevas aglutinaciones de los programas tradicionales en conjuntos más amplios y modernos, privilegiando el componente poblacional. Los autores identifican una evolución de la programación de una posición de "técnica de planificación" (racionalización económica del proceso de producción en salud) hacia un significado de "modelo asistencial o modelo operativo de las prácticas de salud" (tecnología de trabajo), integrando las prácticas médica y sanitaria, presentándola como un campo de experimentación de nuevas formas de trabajo en salud. Puede ser problemático para esta corriente, el grado de subordinación de la vieja clínica a una racionalidad programada. Tal vez sea menos voluntarioso pensar en términos de una tensión permanente entre demanda programada y espontánea, en cuyo contexto se procuraría una hegemonía relativa de la primera, en términos de Vigilancia de la Salud. Se destaca aun la externalidad de las cuestiones de viabilidad en relación al método. Finalmente, es pertinente destacar la evolución dentro de esta corriente, de una visión de ufanismo en relación a las posibilidades de la Epidemiologia como Sujeto de la Planificación (parafraseando el discurso crítico del Lapa), para la comprensión habermasiana de que la planificación integrada del modelo asistencial del SUS es una cuestión de negociación política, de comunicación, condicionando la resolutividad general del sistema.

En relación a la corriente de la Gestión Estratégica y de la Planificación en Salud articulada al Modelo Tecno-Asistencial en Defensa de la Vida del Lapa, ya 
comentamos los esfuerzos desplegados en dirección al desarrollo de una tecnología leve de planificación, a partir del enfoque matusiano y del Zopp (sigla en alemán del Método de Planificación de los Proyectos Orientados por Objetivos). La noción de caja de herramientas (composición de técnicas, procedimientos y enfoques adaptados de la PES, de Mario Testa, de elementos teóricos del psicoanálisis y del análisis institucional, entre otros) da una idea de la flexibilidad de abordaje y de la diversidad de instrumentos manipulados por esta corriente, que experimentó en profundidad tanto la planificación situacional como el enfoque de calidad total. Su riqueza se explica por la acumulación de experiencias (de conducción y de consultaría/investigación) tanto en la red básica como en el campo hospitalario, aunque parta inicialmente de una concepción red-basico-céntrica, proponiendo luego, un cambio de la clásica pirámide hacia un círculo, donde el sistema admitiría diferentes puertas de entrada, según la mejor tecnología y oportunidad para cada usuario. Los profesionales del Lapa, siempre defendieron la flexibilización de los criterios de jerarquización. El territorio es visto con restricciones: es importante definir el área de responsabilidad de las instituciones de salud, pero el usuario no puede quedar preso a un área restricta, pues se moviliza en el sistema buscando satisfacer sus necesidades. La concepción tradicional y verticalista de programas es substituida por la formulación creativa de equipos locales, organizadas, buscando evitar corporativismos y monitoreadas por evaluaciones de desempeño referenciadas por metas vinculadas a los objetivos definidos para los servicios. La propuesta de organización del sistema de salud apunta a dar cuenta de las relaciones entre los diversos tipos de productores, siendo los gerentes locales/regionales una base fundamental de articulación, donde todos los productores deberían estar sometidos al control público. La relación de la unidad de salud con la población es estructurada con algunas nociones tomadas del área de Salud Mental: vínculo, responsabilidad y recepción humanizada, en la búsqueda por desarrollar una relación personalizada y humana.

Compartimos la crítica de los profesionales del Lapa de Campinas a las propuestas tecnocráticas y prescriptivas en planificación y gestión que presuponen una supremacía de los métodos en relación a los sujetos. Según Matus, el método sirve, como máximo para ayudar a sistematizar el conocimiento de la realidad y no substituirlo. Quien planifica es siempre el actor. Para Matus, un actor con conocimiento del problema y capacidad de raciocinio estratégico, con certeza enfrentará mejor un problema, que alguien con bajo conocimiento de la realidad y sólo con conocimiento de método, por mejor que este sea. De todos modos, no hay que negar la importancia de métodos que ayuden a realizar la compleja tarea de gerenciar situaciones que presentan variables no controlables y que exigen respuestas eficaces, creativas y flexibles. 
Compartimos además, de la preocupación por el sujeto, y específicamente por la subjetividad, lo que parece ser una diferenciación analítica en la propuesta del Lapa. Aunque no se tenga aún una clara idea de cómo el análisis institucional recuperaría la subjetividad de los agentes en procesos de autonomización y de institución de nuevas relaciones de poder capaces de democratizar ampliamente estructuras organizacionales, vale señalar, sin embargo, el esfuerzo desarrollado para realizarlo.

El abordaje comunicativo en planificación, que se origina a partir de reflexiones teóricas sobre experiencias con el enfoque de la PES y del establecimiento de un diálogo con la Teoría de la Acción Comunicativa de Habermas, presenta hoy diferentes propuestas teórico-metodológicas y pragmáticas, expuestas en la primera parte de este texto. Algunas de estas bifurcaciones merecen ser profundizadas a través de líneas de investigación, de las cuales resaltamos las siguientes:

- Análisis de la cultura como componente de viabilidad de un proyecto, buscando una metodología de escucha de la cultura, el establecimiento de la relación cultura/problemas frente a un determinado macroproblema y el diseño de estrategias de utilización de la cultura como recurso de la intervención sobre problemas.

- Diseño metodológico y misión institucional, abarcando un análisis comparativo de las posibilidades de la pes y del enfoque de crémadez, en diferentes niveles de atención en salud.

- Desarrollo de habilidades de liderazgo y de negociación, que configuran junto al trabajo cultural, el campo de lo que denominamos gestión a través de la escucha.

- Discusión teórica general sobre la relación entre la gestión a través de la escucha y los métodos racionalistas de gestión.

- Aplicación más sistemática de la prospectiva como recurso crucial dentro del cálculo estratégico.

- Posibilidades de diálogo entre la planificación situacional y los enfoques de la administración estratégica y de la planificación estratégica corporativa, favoreciendo un abordaje del contexto mixto público/privado.

- El rescate de la subjetividad en el campo de la gestión, en procesos de construcción colectiva de proyectos institucionales, a partir de un concepto amplio de razón.

Es importante considerar la interrelación de estas varias líneas y la preocupación con el desarrollo de métodos/enfoques, posturas y conductas que profundicen procesos de solidaridad y generación de compromisos compartidos en un permanente aprender a aprender. 


\section{Referencias Bibliográficas}

ARTMANN, E. O Planejamento Estratégico Situacional: a trilogia matusiana e uma proposta para o nível local de saúde (uma abordagem comunicativa), 1993. Dissertação de Mestrado, Rio de Janeiro: Escola Nacional de Saúde Pública, Fiocruz.

ARTMANN, E. Cultura e Mudança Organiz̧acional. São Paulo: Unicamp, 1997. (Mimeo.)

ARTMANN, E.; AZEVEDO, C. S. \& SÁ, M. C. Possibilidades de aplicação do enfoque estratégico de planejamento no nível local de saúde : análise comparada de duas experiências.Cadernos de Saúde Pública, 13(4):723-740, 1997.

BRASIL. Ministério da Saúde. Regionalização da Assistência à Saúde: aprofundando a descentralização com eqüidade no acesso. Norma Operacional da Assistência à Saúde - Noas-SUS 01/02 (Portaria MS/GM nº 373, de 27/01/2002). Brasília.

CECÍLIO, L. C. O. Uma sistematização e discussão de tecnologia leve de planejamento estratégico aplicada ao setor governamental. In: MERHY, E. E. \& ONOCKO, R. (Orgs.) Agir em Saúde: um desafio para o público. São Paulo: Hucitec, 1997. p.161-167.

CRÉMADEZ, M. Le Management Stratégique Hospitalier. Paris: InterÉditions, 1997.

DUSSAULT, G. Gestão dos serviços de saúde. Características e exigências. RAP, 26:8-19, 1992.

FISHER, R. \& URY, W. Como Chegar ao Sim: a negociação de acordos sem concessões. Rio de Janeiro: Imago, 1985.

FLORES, F. Inventando la Empresa del Siglo XXI. Santiago do Chile: Hataché, 1989.

HABERMAS, J. Teoria da la Acción Comunicativa. Madri: Taurus, 1987.

LIMA, S. M. L. Definição e implementação de objetivos nas organizações públicas de saúde. RAP, 28:38-64, 1994.

MATUS, C. Política, Planejamento e Governo. Brasília: Ipea, 1993.

MATUS, C. Sobre la teoría de las macroorganizaciones. Revista PES n.3, Santafé de Bogotá. 1994a.

MATUS, C. El Metodo PES. Reingenieria pública y la teoría de las conversaciones: trabas y problemas. Revista PES n.2, Santafé de Bogotá, 1994b.

MATUS, C. Chimpanzé, Maquiavel e Ghandi: estratégias políticas. São Paulo: Fundap, 1996. 
MATUS, C. Adeus, Senhor Presidente: governantes e governados. São Paulo: Fundap, 1997.

MERHY, E. E. Planejamento como tecnologia de gestão: tendências e debates em planejamento em saúde no Brasil. In: GALLO, E. (Org.) Razão e Planejamento: reflexões sobre política, estratégia e liberdade. São Paulo/Rio de Janeiro: Hucitec/Abrasco, 1995. p.117-194.

MINTZBERG, H. Mintzberg on Management: inside our strange world of organizations. Nova York: The Free Press, 1989.

PORTER, M. Choix Stratégiques et Concurrence. Paris: Economica, 1980.

PORTER, M. L'Avantage Concurrentiel: comment devancer ses concurrents et maintenir son avance. Paris: InterEditions, 1986.

PORTER, M. A gestão situacional (em saúde) e a organização comunicante. Cadernos de Saúde Pública, 12(3):357-372, 1996 .

PORTER, M. Planejamento estratégico-situacional ou controle de qualidade total? Um contraponto teórico-metodológico. Cadernos Fundap, 19:25-45, 1996b.

PORTER, M. Cultura, Liderança Comunicativa e Gestão. Rio de Janeiro: Escola Nacional de Saúde Pública (Ensp/Fiocruz), 1998a. (Mimeo.)

PORTER, M. Comunicação e Negociação Gerencial (como Requisito das Organizações Profissionais de Saúde). Rio de Janeiro: Escola Nacional de Saúde Pública (Ensp/Fiocruz), 1998b. (Mimeo.)

PORTER, M. Análise Estratégica e Prospectiva. Rio de Janeiro: Escola Nacional de Saúde Pública (Ensp/Fiocruz), 1998c. (Mimeo.)

RIVERA, F. J. U. Agir Comunicativo e Planejamento Social: uma crítica ao enfoque estratégico. Rio de Janeiro: Editora Fiocruz, 1995.

SENGE, P. A Quinta Disciplina: arte e prática da organização que aprende. São Paulo: Best Seller, 1998.

STARKEY, K. Como as Organiżações Aprendem. São Paulo: Futura, 1997.

THÉVENET, M. Audit de la Culture d’Entreprise. Paris: Les Éditions d'Organisation, 1986.

THÉVENET, M. La Culture d'Entreprise. Paris: Presses Universitaires de France, 1993.

TROSA, S. Gestão Pública por Resultados: quando o Estado se compromete. Brasília: Enap/Revan, 2001. 



\section{Análisis estratégico hospitalario y PROYECTO ASISTENCIAL: la perspectiva de Michel Crémadez y François Grateau \\ Francisco Javier Uribe Rivera Elizabeth Artmann}

La Démarche Stratégique representa, originalmente, el enfoque utilizado en la definición de la misión del Centro Hospitalario Regional Universitario (CHRU) de Lille, Norte de Francia. A raíz de una visita a esa estructura hospitalaria, pude conocer este importante instrumento de gerenciamiento, que adaptado por nuestro grupo a Brasil, ya fue aplicado en varias unidades hospitalarias de Río de Janeiro y divulgado por el país ${ }^{1}$.

El término démarche significa proceso, trámite, gestión, y podríamos traducirlo como gestión estratégica. Nos proponemos, en este capítulo, presentar a grandes rasgos, la propuesta metodológica de la Démarche Stratégique, como también algunas de sus más importantes referencias teóricas.

La démarche es un método que supone la adaptación de un enfoque empresarial al sector público de servicios de salud. Este enfoque de planificación/ gestión estratégica se apoya en elementos de la microeconomía, del campo de la estrategia y de la política, y del área del desarrollo organizacional y cultural. Introduce también, algunas categorías propias del área de salud y de la epidemiología, reconociendo la especificidad del sector público de salud en Francia. Está fundamentado por autores como H. Mintzberg (1982), Michel Crozier y Erhard Friedberg (1977), M. E. Porter (1982), M. Thevènet (1993), entre otros.

A partir de su principal referencia, la obra Le Management Stratégique Hospitalier, de M. Crémadez y François Grateau (1992; 1997), este enfoque se propone definir racionalmente la misión de un hospital, situándolo en la perspectiva ideal de una red coordinada de servicios de salud. En este sentido, la organización

Se destacan las experiencias pioneras en el Hospital da Posse y en el Hospital Phillipe Pinel y posteriormente en el Hospital da Lagoa, Cardoso Fontes, Raphael de Paula Souza y Lourenço Jorge, entre otras, mobilizando un grupo constituido por el autor de este capítulo, por Elizabeth Artmann (Ensp/Fiocruz), Clayre Maria Bomfim Lopes (Nesc/UFRJ), Rejane Sobrino (Nesc/UFRJ) y Rosa Maria de Souza Souza (SES-RJ), entre otros. 
hospitalaria es entendida como una organización proactiva, centrada sobre el exterior, que asume el ambiente como recurso y no como restricción. Esto significa que la definición de la misión tendrá que ser negociada con el ambiente externo institucional, incluyendo a los otros hospitales del área a la cual pertenece. De esta manera, se destaca la capacidad proactiva de la organización y su actuación dinámica sobre el ambiente.

Las características de las organizaciones sanitarias tienden naturalmente hacia un patrón que se aleja del ideal. Este ideal estaría representado por la aplicación de criterios de racionalidad económica de la misión, a través de la concepción del ambiente externo como recurso y de una mayor integración intrainstitucional. De todos modos, el patrón presentado por las organizaciones de salud, el cual será analizado posteriormente con mayor profundidad, se constituye de algunos trazos característicos: un proceso de autonomización de los centros operacionales, derivado de una suerte de ruptura entre la dirección estratégica y estos últimos; una extrema diferenciación o atomización de sus estructuras internas en función de la especialización del trabajo, y una desconsideración relativa del ámbito externo a causa de una sobrevalorización corporativa del ámbito interno. Estas características dificultan la posibilidad de un proyecto gerencial que ponga énfasis en la integración intrainstitucional, la racionalidad económica de la misión específica y la negociación de una red de cuidados con los otros establecimientos de un ámbito inmediato. La perspectiva de la démarche es la de promover un tipo de movimiento cultural que contrapese esas tendencias, abriendo camino para el desarrollo de una forma de organización que se aproxime a aquellas premisas ideales (Rivera, 1997; Artmann, 2002).

Específicamente, los objetivos de la démarche son:

- Promover lazos de unión entre la gerencia estratégica y los centros asistenciales, a través de la comunicación;

- Definir la misión del hospital de acuerdo con el criterio de oportunidad, lo cual equivale a determinar preferentemente un patrón de actividades que permita ventajas comparativas, al mismo tiempo que ofrece un servicio de calidad a los usuarios;

- Brindar un lugar de comunicación, donde los actores-servicios puedan llegar a definir un proyecto colectivo;

- Favorecer la integración del hospital en una red de oferta de cuidados estructurada bajo la preocupación por la eficacia y la eficiencia;

- Promover un proceso de transformación cultural progresiva, no necesariamente atado a la búsqueda de objetivos instrumentales inmediatos.

Desde el punto de vista de la estrategia microeconómica, este enfoque cuestiona una visión homogénea de la excelencia, representada por la intención 
de fijar, en la misma escala, todas las áreas de atención. La alternativa a esta visión sería, trabajar la vocación en cada establecimiento, dentro de la perspectiva de la complementariedad. La mejor estrategia para que un establecimiento pueda obtener ventajas comparativas es la diferenciación, que corresponde a la definición de sus áreas de excelencia, con el objetivo de priorizarlas, de expandirlas, negociando con la red de servicios la atención de los usuarios no contemplados por esas áreas (típicas de actividades de menor desarrollo relativo). El núcleo de este enfoque es la idea de intentar transformar la competencia frontal en colaboración, a través de la búsqueda de las capacidades distintivas de cada hospital y de la negociación de las misiones entre los diferentes establecimientos.

En la perspectiva político-organizacional, el enfoque se opone a una definición normativa y tecnocrática de directrices, apostando hacia la responsabilización de los actores, esto implica el desarrollo de procesos comunicativos y de negociación, internos y externos, que redunde en acuerdos relativos a los proyectos asistenciales pertinentes a una red. En relación a la estructura organizacional, el enfoque postula la necesidad de intensificar las estructuras en red interna y el diálogo multidisciplinario, promoviendo la búsqueda de transversalidades.

Presentaremos, a continuación, varios elementos de la propuesta general de gestión estratégica de Crémadez, a partir de un resumen comentado de su obra:

- Las premisas generales, de orden teórico-conceptual del enfoque;

- El método de análisis estratégico de la misión de las especialidades médicas;

- Las estrategias básicas de obtención de ventajas comparativas;

- La propuesta de estructura organizacional en red;

- La cuestión de la padronización de procesos de trabajo apuntando a organizar la diversidad;

- Una propuesta general de análisis y planificación de la distribución de recursos humanos.

\section{Premisas Teóricas Generales del Enfoque de Crémadez}

\section{Dinámica organizacional y práctica decisional de las organizaciones profesionales de salud}

A partir de Mintzberg (1982), Crémadez y Grateau, determinan detalladamente las principales características de una organización profesional:

- Supremacia del centro operacional: engloba un gran número de unidades, independientes, altamente especializadas, que reconocen un ambiente diferencia- 
do. Esto significa que estas unidades son más importantes que otras estructuras/instancias organizacionales reuniendo suficiente saber y autonomía para tomar sus propias decisiones. Cada centro operacional se diferencia por tener sus propias normas, procedimientos, usuarios diferenciados y por estar vinculado a las diferentes entidades o sociedades de especialistas (sociedad de cardiología, sociedad de oftalmología, ortopedia, de cirujanos, etc.).

- Preponderancia de lo relacional: el trabajo es coordinado a través de una adaptación mutua, que presupone relaciones espontáneas e informales entre responsables, y del proceso de padronización de las profesiones, ya que la formación profesional y la socialización en sociedades especializadas contribuyen a la posesión de un patrimonio común del saber, de los métodos y comportamientos. Esta característica refuerza la autonomía profesional y un bajo sentido de pertenencia a la organización.

- Debilidad de la tecnoestructura: la tecnoestructura tiene poco poder de intervención sobre los procesos operacionales de la organización, a no ser en la dimensión económica.

- La logística es importante: el tipo de coordinación es procesal y por resultados y se efectiviza de manera centralizada. Las diferentes lógicas de los universos médico y logístico, puede generar problemas de coordinación. La expansión de la importancia de los medios logísticos típicamente médicos, como equipamientos y tecnología hospitalaria, crea conflictos de interés entre administradores y médicos y al interior de la propia comunidad médica.

- Ausencia de una línea jerárquica rígida: la dirección no tiene la capacidad ni la competencia para dirigir directamente a los jefes de los diferentes servicios. Actúa indirectamente a través de la tecnoestructura y de los servicios funcionales y/o de instancias de concertación.

El resultado dinámico de esta caracterización es una fuerte diferenciación (Lawrence \& Lorsch, 1973), de variadas dimensiones:

- Diferenciación entre el mundo administrativo y el mundo asistencial: el primero está más volcado hacia las instancias de regulación, persigue objetivos cuantitativos y económicos, dentro de una perspectiva política, articulando corto y largo plazo. El segundo busca objetivos más cualitativos vinculados a una perspectiva a corto plazo, representada por la demanda de los pacientes. Está centrado sobre tareas particulares que requieren tan solo la aplicación de medios consagrados. Estas actividades son ejercidas de un modo liberal y tienen poca validez organizacional. El nivel jerárquico, en este caso, está determinado por la capacidad. 
- Diferenciación entre logística y centro operacional: la logística es organizada de un modo más mecanicista y coordinada según criterios económicos, de forma centralizada. El mundo médico es descentralizado y organizado según el propio saber y el saber especializado. Existen choques entre administración y centro operacional en lo referente al control de los equipos y de la tecnología médica descentralizada.

- Diferenciación en el centro operacional: existe una fuerte especialización horizontal, como también una diferenciación al interior de cada servicio entre las diferentes categorías de profesionales y entre cuerpo médico y paramédico.

Para Crémadez, la diferenciación es fuente de eficacia. Es necesario respetar algún grado de diferenciación, valorizar las diferencias sin buscar la homogeneidad o la simetría. Se debe, por ende, compensar los efectos negativos de la diferenciación desarrollando formas de integración de fuerza semejante.

Como resultado de sus características estructurales y dinámicas, la práctica decisional de las organizaciones profesionales es incremental: las decisiones son tomadas en serie, en función del poder de presión momentáneo de los diferentes actores hospitalarios, sin una perspectiva de conjunto. Existe una superposición de objetivos. De este modo no se verifica, el proceso de formulación de una estrategia anterior (ex ante). No se busca o no se quiere una estrategia: esta seria el resultado de decisiones de naturaleza más operacional, puntual. La estrategia emergente es el fruto de una inflexión o de un leve desvío de la estrategia anterior bajo la influencia de sucesivas decisiones no generadas de forma global (Nioche, 1997).

Otros resultados de la dinámica organizacional de los establecimientos de salud se refieren al encierro en relación al exterior (al ambiente) y un bajo sentido de pertenencia hacia la organización por parte de los profesionales médicos. El ambiente es percibido con insatisfacción y los que actúan en él, adoptan una postura reactiva. La organización está centrada sobre si misma.

El proceso de decisión estratégica busca invertir esas tendencias. Pretende ayudar a crear una cultura en donde el ambiente sea percibido como recurso; en donde se anticipen las tendencias del ambiente de modo de actuar creativamente sobre él y donde la organización desarrolle sinergias y trabajos conjuntos con otras instituciones bajo la premisa de construir redes de colaboración.

\section{La práctica decisional de la gestión estratégica}

La gestión estratégica rompe con la disociación entre lo estratégico y lo operacional, buscando diluir esa división vertical. El poder de decidir sobre el 
aprovechamiento de una oportunidad está ampliamente difundido por la organización y ya no queda concentrado en la cúpula. La dirección señala las grandes orientaciones, los valores centrales del proyecto organizacional pero no define la estrategia propiamente dicha, que depende de la articulación de todos los actores organizacionales.

La gestión estratégica introduce un tipo de planificación continua, flexible y ajustada, buscando concretar un conjunto coherente de proyectos. Pone en discusión la cuestión de los objetivos por oposición a una lógica de medios. Es una práctica decisional más integradora. $\mathrm{Al}$ abarcar la mayor cantidad de actores del centro operacional, busca reducir o, al menos transparentar, el juego político interno, a través de diferentes factores:

- La gestión estratégica tendría la virtud de la transparencia representada por la utilización, en el proceso decisional, de datos objetivos sobre la actividad de base, y no de meras impresiones de fundamentación relativa.

- La transparencia estimula la comunicación, desde la construcción de las bases de captura de información, que puede cristalizarse en una nomenclatura común de clasificación y evaluación de los actos médicos, de las patologías, formas de atención, etc. Compartir esa información contribuiría a una armonización del lenguaje entre los actores de base de la organización.

- Es posible reconstituir, a través del proceso de la segmentación estratégica, los diferentes dominios de actividad desmembrados por el juego de la distribución territorial del poder. Las consecuencias de esta transparencia son varias: los diferentes actores de la misma unidad de base pueden reflexionar a partir de una visión más clara y compartida de su actividad, para prever su evolución y consecuencias. La identificación, a partir del análisis estratégico de esa segmentación, de dominios de actividades compartidas, permite explorar las sinergias, elaborar alternativas y estrategias comunes; la verificación de relaciones entre servicios permite establecer puentes entre los mismos. Se crea, de este modo, una interacción permanente entre el mundo administrativo y el médico, pues el sistema de informaciones médicas y determinados tratamientos de datos pasan a incorporar preocupaciones estratégicas, lo que permite asociar el raciocinio gerencial con el técnico.

- La gestión estratégica sería una pedagogía de evaluación, en la medida en que introduciría la preocupación por los resultados, además de una conducta pautada en la aplicación de medios. La cuestión de cómo atender las expectativas de los usuarios de una red, estaría en el centro de una política de evaluación sistemática, como cultura a ser desarrollada. El proceso de evaluación estratégica se traduce, por la vía de la negociación, en proyectos de acción, que se constituyen en un estímulo al cambio, pues ese proceso suscita una inquietud natural en relación a los resultados posibles de los mismos. 
- La gestión estratégica ayuda a formalizar las evaluaciones y los comentarios que las justifican, generando bases más sólidas para dirimir litigios o divergencias de interpretación. La formalización es un elemento capital de la comunicación y de la cohesión entre las diferentes categorías de profesionales.

- La gestión estratégica explora la diversidad, pues enseña a aceptar la posibilidad de abandonar la posesión de una tecnología o de equipos, cuando estos no son competentes dentro de un servicio o del hospital, y cuando se tiene acceso a ellos a través de sinergias o colaboraciones, concentrándose en el estudio de formas alternativas de tipo de atención que pueden valorizar el servicio y, al mismo tiempo, ser útiles para los usuarios.

- La gestión estratégica introduce el discurso de los costos de oportunidad al tomar en cuenta las necesidades de los otros y el grado de satisfacción global obtenido por la organización. La aplicación de un recurso a una actividad debe ser justificada por una mayor ganancia comparativa alcanzada relativamente a usos alternativos. Las diferenciaciones, representadas por la profundización de capacidades distintivas, son estimuladas en la medida en que se subordinan a una perspectiva de mayor eficiencia y eficacia globales, considerando el sistema o la red.

- La gestión estratégica introduce la necesidad de estimular proyectos que permitan captar recursos adicionales, lo que puede ayudar a limitar conflictos de poder y la viabilización de proyectos que, de otra forma, tendrían que ser abandonados o postergados.

La gestión estratégica pretende, de este modo, arbitrar a través de los costos de oportunidad para crear una solidariedad.

\section{La crisis de identidad y la necesidad de renovar el contrato psicológico}

La identidad organizacional es el correlato francés del concepto de cultura. Este último englobaría las representaciones sociales compartidas sobre la organización y su misión, dada su historia y su papel en la sociedad. El concepto de identidad aportaría, a esta visión integradora, una dimensión oculta por la cultura: la de los juegos de poder de los actores y de sus mecanismos psíquicos. Se considera cultura, en esta perspectiva, como "significante" de la identidad, e identidad como algo que recupera la función ideológica de las representaciones organizacionales y su lógica de poder (Strategor, 1997). La identidad es una suerte de lógica coherente de una organización, una visión colectiva, compartida, que resulta de influencias internas y externas. Se inspira y genera paradigmas que 
condicionan la vida de los individuos al interior de la organización. Está en la base de una suerte de contrato psicológico entre cada individuo y la organización, que define la naturaleza y la fuerza de su identificación con ella.

La erosión de ciertos paradigmas tradicionales contribuye a crear una crisis de identidad organizacional. El contrato psicológico que vincula a los individuos con la organización, se debilita como resultado del impacto del cambio de diversos paradigmas: el de la Medicina, del servicio público y el paradigma profesional.

- El cambio del paradigma de la Medicina: existe una especialización y concentración creciente de actividades y de medios tecnológicos en grandes estructuras hospitalarias, que demanda cada vez más una intervención de tipo gerencial. Disminuye el estilo de ejercicio liberal de la profesión y se intensifica el control administrativo de esas estructuras. Al mismo tiempo que el trabajo médico se introduce en estructuras burocráticas, la medicina pasa a ser vista bajo una nueva perspectiva. Una actuación médica eficaz supone entonces, una articulación entre la medicina orgánica/positivista y un enfoque ecológico o ambiental. La oposición entre generalistas y especialistas pierde sentido. El papel del médico actuando aisladamente va siendo substituido por la actuación en equipo. Las colaboraciones se transforman en indispensables, así como la concepción de nuevas formas de hospitalización. La búsqueda de solidariedad entre los actores ocupa el centro de atención.

- El cambio del paradigma del servicio público: la reducción de los recursos lleva al cuestionamiento sobre las posibilidades equitativas del servicio público, o, como diríamos en Brasil, sobre su carácter universal. Atender a todos de manera igualitaria pasa a dañar el principio de equidad, ya que dificulta el acceso para determinados grupos de población. Para muchos, el servicio público se transformó en la defensa de monopolios, actuando con excesiva independencia (acarreando situaciones arbitrarias y de anonimato) y que tiende a reducirse, como concepto, a una ideología tecnocrática. Se plantea que el servicio público debe comenzar a aceptar la competencia, la evaluación, la necesidad de escucha de los usuarios, la apertura al ambiente. Debe transformarse internamente en competitivo (racionalizando sus recursos) y trabajar en red. Se privilegia también la idea de lo contractual y el establecimiento de formas de cooperación y colaboración.

- El cambio del paradigma del profesional: la experiencia deja de ser la base esencial de la capacidad profesional. La veloz renovación de los conocimientos y de las tecnologías, transforma en obsoletos los recursos cognitivos anteriores. Esto provoca un crecimiento de la especialización y una regresión de la autonomía de los especialistas. La complejidad técnica creciente provoca una interpenetración mayor entre lo técnico y lo económico. Frente a ese cuadro, la formación tradicional, más artesanal, de acompañamiento a un 
profesional más antiguo, pierde importancia relativa. La formación y actualización permanente se transforma en una de las claves de la capacidad profesional; la posibilidad de realizar reorientaciones profesionales (cambio de especialidades) será de capital importancia, tanto para el desempeño de las carreras individuales como para la eficiencia organizacional.

Los principales trazos de la identidad organizacional puestos en cuestionamiento serian: la no explicitación de los proyectos organizacionales, la superposición de objetivos; el aislamiento de los profesionales y de los servicios; el rechazo a la evaluación de las capacidades; el corporativismo profesional; el estilo liberal de ejercicio profesional; la informalidad; el predominio de los criterios técnicos sobre los económicos; la marginalización de la gerencia; la poca preocupación por el ambiente externo, entre otros.

Esos cambios generan una crisis de identidad, que acentúa sentimientos y reacciones negativas, como la resistencia de los médicos como grupo dominante, el rechazo a la elección de prioridades y el bloqueo de iniciativas, que sustituyen la voluntad de emprendimiento de los mismos profesionales y la regulación de conflictos por el crecimiento. En el plano externo, el hospital se hace más reactivo, sobrestima la escasez de recursos y pasa a mirar el futuro con inquietud. Forman parte del telón de fondo de esta crisis, la necesidad de fortalecer la regulación administrativa y de introducir criterios económicos de gestión de los centros operacionales, lo que amenaza la autonomía.

La gestión estratégica pretende actuar sobre movimientos que permitan la renovación del contrato psicológico entre los profesionales y la organización, actualmente bastante debilitados. El impacto sobre la identidad organizacional comprendería varios factores:

- Al formular un proyecto de organización más estructurado, basado en la exploración de sinergias y de colaboraciones, la gestión estratégica busca poner en evidencia soluciones (lo que tiene impactos psicológicos naturales) y elegir aquellas que permiten un mayor beneficio colectivo al favorecer la posibilidad de compartir los recursos. La gestión estratégica combina las estrategias individuales dentro de una estrategia de conjunto, desviando la atención de las atribuciones para las contribuciones. La formalización de la información, del análisis y de planes favorece la aprehensión de la organización por todos los actores. La instancia reguladora (Ministerio de Salud) es convocada a decidir sobre objetivos explícitos y no solamente sobre distribución de recursos exíguos. El propio director del hospital fortalece su posición al tener que arbitrar, en definitiva, el contexto de diferentes proyectos médico-asistenciales.

- El proceso de análisis estratégico crea lugares de encuentro, estimula la reflexión colectiva (intra e interprofesional), distribuye responsabilidades 
entre grupos, crea nuevas unidades, aumenta las conexiones externas. El sistema de poder, dividido y atado a los servicios, evoluciona para establecer transversalidades e interdependencias. La naturaleza al mismo tiempo técnica y económica de las decisiones, conduce a la evolución de las relaciones entre administradores y médicos en el sentido de la colaboración. Habría más integración y formalización.

- El mayor conocimiento mutuo, basado en la socialización de un sistema de información, promueve una gestión negociada, que acentúa la necesidad de las sinergias y colaboraciones operacionales. El ambiente pasa a ser el centro de las atenciones. Los diferentes agentes organizacionales pasan a visitarse mutuamente, a conversar, a encontrarse más. Los valores pasan a ser cuestionados, puestos en discusión como fundamento de las decisiones. Determinados tabúes como la capacidad ajena son relativizados. La evaluación estratégica justifica la necesidad de un análisis de la capacidad global de los servicios frente a los usuarios. La rigidez de posiciones corporativas cede lugar, en función de la posibilidad del encuentro, a posiciones más flexibles.

- El imaginario organizacional evoluciona, en síntesis, hacia una valorización de la interdependencia que compensa la reivindicación de autonomía, hacia una apreciación positiva del sentido de bien colectivo de la actividad. Los individuos se apropian de la organización con información, formalización y análisis, y desarrollan una motivación para la acción. Se sienten modelando y adaptando dinámicamente su organización.

La renovación del contrato psicológico depende de la movilización de tres expedientes:

- El papel del liderazgo: las situaciones de crisis exigen la presencia del poder de motivación del líder. Este liderazgo debe transmitir la capacidad de asumir la iniciativa y de explorar nuevas reglas de juego. Debe comunicar con claridad, apuntando a fijar, focalizar progresivamente un nuevo modo de comportamiento, guiado por un estado de espíritu menos individualista, más solidario, más centrado en la acción colectiva, que valorice las contribuciones mutuas, la comunicación, que sea menos jerarquizado, menos prescriptivo, más abierto a las expectativas externas, más transparente. Este liderazgo debe ayudar a proyectar la imagen del sistema político, no como un juego de presiones aleatorias, sino como un proceso de acción interactivo consensual y contributivo.

- El papel de la comunicación: la comunicación ayuda a crear un lenguaje común y a integrar los discursos individuales en una perspectiva global, de modo de aumentar la cohesión social. La comunicación implica el reconocimiento del otro como legítimo otro, el reconocimiento de las expectativas de los 
interlocutores, el reconocimiento de la imagen que proyectamos a los otros y la comparación entre esa imagen y lo deseado. La comunicación exige una relectura de la organización para reconocernos -como colectividad- en el pasado y para explorar determinados trazos culturales que pueden ser útiles para cambiar, o para identificar formas de práctica retrógradas, de las cuales podemos apartarnos positivamente. Comunicar nuestra oferta de actividades es una forma de fortalecer nuestros compromisos frente a los demás integrantes de la red y aumentar nuestro nivel de exigencia.

- La apropiación de la organización por los actores: sin una apropiación de la estrategia por parte de los actores, esta no resultará. Dada las características procesual, adaptable, variable, de los proyectos de los diferentes servicios, se torna necesario que los diferentes actores subscriban una carta de intenciones estratégicas general, que tienda a dar unidad a las iniciativas locales, algo así como el gran proyecto institucional. Como entre el discurso y la modificación real de comportamientos, existe una distancia importante, es fundamental que se asuma el análisis estratégico como un proceso exploratorio, interactivo y progresivo, como aprendizaje permanente.

\section{El modelo de cambio organizacional}

Este modelo de gerenciamiento intenta articular la necesidad de racionalidad con la amplia participación de los actores de la base organizacional. Se opone al Modelo Racional de un Actor Único (la dirección), que busca tan solo una solución única, óptima, de naturaleza económica, a partir de una problemática que se pretende estructurada. Se inserta en la perspectiva del Desarrollo Organizacional, que encara el cambio, no como la gestión del pasaje de un estado de equilibrio hacia un estado de equilibrio diferente, sino como la gestión del desequilibrio que caracteriza toda organización dinámica, donde desequilibrio y movimiento, están íntimamente vinculados. En la perspectiva del Desarrollo Organizacional, cambio y aprendizaje son fenómenos naturales y esenciales, de carácter permanente y no eventos inducidos ocasionalmente desde afuera. Esta perspectiva consiste en impedir la intervención de la jerarquía para que los actores organizacionales investiguen los obstáculos al buen funcionamiento organizacional, que se identifican con frecuencia con el comportamiento interactivo. Otra contribución al nuevo modelo de gerenciamiento es el Análisis Sociológico de las Organizaciones, de Crozier (1977), que defiende la necesidad de una amplia participación, para apoyar el proceso de conquista del mundo exterior, en el potencial energético de actores autónomos que negocian un proyecto solidario. 
Este modelo es racional, ya que acentúa la necesidad de formular objetivos, pautados en una racionalidad de costos de oportunidad y un análisis de tendencias del ambiente exterior. Es un modelo de negociación, participativo, de abajo hacia arriba, que se apoya en la formalización de análisis, evaluaciones y estrategias y en la utilización de un método de trabajo en común.

Es un modelo propicio para el cambio, porque permite desde un inicio, el encuentro donde no había encuentro.

Algunas características de este modelo:

- El proceso supera al modelo: la coherencia es fruto de sucesivos ajustes, de un aprendizaje progresivo sobre la posibilidad de objetivos comunes, aunque parciales. En este proceso de aprendizaje, se destaca la preocupación por la necesidad de un trabajo permanente sobre un ambiente complejo y evolutivo, de manera no reactiva.

- La organización es el producto de las orientaciones: la organización se construye a partir de planes de acción definidos colectivamente y de una política de sinergias.

- Las orientaciones provienen de la base: en una organización diversificada y derrotada, la definición centralizada de la estrategia es necesariamente reductora.

Dos cuestiones son vitales para Crémadez, en la promoción del proceso de cambio: en primer lugar, la necesidad de inversión pedagógica significativa en el territorio de la metodología, y que los actores incorporen la idea de que podrán mantener el controle sobre el proceso, dependiendo los resultados de sus posibilidades; en segundo lugar, la necesidad de obtener resultados rápidos y de que se consolide la idea de que el distanciamiento crítico en relación a las capacidades profesionales ayudará a desbloquear situaciones intrincadas.

Algunos principios son muy importantes en este proceso: ser transparente y argumentativo en el proceso de búsqueda incesante del consenso, evitando apostar al antagonismo para intentar solucionar situaciones cruciales; evitar conductas de exclusión, manteniendo la puerta siempre abierta a la discusión; explorar el poder de compromiso del director, el cual debe explicitar con claridad su voluntad de cambio y trazar, a grandes rasgos, las líneas teóricas de este proceso, considerando la satisfacción de los usuarios, la realización de los actores internos y un mayor alcance de la misión; darse el tiempo necesario, considerando las particularidades de cada servicio y hospital, para que se produzcan los procesos de cambio; apostar a la obtención de resultados concretos para reforzar la creencia en el cambio en el imaginario de los actores; huir de un juego en donde un actor gana y el otro pierde, a través de la exploración de las sinergias y colaboraciones, de la socialización de medios; acelerar los procesos decisivos y combatir la burocracia, para dar señales claras de una menor inercia organizacional. 
Garantizar la viabilidad de permanencia y continuidad de cambio, dependería de tres factores: la transferencia de la metodología a los actores internos, a través de la substitución progresiva de los consultores externos; la evolución progresiva de la tecnoestructura; y la inversión en formación.

\section{El Método}

Las etapas del método y su contenido general son las siguientes:

- El análisis de lo existente: corresponde al diagnóstico del método.

- La segmentación: esta etapa corresponde a la definición de los principales agrupamientos homogéneos de actividades, teniendo en cuenta aquellos que presentan una misma problemática estratégica.

- El análisis del valor y de la posición competitiva de cada uno de los segmentos resultantes de los agrupamientos de actividades: el valor corresponde al interés relativo o al nivel de prioridad relativo que los segmentos tendrían para la especialidad, en función de una política general y depende del interés en la asignación de recursos. Un criterio genérico en la medición de ese valor está representado por la capacidad potencial de atracción de clientes ofertando una atención de excelencia y eficiente; la posición competitiva es evaluada considerándose el grado de control sobre los llamados factores clave de éxito (FCE), que corresponderían a las ventajas o situaciones positivas necesarias para tener éxito en una actividad.

- La construcción del portafolio de actividades, apuntando a la definición de la estrategia general de acción o de los objetivos: el portafolio es un gráfico cuya abscisa está representada por la posición competitiva de la institución y cuya ordenada representa la capacidad de atracción (valor) de los segmentos.

- El Plan de Acción, apuntando a alcanzar los objetivos a partir de las estrategias definidas en términos de tres posibilidades: priorizar el desarrollo de un segmento; estabilizarlo; reducir el reclutamiento de clientes o recortar el segmento.

- El montaje de los indicadores de monitoreo del plan.

Veamos el contenido más específico de cada etapa.

\section{El análisis de lo existente}

El diagnóstico es administrativo y médico.

El diagnóstico administrativo es de tipo tradicional, con informaciones 
como: tiempo medio de espera, número de ingresos, personal médico y paramédico, estructura física, perfil de la demanda, etc.

El diagnóstico médico comprende:

- relación de patologías atendidas por disciplina médica, ordenadas de acuerdo con una complejidad creciente;

- elación de tecnologías utilizadas por disciplina, ordenadas de acuerdo a la complejidad;

- cruzamiento entre patologías y tecnologías, identificándose la incidencia de las tecnologías sobre las patologías;

- relación de las modalidades de atención, considerándose cuatro criterios:

- si las actividades en relación a las patologías son o no programables o electivas

- si la intervención sobre las patologías demanda consulta ambulatorias y/o hospitalización;

- el tipo de hospitalización requerida: el tiempo de internación requerida

- si las patologías enumeradas demandan un tipo particular de capacidad diagnóstica o de exploración funcional (plateau tecnique) existente en el servicio o fuera de él.

La etapa diagnóstica incluye además, la relación entre los competidores y los colaboradores externos, como también el diseño de la red de cuidados.

La red de cuidados es un cuadro que pretende relevar las actividades por segmento, divididas en actividades de diagnóstico, tratamiento y seguimiento, realizadas en el servicio, en otros servicios del mismo hospital y en la red (conexiones externas). (Ver Figura 1).

Figura 1 - Red de Cuidados (filière de soins).

\begin{tabular}{|l|l|l|l|}
\cline { 2 - 4 } \multicolumn{1}{c|}{} & Diagnóstico & Tratamiento & Seguimiento \\
\hline Servicio & & & \\
\hline Hospital (otros servicios) & & & \\
\hline Red (conexiones externas) & & & \\
\hline
\end{tabular}

Fonte: UAS-CHRU, 1995 (adaptado).

El cuadro Red de Cuidados es un instrumento que posibilita identificar superposiciones y complementariedades eventuales entre los tres niveles de servicios referidos, posibilidades de competencia y también ausencia de actividades. 
El mayor objetivo de esta etapa diagnóstica es proporcionar elementos para la etapa siguiente, que consiste en segmentar los servicios según una lógica que veremos a continuación.

\section{La segmentación estratégica}

La segmentación implica definir colectivamente, a nivel de cada servicio, agrupamientos homogéneos de actividades, definidos como aquellos polos de actividades donde predomina la identidad de elementos desde el punto de vista de su problemática estratégica. En este proceso, se deben reducir al mínimo los factores de desacuerdo. En el caso de que existan grandes diferencias, se deben realizar nuevas divisiones de categorías.

El objetivo central de la definición de segmentos homogéneos es crear categorías que permitan un análisis estratégico representativo, teniendo en cuenta que el hospital es una institución multiproducto, donde todos los grupos de actividades no siempre presentan el mismo desarrollo o el mismo valor estratégico. Por lo tanto, se considera, que cada segmento reconoce un ambiente competitivo específico.

La etapa de segmentación, es un análisis multicriterios, en el cual las diferentes actividades son tamizadas a través de diferentes criterios específicos:

- Las patologías presentadas por los pacientes: tipo y localización de la afección; grado de complejidad; superposición entre patologías.

- Las características del proceso de atención: necesidad de internación convencional o específica (camas de aislamiento), grado de programación o de elección de la actividad.

- Las características de las tecnologías utilizadas: necesidad de disponer de una estructura técnica específica (de apoyo diagnóstico, terapéutico o de seguimiento); tamaño de la inversión realizada o a ser realizada; acceso a la estructura técnica general.

- Las capacidades necesarias: grado de sofisticación dentro de la especialidad; multidisciplinariedad (recurrir a las capacidades de diversos especialistas).

- La competencia: número de instituciones y de profesionales que ejercen la actividad y medios disponibles.

- Tipo de población involucrada: edad, sexo, categoría socio-profesional específica, activo o inactivo.

- El lugar de la actividad en la red de cuidados: urgencia, diagnóstico, atención, seguimiento, educación sanitaria, prevención. 
Estos criterios pueden ser integrados en cuatro grupos:

- Las patologías (infarto, insuficiencia cardiaca, arritmias, etc., en cardiología);

- Las tecnologías (radiología, ultra-sonido, láser, etc.);

- Los modos de atención (internación convencional, consulta ambulatoria, hospital de día, etc.)

- Población (alcohólicos, ancianos, niños, mujeres, etc.)

Puede ser interesante un análisis progresivo, comenzando por los criterios médicos patología y tecnología, pero se busca crear agrupamientos homogéneos desde el punto de vista de los cuatro criterios, y no de uno en particular. La definición es situacional, teniendo en cuenta que los implicados pueden privilegiar un determinado criterio o dos. En general, se priorizan, de acuerdo a la experiencia, los criterios médicos. No se trata de descubrir una estructura universal y general, que sirva de referencia para organizaciones que ofrecen actividades análogas, tal como se organiza y recorta el campo de una disciplina científica. La definición de los segmentos está influenciada estratégicamente por la necesidad de presentar, desde el inicio, los conjuntos de actividades típicos de cada hospital, que contribuyen a su diferenciación. La forma como las actividades son organizadas previamente en función de una cultura determinada, también define los recortes particulares. La subjetividad es inherente a la segmentación en la medida en que esta depende de la mirada que depositan los interesados sobre sus actividades y el ambiente externo específico, condicionado por la identidad cultural de la organización.

Cada uno de estos cuatro ángulos de aproximación, en mayor o menor medida, resalta la dimensión médica, organizacional o social de las actividades. De este modo, si los dos primeros son estrictamente del orden médico, el tercero (proceso de atención) se ocupa del contexto organizacional ofrecido a los pacientes, mientras que el cuarto (población), está más centrado en las necesidades de una categoría específica de individuos. Cada elección traduce elecciones estratégicas diferentes en términos de la investigación de ventajas competitivas:

- Un segmento centrado en las patologías traduce la adopción de una posición amplia en la red de cuidados, correspondiendo a una oferta diversificada y a procesos de atención variados (consultas, exploraciones funcionales, cuidados, seguimientos, etc.)

- Un segmento centrado en la tecnología, prioriza una oferta específica correspondiente a una posición más restricta y más puntual de la oferta de cuidados, tanto a nivel de diagnóstico, como a nivel curativo, o a nivel de seguimiento (técnica particular de reeducación, por ejemplo). En general, se elige un segmento tecnológico cuando se trata de técnicas y equipos de 
una cierta complejidad, de uso no indiscriminado, que engloban un conjunto característico de patologías y que constituyen ventajas comparativas o "exclusividades".

- Un segmento centrado en un modo de atención, privilegia el contexto dentro del cual se encuentra el paciente y destaca la respuesta a ciertas necesidades o insatisfacciones a partir de los cuales él mismo puede juzgar si los servicios que le son ofrecidos (urgencia, programación, duración...) se adaptan a sus necesidades.

- Un segmento centrado en una población específica de pacientes, privilegia las expectativas o las necesidades de orden sanitario, pero también las de orden social, de un grupo de individuos a los cuales podemos ofrecer un servicio diferenciado, adaptado a su especificidad.

La importancia dada a una dimensión, patología, por ejemplo, no excluye de ninguna manera las otras dimensiones: tecnología, población, modo de atención, que pueden presentarse de forma subordinada. Estos criterios no predominantes, complementarían la descripción de las características de los segmentos y ayudarían a reflexionar en relación a las sinergias. En una institución, se pueden adoptar, al mismo tiempo, segmentos estratégicos que responden a criterios predominantes diferentes.

La segmentación estratégica es un método que permite tomar una realidad compleja y descomponerla en subconjuntos más simples de entender. Para constituir estos subconjuntos, se privilegian ciertos factores comunes a las actividades que los componen, subordinando los factores que las diferencian. De este modo, se construye un modelo que reduce la realidad, pero presenta un riesgo importante si nos concentramos en las simplificaciones que facilita. Los segmentos no son estancos, ellos poseen conexiones que deben ser estudiadas. La identificación de problemáticas transversales es, por lo tanto, indisociable de la segmentación. Esto permite dar una coherencia de conjunto a las actividades segmentadas anteriormente.

Cuando el punto de partida de la segmentación es la estructura organizacional, se hace evidente la presencia de relaciones entre los servicios, vínculos frecuentemente escamoteados por la dinámica y la diferenciación organizacional, o sacrificados en pos de la preservación territorial. Las problemáticas transversales estarían generalmente vinculadas:

- A oportunidades de colaboración entre disciplinas completamente separadas en el pasado (por ejemplo, el estudio del sueño, a partir de la asociación de capacidades, puede avanzar a través de la neumología, de la neurología y de la psiquiatría).

- A la desestabilización, por innovaciones tecnológicas, de fronteras clásica- 
mente reconocidas, que provoca con frecuencia guerras de apropiación (por ejemplo, entre la endoscopía y la radiología intervencionista).

- A la puesta en evidencia de dependencias mutuas en el seno de una misma red de cuidados (entre la cirugía y la medicina para el diagnóstico y luego para el seguimiento de ciertas formas de cáncer o de transplante, por ejemplo).

- A la evidencia de necesidades comunes a varias disciplinas diferentes (evaluación de los desafíos de la nutrición, por ejemplo).

El tratamiento de las problemáticas transversales puede traducirse, tanto en una nueva segmentación: replanteo del contenido de los segmentos existentes, surgimiento de nuevos segmentos (ejemplo: el vascular, en cardiología), como por la delimitación de nuevos campos de sinergias (ejemplo: entre el segmento vascular de la cardiología y de la neurología).

La sinergia es el excedente de eficacia o eficiencia resultante de la operativización conjunta de dos o más actividades o segmentos distintos. La identificación de las sinergias es fundamental sobre el plan estratégico, ya que permite dar, una vez más, una unidad al conjunto de los segmentos reunidos al interior de una misma organización. Las sinergias definen las líneas de fuerza de la colaboración, a instaurarse entre los diferentes componentes de la organización, o sea, la aplicación en común de los recursos, con el fin de que la gestión de las conexiones entre los segmentos sea fuente de ventajas competitivas. Si la detección de las sinergias es de orden estratégico, la movilización de las mismas puede ser también de orden organizacional, a través de la adaptación de las estructuras en un sentido amplio, principalmente a través de la movilización de estructuras de integración.

Es importante señalar que el proceso de segmentación nunca es definitivo o fijo y no se relaciona al preeexistente, existiendo la posibilidad de surgimiento de segmentos virtuales. Durante este proceso, nuevas e interesantes formas de segmentación pueden surgir. De este modo, una segmentación iniciada a través del predominio del criterio patología puede mostrarse extremadamente extensa y poco operacional y evolucionar posteriormente hacia una segmentación prioritariamente por tipo de atención, con la inclusión subordinada de los criterios tecnología y población. Las áreas de diferenciación estratégica de un hospital pueden cambiar a lo largo del tiempo condicionando nuevas formas de segmentación que deben ser tratadas como un proceso de aproximaciones sucesivas. Este proceso es interactivo, progresivo y exploratorio.

Daremos aquí algunos ejemplos:

Segmentos del Hospital Psiquiátrico Philippe Pinel-SMS-Río de Janeiro

- Ambulatorio de Adultos

- Centro de Orientación Infanto-Juvenil (Coij)

- Cais (Hospital de Día de Adultos) 
- Núcleo de Asistencia Integral a la niñez Autista y Sicótica (Naicap-Hospital de Niños de Día)

- Enfermerías A + B (sicóticos/pacientes graves)

- Unidad de Tratamiento de Alcohólicos (UTA)

- Recepción y Emergencia

- Laboratorio (especializado en psiquiatría)

- Servicio de Imagen Cerebral

Esta segmentación está basada fundamentalmente en un criterio tipo o modo de atención, más allá de que presenten recortes referentes a otros criterios, como, población (adulto/niñez), patología (UTA) y tecnología (Servicio de Imagen Cerebral).

Segmentos de la Cardiología del Hospital da Lagoa-SMS-Río de Janeiro:

- Enfermedad Arterial Coronaria (DAC)

- Arritmias

- Síncopes

- Cardiopatías Congénitas

- Hemodinámica Intervencionista

- Hipertensión Arterial

- Cardiopatías

Esta segmentación es clásica, con un amplio predominio del criterio patología, con la presencia subordinada del criterio tecnología -hemodinámica-, que reúne actividades que inciden sobre algunas de las patologías que definieron segmentos (configurando una superposición).

\section{Análisis del valor de cada segmento}

La determinación del valor implica analizar cada segmento a partir de diferentes criterios/subcriterios, de los cuales destacamos:

- Estado actual y perspectivas del mercado;

- Barreras a la entrada de nuevos competidores;

- Sinergias;

- Grado de motivación interna;

- Oportunidades del ambiente;

- Potencialidades del segmento. 
El objetivo central del análisis del valor es jerarquizar los segmentos por medio de una ponderación de los criterios y de una notación relativa.

Cada criterio general tendría un peso determinado, en términos de porcentajes en la fijación del valor del segmento (como así también los subcriterios específicos). Este peso es variable, situacional y referente a la especialidad seleccionada, aunque esta ponderación relativa pueda variar dentro de una misma especialidad en el caso de hospitales diferentes. Sin embargo, el peso expresado en porcentaje permanece uniforme para la especialidad del hospital en cuestión, como también para todos sus segmentos. Esta ponderación correspondería a la importancia relativa que cada criterio tendría para la comunidad de profesionales involucrada en el análisis estratégico, según la aplicabilidad relativa de los criterios. Definido el peso relativo de cada criterio, se procede a un sistema de notación, atribuyéndose una nota de 0 (cero) a 20 (veinte) por criterio a cada segmento analizado. Esta nota consensuada correspondería a una visión prospectiva de cómo cada segmento, se comportaría en relación a cada criterio. Por lo tanto: ¿cuál seria el nivel de sinergia potencial? ¿Cuáles serian las perspectivas de que crezca o se desarrolle? ¿Qué potencial de captación de clientela y de desarrollo de investigación y de enseñanza es posible establecer?, etc. El valor global del segmento será conferido en función de las notas por criterio y de su peso específico, llegando a un score especifico por segmento.

Pasaremos a discutir brevemente el contenido de estos criterios, basándonos en material recogido en Lille, Francia, en la UAS-CRHU (1995 a, e, b) como también, a partir de la adaptación realizada para la realidad brasilera (ver Anexo).

En relación al mercado, se consideran las perspectivas de desarrollo, el riesgo de fluctuación y la intensidad de la competencia.

Las perspectivas de desarrollo se refieren a la posibilidad de crecimiento futuro de los segmentos de una especialidad, considerándose el escenario epidemiológico-social y el escenario tecnológico. Debe tomarse en cuenta que la evolución de las técnicas de diagnóstico y de terapia pueden contribuir para aumentar o disminuir la demanda de servicios.

Es importante el análisis del riesgo de fluctuación de las técnicas, referente a la previsión del surgimiento de nuevas técnicas capaces de modificar sensiblemente la actividad a corto o mediano plazo.

La intensidad de la competencia corresponde a la previsión de la cantidad de instituciones y de profesionales realizando la misma actividad, y a su expresión en términos del control de los medios necesarios a la oferta de la actividad en cuestión.

Inicialmente, una alta expectativa de crecimiento inducida por los fenómenos epidemiológicos y tecnológicos, una previsión de estabilidad en la evolu- 
ción de las técnicas y la presencia de pocos competidores, contribuirían para valorizar el segmento, al garantizar, teóricamente, más mercado para la especialidad de un hospital. Pero este análisis puede ser relativizado dependiendo del contexto sanitario, social y político de la región donde se encuentra el hospital.

En relación a las barreras a la entrada de nuevos competidores al mercado, se considera fundamentalmente el monto de inversión destinado al desarrollo de los segmentos y las posibilidades de ser rentable u obsoleto. Una inversión elevada ya realizada y la previsión de continuidad, valorizan al segmento en una situación específica, pues significa ventajas comparativas en relación a otras organizaciones que no hayan realizado la misma inversión -que puede ser visto como barrera para la entrada en el mercado.

Esta inversión puede ramificarse en equipamientos y tecnología, capacidad instalada, recursos humanos especializados, etc. Puede considerarse también de forma agregada, priorizándose el componente tecnológico.

Las sinergias se refieren a la posibilidad de compartir equipamientos, tecnologías, capacidad instalada, apoyo logístico, como también la opinión especializada de los profesionales. Este criterio es importante tanto desde el punto de vista de la economía de costos, como de la calidad de los servicios. Se considera también que el sinergismo con otros segmentos y especialidades de un mismo hospital y el potencial de colaboraciones con la red son factores que incentivan el surgimiento de un mercado o de clientes, valorizando por ende, al segmento.

Se debe evaluar el grado de motivación interna, por la disposición del cuerpo profesional de una especialidad, para invertir en los diferentes segmentos. Esta es una variable de contenido subjetivo relacionada al grado de interés que contienen las actividades, en función del status de las mismas, de su complejidad y de la particular formación y cultura de los médicos.

Las oportunidades del ambiente incluyen la posibilidad de traer recursos externos desarrollando cada segmento, mejorar la imagen externa de la especialidad y del hospital, el interés manifiesto de las autoridades sanitarias revelado por la disposición de otorgar financiamientos suplementarios, como también el potencial de innovación derivado de la posibilidad de transferencia de determinadas tecnologías.

Las potencialidades de los segmentos corresponderían a la capacidad de atracción de clientes en nivel regional y local, así como a la generación de actividades de enseñanza e investigación.

La atribución de una nota al segmento por (sub)criterio está basada en la formulación de preguntas-clave. Por ejemplo, la evaluación de las perspectivas de desarrollo sugiere las siguientes preguntas: 
¿La actividad en cuestión progresará en los próximos años?

- ¿ ¿en función de los factores de riesgo (edad, por ejemplo)? o

- ¿ ¿en función de la evolución tecnológica o del savoir-faire (nuevas terapéuticas)?

Una nota alta correspondería a la previsión de un fuerte crecimiento y una nota baja, a la estimación de una disminución importante.

A continuación, presentamos la matriz básica adaptada del cuadro de aferición de valor (Figura 2).

Figura 2 - Matriz de evaluación del valor de los segmentos de especialidad.

Especialidad/Disciplina:

Segmento:

Evaluación del Valor del Segmento:

\begin{tabular}{|l|c|c|c|}
\hline Criterios de evaluación & $\begin{array}{c}\text { Peso } \\
\%\end{array}$ & $\begin{array}{c}\text { Nota } \\
(\mathrm{de} \mathrm{0} \mathrm{a} \mathrm{20)}\end{array}$ & $\begin{array}{c}\text { Score } \\
(=\mathrm{p} \times \mathrm{n})\end{array}$ \\
\hline Mercado & & & \\
\hline $\begin{array}{l}\text { Crecimiento } \\
\text { Riesgo de fluctuación } \\
\text { Intensidad competitiva }\end{array}$ & & & \\
\hline Valor ponderando mercado & & & \\
\hline Barreras a la entrada & & & \\
\hline Sinergias & & & \\
\hline Grado de motivación interna & & & \\
\hline Oportunidades del ambiente & & & \\
\hline Potencialidades del segmento & & & \\
\hline Valor del segmento & 100 & & \\
\hline
\end{tabular}

Fonte: Crémadez \& Grateau, 1992.

En nuestra experiencia, el análisis del valor es considerada según los siguientes criterios: posibilidades de crecimiento; intensidad de la competencia; tamaño de la inversión, como barrera a la entrada; potencial de sinergias (internas al hospital), potencial de colaboraciones externas; potencial local y 
potencial regional de captación de clientes; motivación interna; potencial de enseñanza e investigación; contribución con el proyecto político o con la gran misión del hospital; contribución con la imagen externa. Estos criterios contienen los subcriterios explicitados durante la aplicación del enfoque para hacer más fácil el cálculo.

El resultado de esta etapa es una descripción precisa de la problemática específica del segmento. Este método, a pesar de no partir de la categoría problema, permite, en esta etapa, ir al encuentro de los problemas específicos. Por ejemplo:

- Muchos competidores identificados dan como resultado una nota baja en lo concerniente a la intensidad de la competencia, lo que contribuye a un valor de mercado relativamente menor;

- Una expectativa de pocos aportes externos, compromete el item oportunidades del ambiente;

- Un bajo desarrollo en investigación, puede comprometer las potencialidades de desarrollo general.

Para que los criterios anteriormente aludidos no sean fundamentalmente bases de investigación, sino de evaluación, es necesario someterlos a un proceso de formalización riguroso. De este modo, la evaluación del valor debe ser realizada sobre bases idénticas para todos los segmentos de actividad que conforman una institución. En el caso contrario, la evaluación no aportará elecciones estratégicas, ya que la elaboración de cada una de las escalas específicas estaría apoyada en valores y diferentes modos de aprehensión del medio ambiente, lo que impediría toda comparación significativa.

La formalización de la escala de evaluación debe evitar al máximo los riesgos de interpretaciones divergentes. De este modo, el título del criterio debe acompañarse de una definición precisa del contenido del criterio, de la forma de evaluar (significado positivo de la variación) y del modo de puntuación que será utilizado. Frecuentemente el grado de madurez de la organización frente a la evaluación, definirá la utilización de una puntuación numérica o no. La ventaja de una puntuación numérica es permitir ponderar los diferentes criterios y facilitar la obtención de una nota global.

A pesar de todas las precauciones que se puedan tomar, la no disponibilidad de ciertos datos, como también el hecho de que, en ciertos casos, los especialistas consultados estén involucrados en la puntuación, impiden evitar una buena dosis de subjetividad. La única manera de minimizar esta cuestión es lograr que la puntuación se efectúe en un contexto de participación lo suficientemente amplio como para que exista la necesidad de obtención de un consenso. 


\section{La evaluación de los factores clave de éxito y de la posición competitiva}

El análisis de la posición competitiva o estratégica del hospital corresponde a la identificación de los factores clave de éxito (FCE) y al grado de control relativo por parte del hospital. Los FCE sirven para evaluar la capacidad del hospital para obtener buenos resultados en cada uno de los segmentos de actividad, o sea, para satisfacer la demanda del servicio correspondiente en calidad y cantidad.

Los FCE corresponden a las capacidades/tecnologías que deben ser controladas para tener éxito en las actividades en análisis. La identificación de estos factores clave es equivalente a la definición situacional de elementos de capacidad diferencial, o sea, de capacidades específicas de orden relacional, tecnológica, financiera o de capacidades, cuyo control garantice posiciones de vanguardia.

Este concepto presenta las siguientes características fundamentales:

- Lo que se indica es el conjunto de factores que promueven efectivamente el éxito, es decir, lo que es valorizado por el medio ambiente de los profesionales y de los usuarios. Las confusiones más frecuentes, a las cuales es necesario estar bastante atento, son: confundir FCE y norma profesional (interna o no a la organización), por un lado y, FCE y capacidad disponible, por otro.

- El número de factores considerados debe ser limitado; todo es importante, pero sólo algunos elementos son decisivos.

- El nivel de capacidad requerida puede ser evaluado en términos absolutos (mínimo requerido del orden normativa), pero lo que importa es la capacidad relativa, es decir, lo diferencial en cuanto a las capacidades que se establece en relación a la competencia.

- Los FCE no son invariables. Su composición evoluciona en función de los fenómenos que influyen sobre las expectativas de los usuarios. Estos pueden tener un origen ambiental (fenómenos sobre los cuales se puede actuar frecuentemente, al menos indirectamente) o resultar de los esfuerzos de las organizaciones, a través de la competencia entre ellas mismas, transformando en diferenciales, factores considerados anteriormente como secundarios. Cuando, luego de la puntuación, la diferenciación entre los competidores se muestra relativamente escasa, se puede preguntar sobre la pertinencia de los FCE definidos. En efecto, si todos los competidores están próximos y obtienen una nota satisfactoria, lo que se debe preguntar es si el FCE no pertenece al pasado, si su efecto diferencial puede estar ya superado o si las posiciones de competencia dependen de otros parámetros. Por otro lado, si todos los competidores tienen mala puntuación, es necesario preguntar si no existe un desvío que actúa entre la visión del especialista (su sistema normativo) y la visión del usuario (sus expectativas). 
La identificación de los FCE debe ser realizada basándose, lo máximo posible, en la observación del medio ambiente, analizando lo que determina el éxito de un competidor considerado particularmente amenazador, interrogando a los interesados, tanto a profesionales como a usuarios. Esta identificación es indisociable de la identificación de los competidores y consiste en explorar, a través de la reflexión estratégica, ciertos datos de marketing, interrogándose sobre la persistencia de las expectativas observadas y sobre los factores susceptibles de modificarlas.

El relevamiento de datos sobre FCE se hace en relación al lugar que se ocupa en la red de cuidados correspondiente al segmento estudiado. Ocupar una cierta posición específica en la red de cuidados puede ser, en sí, un FCE. Una vez determinado el espacio a ocupar, conviene movilizar un cierto número de recursos y de capacidades de control para proponer servicios en los que se perciba una calidad superior a los de sus competidores. La obtención de los FCE es fruto de la investigación sistemática sobre tipo, calidad y volumen de los recursos que tendría un efecto diferenciador sobre el desempeño relativo de los competidores involucrados.

Para ser operacional, o sea, conducir a la formulación de planes de acción que permitan mejorar la posición competitiva del establecimiento sobre un segmento de actividad determinado, es necesario que la formulación de los FCE sea precisa. No se trata de decir, por ejemplo, "son necesarios médicos competentes" sino que es necesario precisar cuál es la capacidad que hace la diferencia; en vez de decir "son necesarios equipamientos eficientes" se debe identificar cuál es el equipamiento cuya posesión constituye una real ventaja estratégica.

Lo que lleva al éxito, es aquello que es efectivamente percibido por el consumidor de los servicios ofertados. El hecho de que el universo de la salud sea un universo prescriptivo complica ciertamente el problema en la medida en que puede haber en ciertos casos, dificultades para conciliar las expectativas de los profesionales y las de los pacientes. Es necesario involucrar a todas las partes, especialmente a los usuarios (incluidos aquí los profesionales usuarios de la red), en la investigación de los FCE y evitar asumir la postura dependiente de confundir expectativas con normas técnicas de buena calidad profesional. Las herramientas de información del marketing, los estudios de imagen, de satisfacción y de opinión constituyen en este sentido un soporte muy valioso. Es por ello que la dimensión relacional (colaboraciones, comunicación) es frecuentemente una fuente de elementos diferenciales.

Es importante resaltar que, a diferencia del valor, los FCE no pueden ser idénticos para todos los segmentos de actividad, ya que estos representan la especificidad de la actividad. Y más aún, una gran semejanza en los FCE de diferentes segmentos debe conducir a repensar la segmentación. 
El objetivo central de esta definición es jerarquizar las actividades (los segmentos) en función de su posición competitiva.

El método de análisis consiste en:

- Identificación de los fce;

- Relevamiento de los competidores;

- Ponderación de los fce o definición de su impacto o de su peso relativo sobre la posición competitiva, lo que consiste en distribuir 100 puntos entre los fce en función de su importancia relativa;

- Notación: Acto de atribuir una nota de 0 a 20, a cada fce en función del grado de control real de los mismos, considerando el control propio y también el control de los competidores/colaboradores;

- Determinación de la posición relativa propia y de los competidores, a través de la comparación de los scores pertinentes (el score de cada competidor es determinado a partir de los productos del peso y de la nota por fce);

Es importante señalar aquí, que la definición de la posición competitiva de los competidores implica, a falta de un conocimiento más preciso de la misma, una investigación complementaria a ser realizada in loco (acumulándose datos objetivos sobre el control de los FCE). De este modo, se evita una excesiva subjetividad y los errores inherentes a una mera simulación a la distancia.

La matriz de análisis del control de los FCE con algunos ejemplos, es la siguiente (Figura 3):

Figura 3 - Matriz de análisis de los factores clave de éxito (fce). Posición competitiva.

\begin{tabular}{|l|c|c|c|c|c|c|c|}
\hline \multicolumn{2}{|l|}{ Segmento } & \multicolumn{5}{|c|}{ Competidores - Referencia } \\
\hline Factores clave de éxito & Peso & Nota & A & B & C & D & E \\
\hline Capacidad laboratorial & & & & & & & \\
\hline Cooperación cardiologistas & & & & & & & \\
\hline Recepción & & & & & & & \\
\hline Acompañantes & & & & & & & \\
\hline Disponibilidad scanner & & & & & & & \\
\hline Animación red generalistas & & & & & & & \\
\hline Score segmento & 0 & 0,00 & 0,00 & 0,00 & 0,00 & 0,00 & 0,00 \\
\hline Posición relativa & & & & & & & \\
\hline
\end{tabular}

Fonte: Crémadez \& Grateau, 1992. 


\section{La construcción del portafolio de actividades. La elaboración de una visión de conjunto}

El portafolio de actividades es una matriz de valor/posición competitiva donde son posicionados los segmentos estratégicos de una especialidad para tener una idea de conjunto y de valor comparativo. En la práctica, es un gráfico constituido por el valor como ordenada y por la posición competitiva como abcisa. Cada segmento es representado por un círculo cuyo tamaño representa el volumen relativo de producción de las actividades que representa, y su posición sobre el mapa depende del score, obtenido al momento de la evaluación del valor y del grado de control de los factores clave de éxito, lo que define su posición competitiva. El gráfico es dividido en cuatro cuadrantes, donde los dos cuadrantes superiores corresponden a segmentos de alto valor, y los dos inferiores a segmentos de bajo valor. Los cuadrantes de la derecha se refieren a segmentos de alta posición competitiva, y los de la izquierda, a segmentos de baja competitividad (Figura 4).

Figura 4 - Portafolio de atividades.

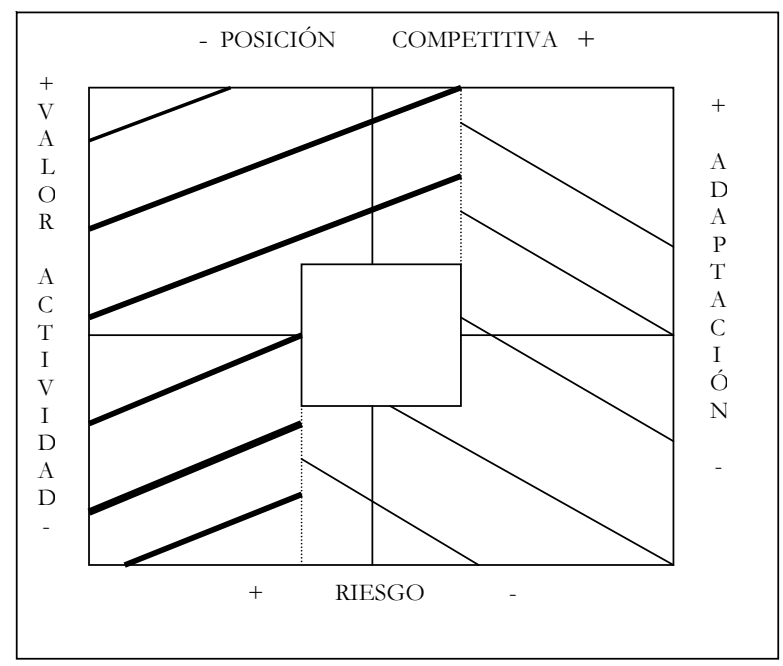

Fonte: Crémadez \& Grateau, 1997.

El examen del portafolio debería permitir un diagnóstico rápido del riesgo estratégico al que se expone el segmento, como resultado de la mayor o menor adaptación a la oferta de servicios (valor de la actividad) y del esfuerzo requerido para suplantar a la competencia (la posición de competitividad). También debería sugerir las grandes líneas de acción, de acuerdo con la posición estratégica a futuro. 
Puede estar estructurado en tres zonas:

- A la derecha, una zona de escaso riesgo estratégico (trazado débil): la no adaptación de los servicios es, en la mayoría de los casos, compensada por la excelencia de la posición de competitividad.

- A la izquierda, una zona de fuerte riesgo estratégico (trazado fuerte): la adaptación de los servicios es, en el mejor de los casos, debilitada por la fragilidad de la posición de competitividad.

- En el centro, una zona de no diferenciación (blanca), que corresponde a las actividades medianamente valorizadas y no diferenciadas con relación a la competencia: zona de fuerte insertaza estratégica.

Figura 5 - Ejemplos de portafolios de actividades.

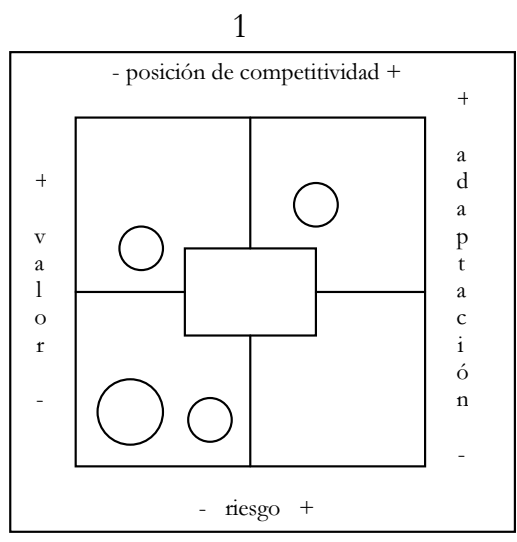

3

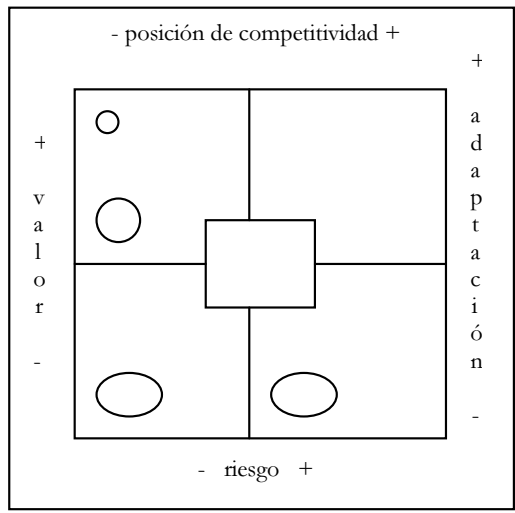

2

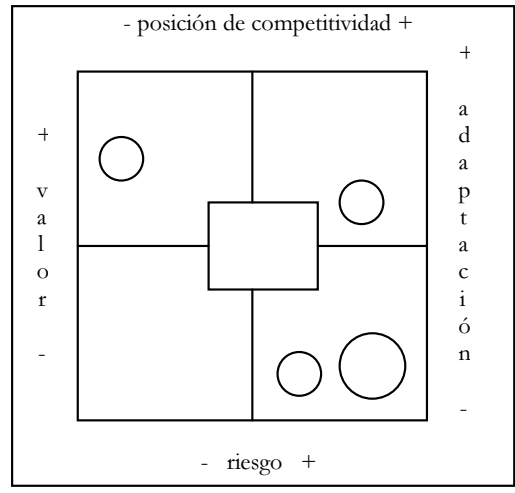

4

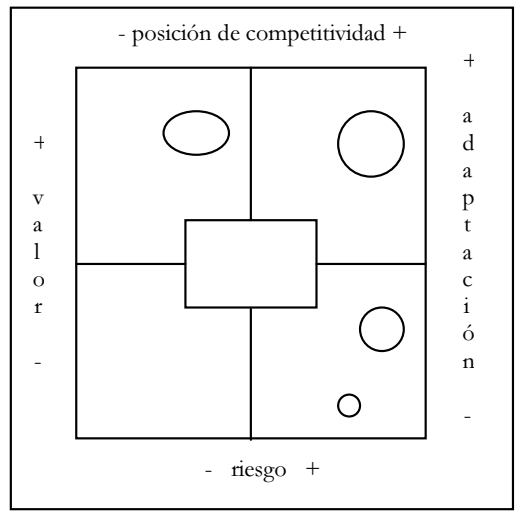


El portafolio número 1, representa alto riesgo, ya que sólo un segmento de actividad, contiene una buena posición de competitividad. En contrapartida, está medianamente adaptado, ya que cerca de la mitad del volumen de actividad se destina a los segmentos mejor posicionados en términos de valor. El principal problema de la institución será desprenderse de los segmentos inadaptados, a fin de canalizar sus recursos en dirección a los segmentos mejor adaptados, y especialmente en dirección al segmento que debería ganar en posición de competitividad. En este caso, será necesario analizar detalladamente el contenido, en términos de población, patología, tecnología y de modo de atención del segmento más importante (en volumen de actividades) y no tan bien posicionado. Esta investigación permite "separar la paja del trigo" y revalorizar las actividades mencionadas, favoreciendo a aquellas que, gracias a una orientación particular, aportarán una respuesta más adaptada a las necesidades de los usuarios. Se trata, en ciertos casos, de concentrarse en la respuesta específica de una categoría de usuarios, que aparece como mayoritaria en un segmento considerado. En otros casos, será conveniente adoptar un modo de atención mejor adaptado y de cambiar de posición en la red de cuidados. Podrá ser el caso, también, de reducir el número de patologías atendidas o de concentrarse sobre aquellas que corresponden más a la vocación del establecimiento. Finalmente, la reorientación podría dirigirse a modificar las tecnologías utilizadas a fin de abrir un nuevo campo de acción. De este modo, la desvinculación de un segmento de actividad no es sinónimo de un simple abandono; este debe ser acompañado de un plan de acción específico y, eventualmente, de un esfuerzo de inversión.

El portafolio número 2, representa poco riesgo: sólo un segmento se muestra en una posición de competitividad desfavorable. Es, en contrapartida, poco adaptado, ya que el segmento que tiene la peor posición de competitividad es precisamente aquel que está representado por el valor más alto. Sin embargo, es difícil hacer evolucionar este portafolio de forma constante, vía redistribución de los recursos entre los segmentos que lo componen. En efecto, cuando una parte importante de la actividad tiene valor escaso, pero una posición de competitividad más fuerte, es difícil deshacerse de ella. Esta situación puede, en ciertos casos, mostrar una insuficiencia de difusión de las tecnologías y/o del savoir-faire. Una de las soluciones puede ser entonces, realizar la transferencia de los segmentos mal posicionados, liberando así recursos que podrán ser reorientados en dirección al segmento de actividad con valores más altos, pero donde debe ser mejorada la posición de competitividad. En ciertas situaciones extremas, donde existe el riesgo de ser definitivamente sobrepasado en relación a este último segmento, por la falta de una reacción más rápida, será necesario invertir sin esperar los efectos de la transferencia. En este caso, es necesario estar muy atento a fin de que la transferencia se haga lo más rápido posible y que los recursos liberados puedan ser reorientados en dirección a otros dominios. Caso 
contrario, a largo plazo, podrá existir una captación de recursos indebida, que perjudicará a las actividades que podrían beneficiarse de esos recursos.

El portafolio número 3, es al mismo tiempo más arriesgado y menos adaptado, que demuestra un escaso dominio del sector en consideración. Necesita, ante todo, un análisis preciso de la competencia, ya que lo encontramos frecuentemente en los dominios de actividad que están sometidas a una evolución científica y/o técnica que abre nuevas perspectivas. En este caso, será necesario ante todo, poner la atención sobre los dos segmentos más valorizados, a fin de definir las estrategias que permitirán hacer progresar su posición estratégica. A veces es necesario deshacerse lo más rápidamente posible de los segmentos de escaso valor. Sin embargo, el tiempo del proceso de desvinculación dependerá de una aceptación psicológica por parte de los profesionales, vinculada a la evolución de los segmentos de alto valor.

El portafolio número 4, aparece como más promisorio y equilibrado, ya que los segmentos menos importantes (en volumen de actividad) no están bien posicionados en términos de valor. Demuestra un fuerte control del dominio considerado. Las preocupaciones son, en este caso, de dos órdenes: por un lado, controlar las maniobras de la competencia para evitar sorpresas desagradables, y por otro, evitar la excesiva asignación de recursos derivada de la influencia interna que podrán adquirir los responsables por el dominio en cuestión.

Estos cuatro ejemplos muestran que, en los casos extremos, es necesario, ante todo, preocuparse por los competidores y por el medio ambiente, descubrir las oportunidades y amenazas y, que conviene, en ciertos casos, analizar con detalle el contenido de las actividades, a partir de los puntos fuertes y débiles identificados.

De la lectura de los portafolios anteriores, podemos concluir que los segmentos prioritarios son los de alto valor. En general, deberían ser estimulados los segmentos de alto valor. Pero, no siempre un segmento de escaso valor es sinónimo de abandono del mismo (especialmente cuando el volumen de actividad es grande y la actividad no es realizada por otros). Por otro lado, cuando los segmentos presentan una baja capacidad competitiva, un valor más alto, significa que la mejor estrategia seria la de invertir en la mejora de la posición competitiva, aumentando el rendimiento y el control de los factores clave de éxito. Lo ideal es encontrar los segmentos a la derecha del portafolio. Pero, el portafolio no debe inspirar movimientos de forma mecánica: es un documento para ayudar a pensar una estrategia.

El portafolio sirve para determinar prioridades, para fijar la estrategia del hospital en términos de tres objetivos posibles, principalmente:

- Desarrollar un segmento: identificar las actividades que deben ser expandidas, priorizadas, desarrolladas particularmente. Este objetivo en general se confunde con la estrategia de diferenciación o de agregado de un plus de valor, 
percibido como mejora de calidad, pudiendo implicar más costos en inversiones específicas para enfrentar los puntos débiles típicos de los FCE. El desafío sería buscar la estrategia de diferenciación que implique relativamente menos costos.

- Mantener o estabilizar un segmento: definir los segmentos a ser mantenidos en "baño maría", al mismo nivel de desarrollo histórico, en lo posible reduciendo costos. Aquí pueden constar segmentos de alta competitividad y valor, los cuales podrían ser apenas mantenidos en la actual posición, reduciendo costos y liberando recursos para otras actividades.

- Reducir el reclutamiento de clientes hacia un segmento: definir cuál seria necesario recortar o focalizar, desestimular, disminuir, negociando la transferencia parcial o total de actividades para la red (se entiende por focalización privilegiar un determinado tipo de usuario o nosología).

Para Porter (1982), habría tres estrategias genéricas, discutidas a continuación a partir de la obra de Crémadez \& Grateau, 1997: diferenciación, que implicaría definir una oferta única, exclusiva, diferenciada, percibida por todos como superior cualitativamente, cuyo acceso también podría ser diferenciado; liderągo en el costo, que representaría disminuir costos para liberar recursos para otros segmentos, sin comprometer la calidad; focalización (que puede evolucionar como estrategia de costos y/o diferenciación).

\section{Elaboración de los planes de acción}

Los planes incluyen los esfuerzos para actuar sobre la red de médicos de consultorio (que cuentan con pacientes), para implementar asociaciones, para formar médicos y personal paramédico, para comunicar el savoir-faire controlado, para adquirir nuevas tecnologías, para implementar nuevos modos de atención, etc.

El Plan de Acción es el "qué hacer" para implementar la Estrategia. Consistiría en un conjunto de actividades, tales como:

- Formas de apropiación/desarrollo de los FCE apuntando a enfrentar los puntos débiles identificados en el análisis, incorporación de tecnologías y de recursos humanos, entrenamientos, desarrollo de factores de calidad, etc.

- Acciones de negociación y de comunicación internas al hospital y con la red, incluyendo el establecimiento de sinergias y colaboraciones externas.

- Acciones apuntando a revalorizar un segmento, actuar sobre algún criterio del análisis del valor de bajo score, factible de intervención (cuando la decisión política es de buscar aumentar el valor). 
- Acciones apuntando a modificar el modelo asistencial, las formas de atención que caracterizan un determinado segmento, el perfil de tecnologías utilizadas.

- Acciones de naturaleza social e intersectorial.

- Acciones que desarrollen objetivos típicamente médicos, como determinadas investigaciones.

La consolidación de un plan de acción significa retomar continuamente el análisis estratégico del valor y de la posición competitiva, con el objetivo de aumentar el control de los FCE, para mejorar la posición estratégica general. El plan culmina con la definición de los indicadores de monitoreo de las acciones para que sea posible acompañar los cambios propuestos.

\section{Evaluación de las dificultades encontradas}

Esta evaluación se basa principalmente, en datos tomados de la Unidad de Análisis Estratégico del Centro Hospitalario de Lille, en los encuentros mantenidos durante nuestra visita a aquel complejo hospitalario, en encuentros desarrollados, con motivo de la presencia en Brasil de Monsieur Le Ludec ${ }^{2}$, en documentos citados que forman parte del material instructivo del enfoque y, en parte, en un análisis todavía parcial de algunas experiencias brasileras.

Entre las dificultades generales, se destacan: el escepticismo, el descreimiento en el cambio, las barreras de lenguaje, la desconfianza, la indiferencia y el rechazo a comprometerse.

En relación al diagnóstico, las mayores dificultades residen en la ausencia de sistemas de información al inicio de la démarche, en la opacidad de la actividad de la competencia, en la selección de la información cualitativa, en la debilidad de la base documental y en la pobreza de los datos epidemiológicos y/o en la dificultad de sistematizarlos.

En la etapa de la segmentación, algunos problemas se tornan evidentes:

- La segmentación es un concepto difícil de aprehender: el grupo médico tiende a confundir segmento y grupo homogéneo de enfermedad, en circunstancias que la segmentación de las prácticas de trabajo puede obedecer a otros criterios (como el tecnológico, el gerencial y el poblacional), más allá del criterio entidad epidemiológica. Esto genera algunas reticencias por parte de los profesionales.

- E lenguaje utilizado se aparta del vocabulario médico;

2 Monsieur Le Ludec es uno de los responsables del desarrollo de la démarche stratégique en Lille, acompañando la experiencia durante nueve años. 
- Existe una tendencia a definir una segmentación "territorial", como reflejo de una lucha por el poder o reveladora de problemas latenteso reveladora de problemas latentes.

Sobre la etapa del análisis estratégico, se detectaron otros problemas:

- La lógica de las escalas no es fácilmente percibida, existe múltiples interrogantes sobre la utilidad de la ponderación y de la notación;

- La notación es considerada definitiva cuando se examinan todos los segmentos;

- Los comentarios deben ser objeto de un consenso absoluto, lo que torna agobiante la formalización;

- Los servicios en posición de monopolio se prestan menos a este tipo de análisis;

- Surge la necesidad de la búsqueda de informaciones adicionales y, muchas veces, existe cierta dificultad en la obtención de los datos.

El proceso de elaboración de los planes, finalmente, enfrenta algunas dificultades:

- Los objetivos son a veces poco o mal definidos por falta de compromiso.

- Ausencia de participación de profesionales no médicos del hospital.

- Planes de acción de naturaleza esencialmente médica, sin vinculación con un proyecto social.

- Indicadores a veces difíciles de poner en práctica.

\section{Análisis crítico general}

En primer lugar, uno de los mayores méritos de la démarche es el de aportar la definición de objetivos médicos y desarrollo de un proceso de evaluación de las actividades institucionales y de la misión organizacional. El gran objetivo de la búsqueda de la articulación gerencial de un proyecto médico es, en gran medida, cumplido. Durante nuestra visita a la Unidad de Análisis Estratégico del CHRU, pudimos relevar y revisar los Proyectos de Establecimiento concluidos a lo largo de cuatro años de aplicación exhaustiva de la démarche. Prácticamente todos los servicios de los diferentes hospitales de este verdadero holding hospitalario fueron involucrados en esta lógica gerencial. Las etapas de desarrollo del proyecto de la démarche varían de servicio a servicio. Por todo esto, esta nueva racionalidad gerencial ya es una realidad, reconocida en Francia como uno de los modelos de gestión respetados. 
La aplicación de la démarche no es un proceso tan solo formal, que se resume a la documentación correspondiente a los proyectos de establecimiento centralizados en la Unidad de Análisis Estratégico. Su lógica de implementación, basada en reuniones colegiadas, tiene como objetivo, motivar una comunicación amplia al servicio de un cambio cultural. El desafío implícito es articular un colectivo en relación a un proyecto único, considerado por la red. Los resultados de la démarche se miden a lo largo del tiempo, en un proceso progresivo, interactivo, siempre exploratorio, capaz de impactos culturales decisivos. Esto no es una tarea fácil, semejante a la condición de una gestión racionalizadora o estabilizadora, de efectos inmediatos. Se trata de construir la colaboración, a través y principalmente, de nuevas colaboraciones, de la profundización de sinergias internas y de una nueva postura, más comunicativa entre los diferentes profesionales/actores.

La Coordinación de la Unidad de Análisis Estratégico garantiza, sin embargo, la existencia de resultados palpables, que constan en trabajos en vías de publicación, a los que tuvimos acceso durante la visita. Estos trabajos, como el de Thomas Le-Ludec (1995), acentúan en general el montaje de estructuras transversales de colaboración entre hospitales, especialidades y segmentos. La producción de resultados instrumentales, situados en la lógica de la optimización de la asignación de recursos y de la colaboración con la red, es, sin duda, una necesidad práctica, apremiante, de carácter legitimador.

Problematicemos un poco más el enfoque. Una de las principales restricciones a la démarche, surgida en nuestras discusiones, se refiere a la eventualidad de la segmentación estratégica "reforzar la atomización", en vez de "ayudar a la integración" (por ser muy molecular). Esta crítica es bastante seria y merece una discusión. Existe la posibilidad de que la segmentación se paute por la especialización del conocimiento médico y por la disputa de territorios. Por otro lado, debe considerarse que la aplicación general del enfoque es realizada servicio por servicio, disciplina por disciplina. Que el análisis estratégico de los segmentos es un trabajo hecho a nivel de pequeños grupos. Surgen preguntas naturales del tipo: ¿cómo promover la asociación, la coordinación horizontal, a fin de garantizar un proyecto integrado, con prioridades únicas por establecimiento? ¿Cómo compensar la tendencia a la diferenciación implícita en una segmentación muy molecular?

En realidad, este problema se plantea más allá de la especialidad, pues considerando la especialidad en sí, como una segmentación bien hecha, aportaría las bases técnicas necesarias para un análisis de prioridades que permitiría llegar, por la vía de la discusión crítica y democrática, a un consenso de la especialidad. Una buena descripción detallada de los grupos homogéneos de actividades ayudaría a establecer una dinámica de evaluación volcada hacia la caracterización de la posición estratégica diferencial de los mismos grupos. No, si es 
bueno en todo. Existen áreas de excelencia y de no excelencia. La no diferenciación de actividades podría ocultar particularidades y diferencias en posición estratégica, dificultando el proceso de priorización de actividades. Por otro lado, una segmentación basada en un diagnóstico médico rico y en la tentativa de agrupar actividades homogéneas a partir de la conjugación de diferentes criterios técnicos y sociales, puede ayudar a desmontar feudos montados a partir del ejercicio del poder y de la informalidad.

La cuestión se refiere al aspecto interespecialidades. Basados en las conversaciones que mantuvimos en la UAS, podemos señalar que la necesidad y la posibilidad de la integración dependen de una dinámica que obliga a asociar y desasociar interactivamente los grupos de trabajo y a buscar instancias de discusión más abarcativas, que superen el microcosmos del segmento, de la disciplina y hasta del hospital. Uno de los grandes desafíos del método está relacionado con la existencia de forum ampliados de asociación de intereses, donde se procesa el gran acuerdo o la gran negociación del proyecto hospitalario, inmanente a la lógica de la démarche.

Es importante subrayar que, si bien por un lado la segmentación puede ser considerada un factor de diferenciación, por otro, es a partir de la categoría celular de segmento que la démarche busca "hilvanar" la idea de una red integrada de oferta de cuidados. Una de las preocupaciones más importantes del plan de acción, consiste en destacar claramente las sinergias y colaboraciones potenciales inherentes a cada segmento para, a partir de allí explorar posibilidades de estructuras en red. No se debe olvidar que uno de los objetivos nucleares del enfoque es justamente el de crear un movimiento de transformación del hospital en una organización abierta. Detectar los puntos de sinergia y de complementariedad es la base para la formulación de lugares organizativos de discusión más amplia. Finalmente, debemos reforzar la idea de que la segmentación puede obedecer a criterios más integradores como el tipo de atención o población, más allá de una división basada en la diversidad de patologías o tecnologías. De esta manera, buscamos argumentar que la segmentación estratégica es la base de un proceso contradictorio de diferenciación y de integración, donde la búsqueda de la complementariedad y de la colaboración, es uno de los requisitos esenciales que debe ser garantizado por un tipo de metodología política de negociación que implique el desarrollo de discusiones transversales y el montaje de estructuras en red.

Una de las mayores dificultades se relaciona con la difícil aplicación de la démarche en situaciones de monopolio. Creemos que la démarche francesa supone un contexto de menor restricción de recursos y de competición, lo que no siempre sucede en los países en vías de desarrollo. Se puede argumentar que en algunos espacios de esos países adquieren mayor fuerza esas condiciones en el 
contexto, pero no en todos. Esta situación no invalida el enfoque, tan solo lo restringe en su aplicación. Podemos señalar que aún en una situación de competencia precaria o inexistente, la simulación de la competencia que puede virtualmente pasar a existir ayuda a establecer estrategias para mejorar el dominio de los factores clave de éxito de las actividades.

De todos modos, la perspectiva de aplicación del enfoque dependería de simplificaciones y adaptaciones a nuestro contexto. Vamos a referirnos, en general, a las principales reformulaciones que serían necesarias, de acuerdo con las discusiones preliminares desarrolladas en nuestro ámbito.

Todo indica que es necesaria una adaptación de los criterios involucrados en la determinación de la capacidad de atracción. En realidad, la relación de criterios y su peso específico son variables, ajustables al método, en función de las características del mercado de servicios de salud en cuestión, en cada momento. En esta línea, la idea de trabajar con un elenco menor de variables representativas, cuidadosamente seleccionadas, es algo absolutamente normal, teniendo en cuenta el contexto local y las posibilidades de manoseo de la metodología.

Otro aspecto que puede ser objeto de adaptaciones se refiere a la definición de objetivos. El método original no enfatiza la creación, por lo menos de forma explícita, de nuevos segmentos como parte de las principales estrategias, aunque esta posibilidad esté contemplada en el abordaje francés. Dada la necesidad eventual de abrir nuevos servicios, en función de carencias sanitarias, situación que es común en países con pocos recursos, la estrategia debería acrecentar las tres dimensiones de objetivo del enfoque (desarrollar, estabilizar, reducir) la meta de la creación de nuevas actividades.

En esta línea de razonamiento, consideramos necesario reforzar los criterios poblacionales y epidemiológicos, para contrarrestar las características de la démarche relacionadas a un modelo típico de planificación basado en la oferta. Esos criterios vinculados a la detección de necesidades de salud, deberían ser tomados en cuenta especialmente, en el análisis de la posibilidad de apertura de nuevos grupos de actividades y en el análisis del valor de los grupos de actividades (re)organizados, valiéndose de la estructura de la oferta preexistente. Debemos decir además, para hacer justicia al método, que el dato epidemiológico está incluido en el criterio "posibilidades de crecimiento" o "desarrollo de los segmentos", como parte del análisis del valor estratégico de los mismos o de su nivel de prioridad relativo.

Con estas consideraciones generales, concluimos aquí nuestra presentación panorámica del método de planificación de la démarche, no sin antes afirmar que vemos este enfoque como un modelo de gestión estratégica y comunicativa de la realidad hospitalaria con enormes posibilidades prácticas, como pudimos constatar en nuestra experiencia de aplicación en Brasil, que no es despreciable. 


\section{La Conquista de Ventajas de Competitividad: estrategias genéricas}

Cuando se retiene la supremacía de una capacidad que es fundamental para tener éxito en un segmento de actividad determinado, se dispone de una ventaja determinante sobre sus competidores. La ventaja competitiva se fundamenta en el hecho de que los usuarios (pacientes, quienes recomiendan, etc.) reconocen en la oferta de un competidor un incremento del valor suficiente para que prefieran recurrir a él. Este diferencial de valor se resume en general a una relación calidad/precio. En circunstancias donde la realidad de precios no impera, se puede apreciar el valor concedido a un servicio, por los esfuerzos hechos por el cliente para tener acceso a él (cambio de lugar, espera consentida...)

Se pueden seguir dos vías estratégicas generales para aumentar la base de ventajas competitivas disponible: aumentar el valor para el usuario o involucrar menos recursos sin disminuir el valor del servicio, tal como es percibido por el usuario, en términos de calidad.

La estrategia de diferenciación acentúa el valor. Esta vía supone la posibilidad de crear un incremento de valor superior al costo suplementario asignado para ese fin. La vía del aumento de la eficiencia, supone en cambio, que seamos capaces de racionalizar la producción de tal manera que la calidad no sea afectada y que esta racionalización genere un aumento de recursos suficiente para que su reasignación produzca una ventaja estratégica dominante.

Para detectar las fuentes de ventajas competitivas, seria necesario una visión analítica de los procesos de creación de valor al interior de una empresa y de sus interacciones, o sea, analizar su cadena de valor y la estructura de costos correspondiente. El término cadena de valor (oriundo de M. Porter) corresponde a la descripción de las actividades que la organización implementa para realizar y poner a disposición de los clientes sus productos o servicios.

Habría diferentes tipos de actividades:

- La gerencia y el conjunto de actividades estructurantes, incluyendo la negociación con los financiadores y los proveedores, la organización de actividades, la gestión de recursos humanos, el financiamiento de la inversión, los estudios de mercado, las elecciones tecnológicas y de tipo de servicios, etc.

- Las actividades de soporte operacional: se considera actividad de soporte operacional, toda actividad logística que no corresponde a un factor-clave de éxito para un segmento determinado de la actividad, pero que es necesaria para la realización de la prestación de servicio. En general, esta actividad corresponde a la logística no médica, factible de ser tercerizada porque no corresponde a un savoir-faire determinante en el juego competitivo. 
- Las actividades operacionales principales: son todas aquellas que compiten principal y directamente en la realización del servicio. Estas actividades pueden ser más o menos específicas de un segmento o ser compartidas por diferentes segmentos, como es el caso de la estructura tecnológica relativa a los sectores de imagen y de biología por ejemplo. Estas tecnologías se organizan en relación a procesos de atención más o menos formalizados, precisos y controlados. La concepción y la conducción de estos procesos deberían estar en el centro de la reflexión sobre el aumento de la eficiencia y el valor. Esta dimensión depende totalmente de la experiencia de los profesionales (médicos y paramédicos) y no es costumbre que sea objeto de intercambio de experiencias. Es, en esos procesos de atención que predominan las prácticas rutinarias y son raramente cuestionadas de forma regular y organizada. Por ende, son causas habituales de incremento del costo: redundancia de exámenes, exámenes inútiles y costosos, entre otros.

Los diferentes componentes de una cadena de valor no son independientes. Existen conexiones entre los diferentes componentes de la cadena de valor de un mismo segmento y entre componentes de segmentos diversos. Estos componentes presentan además conexiones con componentes de la cadena de valor de otras instituciones, con las cuales, la organización mantiene relaciones de referencia de pacientes, de provisión y compra de productos o de intercambio científico.

Las ventajas competitivas serian obtenidas a través de la intervención en estas conexiones, trabajando a nivel de cada componente generador de valor. La exploración de las conexiones es una fuente importante de ventajas, que sobreentiende la existencia de un buen sistema de comunicación/seguimiento. Crémadez incluye la logística médica y la comunicación informatizada como actividades operacionales principales, justamente por este motivo.

Existen innumerables ejemplos de exploración de las conexiones: la salida de un servicio clínico y la entrada en otro; la relación urgencia-servicios para el encaminamiento de los pacientes y la coherencia de su tratamiento; la conexión medicina-cirugía en algunas patologías y actos, como la cancerología, las hernias de disco, la insuficiencia coronaria, los transplantes, etc. y las relaciones de referencia y contra-referencia de pacientes con la red.

El conocimiento de la estructura de costos de los segmentos es de fundamental importancia para la definición de estrategias de obtención de ventajas. La estructura de costos de una actividad se caracteriza sintéticamente, por la proporción de costos fijos de origen central, de costos fijos específicos y de costos variables. Los costos fijos más importantes de las actividades hospitalarias corresponden a la infraestructura de internación/alojamiento, al personal y a las tecnologías implementadas. 
Cuando la estructura de costos de una actividad revela una preponderancia de costos fijos asignados sobre los costos fijos específicos y los costos variables, seria interesante optar por la búsqueda de ventajas estratégicas para los costos. Cuando se visualiza una preponderancia del costo variable unitario directo y de costos fijos específicos, en relación a los costos fijos centrales asignados, seria necesario pensar en términos de diferenciación. La diversidad de actividades de un establecimiento lleva a adoptar un mix de estrategias genéricas.

En otras palabras y según nuestra interpretación, la estrategia de costos, en general, seria justificada principalmente, cuando los segmentos dependen de tecnologías y de infraestructuras de internación, costosas y compartidas (que no representan costos fijos específicos). Sería necesario considerar estos recursos y minimizar la disputa garantizando recursos para todos, lo que demandaría una racionalización, como por ejemplo, controlar el tiempo de espera, bajando costos. A no ser que el segmento presente un fuerte potencial de diferenciación, el hecho de no contar con recursos propios (o potencial de captación de estos recursos) que generen costos fijos, como tecnologías, sugiere que la estrategia de diferenciación no seria la mejor opción. En este caso, la inversión necesaria en capacidad instalada, tecnologías y recursos humanos especializados representaría relativamente una nota menor, debido al bajo control, diminuyendo el score resultante del análisis de valor del segmento. La inversión a ser realizada dificultaría la obtención de ventajas comparativas vía diferenciación.

\section{La estrategia basada en los costos}

Es indispensable concebir una estrategia de costos en todos los segmentos de actividad que precisan de infraestructuras caras y compartidas, que presentan un costo variable unitario poco elevado y escasas formas de diferenciarse significativamente de los competidores.

Generalmente, la estrategia de costos consiste en privilegiar actividades que refuercen el potencial de sinergia ya existente -actividades para las cuales el control de los costos compartidos es un savoir-faire determinante-, como también eliminar costos específicos no justificados para garantizar la conexión más eficaz entre cadenas de valor.

El control del costo operacional de los recursos humanos supone inversiones en formación y en organización. Para el personal paramédico, se recomienda una formación polivalente y/o la creación de grupos polivalentes que permitan una mayor flexibilidad en su distribución a través de la organización, garantizando un fuerte grado de pertenencia a cada servicio específico hacia donde fueron destinados (una posición intermedia entre la gestión global o 
centralizada del cuerpo de profesionales y un destino fijo al interior de uno). Para el personal médico, se recomienda una formación que fomente una visión multidisciplinaria, como también el establecimiento permanente de contactos que apunten a la formulación de consensos sobre las prácticas profesionales.

Los costos de infraestructura son sensibles a la tasa de ocupación y de rotación por un lado y a la adecuación de los pacientes a la vocación de la estructura, por otro.

En una estrategia de costos, seria necesario maximizar la tasa de ocupación lo que dependería, en buena medida, de estructuras menos rígidas, más flexibles, que se adapten a las evoluciones del mercado, al rendimiento y a la propia evolución de la misión de la organización.

La rotación está vinculada al tiempo de espera de los pacientes. Para reducir costos, sería necesario combatir algunos procedimientos relacionados a la entrada y salida de pacientes y privilegiar estructuras de atención especializada, programada y de duración determinada, que exploren las sinergias entre actividades.

Es conveniente, también, regular las relaciones entre las estructuras técnicas de apoyo diagnóstico y terapéutico y los servicios clínicos, tomar en cuenta los puntos críticos no superables a corto plazo y recurrir eventualmente a colaboradores externos.

La adecuación depende del grado de correspondencia entre el tipo de cliente y la especialización de la estructura. La inadecuación es fuente de desperdicio de recursos y resulta, en gran medida, de servicios de selección y de orientación que funcionan mal.

El control del flujo de pacientes es un elemento fundamental en la reducción de costos. Una buena comunicación con los servicios que orientan pacientes y con aquellos que complementan un cuidado, es un factor clave de esa estrategia.

\section{Los costos tecnológicos}

El control de estos costos depende de la oportunidad de adquisición de equipamientos a precios estables, conocidos y que posibiliten un plazo de recuperación corto de las inversiones. Se debe evaluar los riesgos en el caso de superposición de equipamientos en los diferentes competidores y evitar equipamientos inactivos o semi-inactivos.

En segundo lugar es necesario considerar la concentración de equipamientos como factor de economías de escala y su utilización compartida cuando esto es necesario para alcanzar la masa crítica de actividad correspondiente al umbral de rentabilidad. 
El control del aprendizaje de la apropiación de las tecnologías es fundamental. Todas las etapas involucradas en la implementación de una tecnología, más allá de la mera manipulación, deben ser objeto de un entrenamiento que incluya a un conjunto diversificado de personas, de modo de no quedar restringido al operador. Este proceso debe incluir también el control y la gestión del proceso de substitución de tecnologías.

Los ritmos de utilización de los equipamientos, a fin de evitar los costos adicionales derivados de fluctuaciones (súper o subutilización), es otro factor importante en el control de costos tecnológicos, que depende de un buen control de la demanda y de los flujos de llegada.

Un elemento fundamental en una estrategia basada en los costos, es la investigación de innovaciones tecnológicas capaces de disminuir el tamaño de la infraestructura necesaria y/o de generar una substitución tecnológica que permita una mayor programación de la atención, un control creciente de los plazos de tratamiento y una tendencia hacia formas de tratamiento que impliquen tiempos menores de internación (tecnologías para cirugías menos invasivas por ejemplo).

\section{Los costos variables}

Representan una fracción menor del conjunto de recursos asignados en un establecimiento hospitalario, pero el margen de libertad depende en gran parte de su control.

La reducción de costos variables depende de dos medios fundamentales.

- La gestión del abastecimiento y del stock que se basa en el desarrollo de capacidades específicas.

La capacidad de negociación representa un factor importante de reducción de los costos de abastecimiento que no es implementado debidamente. Se basa en la selección, conocimiento del mercado, práctica de la competencia, utilización de los efectos de tamaño y de escala en las compras. Tanto la capacidad para explorar la sensibilidad de la estructura de costos de los proveedores, como el comportamiento del cliente: estabilidad de las especificaciones, plazos de pago, regularidad y volumen de los pedidos unitarios, etc.; son factores de reducción de los costos de los proveedores de los cuales podemos sacar partido en las negociaciones. La tercera capacidad específica es el rigor en la definición de las especificaciones de los productos comprados y, principalmente en la definición de su adaptación por unidades en función de las prácticas de consumo (evitando el desperdicio debido a embalajes no adaptados por ejemplo).

- La formalización de las prácticas de atención y su análisis crítico regular 
La implementación de rutinas profesionales a través de la formalización es indispensable para controlar los costos variables, ya que la formalización actuaría positivamente, en términos de eficiencia, sobre los tres componentes fundamentales de los costos variables: los actos producidos, los productos farmacéuticos consumidos y el material de consumo.

\section{Estrategias de diferenciación}

La diferenciación, en general, se confunde con el desarrollo de una capacidad médica específica, asociada, en ciertos casos, al control de ciertas tecnologías. Esta es la vía de diferenciación más común históricamente. Pero no es y no debería ser la única.

La diferenciación puede operar modificando uno o diferentes elementos de la cadena de valor, explorando las relaciones entre los elementos de las cadenas de valor de dos segmentos que presentan sinergias potenciales y modificando la conexión y la coordinación con los colaboradores externos. Todos estos elementos pueden jugar un papel determinante en la satisfacción global del cliente.

\section{Modificación de la cadena de valor de un segmento}

Esta estrategia puede consistir en introducir un servicio complementario en el seno de la cadena de valor de un segmento: desarrollo de cuidados paliativos en el tratamiento del cáncer; aumento del número de formas de preparación del parto en obstetricia. Puede significar, también, completar o modificar solo un componente de la cadena de valor: el pasaje de un "servicio-puerta de entrada" (selección) para la admisión directa, puede ser una vía de diferenciación que cuestiona los elementos de acceso, recepción, comunicación clientes-sistema de referencia de la cadena de valor de diferentes servicios. Es el complemento normal de la especialización de los servicios clínicos. En efecto, la especialización tiene poco impacto si no es acompañada de una ampliación de las relaciones con el sistema de referencia que permita el recurso directo.

La pérdida de flexibilidad introducida por la especialización puede ser compensada a través de la creación de estructuras intermediarias concebidas para responder a las necesidades de los pacientes fuera de la etapa aguda y para economizar recursos poco frecuentes y costosos (compartir estas estructuras entre los servicios es extremadamente necesario y aún poco experimentado). Una mayor articulación con los colaboradores externos puede evitar una prolongación indebida de las internaciones. 
Modificación de la conexión y coordinación

entre dos segmentos que presentan sinergias

Corresponde a la reestructuración de las relaciones entre dos segmentos con la finalidad de explorar nuevas sinergias: estrechar los lazos entre los médicos especializados y la cirugía en relación a la problemática de los transplantes, o entre la pediatría y la obstetricia para ofrecer un servicio más completo para las futuras madres y para generar efectos positivos en el sentido del recurso posterior a este hospital en lo que concierne al acompañamiento de los hijos.

Modificación de la conexión y de la coordinación con colaboradores externos

Significa el establecimiento de colaboraciones apuntando a suplir carencias de equipamientos, desarrollar investigación clínica, participar de la enseñanza universitaria o de posgraduación, disminuir el tiempo de permanencia, beneficiarse de la transferencia de tecnología, etc.

Como la diferenciación puede implicar el aumento de los costos, el gran desafío que enfrenta esta estrategia es la elección de formas de diferenciación relativamente menos costosas, donde la ganancia en valor o calidad del servicio prestado supere los aumentos de costos.

A estas dos estrategias genéricas deberíamos sumarle una tercera, ya indicada anteriormente, la Focalización, que consistiría en recortar un segmento o en privilegiar dentro del mismo una determinada categoría de usuario, de nosología clínica o de tipo de tecnología de atención. Por ejemplo, restringir el ambulatorio de adultos de un determinado hospital psiquiátrico, a la población sujeta a un área programática menor o a las patologías de mayor complejidad. O más aún, privilegiar dentro del mismo, un tipo de atención para aquellos casos más programables, referenciados (paciente vinculado a una determinado equipo), de naturaleza multidisciplinaria.

\section{El Hospital como Estructura en Red}

Como ya fue señalado, uno de los objetivos estratégicos del enfoque en cuestión es el establecimiento de redes de cooperación interna y externa, y un tipo de estructura organizacional coherente con esa perspectiva. 
Cremadez y Grateau (1992), reconocen la posibilidad de cuatro tipos de cooperación eventual. En este sentido recrean, para el contexto sanitario, las formas de alianza estratégica definidas en el texto sobre Política General de Empresa: "Stratégie, Structure, Décision, Identitee, del grupo Strategor (1997). Estos tipos de estructura organizacional son los siguientes:

- Colaboración vertical: corresponde a la coordinación de los roles de los establecimientos en el seno de un mismo proceso de prestación de cuidados. Por ejemplo, integración entre los niveles primario, secundario y terciario de un determinado dominio de actividad (implantación de un sistema de referencia y contra-referencia materno-infantil).

- Integración Conjunta: corresponde a compartir la tecnología, especialmente de recursos poco frecuentes (diagnóstico y terapia). Aquí, sin eliminar completamente la competencia virtualmente existente, se paraliza un elemento de la misma.

- Acrecentamiento o aumento: En este caso, no existe la competencia. Se articulan establecimientos o unidades en torno a servicios completos, constituyéndose un potencial común. Por ejemplo: organización de investigaciones multicéntricas. En este caso la competencia virtual cede el lugar a la competencia interna.

- Complementación: Consiste en la valorización de las contribuciones complementarias, en la generación de una práctica diferenciada, útil para todos los cooperantes. Ejemplo: cooperación entre redes de cuidados, entre la medicina y la geriatría, substituyendo la competencia por la cooperación.

Es importante rescatar la idea de que el proceso de integración estratégica del enfoque en cuestión no se vincula con una visión monolítica de la salud pública, representada por la propuesta de un único modelo de integración sugerido por la regulación central, considerado un modelo de optimización. La red debe ser vista como el resultado de la imbricación de las oportunidades, de diferentes formas de cooperación, que se les ofrecen a los actores que componen un sistema. Es un concepto que reposa sobre la capacidad de negociación y contractualización de los actores, ya referida. El papel de la regulación seria el de incitar, activar y coordinar este proceso de aproximación y de relacionamiento, respetando la diversidad. En este sentido, la vía de la responsabilización de los actores no tiene nada que ver con un tipo de planificación tecnocrática (Rivera, 1998).

Con respecto al postulado de la organización en red interna, es necesario señalar que actualmente, el paradigma predominante debería ser el de la flexibilidad y adaptabilidad organizacional. Se postulan estructuras planas, con un número mínimo de niveles jerárquicos y unidades de pequeño tamaño y gran amplitud de acción. Este ideal organizacional ya es una realidad en el ámbito 
hospitalario. El gran problema hospitalario es, aún, la falta de integración o la diferenciación exagerada, que debe ser compensada.

La estructura en red interna, planteada como alternativa a la diferenciación desmedida, es definida como la organización de las relaciones entre individuos de multipertenencias, que asumen roles flexibles en el seno de procesos de integración, susceptibles de valorizar el potencial de riqueza y de innovación vinculado a una diferenciación incitada o estimulada.

La estructura pertinente posibilita el aumento de la iniciativa y la innovación, crea la posibilidad de nuevos servicios que pueden significar una ventaja competitiva, y permite el encuentro de dimensiones estratégicas interdependientes y de importancia equivalente (sin jerarquía).

Las principales características de una organización en red interna para Creémadez (1997) serían las siguientes:

- La dinámica organizacional supera (o prevalece sobre) las formas estructurales.

- Un profesional puede ser responsable de una dimensión de la organización y subordinado al responsable de otra dimensión. Esta estructura estimula la capacidad de liderazgo de la organización.

- La misión del liderazgo formal sería movilizar el potencial de iniciativa de la organización al servicio de una perspectiva estratégica.

- El dirigente debe preocuparse por la adhesión de los actores a los ejes de colaboración. La desjerarquización de la participación en las instancias de integración es un imperativo.

- En una estructura en red, la estrategia y las opciones en general son elaboradas en conjunto, en una perspectiva global.

- El Poder se basa en la capacidad de hacer llegar la información a los individuos que están mejor ubicados para utilizarla, sin retenerla.

- La solidaridad predomina, el desempeño es colectivo.

- Los procesos son de auto-organización.

- No se debe descuidar el ámbito externo, que es el peligro implícito en la excesiva preocupación por las relaciones internas.

Una Red estaría compuesta por polos que combinan las unidades de base en función de conexiones que apuntan a obtener la integración deseada. Estas conexiones pueden corresponder estructuralmente a comités permanentes o temporarios o a departamentos y pueden darse en diferentes planos: conexiones económicas, burocráticas, operacionales, culturales, etc., siendo que varias dimensiones pueden estar presentes simultáneamente. 
En relación al poder de activación, de creación de nuevos intercambios, de nuevas conexiones, se defiende un modo de activación controlada: gran efervescencia en la base, limitada por procesos de selección de iniciativas en la cúpula.

El conjunto del dispositivo estaría basado en el principio de la auto-organización de las relaciones entre las unidades, que se desarrolla en los polos de integración, y de la auto-organización de las unidades de base, correspondiendo a un modelo de descentralización, que es más amplio en la medida en que las unidades son de tamaño reducido y que la organización es plana, achatada. La capacidad de representación en las estructuras de integración estaría basada en la competencia relacionada a la problemática tratada y no en la línea jerárquica (en la jefatura tradicional).

El enfoque sugiere la posibilidad de diferentes criterios de definición de ejes transversales: población (ancianos, madre-hijo...), conjunto de patologías (oncología, endocrinología), campo anatómico (visceral, neurológico), implementación de tecnologías más o menos sofisticadas (cirugía, transplantes).

En relación a este último aspecto, algunas técnicas permitirían una estructura de tratamiento multidisciplinario, como por ejemplo (Le Ludec, 1995a apud Rivera, 1998): reagrupar en torno a las técnicas láser a gastroenterólogos, dermatólogos, ginecólogos y cirujanos; reagrupar a fisiólogos, radiólogos y neurólogos en torno a la ecografía vascular; reunir en torno a la cirugía anti-arrítmica de cardiólogos, cirujanos cardiovasculares, ingenieros bio-médicos.

Se trata, por lo tanto, de movilizar las sinergias alrededor de aproximaciones multidisciplinarias, de la problemática de las emergencias, de los ancianos, etc. O sea, superar la rígida atomización entre las unidades de base correspondientes a las tradicionales especialidades médicas, procurando articularlas a partir de los criterios anteriores, considerados en un sentido abarcativo. Se concede una particular importancia, aún, al criterio gerencial: tipo de atención en este proceso de desatomización.

El objetivo central de la estructura en red es desarrollar redes de reflexión estratégica. Las conexiones varían. Algunas son importantes estratégicamente, pero no generan vínculos operacionales pesados y continuos, mientras que otras, si lo hacen.

Cuando el campo transversal de las relaciones aumenta (muchas unidades de base contempladas), la densidad de las relaciones operacionales disminuye, lo que proporciona una centralización vertical en la dimensión estratégica y una descentralización horizontal importante. Esto corresponde a un contexto organizacional donde varias unidades siguen directrices estratégicas comunes con gran autonomía operacional.

En la búsqueda de la transversalidad, el enfoque hace justicia al criterio gerencial, como potencial factor de integración o de encuentro de la diversidad. 
Se sustenta en la necesidad de explorar las formas o modos de atención (ambulatorio, hospital de día, emergencias, etc.) como posibles lugares de negociación interdisciplinaria. Esta forma de gerenciamiento sustenta la necesidad de normalizar los modos de atención para organizar la diversidad, como veremos más adelante. Esta normalización implicaría la definición comunicativa de las características de los procesos de trabajo respectivos y de sus condiciones de éxito o, dicho de otro modo, el establecimiento de diálogos internos volcados hacia generar acuerdos sobre estas variables de las formas de atención. Esta definición daría subsidios complementarios para una política de mayor adaptación del perfil de los recursos humanos.

Este método de gerenciamiento asume la necesidad de cuestionar la rigidez organizacional, promoviendo la movilidad y la polivalencia y una mejor planificación de la asignación de recursos humanos, teniendo en cuenta el grado de adaptación de los mismos a las necesidades tecnológicas del trabajo y sus expectativas de satisfacción. De la misma forma que, en relación al uso de la categoría modo de atención como posibilidad de diálogo normalizador al servicio de la transversalidad, el enfoque asume la gestión de recursos humanos como un gran locus de reflexión estratégica sobre la motivación de los profesionales (recursos humanos), más allá de la especialización, como será desarrollado posteriormente.

\section{La Organización de la Diversidad en Torno al Concepto de Modo de Atención}

Crémadez y Grateau (1997) parten de la premisa de que la evolución tecnológica acarrea diferentes fenómenos, en gran parte articulados: una diversificación importante de los modos de atención; el aumento de infraestructuras compartidas por distintos tipos de profesionales; una interdependencia creciente entre las unidades clínicas y logísticas; la oferta directa por parte de las estructuras técnicas de apoyo diagnóstico y terapéutico de prestaciones específicas. Estos fenómenos corresponden, en general, a la creciente disociación de la actividad clínica de las infraestructuras, en las cuales se ejerce esta actividad (que deja de ser ejercida en un único lugar). Esto multiplica y torna más complejos los procesos de trabajo, las combinaciones de procesos y los lugares y condiciones del ejercicio profesional,

De territorios casi privados, las unidades de cuidados se transforman en herramientas compartidas, en tipos de estructuras técnicas cada vez más diferenciadas, que ofrecen a los profesionales y a los pacientes, recursos adaptados a una concepción más variada y más abierta de las prácticas de cuidados. 
En consecuencia, existe una creciente diversificación de los procesos de atención y, paradójicamente, un aumento del grado de interdependencia de los mismos y de las múltiples actividades que componen la cadena de valor de cada uno de estos procesos. La necesidad de una mayor interdependencia se expresa tanto al interior de cada hospital, como entre éste y la red.

Una diversidad creciente de actores es movilizada por los procesos de trabajo, en función del carácter cada vez más transversal. Frente a este panorama, surge la necesidad de un trabajo de gestión de la diversidad, de análisis y optimización de los procesos, que pueda actuar como "efecto de potenciación" para la comunicación y comprensión entre los actores involucrados; y de eficacia, en relación al control de calidad y de costos. Preocupados con la necesidad de racionalizar el trabajo al interior de los hospitales, Cremadez y Grateau sugieren la propuesta de intentar reducir la diversidad de procesos de producción de cuidados, identificando un número limitado de procesos operacionales/tipos, correspondientes a modos de atención aglutinadores.

El objetivo de este trabajo de gestión o de organización de la diversidad sería promover la modalidad, la normalización de un número limitado de procesos implementados en tantas estructuras diferentes (de servicios especializados) cuanto mayor sea el tamaño del establecimiento. Esta visión, que concede un privilegio a la categoría modo de atención, rompe con la imagen de la práctica médica como un tipo de prestación que depende fundamentalmente de la tecnicidad de sus actos, de la personalidad y capacidad de los profesionales especializados, y que se ejerce a través de un único modo de atención.

Un modo de atención es definido como la normalización del proceso (o el conjunto de su recorrido) que se realiza a partir del seguimiento de un paciente, a fin de satisfacer la necesidad que lo lleva a recorrer esa institución. Un modo de atención caracteriza la organización del trabajo en el seno de la estructura (hospital, especialidad, servicio) que se dedica a su implementación, y el tipo de relaciones que mantiene con las unidades prestadoras de servicios que contribuyen para esta atención. Un modo de atención es de cierta manera, un proceso depurado de las particularidades vinculadas a un dominio de cuidados preciso (especialidad). En este sentido, se puede hablar de normalización.

Los principales modos de atención identificados son: Hospitalización Convencional; Hospitalización Domiciliaria; Consultorio; Emergencias; Hospitalización Programada de Duración Determinada (integración de varias especialidades en un mismo establecimiento que trata de eventos nosológicos programables), etc.

El principal objetivo de esta modalidad es ayudar a la gestión operacional, en la medida en que permite padronizar y controlar procesos productivos, apuntando a una mayor calidad y eficiencia; y adecuar los recursos (especialmente, los recursos humanos) a los mismos. Esta normalización ayuda a los 
prestadores logísticos, a adaptar sus servicios a las características de cada modelo de atención y permite, además, definir los niveles de exigencia que cada uno de ellos debería atender para obtener una ventaja comparativa.

Los autores sugieren una propuesta de lectura y de análisis de estos modelos, constituida por variables que permiten identificar las características de cada modo de atención, y, de variables que corresponden a factores determinantes de su desempeño, como veremos a continuación (Figura 6).

Estas variables permiten diagramar los diferentes modos de atención y compararlos. Esta diagramación implica la atribución por consenso de valores de cero a 4 a las dimensiones y a los factores abarcados por las variables, en función de su importancia relativa para cada modo de atención. Presentaremos dos diagramas correspondientes a emergencia y hospitalización programada de duración determinada (HPDD), considerando los dos tipos de variables señaladas.

El análisis comparativo de los dos modos revela que, desde el punto de vista de los factores determinantes de la satisfacción, la HPDD es mucho más exigente, considerándose las posibilidades de obtención de ventajas comparativas. Este modo es altamente sensible a todos los criterios, mientras que el otro es sensible apenas a algunos. Para que el modo HPDD tenga éxito, debe responder de manera satisfactoria al nivel de exigencia requerido. Cuestiones como la observación de los plazos, el control del desempeño administrativo y una mayor padronización de procedimientos son factores claramente distintivos.

Los dos modos responden a necesidades diferentes. Esto significa que cada vez que se atienda un paciente en emergencia que se beneficiaría más de una HPDD, se genera una satisfacción menor y se aceptarán disfuncionalidades que colocarán a la institución en una posición vulnerable frente a un competidor capaz de ofrecer una atención adaptada.

Una modalidad de este tipo permitiría:

- Encaminar a los pacientes a los modos de atención susceptibles de aumentar su satisfacción.

- Limitar las disfuncionalidades vinculadas a la inadaptación de los procesos y de las estructuras a la diversificación de las necesidades.

- Ofrecer nuevas fuentes de satisfacción a los recursos humanos.

La idea central de esta aproximación es permitir el inicio de un diálogo entre profesionales de distintas especialidades en torno de criterios gerenciales, definidos por los modelos de atención señalados. Este proceso de comunicación (de alcance progresivamente creciente), apuntaría a estructurar un lenguaje o un glosario común, desarrollar una capacidad de concepción operacional, capaz de aglutinar, de integrar, de permitir contactos interdisciplinarios (Rivera, 1998). 


\section{Figura 6 - Caracterización de tipos de atención.}

\begin{tabular}{|c|c|}
\hline Características de los procesos implementados & Comentarios \\
\hline \multicolumn{2}{|l|}{ Parámetros de concepción } \\
\hline Control del tiempo & ¿En qué medida esta dimensión es considerada? \\
\hline Flexibilidad & ¿Existe la necesidad de adaptación? \\
\hline Polivalencia & ¿Cuál es el grado de heterogeneidad de las actividades? \\
\hline \multicolumn{2}{|l|}{ Nivel de complejidad } \\
\hline Sofisticación técnica & ¿Cuál es el grado de sofisticación de los actos practicados? \\
\hline Multiplicidad de intervinientes & ¿Son numerosos los intervinientes? \\
\hline Variantes & ¿Cuál es el grado de ramificación del proceso? \\
\hline \multicolumn{2}{|l|}{ Modo de regulación clave } \\
\hline Formalización/Padronización & ¿Son codificados los procedimientos? \\
\hline Adaptación mutua entre actores & ¿Son densas las relaciones entre los actores? \\
\hline Programación & ¿Es necesaria la planificación? \\
\hline \multicolumn{2}{|l|}{ Capacidad de adaptación } \\
\hline Discontinuidad & ¿Es fundamental la variable de los flujos? \\
\hline Imprevisto & ¿El imprevisto es inherente al modo $x ?$ \\
\hline Insertaza & ¿Es adaptable la atención al proceso? \\
\hline \multicolumn{2}{|l|}{ Actitud clave } \\
\hline Proatividad & ¿Es necesario anticipar? \\
\hline Reactividad & ¿Es necesario reaccionar rápidamente? \\
\hline Selectividad & ¿Es necesario saber escoger (realizar una selección)? \\
\hline
\end{tabular}

\begin{tabular}{|c|c|}
\hline Factores determinantes del desempeño & Comentarios \\
\hline \multicolumn{2}{|l|}{ Relación con el tiempo } \\
\hline $\begin{array}{l}\text { Observación de los plazos } \\
\text { Espera } \\
\text { Duración }\end{array}$ & $\begin{array}{l}\text { ¿En qué medida la satisfacción del paciente depende de la } \\
\text { observación de cada uno de los criterios que califican la relación con } \\
\text { el tiempo característica del modo estudiado? }\end{array}$ \\
\hline \multicolumn{2}{|l|}{ Regulación de las conexiones } \\
\hline $\begin{array}{l}\text { Antes } \\
\text { Interno } \\
\text { Después }\end{array}$ & $\begin{array}{l}\text { ¿En qué medida la calidad de las prestaciones, es función del control } \\
\text { de lo que ocurre antes, durante y después de la hospitalización? }\end{array}$ \\
\hline \multicolumn{2}{|l|}{ Controle de las prestaciones } \\
\hline $\begin{array}{l}\text { Médicas } \\
\text { Logísticas } \\
\text { Administrativas }\end{array}$ & $\begin{array}{l}\text { ¿En qué medida la calidad de este tipo de prestaciones influye sobre } \\
\text { la satisfacción del paciente? }\end{array}$ \\
\hline \multicolumn{2}{|l|}{ Integración } \\
\hline $\begin{array}{l}\text { En el seno del equipo de base } \\
\text { Con actores complementarios } \\
\text { Con otras unidades }\end{array}$ & $\begin{array}{l}\text { ¿En qué medida la calidad de la colaboración entre los tres niveles de } \\
\text { organización del hospital influye sobre la calidad de la prestación y } \\
\text { sobre la satisfacción del cliente? }\end{array}$ \\
\hline \multicolumn{2}{|l|}{ Formalización } \\
\hline $\begin{array}{l}\text { Modo de selección } \\
\text { Protocolos clínicos } \\
\text { Procesos de atención }\end{array}$ & $\begin{array}{l}\text { ¿En qué medida la calidad de la prestación es determinada por una } \\
\text { descripción precisa del campo de acción abarcado por el modo de } \\
\text { atención (quién, porqué, cómo)? }\end{array}$ \\
\hline
\end{tabular}


Figura 7 - Comparación de las características de dos modos de atención.

\section{Emergencia}

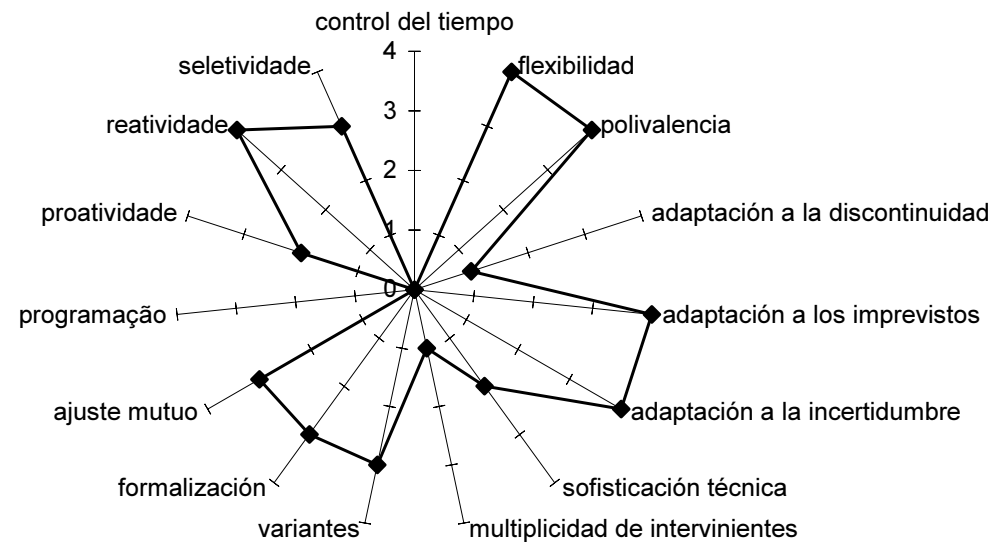

Hospitalización programada de duración determinada

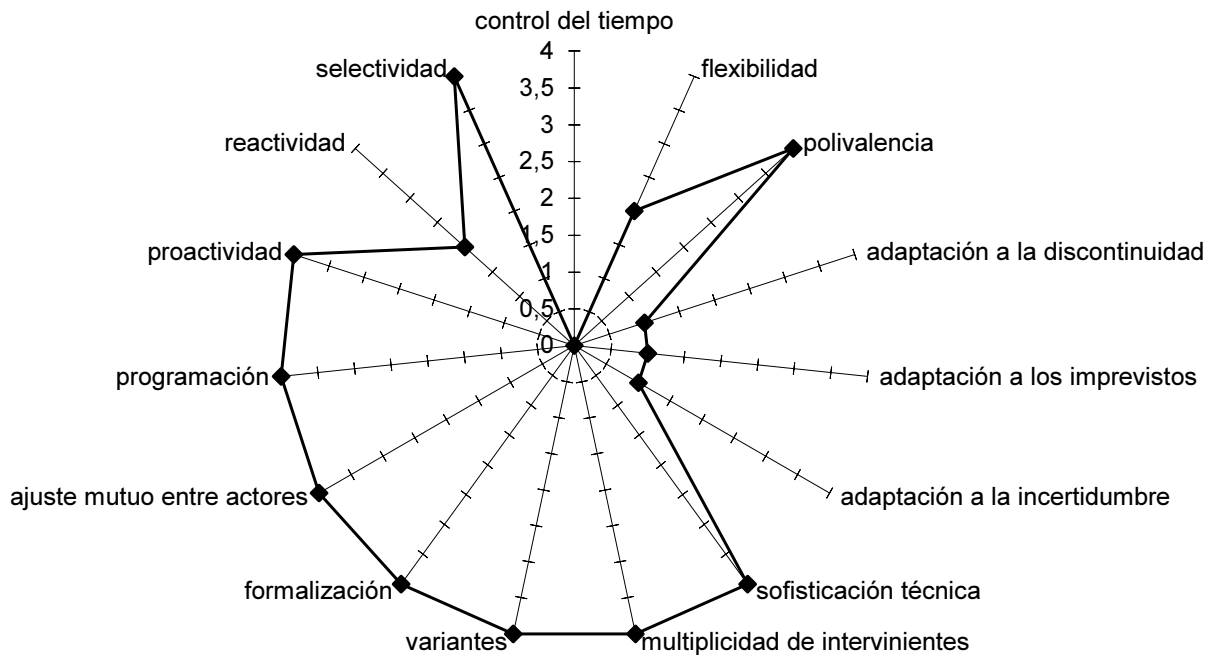


Figura 8 - Comparación de los factores determinantes del desempeño.

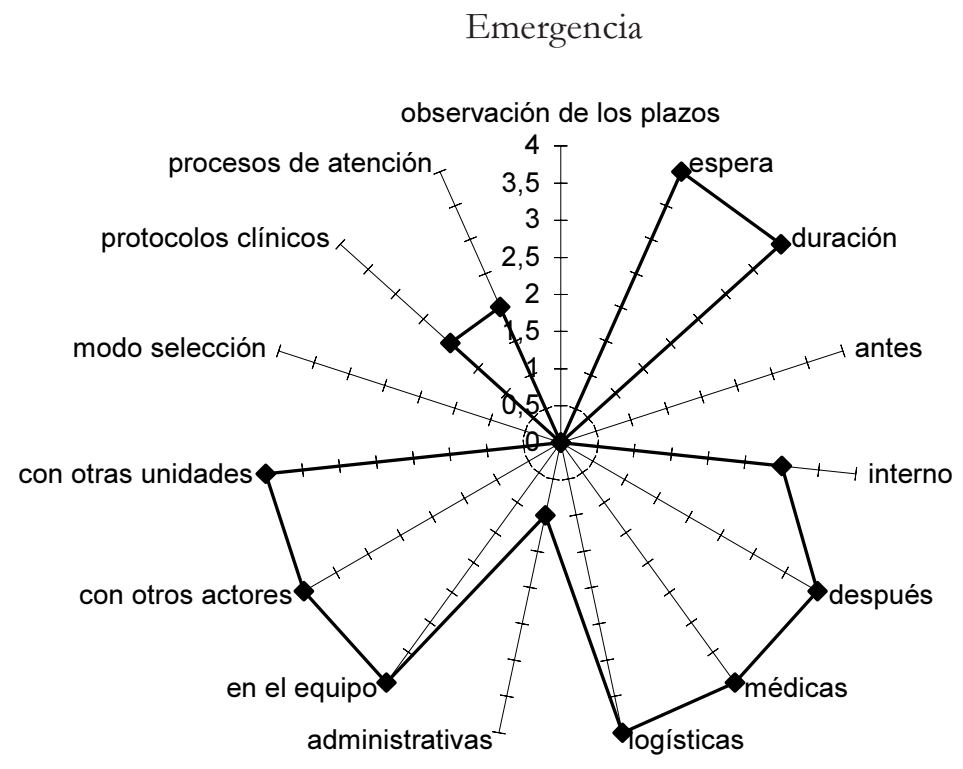

Hospitalización programada de duración determinada

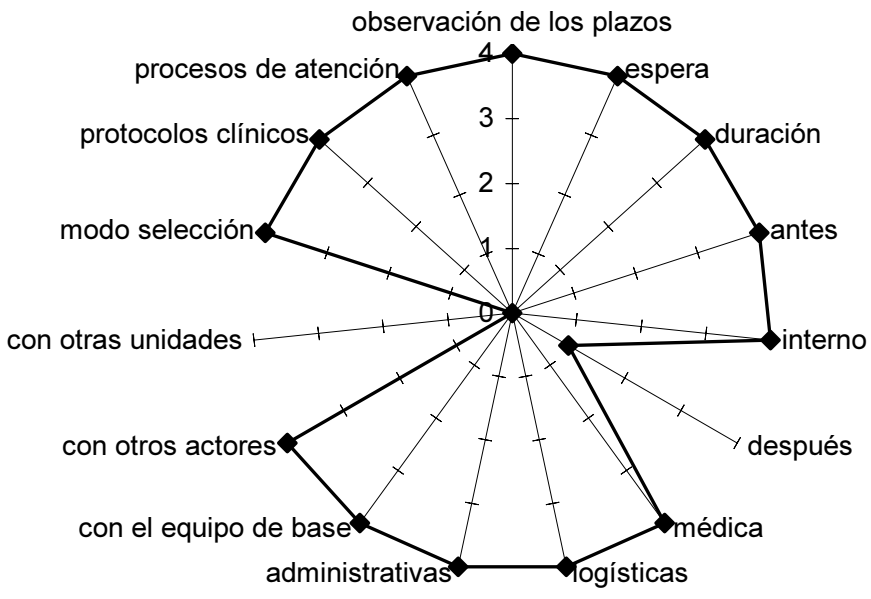


Toda la práctica de la démarche estratégica tiene como objetivo fundamentalmente, la búsqueda de la integración como alternativa a la diferenciación de las organizaciones profesionales, rescatando el trazo cultural de la autonomía, lo que significa apostar a procesos de gestión ascendentes. Aún refiriéndose a la segmentación estratégica (definición de los productos de las especialidades hospitalarias en términos de agrupaciones homogéneas de actividades), esta preocupación está presente: la búsqueda de la transversalidad problemática, de las sinergias operacionales y culturales.

En la práctica, el rescate del componente gerencial tipo, o modo de atención, como fenómeno aglutinador, introduce una nueva forma de transversalidad, que se suma a los criterios de población, tecnología, conjunto de patologías, etc., (de la segmentación estratégica), que permitiría compactar el campo de las posibilidades de estructuras en red interna (Rivera, 1998).

Como afirman los autores (Crémadez \& Grateau, 1997: 395):

Depuis quelques anneés, la diversité s'impose progressivement à l'hôpital, sans qu'il soit preparé à l'assumer, ce qui provoque un certain nombre des convulsions dont nous sommes témoins actuallement. Pour y faire face, il lui faut adapter sa culture e ses modes d' action et être capable de plus de formalization pour faciliter la communication qui devient une variable déterminante de l'efficacité en permettant à l'efficience des différents professionnels de mieux se conjuguer. Mais il lui faut aussi apprendre à standardiser ses pratiques sans les uniformizer et sans perdre la flexibilité et l'adaptabilité que lui confere sa caractéristique de structure organique.

La organización de la diversidad, coherente con la referencia anterior, permite un doble movimiento: normalización-diferenciación. La modalidad de los modos de atención, en función de los procesos abarcados, supondría el movimiento contrario: la adaptación de esa modalidad general al contexto organizacional específico de los profesionales que organizan sus prácticas en función de la población específica que atienden, de las patologías pertinentes y de las tecnologías ad-hoc del servicio.

\section{La Gestión de Recursos Humanos como Interacción en la Búsqueda de la Flexibilidad y de la Motivación}

El enfoque estratégico planteado, se propone cuestionar la rigidez organizacional, desde el punto de vista de los recursos humanos a través de dos fenómenos: la falta de movilidad profesional y la inexistencia de una política de planificación y de gestión operativa de esos recursos, apoyada en la búsqueda de una adaptación entre las exigencias de calidad (de perfil) y las fuentes de satisfac- 
ción implícitas en los procesos de trabajo, por un lado, y la asignación de recursos profesionales, por otro.

La asignación de recursos humanos sigue, predominantemente, una vía jerárquica, caracterizada por el predominio del criterio tecnocrático de la especialidad y de la disciplina médica, sin considerar el criterio gerencial de la diversidad de formas de práctica que una misma especialidad puede asumir. Más allá de la consideración exclusiva de las capacidades técnicas individuales, los autores analizados proponen la necesidad de una nueva concepción de carreras, horizontal, fundamentada en la diversidad de condiciones de ejercicio de las (mismas) capacidades profesionales en el hospital.

En este sentido, se apoyan en el concepto ya analizado de modo de atención. Cada uno de los modos o tipos de atención identificados corresponde a una "situación profesional", representa una faceta del quehacer médico. Cada uno requiere cualidades humanas y profesionales singulares, determina condiciones de trabajo y ofrece fuentes de satisfacción específicas que conceden, a un determinado quehacer, una riqueza singular.

Trabajar en el centro quirúrgico, en reanimación, en un servicio de geriatría, en la unidad ambulatoria de un hospital, en la hospitalización domiciliaria, en consultorio, etc., son situaciones profesionales que requieren aptitudes, saberes específicos, capacidades, características psicológicas diferentes. Por otro lado, estas situaciones necesitan fuentes de satisfacción y de motivación específicas. Caracterizarlas y utilizar su riqueza y diversidad para concebir formas de encaminar las carreras y una gestión de personal moderna, parece ser primordial. Organizar la movilidad sobre la base del concepto de modo o tipo de atención puede ofrecer múltiples formas de satisfacción, nuevas motivaciones y nuevas perspectivas de evolución para los individuos.

Para explicitar lo anterior, se puede realizar un ejercicio análogo al que fue propuesto con relación a la diferenciación de los modos de atención. Básicamente, pueden ser construidos dos cuadros de variables: uno, correspondiente a las cualidades requeridas (en términos de perfil profesional), y otro, representado por las fuentes de satisfacción (Figuras 9 y 10). Ejemplos: 
Figura 9 - Ejemplos de cualidades requeridas.

\begin{tabular}{|l|l|}
\hline \multicolumn{1}{|c|}{ Cualidades requeridas } & \multicolumn{1}{c|}{ Comentarios } \\
\hline Capacidades profesionales & \multicolumn{1}{c|}{$\begin{array}{l}\text { Nivel de tecnicidad requerido } \\
\text { Exigencias de educación de los pacientes } \\
\text { Necesidad de renovar conocimientos y prácticas }\end{array}$} \\
\hline Pécnica & \\
Actualización & Concebir y organizar la atención \\
\hline Aptitudes personales & Decidir frente a situaciones imprevistas \\
\hline Aptitud de Concepción & Abrirse al prójimo y comunicarse \\
Aptitud decisional & \\
Aptitud relacional & $\begin{array}{l}\text { Organización personal, método y rigor } \\
\text { Inserción grupal, contribución al trabajo colectivo } \\
\text { Capacidades de acción coletiva }\end{array}$ \\
\hline $\begin{array}{l}\text { Auto-organización } \\
\text { Trabajo en equipo } \\
\text { Gestión de colaboraciones }\end{array}$ &
\end{tabular}

Figura 10 - Ejemplos de fuentes de satisfacción.

\begin{tabular}{|l|l|}
\hline \multicolumn{1}{|c|}{ Fuentes de satisfacción } & \multicolumn{1}{c|}{ Comentarios } \\
\hline Inserción profesional & $\begin{array}{l}\text { Reconocimiento al interior de un grupo, } \\
\text { sentimiento de pertenencia } \\
\text { Compromiso y capacidad de iniciativa }\end{array}$ \\
Responsabilidad & $\begin{array}{l}\text { Sofisticación de las prácticas profesionales } \\
\text { Involucramiento y sentimiento de utilidad }\end{array}$ \\
Carga afectiva & Facilidad en el relacionamiento interpersonal \\
Control de la relación con el otro & Libertad de acción \\
Autonomía & \\
\hline
\end{tabular}

Estos cuadros de variables nos permiten establecer diferentes diagramas referentes a los diferentes tipos de atención, donde se procura identificar el nivel de exigencia de cada variable y el grado de involucramiento de los factores de motivación señalados en cada modo específico. Para simplificar y considerando que este trabajo es apenas una introducción al tema, presentaremos los casos de hospitalización convencional y de hospitalización domiciliaria (Figura 11).

De este modo, trabajar en una hospitalización domiciliaria puede transformar la capacidad de auto-organización en un elemento clave, mientras que esta presentará un interés mínimo en un contexto sedentario y estructurado como es la hospitalización convencional, que requerirá capacidades de trabajo en equipo, pero menos desarrolladas que en una unidad de tratamiento de emergencia.

Trabajar en consultorio demandaría menos en el plano de las capacidades técnicas que trabajar en la perspectiva de la hospitalización programada de duración determinada. En efecto, la exigencia de actualización técnica no es fundamentalmente diferente. La actitud de concepción sería, en el caso del consultorio, menos solicitada que la actitud decisional. 
Figura 11 - Comparación de las situaciones hospitalarias y extrahospitalarias.

\section{Hospitalización convencional}

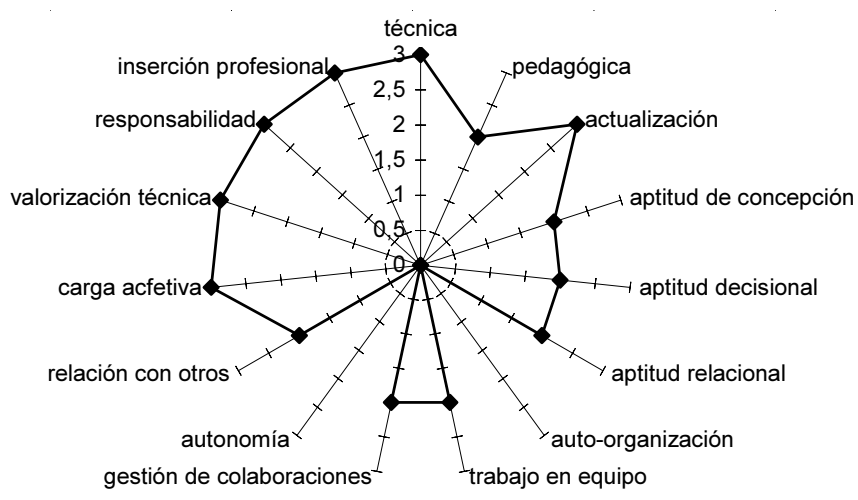

Hospitalización domiciliaria

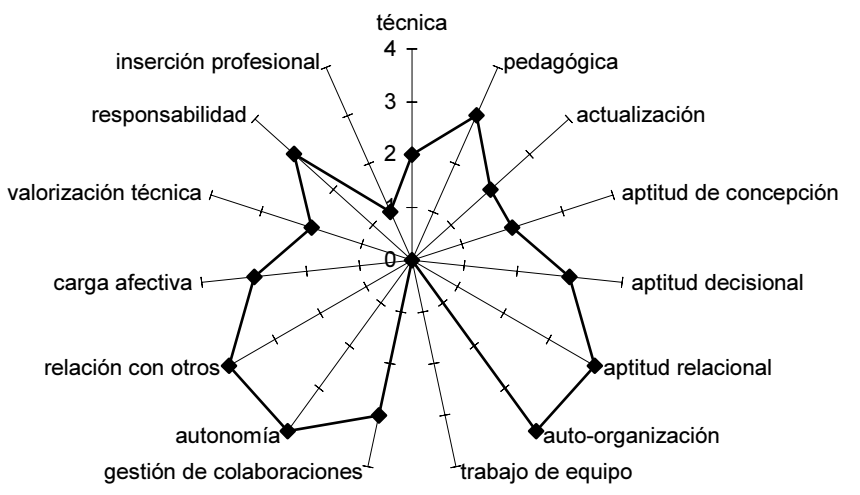

El análisis de las cualidades requeridas, combinadas con el análisis de las características y de los factores de desempeño de un tipo de atención, permite abarcar mejor el clima organizacional, la presión ejercida sobre los individuos y apreciar mejor la naturaleza de la atracción que este puede representar (o no) para los profesionales según su edad, su motivación, sus antecedentes, así como su contexto social. De este modo claramente explicitados, los modos o tipos de atención pueden permitir a un agente proyectarse en una trayectoria profesional, y a la institución contratarlo y promoverlo en función de su perfil y de su evolución y de los medios que puede movilizar para favorecerlo en uno u otro sentido profesional. 
A partir de un análisis multicriterios, se obtienen representaciones de los diferentes tipos de atención. El resultado de este ejercicio practicado por un grupo profesional homogéneo nos muestra que, para sus miembros, la satisfacción proporcionada por la HPDD está más vinculada a la técnica y al trabajo en equipo mientras que, para la hospitalización domiciliaria, los aspectos relacionales y la autonomía son los más importantes. Y que la emergencia implica una carga afectiva muy superior a la del consultorio o a la de la HPDD.

El ejemplo anterior puede parecer caricaturesco, pero es ilustrativo. Lo que importa es explorar las posibilidades de una aproximación determinada, con relación a las necesidades: disponer de un número mayor de criterios, cuya definición precisa constituirá un glosario; seleccionar y definir los criterios con las personas involucradas (el carácter participativo es esencial); y establecer con ellas las representaciones de los diferentes tipos de atención. Deben ser establecidos y confrontados dos tipos de representación: la representación que cada grupo profesional tiene de las características y de la atracción por cada tipo de atención, por un lado, y la representación que de ellos pueden tener los equipos de base que los implementan, por otro.

Esta aproximación no debe ser encarada mecánicamente. De lo que se trata es de generar un diálogo, de proveer herramientas que sean útiles a los profesionales para una mejor comprensión y adaptación a su universo profesional, innovar y hacerlo evolucionar. La búsqueda es obtener una mejor adaptación entre individuos y organización dentro de una perspectiva dinámica, permitiéndoles liberarse justamente de las representaciones caricaturescas ayudándolos a producir las evoluciones deseables para ellos y para la organización donde ejercen.

La aproximación anterior puede tener varias aplicaciones. Una de ellas es concebir modalidades de evaluación de la carga laboral y de determinación del efectivo más pertinente: la evaluación podrá ser realizada de manera diferente en el caso de una hospitalización convencional -donde la clientela es más heterogénea, el servicio es menos codificado, menos formalizado y el tiempo menos restrictivo-, y en el caso de una HPDD que provee servicios de una variedad limitada y conocida, a una clientela seleccionada, en un espacio temporal más restrictivo en términos de plazos y de cronología.

Adaptar los horarios y el tiempo de trabajo: los ritmos de trabajo, y los horarios, podrán ser diferenciados según la necesidad de continuidad en la atención, o por el contrario la ausencia de continuidad, pero también según la distribución de los flujos de pacientes, la importancia de los factores aleatorios o el control cuantitativo de la actividad a través de la programación.

Por último debe recordarse la adaptación de los indicadores de desempeño individual y lograr introducir la noción de desempeño colectivo. La observa- 
ción de los plazos predominará en ciertos casos, sobre la duración; la densidad (complejidad) de los pacientes, sobre el número.

Pero también, organizar la movilidad y la polivalencia en el hospital y concebir los planos de formación conciliando las necesidades institucionales, las necesidades profesionales y las expectativas individuales. La identificación de los tipos de atención permite clarificar en los individuos, las diferentes posibilidades de ejercicio profesional que la institución les ofrece y explicitar sus características, sus desafíos, exigencias y ventajas. Una primera diferenciación de perfiles profesionales está dada por el concepto de modo o tipo de atención normalizada. Una segunda diferenciación deberá realizarse en el sentido de la definición de las especificidades existentes en el nivel de cada tipo de atención, especificidades vinculadas a las exigencias particulares de las poblaciones y de las especialidades médicas. Esta segunda diferenciación revelará toda la variedad en el ejercicio de cada profesión, representada en el hospital. La diferenciación de perfiles, realizada sobre ambas bases, permitiría ofrecer un cuadro general de ayuda a la detección de las posibilidades de cambio para los propios interesados y para la organización. Esta identificación presupondría una confrontación entre las posibilidades de perfil profesional implícitas en los procesos de trabajo y las características específicas de los recursos humanos, conferidas a través de procesos de evaluación de los mismos (Figura 12), donde se buscaría establecer en qué medida, determinadas exigencias de perfil profesional son abarcadas por ellos. La cuestión está en saber en qué medida determinadas exigencias representan puntos fuertes o débiles para un determinado recurso humano.

Figura 12 - Elementos de evaluación.

\begin{tabular}{|l|l|l|}
\hline \multicolumn{1}{|c|}{ Capacidades profesionales } & Puntos fuertes & Puntos débiles \\
\hline Técnica & & \\
1 & & \\
2 & & \\
$3 \ldots \ldots . .$. & & \\
\hline Pedagógica & & \\
\hline Actu............... & & \\
\hline
\end{tabular}

Elementos de un balance de capacidades $(1,2,3$, etc. corresponderían a criterios específicos de cada capacidad, que permitirían calificarla mejor).

El objetivo de generar movilidad es ofrecer a los profesionales la posibilidad de renovar su motivación. Y desde el punto de vista de la institución, permitir una 
asignación de recursos humanos más flexible, que responda a las necesidades de corto y largo plazo y de mayor adaptabilidad, en el sentido de una planificación de RHs que tome en cuenta la evolución de la tecnología y de las necesidades. En este último caso, el componente prospectivo es esencial y puede manifestarse por ejemplo a través de la necesidad de un reequilibrio entre formas de atención (reducción relativa de la hospitalización tradicional en beneficio de la HPDD) o a través del surgimiento de nuevas formas de atención, como sucede en el campo de la psiquiatría a partir del momento en que decide su externalización.

La búsqueda de una mayor flexibilidad y de una mayor adaptabilidad supone un movimiento inverso a aquel que se realiza en el sentido de captar la diferenciación que define toda la riqueza del ejercicio profesional en un hospital. Aumentar la flexibilidad operacional significa definir un marco para organizar la desatomización, los intercambios de experiencia, las substituciones, los equipos de planta, etc. Se trata de recomponer la diversidad buscando ya no los factores de diferenciación sino los factores de integración, las proximidades de cualquier tipo. Los modos o tipos de atención son evidentemente el primer nivel de esta recomposición. Pero se puede ir aún más allá y buscar las similitudes entre modos de atención. Los grupos de polivalencia constituidos de este modo, permitirán ampliar las posibilidades de gestión cualitativa y cuantitativa.

Un grupo de polivalencia será constituido, tanto por una reaproximación de tipos de atención que valorice características comunes a cada uno de los modos reagrupados, como por un reagrupamiento de perfiles diferenciados cuya proximidad habrá sido juzgada sobre un criterio diferente (población, patología, tecnología). La proximidad deberá ser suficiente de modo que los profesionales puedan alternarse (mediante un corto plazo de adaptación derivado de una formación).

Tal forma de gestión de las capacidades de los RH, basada en el criterio gerencial tipo de atención, más allá del criterio técnico de la especialidad médica, tiene el gran mérito de ser una forma de gestión que no busca la adaptación entre el individuo y un puesto de trabajo o que no actúa sobre la base de la descripción de tareas a realizar. Busca analizar la adaptación de los individuos a contextos de acción amplios, definidos bajo una perspectiva organizacional (las relaciones entre los diferentes actores), bajo una perspectiva personal (las cualidades y motivaciones individuales) y bajo una perspectiva estratégica (la calidad del servicio a brindar). De esta manera, se busca un aumento global de la capacidad institucional, además de las capacidades individuales y técnicas. Dada la naturaleza participativa de esta gestión, lo que se valoriza son esencialmente las capacidades de auto-organización de las unidades y lugares de trabajo.

Una propuesta de este tipo supone una nueva forma de encarar la formación. La formación debería estar subordinada a los objetivos institucionales, 
privilegiando una concepción más amplia de la eficacia, que implique la posibilidad de que los diferentes actores perciban las interacciones que condicionan el desempeño global de la organización. La cuestión que se plantea como desafío es integrar las capacidades personales y profesionales en un cuadro de funcionamiento colectivo.

Una nueva propuesta de formación debería integrar tres dimensiones: la dimensión de las capacidades necesarias para cada uno de los grupos profesionales que componen el hospital, centradas en el conjunto: disciplinas, especialidades y grupos de tecnologías/patologías; la dimensión de las interacciones entre profesionales, que caracterizan el modo de funcionamiento operacional de las unidades de base y los procesos implementados; la dimensión de las relaciones entre grupos profesionales que condiciona el funcionamiento global de la organización a través del juego de las relaciones jerárquicas, y de las relaciones 'logística-tecnoestructura-centro operacional'.

A cada uno de estos campos le correspondería un tratamiento apropiado de la formación, que permita realizar el doble movimiento indispensable de diferenciación y de integración. Diferenciación a través de la puesta en práctica de acciones que permitan dotar a cada grupo profesional de las capacidades específicas necesarias para el buen desempeño de su rol; integración a través de la implementación de acciones que permitan a los diferentes profesionales, convocados a colaborar, un mejor control de las condiciones de su colaboración. Cada uno de estos campos está caracterizado por un determinado "mix" profesional y de contenidos de formación específicos: dominante técnica para el primero, dominante relacional para el segundo, dominante gerencial para el tercero. El interés por este tipo de propuesta de formación depende de su asociación a una renovación de la concepción de carreras de personal y a la valorización de la formación continua como herramienta de formación profesional.

\section{Referencias Bibliográficas}

ARTMANN, E. Démarche Stratégique (Gestão Estratégica Hospitalar): um enfoque que busca a mudança através da comunicaşão e solidariedade em rede, 2002. Tese de Doutorado, Campinas: Departamento de Medicina Preventiva da Faculdade de Ciências Médicas, Unicamp.

CRÉMADEZ, M. \& GRATEAU, F. Le Management Stratégique Hospitalier. Paris: InterÉditions, 1992 (1ª ed.), 1997 (2ed.). 
CROZIER, M. \& FRIEDBERG, E. L'Acteur et le Système. Paris: Éditions du Seuil, 1977.

LAWRENCE, P. R. \& LORSCH, J. H. Adapter les Structures de l'Entreprise. Éditions d'Organisation, 1973.

LE LUDEC, T. L'autonomie stratégique des établissements de santé: Frein ou levier pour la régulation du système hospitalier? Actes du Colloque de la Société Française d'Évvaluation des Stratégies. Montpellier, 1995.

MINTZBERG, H. Structure et Dynamique des Organisations. Paris: Éditions d'Organisation, 1982.

PORTER, M. E. Choix Stratégiques et Concurrence. Paris: Ed. Econômica, 1982.

RIVERA, F. J. U. A “démarche” estratégica: a metodologia de gestão do Centro Hospitalar Universitário de Lille, França. Cadernos de Saúde Pública, 13(1):73-80,jan/mar., 1997.

RIVERA, F. J. U. O enfoque de integração estratégica de Crémadez e Grateau e a gestão de recursos tecnológicos e humanos. RAP, 32(6):179-208, 1998.

STRATEGOR. Stratégie, Structure, Décision, Identité: politique générale d'entreprise. Paris: Dunod, 1997.

THÉVENET, M. Audit de la Culture d'Entreprise. Paris: Éditions d'Organization, 1986.

UAS-CHRU (Unité d'Analyse Stratégique - Centre Hospitalaire Régional Universitaire). La Démarche Stratégique. Guide Méthodologique. Material Instrucional. Lille: UAS-CHRU, 1995a. (Mimeo.)

UAS-CHRU (Unité d'Analyse Stratégique - Centre Hospitalaire Régional Universitaire). La Démarche Stratégique. Sommaire. Material Instrucional. Lille: UAS-CHRU, 1995b. (Mimeo.) 



\section{Aplicación de la démarche stratéGIQue AL HOSPITAL PHILIPPE PINEL: pensando en red}

Fernando Augusto de Cunha Ramos Liliane Mendes Penello

Francisco Javier Uribe Rivera

Este capítulo es una condensación del trabajo final del Curso de Especialización en Gestión Hospitalaria de la Escuela Nacional de Salud Pública, de 1997. Fue desarrollado por un grupo de alumnos de Salud Mental, predominantemente del Hospital Philippe Pinel. De esta experiencia participaron otros técnicos vinculados a gestión estratégica del Hospital, dirigido en aquella época por el Dr. Fernando Augusto da Cunha Ramos, principal responsable de este trabajo ${ }^{1}$.

El Hospital Philippe Pinel era una unidad federalizada, que fue municipalizada recientemente (1999). Está ubicada en la Área Programática 2.1 de la Secretaría Municipal de Salud de Río de Janeiro, en el barrio de Botafogo (próximo a la Urca). Esta unidad no restringe su atención al área programática pertinente y a los barrios adyacentes, sino que recibe la población de toda la ciudad y a veces del Estado. Dispone de actividades tradicionales de internación, de emergencia y de ambulatorio, y recientemente incorporó diversas formas de atención en la línea de hospital de día, asumidas cada vez más como la imagen objetivo de la unidad. Tiene 91 camas (para pacientes agudos, para unidad de tratamiento de alcohólicos y para emergencias) y 70 consultorios (distribuidos por los ambulatorios de adultos y niños, por los hospitales de día y otras formas de atención pertinentes).

El trabajo original contiene, además de una aplicación del enfoque de gestión estratégica de Crémadez (1997) variaciones metodológicas importantes que enriquecen de manera importante al método en sí. Fue realizada, por ejemplo, un meta-análisis de los factores-clave de éxito de los diferentes segmentos de la Unidad, apuntando a ponderar la importancia relativa de las principales categorías agrupadas de factores (metafactores). El grupo simuló además diferentes

1 Participaron del trabajo original, además de los responsables de su reformulación para esta versión, João Luis Barroca de Andrea, João Paulo Bastos Hildebrand, Maria Lelita Xavier e Sonia Maria da Conceição Marçal. 
portafolios prospectivos, correspondientes a situaciones-objetivo a ser alcanzadas progresivamente en función de la implementación de la estrategia. De esa propuesta global, presentamos aquí tan solo la parte relativa a la aplicación tradicional del enfoque, en el intento de mostrar de un modo ilustrativo cómo analizar un servicio y preparar una estrategia de intervención.

Es importante afirmar que, por falta de tiempo, esta experiencia fue segmentada de manera intuitiva y estratégica, en base a la experiencia acumulada. Por lo tanto, el diagnóstico inicial del enfoque no fue desarrollado de manera formal, aunque fuese contemplado de manera implícita en la segmentación.

Toda la parte doctrinaria del trabajo, referente al ideario de la reforma psiquiátrica y a la propuesta de los Centros de Atención Diaria (Caps's), también fue retirada, para privilegiar el método de trabajo en sí. Esto puede haber significado un empobrecimiento de aquel documento original, que se refleja en un tipo de presentación donde predominan el cálculo y el cumplimiento de los formatos del enfoque. Por ende, estimamos que este caso ayuda a visualizar la forma de aplicación de los criterios del análisis del valor de los segmentos, el análisis de la competitividad de los mismos, la lectura de un portafolio y la formulación de una estrategia y de un plan de acción. Complementa, de este modo, la presentación del gran esqueleto teórico-metodológico de la démarche stratégique, realizada en el capítulo anterior, e ilustra el uso de la guía de aplicación del enfoque, anexado al final del libro. (Anexo: La gestión estratégica hospitalaria)

\section{Aplicación del Método: consideración etapa por etapa}

\section{El análisis de lo existente}

El Instituto Philippe Pinel (IPP) se encuentra constituido por tres macrosegmentos, a saber: asistencial, enseñanza e investigación y administrativo-logístico. Para el análisis realizado en este trabajo, optamos por profundizar el estudio del macrosegmento asistencial, eje-síntesis de la misión institucional.

\section{La segmentación estratégica}

El primer criterio de segmentación adoptado fue el de macrosegmentación de la misión institucional, realizándose el recorte de su función asistencial. Luego se 
efectuó una microsegmentación de este recorte inicial, tomándose como criterio principal el modo de atención y como criterios accesorios los de patología (Naicap y UTA) y de población (Ambulatorio de Adultos, Coij, Naicap y Cais).

\section{Segmentos a estudiar}

1. Ambulatorio de Adultos

2. Centro de Orientación Infanto-Juvenil (Coij)

3. Cais (Hospital de Día de Adultos)

4. Núcleo de Asistencia Integral al Niño Autista y Sicótico (Naicap-Hospital de Niños de Día)

5. Enfermerías A + B (sicóticos/pacientes graves)

6. Unidad de Tratamiento de Alcohólicos (UTA)

7. Recepción y Emergencia

8. Laboratorio (especializado en psiquiatría)

9. Servicio de Imagen Cerebral

Observamos aquí, una vez más, la necesidad de definir el escenario actual y futuro de la Institución a fin de pasar a la tercera etapa del método, o sea: el análisis del valor (capacidad de atracción) de los segmentos y el análisis de la posición competitiva de cada segmento. Solo a partir de estos escenarios podemos pensar la adaptación de los criterios de evaluación.

\section{Propuestas de trabajo (escenario diseñado)}

- Red de Salud Mental, organizada en líneas generales (mínimas) de la siguiente forma: Centros de Atención Diaria (más de uno por Área Programática); Sistema de Soporte y Retaguardia de Emergencia e Internación (máximo de 01 por AP); Servicios de Referencia en Laboratorio Especializado e Imagen cerebral (01 como mínimo, $02 \mathrm{APs}$ )

- Red Municipal prevista por la Constitución y por las Leyes Orgánicas de Salud.

- Voluntad política del actual Gobierno Federal para patrocinar el proceso de descentralización de sus propias unidades.

Trabajar con el escenario de la municipalización, entre otros aspectos, implica (en el Municipio de Río de Janeiro) un modelo de gestión centralizador, esto es, con baja autonomía administrativa de las unidades. Entendemos que, en este caso, la lógica de red apunta hacia una competencia más relacionada a los 
recursos que a la población. Por lo tanto estaremos disputando recursos con: los Hospitales Generales, de Emergencia o de Alta Tecnología (hospitales de costo elevado); y con las Unidades de la propia Red Específica de Salud Mental.

\section{El Análisis del Valor de Cada Segmento}

La determinación del valor de cada segmento implica el análisis de diferentes criterios genéricos (con subcriterios) que presentan un peso determinado en términos porcentuales. Este peso es variable y relativo entre los diversos criterios, por ende, se mantiene el mismo para todos los segmentos estudiados. La nota (0-20) dada a cada uno de los criterios de valoración constituye el factor variable entre los diversos segmentos. Esta nota se basa en la formulación de preguntas claves. Una nota alta en el item posibilidad de crecimiento del segmento, por ejemplo, correspondería a la previsión de un fuerte aumento de este, y una nota baja a la estimación de una disminución importante.

El valor global de cada segmento resultará de la sumatoria del productos del peso por la nota (= score) de cada criterio evaluado. El objetivo central del análisis del valor es jerarquizar los segmentos. A continuación, encontraremos la matriz utilizada en el análisis del valor de los segmentos del IPP (Figura 1):

Figura 1 - Criterios de evaluación del valor.

\begin{tabular}{|l|c|}
\hline \multicolumn{1}{|c|}{ Criterios de evaluación } & Peso \\
\hline $\begin{array}{l}\text { Contribución para el Proyecto Político General (y la imagen del hospital) } \\
\text { Motivación Interna }\end{array}$ & $15 \%$ \\
$\begin{array}{l}\text { Sinergia con los demás segmentos } \\
\text { Posibilidades de colaboración externa }\end{array}$ & $10 \%$ \\
\hline Potencial Regional & $8 \%$ \\
\hline $\begin{array}{l}\text { Posibilidad de Crecimiento } \\
\text { Intensidad de Competencia } \\
\text { Posibilidad de Conseguir Recursos Externos }\end{array}$ & $6 \%$ \\
\hline Inversión (barreras a la entrada) & \\
\hline
\end{tabular}

La distribución porcentual de los pesos reflejó la valoración y jerarquización, por parte del grupo, de los nueve criterios previamente determinados por la matriz de la démarche.

De esta forma, entendemos que los items contribución para el proyecto político general (y la imagen del hospital), motivación interna, sinergia con los demás segmentos y 
posibilidades de colaboración externa, deberían tener una importancia mayor en el análisis del valor y, por esa razón, atribuimos a cada uno de esos criterios 15\% de peso. A los items potencial regional y posibilidad de crecimiento, atribuimos 10\%, al item intensidad de la competencia $8 \%$ y a los items posibilidades de conseguir recursos internos e inversiones (barreras a la entrada) 6\%. Con esos pesos definidos, pasamos a evaluar segmento por segmento, recordando que el sistema de notación utiliza como instrumento la resultante entre la evaluación de cada criterio en el escenario proyectado (idealizado) y la evaluación del mismo en el escenario actual (real).

Iniciamos, de este modo, el análisis del valor de cada segmento contraponiendo dos importantes criterios: su posibilidad de crecimiento comparada a su contribución para el proyecto politico general y para la imagen de la Institución como un todo. Sugerimos que el análisis de cada segmento esté acompañado de una consulta a la respectiva matriz, a fin de facilitar su comprensión.

\section{El Análisis de la Posición Competitiva de Cada Segmento y la Evaluación Según el Grado de Control de los Factores Estratégicos de Éxito ${ }^{2}$}

Se trata, en este caso, de evaluar las ventajas o condiciones positivas necesarias para tener éxito en una actividad.

Los pasos a seguir son:

- Identificación de los factores estratégicos de éxito (factores claves de éxito) o elementos de capacidad discriminante.

- Relevamiento de los competidores.

- Ponderación de los factores estratégicos de éxito (definición de su impacto o de su peso sobre a posición competitiva).

- Notación.

2 Sinónimo de factores clave de éxito. 


\section{Segmento I-Ambulatorio de Adultos}

\section{Análisis del valor}

Aquí, por ejemplo, la posibilidad de crecimiento es bastante significativa dado el constante aumento del fenómeno de medicalización y consiguiente psiquiatrización del malestar en nuestra sociedad y, también, porque el modelo ambulatorial constituye una forma ya consagrada y simplificada de asistencia extra-hospitalaria; de este modo el peso se torna relativamente mayor. La nota, a su vez, reflejará la respuesta del segmento a esa tendencia, lo que dependerá del proyecto político del Instituto. En este caso, creemos que debemos invertir en la reducción de las internaciones y del tiempo promedio de permanencia de los pacientes, lo que significa aumento y calificación de acciones en la recepción y emergencia, y en el ambulatorio. Por otro lado, consideramos que esa posibilidad de crecimiento no debe dirigirse al ambulatorio tradicional que conocemos, ya que, en relación a su contribución al proyecto político institucional, ese ambulatorio clásico recibe nota baja.

La gran competencia que existe para este segmento implica una nota baja (menor valor de mercado) en este item. En cuanto a la motivación interna, creemos que la llegada de nuevos profesionales (admisible dentro del escenario de la municipalización o de flexibilización gerencial) -nuevos tanto en el sentido etário como en el de formación profesional- producirá un aumento de la motivación global: directamente por el trabajo de estos, o indirectamente a través del contagio de los profesionales más antiguos.

Las inversiones ya realizadas en ese segmento no constituyen barreras a la entrada de nuevas inversiones. La notación fue media.

La evaluación de las sinergias muestra cuánto se trabaja actualmente y cuánto aún es necesario trabajar de forma compartida. La notación fue alta.

La posibilidad de colaboraciones externas existe; la notación por debajo de la media refleja el resultado de la proyección de esa posibilidad en el escenario de un Caps, por ejemplo, comparada a la misma posibilidad en un ambulatorio tradicional.

El potencial regional fue evaluado con una por debajo de la media, considerando que esa atención tradicional puede ser realizada en otros servicios del área (presupone una base territorial indefinida).

La posibilidad de conseguir recursos externos recibió una nota bastante baja, por la misma lógica descripta en el item colaboraciones externas. Resaltamos, sin embargo, la posibilidad de situar investigaciones en las diversas áreas relacionadas al comportamiento humano.

Por este análisis el segmento obtuvo el score de 9,36. 


\section{Análisis de la posición competitiva}

Para este segmento se establecieron los factores estratégicos de éxito siguientes:

1. Equipo multiprofesional, técnicamente bien formado y motivado para el trabajo.

2. Acceso a Servicios de Apoyo Diagnostico y Terapéutico (SADT).

3. Disponibilidad de medicamentos.

4. Flexibilidad de respuesta a la demanda (tanto en lo referente al tipo, como al número de atenciones ofrecidas).

5. Integración a la red de servicios de Salud.

Siguiendo el método de análisis adoptado, partimos hacia la evaluación del peso de cada item dentro de una visión prospectiva capaz de proyectar un nuevo modelo asistencial, donde la consulta ambulatoria se presente como un modo de atención entre otras modalidades asistenciales, y no corporizada como elemento definidor de un servicio específico y cristalizado.

Consideramos, en realidad, una forma de asistencia inspirada en la experiencia de los Caps y Naps, donde cada paciente está vinculado a un equipo de referencia, que deberá acompañarlo en cualquier situación que se presente.

De este modo distribuimos el peso, otorgando $25 \%$ para los items 4 y 5 , flexibilidad de respuesta a la demanda e integración a la red de servicios, respectivamente, una vez que estos factores detentan en sí la lógica de esa modalidad de atención.

El item equipo multiprofesional obtuvo $20 \%$ porque la lógica propuesta anteriormente será ejecutada por los recursos humanos existentes, los cuales precisan estar calificados de este modo: profesionales variados, con buena formación técnica, dispuestos a interactuar unos con otros y adecuadamente motivados para el difícil trabajo que se proponen.

Los otros dos items obtuvieron $15 \%$ en la división porcentual y representan el acceso al SADT, fundamental para el acompañamiento integral del paciente y monitoreo seguro del tratamiento psiquiátrico. La disponibilidad de medicamentos apunta a garantizar la continuidad del tratamiento en esa esfera, además de la posibilidad de elección de la droga más indicada para cada caso.

Continuando con las indicaciones del método, pasamos a ejecutar la notación de 0 a 20 para cada uno de esos items, considerando la evaluación actual de esos factores y el grado de control que poseemos sobre los mismos.

Existe una dificultad a considerar en lo referente a la evaluación de la competencia. Para esta evaluación recurrimos a todas las informaciones con que disponíamos sobre los competidores, a fin de lograr crear un escenario cercano 
a la realidad. Para este segmento determinamos los siguientes competidores: el ambulatorio del Instituto de Psiquiatría de la Universidad Federal de Rio de Janeiro (IPUFRJ), la atención prestada por los Departamentos y Servicios de Psicología Aplicada (DPA) de la Universidad Federal de Rio de Janeiro (UFRJ), de la Universidad Santa Úrsula (USU), y de la Pontificia Universidad Católica (PUC), y Clínicas Sociales de las Sociedades Psicoanalíticas, todos ubicados en nuestra Área Programática (AP).

Los scores finales fueron:

- Instituto Philippe Pinel (IPP) - 11,00

- IPUFRJ - 8,65

- DPA's - 3,00

- Clínicas Sociales - 1,50

Consideramos como un fuerte competidor al IPUFRJ, principalmente porque camina en la misma lógica del IPP.

Percibimos que dos items se destacan en el IPP, impulsando el score hacia arriba: el acceso a $S A D T$, que en nuestro caso se concentra en el segmento Laboratorio Especializado, y la disponibilidad de medicamentos, que en nuestro caso es excelente.

En cuanto al equipo multiprofesional, el IPUFRJ cuenta con mayor variedad de profesionales. Creemos, sin embargo, que sus dificultades en cuanto a la integración de los profesionales y a su motivación para el trabajo son bastante semejantes a las nuestras o hasta mayores.

En lo referente a la flexibilidad de respuesta a la demanda, la notación fue baja para ambos, aunque con alguna ventaja para el IPP, ya que este, en su papel de polo de internaciones, recibe una demanda espontánea diferente del IPUFRJ que, por su perfil académico, selecciona situaciones y casos más adecuados a la formación de sus alumnos de posgraduación y a sus proyectos de investigación.

En cuanto al item integración a la red de servicios, las notaciones también son semejantes para ambas instituciones, aunque, por los mismos motivos citados anteriormente, el IPP lleva una pequeña ventaja.

El análisis de esos dos últimos items nos lleva a pensar en otro factor estratégico de éxito que no utilizamos aquí, pero que recuperaremos al final de este trabajo, dentro de la formulación del plan de acciones: se trata de la base territorial (Figuras 2 y 3 ). 
Figura 2 - Evaluación del valor (capacidad de atracción) del segmento ambulatorio de adultos.

\begin{tabular}{|l|c|c|c|}
\hline \multicolumn{4}{|c}{ Nombre del segmento: Ambulatorio de Adultos } \\
\hline Criterios de evaluación & $\begin{array}{c}\text { Peso } \\
\%\end{array}$ & $\begin{array}{c}\text { Nota } \\
0-20\end{array}$ & $\begin{array}{c}\text { Score } \\
(=\text { PxN/100) }\end{array}$ \\
\hline 1. Posibilidad de Crecimiento & 10 & 15 & 1,50 \\
\hline 2. Intensidad de Competencia & 8 & 8 & 0,64 \\
\hline 3. Inversión (barreras a la entrada) & 6 & 10 & 0,60 \\
\hline $\begin{array}{l}\text { 4. Sinergias (a nivel de capacidades e } \\
\text { infraestructuras compartidas) }\end{array}$ & 15 & 15 & 2,25 \\
\hline $\begin{array}{l}\text { 5. Motivación Interna } \\
\text { 6. Posibilidades de Colaboración Externa }\end{array}$ & 15 & 10 & 1,50 \\
\hline 7. Potencial Regional & 10 & 8 & 0,80 \\
\hline 8. Posibilidad de Conseguir Recursos Externos & 6 & 2 & 0,12 \\
\hline 9. Contribución para el Proyecto Político General & 15 & 5 & 0,75 \\
\hline (y la imagen del hospital) & 100 & & 9,36 \\
\hline Valor del Segmento & & 8 & 1,20 \\
\hline
\end{tabular}

Figura 3 - Evaluación de la posición competitiva del segmento ambulatorio de adultos.

\begin{tabular}{|c|c|c|c|c|c|c|c|c|c|}
\hline \multicolumn{10}{|c|}{ Control de los factores estratégicos de éxito } \\
\hline \multirow{3}{*}{ Factores estratégicos de éxito } & \multirow{2}{*}{\multicolumn{3}{|c|}{$\begin{array}{c}\text { Hospital } \\
\text { IPP }\end{array}$}} & \multicolumn{6}{|c|}{ Competidores } \\
\hline & & & & \multicolumn{2}{|c|}{ IPUFRJ } & \multicolumn{2}{|c|}{ DPAs } & \multicolumn{2}{|c|}{ CSPs } \\
\hline & Peso & Nota & Score & Nota & Score & Nota & Score & Nota & Score \\
\hline $\begin{array}{l}\text { 1. Equipo multiprofesional } \\
\text { motivado y capacitado }\end{array}$ & 20 & 10 & 2,00 & 13 & 2,60 & 10 & 2,00 & 5 & 1,00 \\
\hline $\begin{array}{l}\text { 2. Acceso a servicios de apoyo } \\
\text { diagnóstico }\end{array}$ & 15 & 15 & 2,25 & 12 & 1,80 & 0 & 0,00 & 0 & 0,00 \\
\hline $\begin{array}{l}\text { 3. Disponibilidad de } \\
\text { medicamentos }\end{array}$ & 15 & 20 & 3,00 & 10 & 1,50 & 0 & 0,00 & 0 & 0,00 \\
\hline $\begin{array}{l}\text { 4. Flexibilidad de respuesta a la } \\
\text { demanda }\end{array}$ & 25 & 5 & 1,25 & 3 & 0,75 & 0 & 0,00 & 0 & 0,00 \\
\hline 5. Integración a la red de Salud & 25 & 10 & 2,50 & 8 & 2,00 & 4 & 1,00 & 2 & 0,50 \\
\hline Score sobre el segmento & 100 & \multicolumn{2}{|c|}{11,00} & \multicolumn{2}{|c|}{8,65} & \multicolumn{2}{|c|}{3,00} & \multicolumn{2}{|c|}{1,5} \\
\hline Posición relativa & \multicolumn{3}{|c|}{1} & \multicolumn{2}{|c|}{2} & \multicolumn{2}{|c|}{3} & \multicolumn{2}{|c|}{4} \\
\hline
\end{tabular}

Competidores: IPUFRJ, DPA y Clínicas Sociales Psicoanalíticas (CSP). 


\section{Segmento 2 - Coij (Ambulatorio Infanto-Juvenil)}

\section{Análisis del valor}

En cuanto a la posibilidad de crecimiento, afirmamos que es bastante grande por los mismos motivos señalados en el segmento 1. Sumaríamos aquí, sin embargo, la tendencia también a la psiquiatrización y a la medicalización de las alteraciones de comportamiento y de las dificultades de aprendizaje manifestadas en el ambiente escolar, frecuentemente causadas por la exigencia de adaptación a una estructura escolar fallida e inadecuada. Nota alta.

En relación al proyecto político general y a la imagen del hospital, recordamos que la psiquiatría infantil tiene tan solo 50 años de historia y que los cuadros psiquiátricos graves son menos predominantes en la infancia que en la edad adulta. Notación media.

Desde el punto de vista de las sinergias, es un segmento que por sus especificidades es más cerrado intrainstitucionalmente que el segmento 1. Recibió nota media. En cuanto a la intensidad de competencia, existen pocos competidores, lo que le confiere nota alta.

En el item barreras a la entrada de nuevas inversiones, consideramos que ya hubo por parte de la Institución, una gran inversión en el sector, lo que implica partir de un piso más elevado para mayores inversiones. Nota por encima de la media.

La motivación interna para este tipo de trabajo es grande: trabajar con niños abre un mayor abanico de posibilidades terapéuticas y estimula el uso de la creatividad. Nota alta.

La posibilidad de colaboraciones externas es grande, teniendo en cuenta la poca oferta de servicios especializados en este campo, incluso en el área privada. Nota por encima de la media.

El potencial regional recibe una nota por encima de la media, dado que, por las especificidades, la base territorial tenderá a ser amplia.

Recursos externos reciben una nota baja dada la situación actual, lo que puede ser revertido con un cambio de escenario.

Score del segmento: 11,91.

\section{Análisis de la posición competitiva}

Para este segmento mantuvimos los cinco factores estratégicos de éxito del segmento anterior, acrecentando al primero referente al equipo, los términos 
interdisciplinario y ampliado que comentaremos más adelante. Adicionamos, por ende, un sexto factor: integración a la red escolar.

Para la evaluación del peso de cada factor presentado, mantuvimos la idea del análisis prospectivo, volcado ahora hacia la prestación de atención en la área infanto-juvenil.

Observamos que en esa franja etaria el peso del equipo sube a $25 \%$, o sea, el trabajo integrado de los diferentes profesionales (equipo ampliado e interdisciplinario) plantea diferencias bastante significativas en el resultado del trabajo terapéutico con niños y adolescentes, aún en el contexto de un servicio ambulatorio. El trabajo con padres y familias se plantea como fundamental, ya que buena parte del sufrimiento psíquico del niño está relacionado con las divisiones, desacuerdos y conflictos familiares. Esta característica aumenta significativamente el nivel de desafío para el equipo terapéutico, exigiendo mayor complejidad de actuación, independientemente de las técnicas o teorías adoptadas.

Por la misma razón, la integración con el resto de la red de salud -principalmente servicios de pediatría y de educación-, es fundamental. En la escuela, a menudo, es donde se manifiesta por primera vez el sufrimiento del niño, lo cual puede revelarse incluso bajo la forma de síntomas corporales, lo que llamamos somatización. Para estos items establecemos $20 \%$ de peso para cada uno.

Acceso a SADT obtuvo el mismo porcentaje de 15\%, subrayando lo apuntado en el segmento anterior, o sea, la necesidad de monitoreo y acompañamiento integral y seguro del paciente, más aún tratándose de un niño.

El item disponibilidad de medicamentos no presenta aquí un peso tan importante, ya que la psicofarmacología tiene un rol menos destacado en esa franja etaria, por ser generalmente desaconsejable el uso de medicación en niños con menos de seis años. El trabajo principal es de naturaleza psicoterapéutica, fonoaudiológica y de terapia ocupacional entre otros. Volvemos aquí a la importancia del funcionamiento interdisciplinario del equipo. En relación a la notación, recordamos nuevamente que esta se realiza considerando el panorama actual: aquellos recursos con los cuales contamos en el momento.

La mayor notación (20) fue dada a la disponibilidad de medicamentos, que es abundante y ofrece una excelente gama de opciones.

El acceso a SADT recibió nota 15 , básicamente por la calidad de nuestro laboratorio y por la posibilidad de realización de exámenes electroencefalográficos en la clínica de epilepsia del IPP.

El equipo, como ya señalamos, precisa necesariamente integrarse para ser capaz de responder a las complejas cuestiones traídas por los niños y sus familias, lo que produce mayor motivación hacia el trabajo. La flexibilidad de respuesta a la demanda recibe una nota baja por las mismas razones presentadas en la 
evaluación del segmento anterior. Este item, sumado a la mayor integración a la red de Salud y a la red escolar son verdaderamente los puntos cruciales en el proceso de modificación y de reorganización del modelo asistencial que disponemos. Por estas razones, actualmente, reciben nota baja.

En este segmento, el análisis de la competencia fue realizado en relación al IPUFRJ y al Instituto de Neurología Deolindo Couto (INDC). Este último fue escogido dada la frecuente derivación de niños al neurólogo en función de quejas de desvinculación o hiperactividad en el aula, generalmente para realizar un electroencefalograma.

Este segmento, prácticamente no presenta otros competidores, siendo el IPUFRJ la institución que se encuentra más próxima en términos de la asistencia prestada. En general, la oferta de este tipo de servicio es pequeña en la red pública de salud, especialmente para pre-púberes.

Aquí tampoco analizamos la base territorial, lo que será retomado al momento de discutir el plan de acciones.

Nuestra posición competitiva es, según nuestro análisis, superior en relación a los dos competidores, mientras el IPUFRJ se encuentra bastante próximo.

Los scores obtenidos fueron:

- $\quad$ IPP $-11,35$.

- IPUFRJ $-10,55$.

- $\quad$ INDC - 7,30.

Nuestras ventajas en relación al IPUFRJ están dadas por una mejor disponibilidad de medicamentos y mayor flexibilidad de respuesta a la demanda.

La superioridad en relación al INDC es aún mayor: al no trabajar con la lógica de equipo interdisciplinario, presenta una disponibilidad insuficiente de medicamentos, no tiene prácticamente ninguna flexibilidad de respuesta a la demanda, y revela baja integración a la red de salud. La integración (relación con) a la red escolar, sin embargo, es un poco mayor a la nuestra, por los motivos ya expuestos (Figuras 4 y 5 ). 
Figura 4 - Evaluación del valor (capacidad de atracción) del segmento Coij.

\begin{tabular}{|l|c|c|c|}
\hline \multicolumn{4}{|c|}{ Nombre del segmento: COIJ (ambulatorio infanto-juvenil) } \\
\hline Criterios de evaluación & $\begin{array}{c}\text { Peso } \\
\%\end{array}$ & $\begin{array}{c}\text { Nota } \\
0-20\end{array}$ & $\begin{array}{c}\text { Score } \\
(=\text { PxN/100) }\end{array}$ \\
\hline 1. Posibilidad de Crecimiento & 10 & 15 & 1,50 \\
\hline 2. Intensidad de Competencia & 8 & 15 & 1,20 \\
\hline 3. Inversión (barreras a la entrada) & 6 & 12 & 0,72 \\
\hline $\begin{array}{l}\text { 4. Sinergias (a nivel de capacidades e } \\
\text { infraestructuras compartidas) }\end{array}$ & 15 & 10 & 1,50 \\
\hline 5. Motivación Interna & 15 & 15 & 2,25 \\
\hline 6. Posibilidades de Colaboración Externa & 15 & 12 & 1,80 \\
\hline 7. Potencial Regional & 10 & 12 & 1,20 \\
\hline 8. Posibilidad de Conseguir Recursos Externos & 6 & 4 & 0,24 \\
\hline 9. Contribución para el Proyecto Político General \\
(y la imagen del hospital)
\end{tabular}

Figura 5 - Evaluación de la posición competitiva del segmento Coij.

\begin{tabular}{|l|c|c|c|c|c|c|c|}
\hline \multicolumn{4}{|c}{ Control de los factores estratégicos de éxito } \\
\hline \multirow{2}{*}{ Factores estratégicos de éxito } & \multicolumn{3}{|c|}{ Hospital } & \multicolumn{3}{c|}{ Competidores } \\
\cline { 2 - 11 } & \multicolumn{3}{|c|}{ IPP } & \multicolumn{2}{c|}{ IPUFRJ } & \multicolumn{2}{c|}{ INDC } \\
\cline { 2 - 10 } & Peso & Nota & Score & Nota & Score & Nota & Score \\
\hline $\begin{array}{l}\text { 1. Equipo interdisciplinario motivada, } \\
\text { capacitada y "ampliada" }\end{array}$ & 25 & 15 & 3,75 & 15 & 3,75 & 5 & 1,25 \\
\hline $\begin{array}{l}\text { 2. Acceso a servicios de apoyo diagnóstico } \\
\text { y terapéutico }\end{array}$ & 15 & 15 & 2,25 & 15 & 2,25 & 15 & 2,25 \\
\hline $\begin{array}{l}\text { 3. Disponibilidad de medicamentos } \\
\text { 4. Flexibilidad de respuesta a la demanda }\end{array}$ & 5 & 20 & 1,00 & 10 & 0,50 & 5 & 0,25 \\
\hline 5. Integración a la red de Salud & 20 & 8 & 1,60 & 8 & 1,60 & 5 & 1,00 \\
\hline 6. Integración a la red escolar & 20 & 10 & 2,00 & 10 & 2,00 & 12 & 2,40 \\
\hline Score sobre el segmento & 100 & 11,35 & 10,55 & 7,30 \\
\hline Posición relativa & & 1 & & & 2 & & 3 \\
\hline
\end{tabular}

Competidores: IPUFRJ, Instituto de Neurología Deolindo Couto (INDC). 


\section{Segmento 3 - Cais (Hospital de Día de Adultos)}

\section{Análisis del valor}

Analizando en conjunto, la contribución para el proyecto politico e imagen del hospital y la posibilidad de crecimiento, llegamos a la conclusión que este segmento es actualmente el que más se aproxima al nuevo modelo de atención que deseamos prestar al cliente. Tal evaluación contó con la nota máxima en ambos casos. Queremos subrayar que este segmento es el generador de la mayor parte de los trabajos del IPP que portan la rúbrica del ideario de la reforma psiquiátrica, se trata, por lo tanto, del propio cuerpo del proyecto político del Instituto en expansión. El Cais es el puerto seguro de los pacientes graves, con el que se vinculan, de forma diferencial en relación a la internación tradicional o con el ambulatorio clásico. En este sentido, el Cais podría llegar a ser, ampliando y diversificando sus acciones, el núcleo formador de un verdadero Centro de Atención Diaria en el Instituto (Caps-IPP).

La intensidad de la competencia es baja, tomando en cuenta la diferenciación de los servicios prestados; lo que da como resultado una nota alta.

El item barreras a la entrada de nuevas inversiones cuestiona la necesidad de una alta inversión en este segmento, principalmente en lo referente a recursos humanos. La nota es alta.

Las sinergias ya son y deberán ser aún mayores. Nota alta. La motivación interna es grande para este trabajo que exige interdisciplinariedad y es innovador. Nota alta.

Las posibilidades de colaboraciones externas son grandes. La demanda por este tipo de atención es mayor que la oferta. Nota alta.

El potencial regional es elevadísimo. Nota alta.

La posibilidad de conseguir recursos externos sigue la lógica de las colaboraciones, no obstante, la existencia de la Asociación de Amigos del Cais (Amocais) puede constituirse en una importante fuente de captación de recursos financieros y materiales. Nota alta.

El segmento obtuvo el score de 17,80.

\section{Análisis de la posición competitiva}

En el caso de este segmento, relacionamos ocho factores estratégicos de éxito: 1. Equipo interdisciplinario "referenciado". 
2. Espacio físico diversificado y ampliado (flexible)

3. Acciones intersectoriales en cuatro áreas: trabajo, recreación, educación y vivienda.

4. Base territorial/poblacional.

5. Acceso a SADT.

6. Fuerte sinergia interna.

7. Disponibilidad de medicamentos.

8. Atención domiciliaria.

Los factores estratégicos de éxito establecidos para el Hospital de Día de Adultos (Cais) fueron evaluados a través del proceso explicado anteriormente: en relación a la distribución de peso, la evaluación fue realizada en términos prospectivos.

De este modo, el item más importante, al cual asignamos peso 20, nos pareció aquel referente a la base territorial/poblacional, delimitada y circunscripta a una parte de nuestra área programática. Aquí la idea es centrar la atención en la población que vive próxima al servicio, fortaleciendo los vínculos entre la institución y la comunidad asistida. De esta forma, la institución pasa a ser representada por sus equipos técnicos de referencia, dando forma, voces y rostros a aquellos que prestan asistencia a cada paciente, quien será atendido de forma individualizada y de acuerdo con sus necesidades inmediatas. La atención de guardia por la noche, en fines de semana y feriados será prestada por la recepción y emergencia del propio IPP.

En ese caso, tendríamos tal vez una disminución total del número de pacientes atendidos de forma continua por la Institución, por ende, ganancias terapéuticas evidentes para los usuarios. El trabajo diferenciado de un equipo interdisciplinario de referencia, que pasa a dedicarse concretamente a la función de proporcionar continuidad y flexibilidad de atención a sus usuarios, es indispensable para un trabajo terapéutico bien conducido y con chances resolutivas. A este item (equipo), otorgamos peso 15, como a los items acciones intersectoriales, fuerte sinergia interna y atención domiciliaria.

Evidentemente, la idea presentada aquí es la de un fortalecimiento de una red dinámica de cuidados que se movilice en diferentes sentidos y direcciones de manera de atender, en lo posible, las diferentes demandas y necesidades de aquellos individuos en tratamiento dentro de la unidad.

Los cuidados demandados son múltiplos y variados, como vimos anteriormente, y dependen de la complejidad de la situación. Los propios factores enumerados dan una idea de esas necesidades: desde la atención domiciliaria, cuando el cliente no presenta condiciones mínimas para enfrentar el "mundo 
exterior", al uso de un espacio físico adecuado (adaptación que es flexible), pasando por la integración con los demás segmentos internos (enfermerías, emergencia, farmacia, laboratorio, etc.), hasta llegar a las áreas no específicas del sector salud, aunque pertenecientes al ámbito de la salud en tanto bien social; o sea, trabajo, educación, recreación, vivienda.

En cuanto a la notación, volcada hacia el aquí y ahora, evaluamos que en apenas tres items no precisamos de mayores inversiones, nos basta con mantener lo ya conquistado: espacio físico adecuado, acceso a $S A D T$ y disponibilidad de medicamentos.

El equipo actual funciona de manera bastante integrada, existiendo interdisciplinariedad, pero aún distante de la forma plenamente referenciada tal como recomendamos, por esta razón recibió una nota media.

Los items restantes recibieron una baja notación y con certeza surgirán como objetivos a ser alcanzados en nuestro plan de acciones.

El análisis competitivo fue realizado en base a un hospital de día público, el del IPUFRJ, y uno del sector privado, el Casa Verde, hospital de día acreditado por la Caja de Asistencia del Banco do Brasil (CASSI).

El hospital de día del IPUFRJ, con algunas pequeñas diferencias de puntuación, se asemeja al nuestro, mientras el Casa Verde obtuvo un score mucho más alto, debido a los recursos que tiene a su disposición en la red acreditada por la CASSI. Cabe resaltar aquí, que este hospital no funciona en la lógica de la base territorial/poblacional.

Los scores fueron:

- $\quad$ IPP - 7,35.

- $\quad$ IPUFRJ - 6,30

- Casa Verde - 12,65.

De esta manera, en términos de posición competitiva, nuestro segmento se encuentra en condiciones medias (Figuras 6 y 7 ). 
Figura 6 - Evaluación del valor (capacidad de atracción) del segmento Cais.

\begin{tabular}{|c|c|c|c|}
\hline \multicolumn{4}{|c|}{ Nombre del segmento: Cais (Hospital de Día de Adultos) } \\
\hline Criterios de evaluación & $\begin{array}{l}\text { Peso } \\
\%\end{array}$ & $\begin{array}{l}\text { Nota } \\
0-20\end{array}$ & $\begin{array}{c}\text { Score } \\
(=\text { PxN/100) }\end{array}$ \\
\hline 1. Posibilidad de Crecimiento & 10 & 20 & 2,00 \\
\hline 2. Intensidad de Competencia & 8 & 18 & 1,44 \\
\hline 3. Inversión (barreras a la entrada) & 6 & 14 & 0,84 \\
\hline $\begin{array}{l}\text { 4. Sinergias (a nivel de capacidades e infraestructuras } \\
\text { compartidas) }\end{array}$ & 15 & 20 & 3,00 \\
\hline 5. Motivación Interna & 15 & 15 & 2.25 \\
\hline 6. Posibilidades de Colaboración Externa & 15 & 17 & 2,55 \\
\hline 7. Potencial Regional & 10 & 20 & 2,00 \\
\hline 8. Posibilidad de Conseguir Recursos Externos & 6 & 12 & 0,72 \\
\hline $\begin{array}{l}\text { 9. Contribución para el Proyecto Político General } \\
\text { (y la imagen del hospital) }\end{array}$ & 15 & 20 & 3,00 \\
\hline Valor del Segmento & 100 & & 17,80 \\
\hline
\end{tabular}

Figura 7 - Evaluación de la posición competitiva del segmento Cais.

\begin{tabular}{|c|c|c|c|c|c|c|c|}
\hline \multicolumn{8}{|c|}{ Control de los factores estratégicos de éxito } \\
\hline \multirow{3}{*}{ Factores estratégicos de éxito } & \multirow{2}{*}{\multicolumn{3}{|c|}{$\begin{array}{c}\text { Hospital } \\
\text { IPP }\end{array}$}} & \multicolumn{4}{|c|}{ Competidores } \\
\hline & & & & \multicolumn{2}{|c|}{ IPUFRJ } & \multicolumn{2}{|c|}{ C. Verde } \\
\hline & Peso & Nota & Score & Nota & Score & Nota & Score \\
\hline $\begin{array}{l}\text { 1. Equipo interdisciplinario motivado, } \\
\text { capacitado y "referenciado" }\end{array}$ & 15 & 10 & 1,50 & 10 & 1,50 & 17 & 2,55 \\
\hline $\begin{array}{l}\text { 2. Espacio físico diversificado, flexible y } \\
\text { "ampliado" }\end{array}$ & 10 & 15 & 1,50 & 15 & 1,50 & 15 & 1,50 \\
\hline $\begin{array}{l}\text { 3. Acciones intersectoriales (vivienda, trabajo, } \\
\text { cultura, recreación) }\end{array}$ & 15 & 4 & 0,60 & 4 & 0,60 & 6 & 0,90 \\
\hline 4. Base territorial/poblacional & 20 & 4 & 0,80 & 4 & 0,80 & 0 & 0,00 \\
\hline $\begin{array}{l}\text { 5. Acceso a servicios de apoyo diagnóstico y } \\
\text { terapéutico }\end{array}$ & 5 & 15 & 0,75 & 10 & 0,50 & 20 & 1,00 \\
\hline 6. Fuerte sinergia interna con otros segmentos & 15 & 4 & 0,60 & 3 & 0,45 & 18 & 2,70 \\
\hline 7. Disponibilidad de medicamentos & 5 & 20 & 1,00 & 10 & 0,50 & 20 & 1,00 \\
\hline 8. Atención domiciliaria & 15 & 4 & 0,60 & 3 & 0,45 & 20 & 3,00 \\
\hline Score sobre el segmento & 100 & \multicolumn{2}{|c|}{7,35} & \multicolumn{2}{|c|}{6,30} & \multicolumn{2}{|c|}{12,65} \\
\hline Posición relativa & \multicolumn{3}{|c|}{2} & \multicolumn{2}{|c|}{3} & \multicolumn{2}{|c|}{1} \\
\hline
\end{tabular}

Competidores: IPUFRJ, Casa Verde. 


\section{Segmento 4 - Naicap - Núcleo de Atención Integral al Niño Autista y Sicótico (Hospital de Niños de Día)}

\section{Análisis del valor}

El hospital de día infantil obtuvo la nota máxima en lo referente al proyecto político general e imagen del hospital, porque además de poseer las características ya citadas para el Cais, trabaja con la rehabilitación de niños sicóticos, autistas y en grave sufrimiento psíquico, lo que lo constituye en un servicio poco frecuente en nuestra precaria red de salud mental.

La posibilidad de crecimiento, se ubica un poco por encima de la media, porque la porción de población que demanda atención en esa área es menor. La intensidad de competencia es bajísima, lo que da como resultado la nota máxima en este item.

Las inversiones ya realizadas y las barreras a la entrada siguen la lógica del Coij y del Cais, con una nota por sobre la media.

Las sinergias tienden a ocurrir externamente, principalmente con escuelas y servicios de pediatría. Podrá, sin embargo, aumentar internamente con el Coij. El hecho de que ambos servicios ocupen actualmente un mismo predio diseñado específicamente para la asistencia de niños y adolescentes, existiendo varias áreas de uso en común; debe resultar un facilitador de esta integración. Otro factor de integración se refiere al hecho de que ambos servicios pertenecen actualmente a una única división asistencial en el organigrama/régimen interno del Instituto. La nota queda por encima de la media.

La motivación interna es bastante alta, exigiendo capacitación, entrenamiento y supervisión constante de los recursos humanos. Nota alta.

Las posibilidades de colaboraciones externas son grandes, recibiendo una nota alta. Los recursos externos pueden ser conseguidos dentro de esa lógica. Nota media.

El potencial regional es altísimo, con la nota máxima.

Score igual a 15,93 .

\section{Análisis de la posición competitiva}

Para este segmento resolvimos mantener los ocho factores estratégicos de éxito establecidos para el hospital de día de adultos (Cais), con pequeñas modificaciones, de manera de adecuarlos a la faja etaria específica que abarca el servicio:

1. Equipo interdisciplinario motivado, capacitado, ampliado y referenciado.

2. Espacio físico diversificado, ampliado y exclusivo. 
3. Acciones intersectoriales (educación y recreación).

4. Base territorial/poblacional.

5. Acceso a SADT.

6. Fuerte sinergia con los demás segmentos.

7. Disponibilidad de medicamentos.

8. Atención domiciliaria.

En cuanto al item equipo interdisciplinario, es interesante observar cuán necesario fue cubrirlo de adjetivos a fin de resaltar su adaptación para la función holding (soporte), especialmente necesaria en el trabajo terapéutico con niños portadores de patologías psíquicas graves. De este modo, a ese factor le otorgamos peso 20 en términos porcentuales, al igual que a los dos próximos factores enumerados, también por razones de importancia.

La notación de este item fue media (10) por considerar que nuestro equipo actual no reúne todas las especificaciones, principalmente en lo referente al funcionamiento en modo referenciado pleno.

El item espacio físico, también fue bastante adjetivado, y en este caso resaltamos la función setting (los límites y contenciones adecuadas del ambiente), que también es de especial importancia en el tratamiento de niños. El peso porcentual es 20, coincidiendo con la notación, ya que actualmente contamos con todas esas calificaciones.

En lo referente a las acciones intersectoriales, analizamos las articulaciones existentes con las áreas de educación y recreación. Fue dado a este item peso 20 y nota 8 , indicando que por el momento consideramos baja aún la integración del segmento con estas áreas.

La base territorial poblacional, es amplia en este segmento, aunque indefinida en cuanto a los límites. Esto sucede porque en este segmento, la conjunción de los criterios de segmentación por patología y por población implica una base territorial bastante imprecisa, tomando en cuenta el bajo predominio de niños autistas y sicóticos en la población en general (cerca de 4 a 5 por cada diez mil niños). Más aún, al aumentar la distancia entre la vivienda y el local de tratamiento, la base geográfica ampliada dificulta la atención a niños con patologías graves, generando ausencias frecuentes e interrupciones del tratamiento. De este modo, tomando en cuenta la necesidad de conciliar el bajo predominio con la necesidad de definición de una base territorial geográficamente razonable, se presentó la propuesta de trabajar con dos Caps infantiles: uno en el IPP, desarrollado a partir del NaicapCoij, y otro en el Centro Psiquiátrico Pedro II (CPP-II), basado en el PaicapAmbulatorio Infantil, siendo que este último podría funcionar además como guardia para las escasas internaciones de niños y adolescentes. Los dos juntos constituirían (lo que en gran medida son actualmente) centros de referencia para otros municipios en términos de enseñanza, investigación y asesorías en el campo de la salud 
mental infantil. El Caps-IPP infantil modificaría ese criterio por patologías (diagnósticos por categorías) adoptando aquellos que sean de gravedad.

En términos porcentuales definimos peso 5, porque en relación a los demás, ese factor ya está parcialmente definido en cuanto a su amplitud. Falta definir mejor los límites geográficos. La nota baja atribuida, se refiere a su actual falta de control sobre los dos items mencionados.

Consideramos el item acceso a $S A D T$, de gran importancia, cuando la población de niños autistas y sicóticos necesita de exámenes específicos y sofisticados (genéticos e inmunológicos) para el diagnóstico diferencial de estos trastornos. Por esta razón atribuimos peso porcentual 10. La nota 10, se relaciona con el hecho de no poseer esos exámenes en nuestro laboratorio.

En relación a la sinergia con los demás segmentos, esta se encuentra en verdad, reducida, aún hasta por la función setting descrita anteriormente. La nota 4 se basa en la idea, de que aquellas sinergias que podrían estar más desarrolladas, por ejemplo con el Coij, aún no se dan.

El item 7, disponibilidad de medicamentos, no tiene peso alto en ese área, dado que el uso de medicación no constituye un instrumento terapéutico fundamental; de allí el peso 5. La nota 20 (máxima) se refiere al amplio espectro de medicamentos disponibles, aunque no sean esenciales.

En cuanto a la atención domiciliaria, por las mismas razones ya consideradas en el hospital de día de adultos, el peso y la nota son, respectivamente, 15 y 4.

El análisis de la competencia fue realizada en relación al Programa de Atención Integral al Niño Autista y Sicótico (Paicap) del CPP-II, que obtuvo en este análisis algunas ventajas sobre el Naicap, principalmente en lo referente a los siguientes items:

- Acciones intersectoriales (educación) - un convenio con la Secretaría Municipal de Educación (SME), que creó la Escuela Especial Ulisses Pernambucano. Allí fueron matriculados los niños atendidos en el ambulatorio infantil con cuadros de psicosis y autismo. Este fue el primer programa con la SME para niños con cuadros sicóticos. A posteriori surge el Paicap, con la propuesta de hospital de día para esos mismos niños, siendo esta su base territorial de referencia (red escolar de la región).

- Fuerte sinergia con los demás segmentos, principalmente, como hemos señalado anteriormente, con el ambulatorio infantil.

Los scores son:

- $\quad$ Naicap - 10,70.

- $\quad$ Paicap - 11,95.

(Ver Figuras 8 y 9) 
Figura 8 - Evaluación del valor (capacidad de atracción) del segmento Naicap.

\begin{tabular}{|c|c|c|c|}
\hline \multicolumn{4}{|c|}{ Nombre del segmento: Naicap (Hospital de Día de Niños Autistas y Sicóticos) } \\
\hline Criterios de evaluación & $\begin{array}{c}\text { Peso } \\
\%\end{array}$ & $\begin{array}{c}\text { Nota } \\
0-20\end{array}$ & $\begin{array}{c}\text { Score } \\
(=\mathrm{PxN} / 100)\end{array}$ \\
\hline 1. Posibilidad de Crecimiento & 10 & 12 & 1,20 \\
\hline 2. Intensidad de Competencia & 8 & 20 & 1,60 \\
\hline 3. Inversión (barreras a la entrada) & 6 & 13 & 0,78 \\
\hline $\begin{array}{l}\text { 4. Sinergias (a nivel de capacidades e infraestructuras } \\
\text { compartidas) }\end{array}$ & 15 & 12 & 1,80 \\
\hline 5. Motivación Interna & 15 & 18 & 2,70 \\
\hline 6. Posibilidades de Colaboración Externa & 15 & 15 & 2,25 \\
\hline 7. Potencial Regional & 10 & 20 & 2,00 \\
\hline 8. Posibilidad de Conseguir Recursos Externos & 6 & 10 & 0,60 \\
\hline $\begin{array}{l}\text { 9. Contribución para el Proyecto Político General } \\
\text { (y la imagen del hospital) }\end{array}$ & 15 & 20 & 3,00 \\
\hline Valor del Segmento & 100 & & 15,93 \\
\hline
\end{tabular}

Figura 9 - Evaluación de la posición competitiva del segmento Naicap.

\begin{tabular}{|c|c|c|c|c|c|}
\hline \multicolumn{6}{|c|}{ Control de los factores estratégicos de éxito } \\
\hline \multirow{3}{*}{ Factores estratégicos de éxito } & \multicolumn{3}{|c|}{ Hospital } & \multicolumn{2}{|c|}{ Competidor } \\
\hline & \multicolumn{3}{|c|}{ IPP } & \multicolumn{2}{|c|}{ Paicap } \\
\hline & Peso & Nota & Score & Nota & Score \\
\hline $\begin{array}{l}\text { 1. Equipo interdisciplinario motivado, capacitado, "ampliado" } \\
\text { y "referenciado" }\end{array}$ & 20 & 10 & 2,00 & 10 & 2,00 \\
\hline 2. Espacio físico diversificado, ampliado y exclusivo & 20 & 20 & 4,00 & 20 & 4,00 \\
\hline 3. Acciones intersectoriales (educación y recreación) & 20 & 8 & 1,60 & 15 & 3,00 \\
\hline 4. Base territorial/poblacional & 5 & 6 & 0,30 & 6 & 0,30 \\
\hline 5. Acceso a servicios de apoyo diagnóstico y terapéutico & 10 & 10 & 1,00 & 8 & 0,80 \\
\hline 6. Fuerte sinergia con los demás segmentos & 5 & 4 & 0,20 & 10 & 0,50 \\
\hline 7. Disponibilidad de medicamentos & 5 & 20 & 1,00 & 15 & 0,75 \\
\hline 8. Atención domiciliaria & 15 & 4 & 0,60 & 4 & 0,60 \\
\hline Score sobre el segmento & 100 & \multicolumn{2}{|c|}{10,7} & \multicolumn{2}{|c|}{11,95} \\
\hline Posición relativa & \multicolumn{3}{|c|}{2} & \multicolumn{2}{|c|}{1} \\
\hline
\end{tabular}

Competidores: Paicap. 


\section{Segmento 5 - Enfermerías $A+B$}

\section{Análisis del valor}

Al definirse por una lógica no asilar, como es el compromiso del IPP, se está tomando el camino de la deshospitalización y de la desinstitucionalización (deshospitalización/desinstitucionalización del manicomio, o sea, del lugar cero de la psiquiatría), en consecuencia, resta al hospital (a las enfermerías) el papel apropiado y circunscrito de lugar de atención de aquellas situaciones psiquiátricas agudas que requieren, simultáneamente, intensividad de tecnologías humanas, disponibilidad de equipamientos médicos y protección ambiental.

En la lógica del modelo manicomial, existe siempre la posibilidad -para no decir presión-, de crecimiento de las internaciones, dado que la exclusión del loco constituye siempre el camino más fácil para el enfrentamiento de crisis en una sociedad intolerante con la diferencia, así como la vía económicamente más rentable para una corporación de empresarios del área de salud que vive del financiamiento gubernamental directo. A pesar de esto, dentro del proyecto político adoptado por el IPP, en cuyo ámbito se busca ofertar un amplio menú de acciones terapéuticas y rehabilitadoras, cabe a la internación, tan solo un papel complementario. El futuro de este proyecto es la aceleración de la tendencia ya existente de reducción de las internaciones y su substitución por otros modos de atención. En este sentido, las enfermerías de "puertas abiertas" existentes en el Instituto, limpias, trabajadas con un buen nivel técnico, producen una disminución de los preconceptos asociados a la peligrosidad e incurabilidad de los enfermos mentales, contraponiéndose a la imagen violenta de las salas fortificadas, de las camisas de fuerza y de las rejas protectoras, que son marcas registradas del manicomio. Por estas razones, fue dado un peso intermedio para el criterio posibilidad de crecimiento y un peso más alto para el item contribución para el proyecto politico general (y la imagen del hospital). La notación media en ambos casos indica que, en el escenario anteriormente diseñado, las enfermerías no tienden al crecimiento.

La intensidad de la competencia es elevada, tomando en cuenta que la mayor parte de los camas psiquiátricos del área de referencia del IPP están en los hospitales (manicomios) de la red contratada del SUS. Sin embargo, como la calidad de la asistencia prestada en esas instituciones es muy baja, comparada a la ofrecida por el IPP, establecimos un peso relativamente menor para este item. La nota también es baja.

El item barreras a la entrada de otros inversores tuvo un peso bajo por el hecho de existir poco interés por parte de la iniciativa privada -detentora de la 
mayor parte de los camas psiquiátricas- de invertir en la mejora de los camas contratados por el SUS. Por otro lado, el mismo item recibió una nota por encima de la media por la importante inversión realizada por el IPP en el sector de internación en estos últimos años en infraestructura y hotelería.

Considerando el papel complementario de la internación dentro de una enorme gama de posibilidades terapéuticas, es fundamental la sinergia de las unidades de internación con los demás segmentos. Por lo tanto, el peso y la nota en este item son elevados.

Por las mismas razones, el criterio motivación interna obtuvo peso elevado. La nota media se refiere al hecho de que aún existe una fuerte necesidad de inversión en recursos humanos en este segmento.

Tanto las posibilidades de colaboración, como la obtención de recursos externos, son buenas, teniendo en cuenta la óptima calidad asistencial ofrecida por este segmento, como así también la posibilidad de generar investigaciones.

El potencial regional es alto, recibiendo un valor por encima de la media.

El segmento obtuvo un store de 11,09.

\section{Análisis de la posición competitiva}

Los factores estratégicos de éxito del segmento fueron:

1. Equipo interdisciplinario motivado, capacitado y ampliado

(con presencia de clínico general).

2. Integración del equipo técnico de enfermería.

3. Acceso a SADT.

4. Espacio físico diversificado y "ampliado" (cuartos con pocas camas y baños individuales, puertas abiertas, espacios de convivencia y recreación).

5. Fuerte sinergia con los demás segmentos.

6. Disponibilidad de medicamentos.

Con relación al primer factor, se trata de garantizar el mejor abordaje posible de las situaciones complejas que encierran el sufrimiento psíquico y la ruptura de la vida de los pacientes internados, como también el establecimiento de proyectos terapéuticos individualizados, respetándose la presencia de la singularidad y de la diversidad en las demandas de cada paciente (superación de la masificación y homogeneización de las acciones típicas del modelo asilar). Para ello, es necesario un equipo enriquecido en la variedad de sus miembros y en su capacidad interactiva de responder con acciones flexibles y creativas a situaciones inesperadas y frecuentemente cubiertas de incertidumbre. 
Es importante considerar también, que la demanda de los usuarios por asistencia médico-clínica es enorme, ya que a menudo, el cuerpo del paciente es simplemente olvidado o ignorado por la gravedad de la patología mental. El cartesianismo de la separación mente-cuerpo aún prevalece en el pensamiento de la mayoría de los profesionales de la Salud, a pesar de los avances que se produjeron en las neurociencias teóricas y en la filosofía de la mente. Por otro lado, la población atendida en una institución pública de salud mental, tanto por su condición socioeconómica (generalmente desfavorable) como por el propio estigma de la enfermedad mental, tiene un acceso bastante dificultoso a la atención médica en general. Por tales razones, atribuimos peso 15 y nota 10 a este factor, teniendo en cuenta las actuales limitaciones del cuadro de recursos humanos del hospital.

Consideramos que el factor integración plena del equipo técnico de enfermería al equipo interdisciplinario, es absolutamente estratégico para la superación de una división del trabajo estancada y estática, realizada a partir de criterios corporativos y jerárquicos, basados en el status profesional. Tal actitud genera un falso trabajo en equipo, dado que no existe distribución del poder y de responsabilidades, o alguna posibilidad de compartir roles terapéuticos entre los participantes del supuesto equipo. Lo que existe, en realidad, es un equipo-pirámide, cuyo vértice está constituido por el psiquiatra o por el psicoanalista (que visitan al paciente) y cuya base está conformada por los técnicos y auxiliares de enfermería (que aguantan al paciente). En el vínculo entre equipo y pacientes internos, los profesionales de enfermería, principalmente los de nivel medio, tanto por su trabajo específico (suministrar medicamentos, monitorear signos vitales, etc.) o por el tiempo mayor de contacto con ellos, son los que más interactúan con los pacientes. Es necesario, por lo tanto, invertir en su capacitación técnica, en la valorización ética y en la promoción de las condiciones de trabajo de estos profesionales, a fin de poder mostrar plenamente su importancia en el proceso de transformación de las prácticas psiquiátricas tradicionales. Sin embargo, este esfuerzo de integración no puede ser unilateral y debe ser realizado junto a los demás profesionales del equipo, que tienden a tratar a los profesionales de enfermería como meros ejecutores de acciones prescriptivas y que, por lo tanto, crean resistencias a su integración al conjunto del equipo interdisciplinario. Atribuimos, por consiguiente, peso 20 a este factor, pero al recibir nota 5 , se constatan las limitaciones actuales del equipo técnico y su insuficiente integración.

En cuanto al acceso a $S A D T$, es un factor estratégico para la planificación y monitoreo terapéutico de los pacientes internos: tanto el diagnóstico diferencial como la seguridad en el uso de métodos terapéuticos somáticos exigen un óptimo nivel de soporte de exámenes de laboratorio o de imágenes. Atribuimos a este factor peso 15 y nota 15 , teniendo en cuenta que nuestro laboratorio es referencia en psiquiatría. 
En el siguiente item, se considera como factor estratégico el espacio físico diversificado, reconociendo su importancia en el proceso de reforma psiquiátrica. La existencia de enfermerías de "puertas abiertas", subdivididas en espacios más privados, la oferta de áreas de recreación y de lugares informales de convivencia e integración espontánea, superan la "arquitectura asilar" -fruto del modelo de exclusión, segregación y abandono- contribuyendo significativamente a la transformación de las propias acciones terapéuticas. Atribuimos a este factor peso 15 y nota 15 ya que consideramos que nuestro espacio físico se adecua bastante al nuevo modelo.

El item fuerte sinergia con otros segmentos se constituye en factor estratégico al reconocer que la atención integral de los pacientes, a partir del establecimiento de vínculos terapéuticos fuertes con el equipo técnico, presupone la superación de los compartimientos estancos en que las instituciones psiquiátricas tradicionales tienden a subdividirse: emergencia, ambulatorio y enfermerías. Atribuimos peso 20 y nota 5 por considerar que aún necesitamos trabajar bastante ese factor para poder controlarlo y superar las divisiones internas.

El item disponibilidad de medicamentos, es un factor estratégico de gran importancia en relación a la formulación terapéutica individualizada y adecuada a cada paciente, por tal razón atribuimos peso 15 y nota 20.

Obtuvimos una buena posición competitiva en relación a los competidores, especialmente en los items: acceso a SADT, fuerte sinergia con los demás segmentos y disponibilidad de medicamentos. La clínica evaluada contratada por el SUS (Clínica da Gávea) no presentó ventajas en ninguno de los factores examinados.

Los scores finales fueron:

- $\quad$ IPP $-11,00$.

- IPUFRJ - 8,95.

- Clínica da Gávea - 1,44.

(Ver Figuras 10 y 11) 
Figura 10 - Evaluación del valor (capacidad de atracción) del segmento enfermerías.

\begin{tabular}{|c|c|c|c|}
\hline \multicolumn{4}{|c|}{ Nombre del segmento: Enfermerías $\mathrm{A}+\mathrm{B}$} \\
\hline Criterios de evaluación & $\begin{array}{c}\text { Peso } \\
\%\end{array}$ & $\begin{array}{l}\text { Nota } \\
0-20\end{array}$ & $\begin{array}{c}\text { Score } \\
(=\mathrm{PxN} / 100)\end{array}$ \\
\hline 1. Posibilidad de Crecimiento & 10 & 10 & 1,00 \\
\hline 2. Intensidad de Competencia & 8 & 8 & 0,64 \\
\hline 3. Inversión (barreras a la entrada) & 6 & 12 & 0,72 \\
\hline $\begin{array}{l}\text { 4. Sinergias (a nivel de capacidades e } \\
\text { infraestructuras compartidas) }\end{array}$ & 15 & 15 & 2,25 \\
\hline 5. Motivación Interna & 15 & 10 & 1,50 \\
\hline 6. Posibilidades de Colaboración Externa & 15 & 12 & 1,80 \\
\hline 7. Potencial Regional & 10 & 12 & 1,20 \\
\hline 8. Posibilidad de Conseguir Recursos Externos & 6 & 8 & 0,48 \\
\hline $\begin{array}{l}\text { 9. Contribución para el Proyecto Político General } \\
\text { (y la imagen del hospital) }\end{array}$ & 15 & 10 & 1,50 \\
\hline Valor del Segmento & 100 & & 11,09 \\
\hline
\end{tabular}

Figura 11 - Evaluación de la posición competitiva del segmento enfermerías.

\begin{tabular}{|c|c|c|c|c|c|c|c|}
\hline \multicolumn{8}{|c|}{ Control de los factores estratégicos de éxito } \\
\hline \multirow{3}{*}{ Factores estratégicos de éxito } & \multirow{2}{*}{\multicolumn{3}{|c|}{$\begin{array}{c}\text { Hospital } \\
\text { IPP }\end{array}$}} & \multicolumn{4}{|c|}{ Competidores } \\
\hline & & & & \multicolumn{2}{|c|}{ IPUFRJ } & \multicolumn{2}{|c|}{ Gávea } \\
\hline & Peso & Nota & Score & Nota & Score & Nota & Score \\
\hline $\begin{array}{l}\text { 1. Equipo interdisciplinario motivado, } \\
\text { capacitado y "ampliado" ( + clínico general) }\end{array}$ & 15 & 10 & 1,50 & 10 & 1,50 & 3 & 0,45 \\
\hline $\begin{array}{l}\text { 2. Integración del equipo técnico de } \\
\text { enfermería }\end{array}$ & 20 & 5 & 1,00 & 7 & 1,40 & 1 & 0,20 \\
\hline $\begin{array}{l}\text { 3. Acceso a servicios de apoyo diagnóstico } \\
\text { y terapéutico }\end{array}$ & 15 & 15 & 2,25 & 10 & 1,50 & 0 & 0,00 \\
\hline $\begin{array}{l}\text { 4. Espacio físico diversificado y "ampliado" } \\
\text { ( puertas abiertas) }\end{array}$ & 15 & 15 & 2,25 & 15 & 2,25 & 0 & 0,00 \\
\hline 5. Fuerte sinergia con los demás segmentos & 20 & 5 & 1,00 & 4 & 0,80 & 0 & 0,00 \\
\hline 6. Disponibilidad de medicamentos & 15 & 20 & 3,00 & 10 & 1,50 & 5 & 0,75 \\
\hline Score sobre el segmento & 100 & \multicolumn{2}{|c|}{11,00} & \multicolumn{2}{|c|}{8,95} & \multicolumn{2}{|c|}{1,40} \\
\hline Posición relativa & \multicolumn{3}{|c|}{1} & \multicolumn{2}{|c|}{2} & \multicolumn{2}{|c|}{3} \\
\hline
\end{tabular}

Competidores: IPUFRJ, Clínica da Gávea. 


\section{Segmento 6 - UTA (Unidad de Tratamiento de Alcohólicos)}

\section{Análisis del valor}

Aquí, antes que nada, es preciso destacar de que el análisis de este segmento fue realizado, conforme exige la metodología, tomando como punto de partida la misión institucional, la cual se basa en el tema de la locura y las transformaciones de las prácticas psiquiátricas necesarias para la creación de formas innovadoras de actuación en salud mental, capaces de superar el modelo asilar/manicomial. Claramente el resultado de este análisis habría sido diferente si el punto de partida hubiese sido la importancia epidemiológica que el alcoholismo ocupa dentro de una política global de salud pública, ya que el alcoholismo constituye en Brasil y en el Mundo uno de los problemas más importantes de salud.

Este segmento propone algunos temas importantes en el análisis de su valor: por ejemplo, la segmentación por "patología” (alcoholismo), en la cual el componente psiquiátrico constituye tan solo uno, entre los tantos otros variados aspectos de este trastorno complejo. En el alcoholismo, frecuentemente, tanto a los efectos de una internación, como en términos de gravedad, se evidencian como más importantes las secuelas o manifestaciones clínicas y neurológicas de este disturbio, que las alteraciones psiquiátricas. Tales manifestaciones médicas (aún cuando son acompañadas de alteraciones psiquiátricas) deberían ser tratadas en unidades/enfermerías de clínica médica, las cuales disponen de los recursos tecnológicos humanos y materiales adecuados para lidiar con estas situaciones, ya que algunas revisten una importante morbilidad y mortalidad.

Para el proyecto político-asistencial del Instituto, la lógica sería acoger a aquel alcohólico que se encuentra en sufrimiento psíquico importante o con un cuadro psiquiátrico primario asociado (esquizofrenia, trastorno del humor, etc.), mientras no predominen los problemas clínicos. En este caso, no estaríamos excluyendo al individuo portador de alcoholismo del IPP, pero sí abandonando la segmentación por patología y adoptando la de modo de atención, utilizada para las otras enfermerías y para la mayoría de los segmentos de la Institución. De este modo, atribuimos nota cero a este item. En relación a la posibilidad de crecimiento, sin embargo, constatamos que la tradición y el sentido común aún defienden fuertemente, la internación de pacientes alcohólicos en instituciones psiquiátricas, lo que implicó una nota media.

La intensidad de competencia es alta, ya que son muchos los competidores potenciales. Por lo tanto, la nota es baja. La inversión realizada no fue muy grande, lo que implica una nota por debajo de la media. Las sinergias intrainstitucionales son insuficientes. Nota baja. 
El equipo que trabaja en este segmento (altamente capacitado) se muestra integrado y motivado, aunque necesite de más personal. La notación es por encima de la media.

Existen posibilidades de colaboraciones externas, por la calidad de la atención prestada, lo que implica una notación por encima de la media.

En el item potencial regional, adoptamos una notación baja, ya que en este caso no podemos funcionar como polo para la internación de pacientes alcohólicos. En el IPUFRJ, la internación psiquiátrica constituye tan solo una -y no siempre la más importante- entre muchas otras formas de atención posibles o necesarias en estos casos.

Score igual a 6,93 .

\section{Análisis de la posición competitiva}

Fueron enumerados los siguientes factores estratégicos de éxito:

1. Equipo interdisciplinario motivado, capacitado y "ampliado"

(incluyendo clínico general).

2. Integración del equipo técnico de enfermería.

3. Acceso a SADT.

4. Soporte hospitalario.

5. Fuerte sinergia con los demás segmentos.

6. Disponibilidad de medicamentos.

7. Colaboración con organizaciones civiles o estatales que

lidian con alcoholismo.

En el item equipo interdisciplinario, la inclusión del médico clínico fue considerada fundamental, debido a las frecuentes complicaciones médicas (secuelas físicas) observadas en los pacientes con historia de uso abusivo de bebidas alcohólicas, especialmente en aquellos traídos a una guardia, como es el caso del IPP. Fue atribuido peso 15 y nota 1, dada la dificultad de garantizar la presencia constante de ese profesional en el equipo, ya que el IPP dispone tan solo de un médico clínico para toda la institución.

En lo referente a la integración del equipo técnico de enfermería, lo consideramos un factor importantísimo de éxito, de la misma forma que lo señalamos para las otras dos enfermerías del IPP. Pero, por no haber llegado a este nivel de integración, atribuimos nota 5 , a pesar de tener un peso 20 .

El acceso a $S A D T$, es de enorme importancia, al ser habituales los cuadros clínicos derivados del alcoholismo crónico. Tal característica requiere de instru- 
mentos de apoyo diagnóstico y terapéutico adecuados. El peso atribuido fue 20 y la nota 15 , dado que ya tenemos un control importante sobre este factor estratégico en función del buen soporte de nuestro laboratorio.

El item soporte hospitalario, fue pensado una vez más, considerando tanto los frecuentes ataques a los médicos manifestados por pacientes portadores de alcoholismo crónico que necesitan de internación clínica, como por la dificultad de derivar estos pacientes a la red pública de hospitales generales y de emergencia, la cual, además de encontrarse desbastada y sobrecargada por una demanda excesiva, revela preconceptos con relación a estos pacientes. El peso atribuido fue 20 y la nota 5. La nota baja se relaciona al bajo control que disponemos sobre este factor.

En el item fuerte sinergia, constatamos que, dado que este segmento está definido por patología, su sinergia inevitablemente, se encuentra restringida en una institución cuya segmentación se determina por el criterio modo de atención. Nótese, por ende, que el circuito emergencia-internación en la UTA, con baja adhesión ambulatorial, es notorio, lo que contribuye a una notación y peso igualmente bajos: ambos de 5 .

$\mathrm{El}$ item disponibilidad de medicamentos, es un factor estratégico por su importancia en la elaboración del plan terapéutico individualizado y capaz de dar cuenta de la complejidad de las manifestaciones psiquiátricas y complicaciones clínicas derivadas del alcoholismo. Le fue atribuido peso 10 y nota 20 ya que disponemos de un stock de medicamentos excelente, aunque más vinculado a los cuadros psiquiátricos que a las complicaciones clínicas.

El factor colaboración con (otras) organizaciones que lidian con el alcoholismo, es relevante, considerando la complejidad del problema de salud pública representado por el alcoholismo y la insuficiente capacidad de respuesta del sistema de salud formal. Le fue atribuido peso 10 y nota 1 , porque a pesar de que en el IPP existe un grupo de Alcohólicos Anónimos (AA), este funciona los sábados de forma autónoma. No tenemos ninguna vinculación con organizaciones no gubernamentales (ONG's) que tengan como foco de interés el tema del alcoholismo.

Desde el punto de vista del análisis de la competencia obtuvimos una pequeña ventaja en relación al IPUFRJ, básicamente por tener mejor acceso a SADT, por ende en los demás items el análisis fue similar. En relación a la clínica con convenio, obtuvimos una superioridad en todos los items, lo que no es extraño, dado que esta clínica trabaja con un modelo predominantemente manicomial.

Los scores son:

- $\quad$ IPP $-8,85$.

- $\quad$ IPUFRJ - 8,60.

- Clínica da Gávea - 1,85.

(Ver Figuras 12 y 13) 
Figura 12 - Evaluación del valor (capacidad de atracción) del segmento UTA.

\begin{tabular}{|l|c|c|c|}
\hline \multicolumn{4}{|c|}{ Nombre del segmento: Unidad de Tratamiento de Alcohólicos (UTA) } \\
\hline Criterios de evaluación & $\begin{array}{c}\text { Peso } \\
\%\end{array}$ & $\begin{array}{c}\text { Nota } \\
0-20\end{array}$ & $\begin{array}{c}\text { Score } \\
(=\text { PxN/100) }\end{array}$ \\
\hline 1. Posibilidad de Crecimiento & 10 & 10 & 1,00 \\
\hline 2. Intensidad de Competencia & 8 & 5 & 0,40 \\
\hline 3. Inversión (barreras a la entrada) & 6 & 9 & 0,54 \\
\hline $\begin{array}{l}\text { 4. Sinergias (a nivel de capacidades e } \\
\text { infraestructuras compartidas) }\end{array}$ & 15 & 5 & 0,75 \\
\hline $\begin{array}{l}\text { 5. Motivación Interna } \\
\text { 6. Posibilidades de Colaboración Externa }\end{array}$ & 15 & 12 & 1,80 \\
\hline 7. Potencial Regional & 10 & 4 & 0,40 \\
\hline 8. Posibilidad de Conseguir Recursos Externos & 6 & 4 & 0,24 \\
\hline $\begin{array}{l}\text { 9. Contribución para el Proyecto Político General } \\
\text { (y la imagen del hospital) }\end{array}$ & 15 & 0 & 0,00 \\
\hline Valor del Segmento & 100 & 6,93 \\
\hline
\end{tabular}

Figura 13 - Evaluación de la posición competitiva del segmento UTA.

\begin{tabular}{|l|c|c|c|c|c|c|c|}
\hline \multirow{2}{*}{ Control de los factores estratégicos de éxito } \\
\hline \multirow{2}{*}{ Factores estratégicos de éxito } & \multicolumn{3}{|c|}{ Hospital } & \multicolumn{3}{c|}{ Competidores } \\
\cline { 2 - 10 } & \multicolumn{3}{|c|}{ IPP } & \multicolumn{2}{c|}{ IPUFR } & \multicolumn{2}{c|}{ Gávea } \\
\cline { 2 - 10 } & Peso & Nota & Score & Nota & Score & Nota & Score \\
\hline $\begin{array}{l}\text { 1. Equipo interdisciplinario motivado, } \\
\text { capacitado y "ampliado" (+ clínico general) }\end{array}$ & 15 & 10 & 1,50 & 10 & 1,50 & 3 & 0,45 \\
\hline $\begin{array}{l}\text { 2. Integración del equipo técnico de } \\
\text { enfermería }\end{array}$ & 20 & 5 & 1,00 & 7 & 1,40 & 1 & 0,20 \\
\hline $\begin{array}{l}\text { 3. Acceso a servicios de apoyo diagnóstico } \\
\text { y terapéutico }\end{array}$ & 20 & 15 & 3,00 & 10 & 2,00 & 0 & 0,00 \\
\hline \begin{tabular}{l} 
4. Soporte hospitalario \\
\hline 5. Fuerte sinergia con los demás segmentos
\end{tabular} & 20 & 5 & 1,00 & 5 & 1,00 & 1 & 0,20 \\
\hline 6. Disponibilidad de medicamentos & 10 & 20 & 2,00 & 20 & 2,00 & 10 & 1,00 \\
\hline $\begin{array}{l}\text { 7. Colaboraciones con organizaciones civiles o } \\
\text { estatales que lidian con el alcoholismo }\end{array}$ & 10 & 1 & 0,10 & 5 & 0,50 & 0 & 0,00 \\
\hline Score sobre el segmento & 100 & 8,85 & 8,60 & 1,85 \\
\hline Posición relativa & & 1 & & 2 & 0,20 & 0 & 0,00 \\
\hline
\end{tabular}

Competidores: IPUFRJ, Clínica da Gávea. 


\section{Segmento 7 - Recepción y Emergencias}

\section{Análisis del valor}

Si tomamos en cuenta la política/coyuntura de salud pública vigente, que estimula la demanda de atenciones de emergencias (en detrimento de la atención básica o de rehabilitación) en una red de servicios públicos desbastada y desorganizada, al momento de evaluar este segmento en relación a su posibilidad de crecimiento, recibe naturalmente una notación alta. No es poco común, por ejemplo, que un individuo que presenta una fuerte cefalea acompañada de insomnio, al que se le haya negado atención en servicios de clínica médica o neurología, procure ser atendido en el servicio de Emergencias del IPP, porque es donde termina obteniendo algún tipo de atención. Desde el punto de vista del paciente, no tiene importancia si la asistencia que recibe es clínica, neurológica o psiquiátrica, lo que él procura (y tiene dificultad de obtener) es cualquier tipo de atención médica. Lo que percibimos, a pesar de todas las explicaciones dadas al usuario en relación a estas diferencias, es que sintiéndose comúnmente "bien atendido", tiende a regresar al servicio, buscando otra tipo de atención para sí o para sus familiares, amigos y vecinos.

De este modo, la buena (relativa) atención funciona como estimuladora de la demanda de usuarios diversos que deberían estar siendo atendidos en otros servicios. Esta presión de la demanda, aumenta nuestra dificultad en atender adecuadamente a aquella parte de la población portadora de trastornos mentales que nos cabe asistir con cuidados especiales a fin de interrumpir el circuito emergencia-internación, o sea, el inicio o la perpetuidad de una "carrera psiquiátrica". Por todas estas razones, la nota es bastante baja en el item contribución para el proyecto politico del hospital y la imagen del hospital.

La intensidad de competencia es baja (tan solo con lo que resta del sector público), lo que nos otorga nota máxima.

La inversión realizada tiene, más o menos el mismo grado de importancia que en las demás enfermerías, como consecuencia de las Camas para Diagnóstico. La nota es media.

Las sinergias deben ocurrir interna y externamente en los contactos con la red. Nota alta.

En cuanto a la motivación interna, la notación es bastante baja. Los profesionales que trabajan allí sufren exigencias de todo tipo, enfrentando dificultades de naturaleza práctica, técnica y ética, como por ejemplo, ser obligados a realizar verdaderas "elecciones de Sofía" donde deben decidir cuáles pacientes recibirán el mejor tratamiento. En la emergencia clásica se termina respondiendo superfi- 
cialmente tan solo a la demanda de atención, y no a las verdaderas necesidades de vida y de salud de los pacientes.

La posibilidad de colaboraciones externas, dentro del modelo clásico, es grande. Nota alta. También existe alguna posibilidad de obtención de recursos externos, recibiendo una nota un poco por debajo de la media.

El potencial regional también es alto, ya que funciona como polo. Nota alta.

El Score del segmento es igual a 11,38.

\section{Análisis de la posición competitiva}

Para este segmento se establecieron los siguientes factores estratégicos de éxito:

1. Equipo interdisciplinario motivado, capacitado y ampliado.

2. Base territorial/poblacional.

3. Acciones intersectoriales (justicia).

4. Atención domiciliaria.

5. Integración a la red de salud.

6. Fuerte sinergia con los demás segmentos.

7. Acceso a SADT.

8. Disponibilidad de medicamentos.

El item equipo interdisciplinario, recibe la calificación adicional de ampliado porque deben estar presentes, además de los profesionales de salud mental, psiquiatras de guardia y clínico general. Se trata de un factor estratégico fundamental para permitir un mejor abordaje y manejo de las situaciones de urgencia y de crisis, superando el modelo tradicional de las guardias psiquiátricas. Con frecuencia, tanto por una propuesta asistencial inadecuada como por las pésimas condiciones de funcionamiento, estas guardias no alcanzan ningún grado de eficacia, transformándose burocráticamente, en meros servicios de selección de pacientes para internación; lo que resulta en internaciones innecesarias y prolongadas. Un mejor abordaje de las emergencias consigue rápidamente, una disminución considerable del número de internaciones psiquiátricas, lo que fue demostrado concretamente, a partir de 1983, con el inicio de la regionalización de la asistencia psiquiátrica en el Municipio de Río de Janeiro y la creación de los cinco polos regionales de emergencias y emisión de Autorizaciones de Internación Hospitalaria (AIH).

La presencia del psiquiatra de guardia y del clínico es fundamental para la óptima realización de un diagnóstico diferencial, particularmente en aquellas situaciones en donde los trastornos orgánicos están asociados a los cuadros 
psiquiátricos. Un buen diagnóstico diferencial, aún entre los trastornos psiquiátricos, es de fundamental importancia en la priorización de los cuidados inmediatos a ser prestados, así como para la consiguiente planificación terapéutica. Establecemos para este item peso 20. La nota 12 indica que aún no obtuvimos la eficiencia suficiente en este item.

$\mathrm{El}$ item base territorial, fue considerado factor estratégico de éxito siguiendo los principios de un nuevo paradigma para la reorganización de la asistencia psiquiátrica, donde la guardia psiquiátrica deja de ser el portón abierto del hospicio para ser la puerta de entrada de una red de cuidados diversificada y territorializada (Caps, Naps, espacios resguardados, pensiones protegidas, etc.). La lógica territorial prevé una intensa solidaridad entre la institución de salud y la comunidad asistida, que resulta indispensable para una asistencia de calidad en salud mental. Vemos, de este modo, la definición de una base territorial como condición necesaria para una planificación de acciones que presuponga la responsabilización de todos los actores involucrados.

La recepción/emergencias del IPP como referencia para toda la AP-2 implica una base territorial excesivamente grande para ser eficaz, por lo tanto podría asumir el rol de una guardia para la red local de Centros de Atención Diaria. Esta forma de organización será desarrollada con mayor claridad, al final de este trabajo, en la ilustración gráfica que denominamos mandala territorial del IPP. El peso 15 considera la importancia de este factor. La nota 5 responde al bajísimo control que poseemos sobre el mismo. En este punto debemos considerar las falencias de la red pública (anulación de los polos de la AP-5 y AP-1), recayendo sobre el IPP y el CPP-II la mayor parte de la responsabilidad en la atención de emergencias del municipio de Río de Janeiro y de otros municipios de la Baixada Fluminense.

Las acciones intersectoriales fueron consideradas principalmente en el aspecto relacionado al área judicial. Aquí, nos preocupa especialmente, las cuestiones ético-legales involucradas en las internaciones involuntarias y su repercusión sobre los derechos humanos y el ejercicio de ciudadanía de los pacientes psiquiátricos. El peso 5 señala la necesidad del establecimiento de una vía de acción en esa dirección, mientras que la nota 0 demuestra la ausencia actual de control sobre este factor.

El item atención domiciliaria, se relaciona estrechamente al establecimiento de una base territorial, ya que depende de esta. La realización de la atención domiciliaria representa la posibilidad de superación de la escena tradicional y banalizada de pacientes traídos a la guardia psiquiátrica en vehículos policiales o en carros del cuerpo de bomberos, frecuentemente de forma arbitraria y violenta. El peso 15 se refiere a la importancia del factor. La nota 0 indica la inexistencia de control sobre el mismo. 
La integración a la red de salud, es un factor estratégico por ser la garantía de las referencias y contra-referencias de la población en el ámbito de la red pública de salud, especialmente para la derivación de situaciones médicas de urgencia, para la reorientación de los pacientes en busca de otros tipos de tratamiento y para la derivación de los pacientes con necesidad de atención extra-hospitalaria en salud mental. El peso relativamente alto se relaciona a la importancia del factor y la nota baja a nuestra falta de control sobre el mismo.

Fuerte sinergia interna, es un factor estratégico considerando la necesaria relación entre el buen funcionamiento de la puerta de entrada-principalmente en la perspectiva de creación de un Caps/IPP- y el nivel de integración con los demás segmentos de la Institución. La notación baja demuestra el control insuficiente de este factor en la actualidad.

El acceso a $S A D T$, constituye sin duda, un factor estratégico para la adecuada evaluación diagnóstica de un paciente en situación de crisis/emergencia. Se de una herramienta indispensable para que un equipo interdisciplinario ampliado pueda, como ya señalamos anteriormente, realizar un buen diagnóstico diferencial. Atribuimos el peso máximo a este item. La nota 8 se refiere al control aún insuficiente que tenemos sobre este factor, principalmente por el hecho de que nuestro laboratorio no funciona las 24 horas ni todos los días de la semana.

$\mathrm{El}$ item disponibilidad de medicamentos, es indiscutiblemente importante en la atención de los cuadros de emergencias, por ende le atribuimos peso bajo, dado que en esa etapa del tratamiento no es necesario un abanico muy variado de medicamentos. La nota 20 , sin embargo, apunta a la gran disponibilidad y diversidad de medicamentos en el IPP.

La puerta de entrada de Casa Verde, habilitada por la CASSI, aunque no trabaje plenamente con la lógica del equipo interdisciplinario, dispone, sin embargo, de una amplia variedad de profesionales. El Casa Verde no trabaja con acciones intersectoriales y no realiza atención domiciliaria con su propio equipo, sino a través de servicios contratados. Lo que más lo diferencia, son los factores: acceso a SADT, integración a la red de salud y disponibilidad de medicamentos. Esto ocurre debido a la amplia red habilitada por la CASSI.

El CPP-II se presenta en desventaja en todos los items relacionados, excepto en el relacionado a la disponibilidad de medicamentos, que es buena.

Los scores son:

- $\quad$ IPP $-6,35$.

- $\quad$ CPP-II - 4,25.

- Casa Verde - 14,00.

(Ver Figuras 14 y 15) 
Figura 14 - Evaluación del valor (capacidad de atracción) del segmento recepción y emergencias.

\begin{tabular}{|l|c|c|c|}
\hline \multicolumn{4}{|c|}{ Nombre del segmento: Recepción y Emergencia } \\
\hline Criterios de evaluación & $\begin{array}{c}\text { Peso } \\
\%\end{array}$ & $\begin{array}{c}\text { Nota } \\
0-20\end{array}$ & $\begin{array}{c}\text { Score } \\
(=\text { PxN/100) }\end{array}$ \\
\hline 1. Posibilidad de Crecimiento & 10 & 15 & 1,50 \\
\hline 2. Intensidad de Competencia & 8 & 20 & 1,60 \\
\hline 3. Inversión (barreras a la entrada) & 6 & 10 & 0,60 \\
\hline $\begin{array}{l}\text { 4. Sinergias (a nivel de capacidades e } \\
\text { infraestructuras compartidas) }\end{array}$ & 15 & 15 & 2,25 \\
\hline 5. Motivación Interna & 15 & 3 & 0,45 \\
\hline 6. Posibilidades de Colaboración Externa & 15 & 15 & 2,25 \\
\hline 7. Potencial Regional & 10 & 15 & 1,50 \\
\hline 8. Posibilidad de Conseguir Recursos Externos & 6 & 8 & 0,48 \\
\hline 9. Contribución para el Proyecto Político General & 15 & 5 & 0,75 \\
\hline (y la imagen del hospital) & 100 & & 11,38 \\
\hline Valor del Segmento & & & \\
\hline
\end{tabular}

Figura 15 - Evaluación de la posición competitiva del segmento recepción y emergencias.

\begin{tabular}{|c|c|c|c|c|c|c|c|}
\hline \multicolumn{8}{|c|}{ Control de los factores estratégicos de éxito } \\
\hline \multirow{3}{*}{ Factores estratégicos de éxito } & \multirow{2}{*}{\multicolumn{3}{|c|}{$\begin{array}{c}\text { Hospital } \\
\text { IPP }\end{array}$}} & \multicolumn{4}{|c|}{ Competidores } \\
\hline & & & & \multicolumn{2}{|c|}{ C. Verde } & \multicolumn{2}{|c|}{ CPP-II } \\
\hline & Peso & Nota & Score & Nota & Score & Nota & Score \\
\hline $\begin{array}{l}\text { 1. Equipo interdisciplinario motivado, } \\
\text { capacitado y "ampliado" }\end{array}$ & 20 & 12 & 2,40 & 15 & 3,00 & 5 & 1,00 \\
\hline 2. Base territorial/poblacional & 15 & 5 & 0,75 & 15 & 2,25 & 5 & 0,75 \\
\hline 3. Acciones intersectoriales (justicia) & 5 & 0 & 0,00 & 0 & 0,00 & 0 & 0,00 \\
\hline 4. Atención domiciliaria & 15 & 0 & 0,00 & 5 & 0,75 & 0 & 0,00 \\
\hline 5. Integración a la red de salud & 10 & 3 & 0,30 & 20 & 2,00 & 3 & 0,30 \\
\hline 6. Fuerte sinergia con los demás segmentos & 10 & 3 & 0,30 & 10 & 1,00 & 2 & 0,20 \\
\hline $\begin{array}{l}\text { 7. Acceso a servicios de apoyo diagnóstico } \\
\text { y terapéutico }\end{array}$ & 20 & 8 & 1,60 & 20 & 4,00 & 5 & 1,00 \\
\hline 8. Disponibilidad de medicamentos & 5 & 20 & 1,00 & 20 & 1,00 & 20 & 1,00 \\
\hline Score sobre el segmento & 100 & \multicolumn{2}{|c|}{6,35} & \multicolumn{2}{|c|}{14,00} & \multicolumn{2}{|c|}{4,25} \\
\hline Posición relativa & \multicolumn{3}{|c|}{2} & \multicolumn{2}{|c|}{1} & \multicolumn{2}{|c|}{3} \\
\hline
\end{tabular}

Competidores: Casa Verde, Centro Psiquiátrico Pedro II (CPP-II). 


\section{Segmento 8 - Laboratorio Especializado en Psiquiatría}

\section{Análisis del valor}

El laboratorio del IPP recibió una importante inversión en los últimos años en términos de nuevos recursos tecnológicos. Su valor para la institución es alto en la medida que ofrece apoyo seguro en el campo diagnóstico y terapéutico, garantizando resultados confiables y de calidad para los usuarios y técnicos del IPP. En términos de contribución para el proyecto político general, se trata de un servicio de apoyo que, por su excelencia y presencia destacada en la red, contribuye significativamente a la imagen del Instituto. Nota por encima de la media.

La posibilidad de crecimiento es grande. Actualmente, la producción del laboratorio del IPP incluye un porcentaje importante de exámenes realizados para pacientes de otras instituciones de la red pública de salud, demostrando la existencia de colaboraciones externas. La nota es, por lo tanto, alta. El laboratorio tiene capacidad de transformarse en referente en más de un área programática (si aumenta el número de sus técnicos), pudiendo abarcar a todo el municipio. A nota es alta, al igual que la destinada al potencial regional.

La intensidad de competencia, es pequeña, como consecuencia de los exámenes específicos que realiza, obteniendo una nota bastante alta en este item.

Con relación al item barreras a la entrada para nuevas inversiones, la inversión ya realizada es grande, lo que exige a los nuevos inversores una inversión equivalente para equiparar el nivel alcanzado por el IPP. Nota alta.

Las sinergias son grandes, ya que se integra con todos los sectores del IPP. Nota alta.

La motivación interna es buena, existiendo sin embargo, falta de personal técnico. Nota media. También es buena la posibilidad de conseguir recursos externos en la lógica de colaboración. Nota por encima de la media.

Score alcanzado igual a 14,52

\section{Análisis de la posición competitiva}

Los factores estratégicos de éxito del segmento son los siguientes:

1. Analizador de bioquímica, drogas y lítio.

2. Analizador de hormonas e inmunocomponentes.

3. Centrífuga preparadora de líquidos..

4. Profesionales calificados (nivel medio y superior). 
5. Abastecimiento adecuado del material de consumo.

6. Renovación continua de equipos.

7. Mantenimiento preventivo y correctivo de los equipos.

8. Colaboraciones externas.

9. Control de calidad permanente (interno y externo).

Para el item analizador de bioquímica, que ya poseemos, atribuimos peso $15 \mathrm{y}$ nota 20.

Para el item 2 atribuimos peso 10, teniendo en cuenta la consabida importancia del analizador de hormonas e inmunocomponentes para la formulación de diagnósticos diferenciales más precisos y en el control de posibles síndromes iatrogénicos, tales como el hipotiroidismo y la hiperprolactinemia. La nota 0 se debe a que aún no contamos con este recurso.

El item centrifuga preparadora de líquidos presenta un peso ligeramente menor que el item anterior por tener una utilidad más restricta. La notación (cero) se debe a la inexistencia de este equipamiento.

En cuanto a los recursos humanos necesarios para el adecuado funcionamiento del laboratorio, atribuimos peso 15 y nota 10, ya que por el momento contamos con aproximadamente la mitad de los recursos considerados como ideales.

Los tres próximos items hablan de abastecimiento adecuado del material de consumo, renovación continua de los equipos (que puede darse a través del instrumento comodato) y manutención preventiva y correctiva de los mismos. Les atribuimos pesos y notas medias, con excepción del item manutención, dado que ya contamos con contratos adecuados para este fin.

Colaboraciones externas y control de calidad, ya vienen desarrollándose (por ello nota media), no obstante pueden crecer bastante. El item control de calidad permanente debe llegar a las especificaciones del Inmetro, por ejemplo. En cuanto a las colaboraciones externas, entendemos que pueden servir también como moneda de cambio para la obtención de acceso a servicios de imagen cerebral, que constituye el objeto del próximo segmento estudiado.

Para la evaluación competitiva utilizamos los laboratorios del IPUFRJ, del Hospital Municipal Rocha Maia (HMRM) y del Hospital de Día Casa Verde, o sea: una unidad pública de la red de salud mental, una unidad pública de la red de salud general y una unidad privada acreditada por la Cassi, respectivamente. En la competición con las unidades públicas obtuvimos un mejor posicionamiento, básicamente por los recursos tecnológicos y humanos que ya poseemos, aliados a un adecuado mantenimiento de los equipos. En relación al Casa Verde, notamos que se trata allí de una atención modelo dentro del área, alcanzando una evaluación bastante superior. 
Los scores fueron los siguientes:

- $\quad$ IPP $-10,55$.

- $\quad$ IPUFRJ $-8,85$.

- HMRM - 7,35.

- Casa Verde - 18,95.

(Ver Figuras 16 y 17)

Figura 16 - Evaluación del valor (capacidad de atracción) del segmento laboratorio.

\begin{tabular}{|l|c|c|c|}
\hline \multicolumn{4}{|c|}{ Nombre del segmento: Laboratorio (especializado en psiquiatría) } \\
\hline Criterios de evaluación & $\begin{array}{c}\text { Peso } \\
\%\end{array}$ & $\begin{array}{c}\text { Nota } \\
0-20\end{array}$ & $\begin{array}{c}\text { Score } \\
(=\text { PxN/100) }\end{array}$ \\
\hline 1. Posibilidad de Crecimiento & 10 & 15 & 1,50 \\
\hline 2. Intensidad de Competencia & 8 & 18 & 1,44 \\
\hline 3. Inversión (barreras a la entrada) & 6 & 15 & 0,90 \\
\hline $\begin{array}{l}\text { 4. Sinergias (a nivel de capacidades e } \\
\text { infraestructuras compartidas) }\end{array}$ & 15 & 18 & 2,70 \\
\hline 5. Motivación Interna & 15 & 10 & 1,50 \\
\hline 6. Posibilidades de Colaboración Externa & 15 & 15 & 2,25 \\
\hline 7. Potencial Regional & 10 & 15 & 1,50 \\
\hline 8. Posibilidad de Conseguir Recursos Externos & 6 & 13 & 0,78 \\
\hline 9. Contribución para el Proyecto Político General & 15 & 13 & 1,95 \\
\hline (y la imagen del hospital) & 100 & & 14,52 \\
\hline
\end{tabular}


Figura 17 - Evaluación de la posición competitiva del segmento laboratorio.

\begin{tabular}{|c|c|c|c|c|c|c|c|c|c|}
\hline \multicolumn{10}{|c|}{ Control de los factores estratégicos de éxito } \\
\hline \multirow{3}{*}{ Factores estratégicos de éxito } & \multirow{2}{*}{\multicolumn{3}{|c|}{$\begin{array}{c}\text { Hospital } \\
\text { IPP }\end{array}$}} & \multicolumn{6}{|c|}{ Competidores } \\
\hline & & & & \multicolumn{2}{|c|}{ IPUFRJ } & \multicolumn{2}{|c|}{ C. Verde } & \multicolumn{2}{|c|}{ HMRM } \\
\hline & Peso & Nota & Score & Nota & Score & Nota & Score & Nota & Score \\
\hline $\begin{array}{l}\text { 1. Analizador de bioquímica, } \\
\text { drogas y lítio }\end{array}$ & 15 & 20 & 3,00 & 12 & 1,80 & 18 & 2,70 & 8 & 1,20 \\
\hline $\begin{array}{l}\text { 2. Analizador de hormonas e } \\
\text { inmunocomponentes }\end{array}$ & 10 & 0 & 0,00 & 12 & 1,20 & 20 & 2,00 & 15 & 1,50 \\
\hline $\begin{array}{l}\text { 3. Centrífuga preparadora de } \\
\text { líquidos }\end{array}$ & 8 & 0 & 0,00 & 0 & 0,00 & 20 & 1,60 & 0 & 0,00 \\
\hline $\begin{array}{l}\text { 4. Profesionales calificados } \\
\text { (nivel medio y superior) }\end{array}$ & 15 & 10 & 1,50 & 5 & 0,75 & 15 & 2,25 & 7 & 1,05 \\
\hline $\begin{array}{l}\text { 5. Abastecimiento adecuado de } \\
\text { material de consumo }\end{array}$ & 11 & 12 & 1,32 & 20 & 2,20 & 20 & 2,20 & 5 & 0,55 \\
\hline $\begin{array}{l}\text { 6. Renovación continua de los } \\
\text { equipos }\end{array}$ & 12 & 10 & 1,20 & 10 & 1,20 & 20 & 2,40 & 5 & 0,60 \\
\hline $\begin{array}{l}\text { 7. Mantenimiento preventivo y } \\
\text { correctivo de los equipos }\end{array}$ & 9 & 17 & 1,53 & 10 & 0,90 & 20 & 1,80 & 5 & 0,45 \\
\hline 8. Colaboraciones externas & 10 & 10 & 1,00 & 3 & 0,30 & 20 & 2,00 & 15 & 1,50 \\
\hline $\begin{array}{l}\text { 9. Control de calidad } \\
\text { permanente (interno y externo) }\end{array}$ & 10 & 10 & 1,00 & 5 & 0,50 & 20 & 2,00 & 5 & 0,50 \\
\hline Score sobre el segmento & 100 & \multicolumn{2}{|c|}{10,55} & \multicolumn{2}{|c|}{8,85} & \multicolumn{2}{|c|}{18,95} & \multicolumn{2}{|c|}{7,35} \\
\hline Posición relativa & \multicolumn{3}{|c|}{2} & \multicolumn{2}{|c|}{3} & \multicolumn{2}{|c|}{1} & \multicolumn{2}{|c|}{4} \\
\hline
\end{tabular}

Competidores: IPUFRJ, Casa Verde, Hospital Municipal Rocha Maia (HMRM).

\section{Segmento 9 - Servicio de Imagen Cerebral (Virtual)}

\section{Análisis del valor}

Se trata de un segmento virtual, pensado como servicio de apoyo diagnóstico y terapéutico, sin alterar significativamente el proyecto politico y la imagen del hospital, lo que le otorga nota baja. En cuanto a la posibilidad de crecimiento, es total: estamos en la "Década del Cerebro". Nota máxima.

No tenemos ningún tipo de inversión realizada en este segmento, por consiguiente la cantidad de recursos necesaria para la creación de este servicio tendría que ser muy elevada, lo que implica una nota alta. Las Sinergias también son grandes con todos los segmentos, lo que también implica nota alta. 
La motivación interna también es elevada; este tipo de trabajo implica mayor status profesional y mayor salario. Nota por encima de la media.

Evaluamos en este segmento la altísima posibilidad de colaboraciones externas, lo que justificó su análisis. Nuestra localización física nos impulsa hacia ello, dado que estamos situados dentro del campus de la UFRJ, rodeados por dos Institutos de esta Universidad (Psiquiatría y Neurología) presentando mayores condiciones de recibir inversiones en alta tecnología. Podemos, por el momento, efectuar intercambios importantes con los productos del laboratorio. La nota es alta.

El potencial regional también es elevado. Nota alta. La posibilidad de conseguir recursos externos está vinculada a los dos items anteriormente mencionados. Nota alta.

Score del segmento: 13,60

\section{Análisis de la posición competitiva}

Seleccionamos para este segmento seis factores estratégicos de éxito:

1. Equipo de resonancia nuclear magnética (RNM).

2. Mapeador cerebral.

3. Profesionales calificados.

4. Renovación continua de los equipos.

5. Capacitación continua del conjunto de los profesionales.

6. Acceso a financiamiento.

Los pesos de los diversos factores de este segmento quedaron distribuidos de este modo: $15 \%$ para los cuatros primeros items; $20 \%$ para los dos últimos. El IPP recibe nota 0 en todos los items, por tratarse de un segmento totalmente virtual.

El IPUFRJ posee un mapeador cerebral, lo que le da nota máxima en este item, por lo cual recibe nota media para los items profesionales calificados y renovación continua de la planta tecnológica. En el factor capacitación continua del conjunto de profesionales El IPUFRJ recibe nota reducida, ya que su controle sobre este factor es bajo. Lo mismo ocurre en lo referente al acceso a la fuente de financiamiento.

Una vez más es importante señalar que optamos por el análisis de este segmento debido a su creciente importancia en el auxilio diagnóstico y en el monitoreo terapéutico en psiquiatría. La idea, por el momento, es desarrollar colaboraciones con otras instituciones a fin de obtener acceso a esta tecnología fundamental.

Los scores fueron:

- $\quad$ IPP -0 .

- $\quad$ IPUFRJ - 8 .

(Ver Figuras 18 y 19) 
Figura 18 - Evaluación del valor (capacidad de atracción) del segmento imagen cerebral.

\begin{tabular}{|l|c|c|c|}
\hline \multicolumn{4}{|c}{ Nombre del segmento: Servicio de Imagen Cerebral (Virtual) } \\
\hline Criterios de evaluación & $\begin{array}{c}\text { Peso } \\
\%\end{array}$ & $\begin{array}{c}\text { Nota } \\
0-20\end{array}$ & $\begin{array}{c}\text { Score } \\
(=\text { PxN/100) }\end{array}$ \\
\hline 1. Posibilidad de Crecimiento & 10 & 20 & 2,00 \\
\hline 2. Intensidad de Competencia & 8 & 10 & 0,80 \\
\hline 3. Inversión (barreras a la entrada) & 6 & 15 & 0,90 \\
\hline $\begin{array}{l}\text { 4. Sinergias (a nivel de capacidades e } \\
\text { infraestructuras compartidas) }\end{array}$ & 15 & 18 & 2,70 \\
\hline 5. Motivación Interna & 15 & 12 & 1,80 \\
\hline 6. Posibilidades de Colaboración Externa & 15 & 15 & 2,25 \\
\hline 7. Potencial Regional & 10 & 15 & 1,50 \\
\hline 8. Posibilidad de Conseguir Recursos Externos & 6 & 15 & 0,90 \\
\hline 9. Contribución para el Proyecto Político General & 15 & 5 & 0,75 \\
\hline (y la imagen del hospital) & 100 & & 13,60 \\
\hline Valor del Segmento & & & \\
\hline
\end{tabular}

Figura 19 - Evaluación de la posición competitiva del segmento.

\begin{tabular}{|c|c|c|c|c|c|}
\hline \multicolumn{6}{|c|}{ Control de los factores estratégicos de éxito } \\
\hline \multirow{3}{*}{ Factores estratégicos de éxito } & \multicolumn{3}{|c|}{ Hospital } & \multicolumn{2}{|c|}{ Competidor } \\
\hline & \multicolumn{3}{|c|}{ IPP } & \multicolumn{2}{|c|}{ IPUFRJ } \\
\hline & Peso & Nota & Score & Nota & Score \\
\hline 1. Equipos de Resonancia Nuclear Magnética (RNM) & 15 & 0 & 0,00 & 0 & 0,00 \\
\hline 2. Mapeador Cerebral & 15 & 0 & 0,00 & 20 & 3,00 \\
\hline 3. Profesionales calificados & 15 & 0 & 0,00 & 10 & 1,50 \\
\hline 4. Renovación continua de los equipos & 15 & 0 & 0,00 & 10 & 1,50 \\
\hline 5. Capacitación continua del conjunto de los profesionales & 20 & 0 & 0,00 & 5 & 1,00 \\
\hline 6. Acceso a financiamiento & 20 & 0 & 0,00 & 5 & 1,00 \\
\hline Score sobre el segmento & 100 & \multicolumn{2}{|c|}{0,00} & \multicolumn{2}{|c|}{8,00} \\
\hline Posición relativa & \multicolumn{3}{|c|}{2} & \multicolumn{2}{|c|}{1} \\
\hline
\end{tabular}

Competidores: IPUFRJ. 


\section{El Portafolio de Actividades y la Definición de la Estrategia y de los Planos de Desarrollo por Segmento}

Presentamos aquí el portafolio del IPP, utilizado para la definición de la macroestrategia y de los planes de cada servicio (Figura 20).

Figura 20 - Portafolio de actividades - IPP.

PORTAFOLIO DE ACTIVIDADES

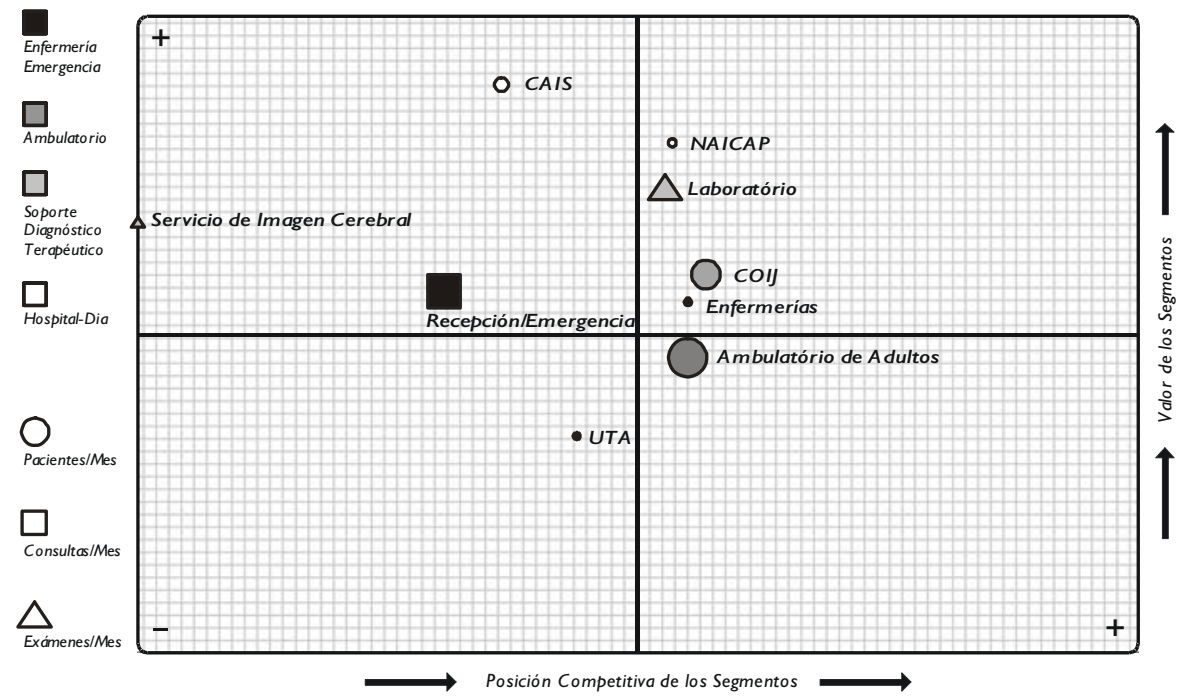

\section{Directrices Estratégicas (nivel macro)}

No es intención del IPP desarrollar el segmento de Imagen cerebral, aunque reconozca la importancia fundamental de esta tecnología en el presente y, principalmente, para el futuro de la psiquiatría. Tanto la falta de inversión en este tipo de tecnología, como la necesidad de un alto grado de inversión en equipamientos y recursos humanos para la viabilización de este servicio, justifican que el IPP busque colaboraciones con las dos instituciones universitarias vecinas (el Instituto de Psiquiatría y el Instituto de Neurología Deolindo Couto, ambos de la UFRJ) a fin de obtener acceso a estas nuevas formas de tecnología diagnóstica. La propuesta de utilización del Laboratorio Especializado del IPP por parte del Instituto de Psiquiatría podría ayudar en esta negociación.

La UTA presenta un valor y una posición competitiva relativamente desfavorables. Este segmento no valoriza el proyecto asistencial del Hospital. Se re- 
comienda negociar con los Hospitales Generales la transferencia de pacientes, reducir la permanencia de los pacientes en el hospital al período exclusivo de desintoxicación, con la rápida derivación del paciente.

El ambulatorio de adultos es un segmento de gran volumen de atención, por ende tendría poco valor dado que prevalece allí un tipo de atención poco programada, aleatoria, sin continuidad y de naturaleza eminentemente médicopsiquiátrica. Dada la imposibilidad de desvinculación, se recomienda una estrategia inicial de focalización, que consistiría en aplicar el principio de la base territorial-geográfica, atendiendo una población más sujeta al área programática pertinente, y en atender a un cuadro nosológico de mayor complejidad relativa (guardia ambulatoria). Se propone, también, una estrategia de diferenciación para este segmento recortado, en el sentido de que asuma gradualmente un tipo de modalidad asistencial más próxima a la lógica del hospital de día, o sea, una atención multidisciplinaria, programada, que asegure a través de las sinergias necesarias la continuidad de la atención. Estimular el referenciamiento de los pacientes a equipos, de modo tal de garantizar un vínculo o una atención más personalizada.

El Cais u Hospital de Día de adultos es casi que el modelo de atención del hospital, presentando un alto valor, pero una posición competitiva desfavorable. La estrategia sugerida es de diferenciación a partir de inversión y de un conjunto de acciones que aumentarían el valor o la calidad de la atención. Esta estrategia supone la incorporación de nuevas formas de atención, como la domiciliaria, estimular las sinergias internas y la intersectorialidad, mejorar el perfil de las equipos, etc., de modo de transformar los puntos débiles reconocidos en la matriz de los FCS, en objetivos.

El Naicap, con la misma lógica solo que en una posición competitiva relativamente mejor, debería acompañar la orientación anterior.

En relación al laboratorio, se recomienda una diferenciación mayor a partir de una inversión específica, de un control de calidad riguroso y de acciones pertinentes. La base de la estrategia consistiría en enfrentar los puntos débiles de la matriz de los FCS..., de modo de avanzar en dirección a un modelo de laboratorio como centro de referencia municipal.

En relación a la recepción/emergencias, se propone recortar la atención, a través de la definición de la base territorial de este segmento, y de la incorporación del mismo como servicio de guardia de una red de servicios complejos de atención diaria. Se sugieren medidas que se encaminen hacia el sentido de la diferenciación de calidad, como: restringir el trabajo en régimen de guardia (oligoprofesional y discontinuo) a tan solo aquellas situaciones inevitables, privilegiando el trabajo en equipos interdisciplinarios de régimen diario; realizar acciones gerenciales y técnicas junto a los equipos, explorando sobre todo el rol 
estratégico de los profesionales de enfermería, apuntando a la aceleración del proceso transformador de los modos de atención para las situaciones de crisis y de urgencia en salud mental; mejorar el transporte de pacientes; etc.

Restringir la internación a solo aquellos casos que no pueden ser enfrentados a través de una atención extrahospitalaria (control riguroso de las internaciones); mejorar la sinergia entre la internación y los otros segmentos, a fin de encaminar y acompañar mejor el tratamiento de los pacientes; estimular la rotación de los equipos de internación por los otros segmentos para que adquieran una visión de conjunto; desarrollar la capacitación necesaria al cambio de cultura; garantizar la supervisión técnica permanente para algunos equipos; estimular la investigación; etc.

La estrategia general privilegia la sinergia entre segmentos y la aplicación del principio de la base territorial.

La estrategia propone una resegmentación que consistiría en la fusión progresiva de la recepción/emergencias, del ambulatorio y del hospital de día, articulación que redundaría en un macrosegmento equivalente a un Centro de Atención Psicosocial Diario, imagen objetivo del hospital.

\section{Factores clave de éxito (FCE) y estrategia}

El meta-análisis realizado de los FCE permitió definir los factores más importantes del IPP, así como los factores más importantes involucrados en la propuesta de re-segmentación de los tres segmentos originales: Ambulatorio, Cais y Recepción/Emergencias, originando el Caps-IPP. El cruzamiento de los nueve FCE más importantes del IPP con los 10 factores que surgen de la resegmentación, permitió seleccionar los siete FCE sobre los cuales es condición sine qua non trabajar:

- Equipo multidisciplinario

- Flexibilidad de respuesta a la demanda

- Espacio físico adecuado

- Atención domiciliaria

- Base territorial/poblacional

- Integración/colaboración con la red de salud

- Necesidad de acciones intersectoriales

Podemos observar - a partir del orden establecido intencionalmente- que los cuatro primeros factores (metafactores) se encuentran bajo un control significativo de la Institución, tanto por haber realizado importantes inversiones has- 
ta el momento sobre estos factores o porque la institución posee una autonomía razonable sobre los mismos para modificarlos o desarrollarlos. Por otro lado, los tres últimos se refieren al posicionamiento de la institución dentro de una red de servicios sanitarios y sociales, donde la obtención del control sobre estos depende de un importante esfuerzo de negociación con los gestores de las diversas esferas de gobierno, con las autoridades de las diferentes áreas sociales del sector estatal, con los dirigentes de otras unidades de salud, y finalmente, con la comunidad de usuarios y sus familiares.

Si a corto plazo, los cuatro primeros ofrecen mayor facilidad de generar acciones y, por consiguiente, deben ser enfrentados rápidamente y con energía, por otro lado, el resultado a medio y largo plazo de las acciones realizadas sobre estos depende, esencialmente, del éxito en la obtención de resultados importantes en los otros tres factores, los cuales están vinculados a la interactividad de la organización con su entorno comunitario e institucional. De esta forma, si bien podemos hablar de un primer y un segundo tiempo, en un sentido metodológico-estratégico, no podemos entenderlos como tiempos concretos y secuenciales, dado que es necesario, desde el inicio, un esfuerzo sustancial de acciones paralelas sobre los dos grupos de factores.

\section{Microestrategia: plan de acciones por segmento}

\section{Ambulatorio de adultos}

- Trabajar junto al equipo multiprofesional las necesarias transformaciones del modo de atención clásica y fragmentada actual para una actuación progresivamente más interdisciplinaria y diversificada, apuntando hacia una aproximación de este segmento con otros segmentos más dinámicos e innovadores de la Institución. Tales medidas abren camino hacia el proceso de resegmentación propuesto en la macroestrategia.

- Definir la base territorial/poblacional, a fin de tener claridad de la demanda que atenderá el nuevo segmento.

- Establecer un vínculo creciente con los demás segmentos, a través de reuniones, sesiones clínicas, etc.

- Crear normas y rutinas mínimas (programación), las cuales, asociadas a estructuras y acciones flexibles, posibiliten una atención diversificada e individualizada, sin desorganizar el servicio.

- Desconcentrar el ambulatorio en términos de recursos humanos, distribuyendo el trabajo de los técnicos (por lo menos una parte) también por los 
otros servicios, que deberán participar de la resegmentación propuesta en la macroestrategia, dado que esto constituye un procedimiento facilitador de este proceso.

- Coij (Ambulatorio Infanto-Juvenil)

- Trabajar la integración entre los equipos del Coij y Naicap en el sentido de una futura re-segmentación/fusión de estos servicios.

- Definir la base territorial del nuevo segmento, entendiendo que esta debe ser mayor que la de otros segmentos/servicios del IPP.

- Negociar junto a los Consejos de Salud de la AP-2.1 y AP-2.2 y a las instituciones de salud del área el Programa de Atención Integral a la Niñez.

- Desarrollar acciones junto a las Secretarias Estatal/Municipal de Educación, buscando una mejor integración con la red escolar de la región.

\section{Cais (hospital de día de adultos)}

- Discutir con el equipo la resegmentación del IPP y las estrategias para la construcción de un Centro de Atención Psicosocial que englobe y prolongue el Cais.

- Definir base territorial.

- Desarrollar programas de capacitación, entrenamiento y educación continua para el equipo, así como la utilización de supervisión externa.

- Programar reuniones/seminarios con los diversos segmentos a fin de fortalecer la sinergia interna con estos.

- Desarrollar colaboraciones junto a las Secretarias de Desarrollo Social, Vivienda, Trabajo, Deporte y Recreación, y Cultura.

- Adecuar la estructura logística (servicio de transporte) y el trabajo del equipo técnico de modo de viabilizar la atención domiciliaria como una acción habitual.

- Promover el máximo de diversidad en las prácticas terapéuticas, entendiendo que en estas también están incluidas acciones terapéuticas informales, fundamentales para lidiar cotidianamente con pacientes frecuentemente en crisis, extremadamente diversa y fuertemente imprevisible.

\section{Naicap (hospital de día de niños)}

- Integrar el equipo de este servicio al del Coij (Centro de Orientación Infanto-Juvenil), buscando, en el futuro, la creación de un único servicio de atención diaria a la infancia y adolescencia en sufrimiento psíquico. 
- Definir claramente su base territorial.

- Redefinir la forma de segmentación del servicio, utilizando la complejidad y las formas diferenciadas de atención practicadas allí, en vez de basarse en el criterio de patología clínica.

- Desarrollar colaboraciones con las Secretarias de Educación y Recreación del Municipio de Río de Janeiro.

- Establecer colaboraciones con organizaciones no gubernamentales (ONG's) dedicadas a la protección de la infancia y de la juventud.

- Ampliar el acceso a tecnologías de apoyo diagnóstico (exámenes inmunológicos, investigación de errores innatos del metabolismo, cariotipos y estudios genéticos).

- Instituir mayor integración con los demás segmentos del IPP.

- Establecer la atención domiciliaria como acción de rutina.

\section{Enfermerías $A$ y $B$}

- Participar de reuniones, seminarios y sesiones clínicas, a fin de fortalecer la sinergia con los demás segmentos.

- Redimensionar y perfeccionar los servicios de internación, estableciendo criterios claros y rigurosos para la hospitalización de los pacientes, recurriendo a esta solo cuando el tratamiento extra-hospitalario sea inviable para un determinado paciente en un momento específico de su tratamiento o de su vida.

- Utilizar la internación como un instrumento terapéutico de excepción, lo que debe reflejarse en tiempos de permanencia cortos.

- Desarrollar con mayor empeño acciones terapéuticas en el sentido de la integración social del paciente con posterioridad a su internación, ofreciendo recursos semejantes a los existentes en otros segmentos de la Institución que trabajan con rehabilitación psicosocial.

- Interrelacionar el trabajo de las enfermerías entre sí y de estas con el Ambulatorio y el Cais, a fin de mejorar la derivación y el acompañamiento del tratamiento de los pacientes.

- Desarrollar programas de capacitación, entrenamiento y educación continua del equipo técnico de enfermería, propiciando mecanismos facilitadores de la comprensión de la misión del IPP e integrándola como parte fundamental del proceso de cambio de la cultura institucional.

- Viabilizar estudios sobre los posibles daños a la salud física y mental de los técnicos de enfermería y sus causas, teniendo en cuenta que estos profesio- 
nales están más expuestos a un contacto intenso e intensivo con los pacientes en crisis. Cuidar de la salud de estos profesionales significa también cuidar de la salud de aquellos pacientes que se encuentran bajo sus cuidados, ya que el contacto intenso y continuo entre ambos es recíproco.

- Estimular la participación del equipo de enfermería en todos los proyectos y programas de los diversos segmentos del IPP que puedan beneficiarse de las acciones de enfermería (Ej: rotación del equipo de enfermería por estos segmentos), siendo esta constante participación, una forma de entrenamiento en servicio para estos profesionales.

- Garantizar la supervisión técnica las 24 horas para el equipo de enfermería.

- Integrar los equipos especializados de las enfermerías con el área de investigación, apuntando a la profundización del estudio de diferentes asuntos de relevancia, como, por ejemplo, las especificidades del adolecer psíquico de la mujer.

\section{Unidad de Tratamiento de Alcohólicos (UTA)}

Negociar junto a la Secretaría Municipal de Salud:

- La oferta de camas clínicas en la red de salud para pacientes alcohólicos que demanden atención médico hospitalaria (incluyendo desintoxicación).

- La creación de una red de servicios especializados para la atención diaria al alcoholismo: Day Clinics.

- La participación del IPP en la creación de esos servicios especializados, contribuyendo con los profesionales altamente calificados y con experiencia en el tema, tanto en la composición de los equipos como en actividades de supervisión y consultaría.

- El mantenimiento en el IPP de la internación de aquellos pacientes que además del alcoholismo también manifiesten cuadros psiquiátricos primarios agudos.

- El apoyo a iniciativas no gubernamentales, sin fines lucrativos, que tengan como objetivo el auxilio y el tratamiento de pacientes alcohólicos.

\section{Recepción y Emergencias}

- Invertir intensamente en acciones gerenciales y técnicas junto al equipo que realiza las acciones de recepción y emergencias, a fin de acelerar el proceso transformador de los modos de atención en las situaciones de crisis y urgencias en salud mental. En este caso se debe poner énfasis especial a los 
profesionales de enfermería, teniendo en cuenta el rol estratégico de estos dentro del equipo técnico en general.

- Definir claramente la base territorial de este segmento, a partir de negociaciones con las instancias gubernamentales competentes.

- Mantener foros permanentes de discusión con las demás unidades que realizan acciones de recepción y emergencias en salud mental en el municipio de Río de Janeiro.

- Restringir el trabajo de régimen de guardia (oligoprofesional y discontinuo) solo a aquellas situaciones inevitables, privilegiando el trabajo interdisciplinario de régimen diario.

- Adecuar el Servicio de Recepción y Emergencias para que, gradualmente, pase a ocupar un papel de guardia para una red de servicios complejos de atención diaria.

- Proveer a este segmento con los medios adecuados para el transporte de pacientes, de modo de asegurar la derivación segura de usuarios para otros hospitales, servicios de salud mental o domicilios siempre que esté indicado.

- Garantizar el acceso continuo, durante las 24 horas del día, a los servicios de apoyo diagnóstico y terapéutico.

- Garantizar la supervisión técnica, las 24 horas, para el equipo de enfermería.

- Articular junto a las instancias gubernamentales, a las asociaciones de usuarios y familiares, a los diversos consejos de clase, a los consejos municipales y de los distritos federales y a los órganos judiciales competentes, formas de control y acompañamiento de las internaciones involuntarias.

\section{Laboratorio (especializado en psiquiatría)}

- Continuar el desarrollo del laboratorio del IPP en el sentido de consolidarlo como centro de referencia en el campo de la salud mental ${ }^{3}$, especializado en el diagnóstico diferencial (rutinas y algoritmos diagnósticos específicos) y en la bioseguridad (monitoreo de drogas y prevención, y diagnóstico de síndromes iatrogénicos) de pacientes en tratamiento psiquiátrico.

- Negociar junto a las instancias gubernamentales competentes el rol del Laboratorio del IPP como centro de referencia para toda la red de salud mental existente en el municipio de Rio de Janeiro.

3 En este aspecto, o laboratorio del IPP ya alcanzó en parte este rol de referencia. A título de ejemplo: el Manual de Monitoreo de Psicofármacos publicado por el Ministerio de Salud y en vias de ser distribuido para todo el país fue producido por la atual coordinadora de la División de Apoyo Diagnóstico y Soporte Terapéutico del IPP, Salete Cursi Barroca de Andrea. 
- Adquirir, a través de comodato (forma más económica y que permite mayor agilidad en términos de renovación tecnológica), analizador de hormonas e inmunocomponentes, así como centrífuga preparadora de líquidos. Tales equipamientos llevarían al laboratorio, a estar plenamente capacitado para satisfacer su rol de referencia.

- Instituir el control de calidad externo y perfeccionar los mecanismos internos de evaluación de calidad existentes.

- Negociar la reposición y complementación de los recursos humanos necesarios (nivel medio y superior) junto a las instancias gubernamentales competentes y junto a las demás unidades de salud mental en el municipio de Río de Janeiro.

- Desarrollar capacitación y entrenamiento continuo para todos los profesionales del laboratorio.

- Perfeccionar el proceso de abastecimiento de material de consumo del laboratorio.

- Extender la actuación del laboratorio al período de 24 horas y a todos los días de la semana.

\section{La Mandala Territorial}

El concepto de mandala territorial (Figura 21), inspirado en la conocida imagen budista tibetana, se trata de una invención creativa del grupo para ilustrar, gráficamente, variadas formas y amplitudes distintas de inserción del IPP en una red de salud mental en el municipio de Río de Janeiro.

La idea central es que, siendo el IPP una organización profesional compleja y de productos múltiples, su inserción en la red también es diversa y múltiple. El IPP, además de los diversos modos y niveles de atención en salud mental (aspecto que destacamos en este trabajo), produce también acciones y proyectos en las áreas de enseñanza (programas de residencia y prácticas curriculares), intervención cultural (producción de videos/TV-Pinel, eventos culturales en espacios públicos), asesoramiento a organizaciones de servicios y políticas de salud mental, y actividades intersectoriales de rehabilitación psicosocial (Cooperativa de la Praia Vermelha, Club de la Esquina, Proyecto Lar Abrigado).

El núcleo de la mandala es, precisamente, el Centro de Atención Diaria (Caps-IPP) que constituye el eje asistencial en torno del cual gira la Institución y a través del cual el IPP se conecta con mayor profundidad a la red de salud mental. De todo el IPP, el Caps es aquel que posee la base territorial menor 
(aunque es significativa), pues se trata de un Caps entre otros existentes en la subred local a la cual pertenece. Estos en conjunto, a su vez, deben dar cobertura integral y flexible en salud mental a la toda la población de su área de referencia, durante los días hábiles y en el horario normal de atención al público. Cada Caps es responsable por una fracción definida de esta comunidad.

Si bien el Caps-IPP tiene la menor base territorial de toda la Institución, es allí donde la vinculación del Instituto con su entorno comunitario se da de forma más intensa, duradera y solidaria.

En un segundo nivel, el IPP puede perfectamente ofrecer guardias para la atención de emergencias en los períodos nocturnos, en los fines de semana y feriados, así como para internaciones eventuales, para toda el área de referencia de la red local de Caps.

Un tercer nivel sería el de exámenes de laboratorio dirigidos a las necesidades de pacientes con problemas mentales (diagnósticos diferenciales, bioseguridad). En este aspecto, el Laboratorio del IPP ha acumulado un alto nivel de especialización y de capacitación en el área. Teniendo en cuenta el elevado nivel de tecnología especializada y automatización alcanzados por el laboratorio del IPP, podría seguramente abarcar (base territorial) toda la red de salud mental del municipio de Rio de Janeiro.

Por último, un cuarto nivel de actuación, traspasando los límites del recorte asistencial, se refiere a las ya citadas áreas de enseñanza, investigación y asesoría, entre otras, las cuales no necesitan restringir sus acciones al distrito local o al municipio, pudiendo producir acciones a nivel estatal y federal.

Existe, por lo tanto, una relación inversa entre la amplitud de la base territorial y el nivel de vinculación establecido entre la Institución y sus usuarios. Un paciente sicótico grave tratado en el Caps del IPP necesita de un tipo de vinculación en términos de tiempo, espacio y relación personal que un alumno de residencia del IPP proveniente de Manaus, por ejemplo, puede y debe dispensar al finalizar su período de formación. Este último, al retornar a su ciudad natal, podrá cumplir el papel importantísimo de agente multiplicador de los nuevos saberes y prácticas terapéuticas aprendidas, tarea indispensable para el avance del proceso de reforma psiquiátrica en el país.

Como última observación, cabe destacar que, dentro del simbolismo gráfico de la mandala, las formas circulares se refieren siempre a actividades asistenciales, mientras que el recuadro exterior contiene las otras importantes acciones ejecutadas por esta institución compleja llamada Instituto Philippe Pinel. 
Figura 21 - Mandala Territorial del Instituto Philippe Pinel (Macroestrategia en Red).

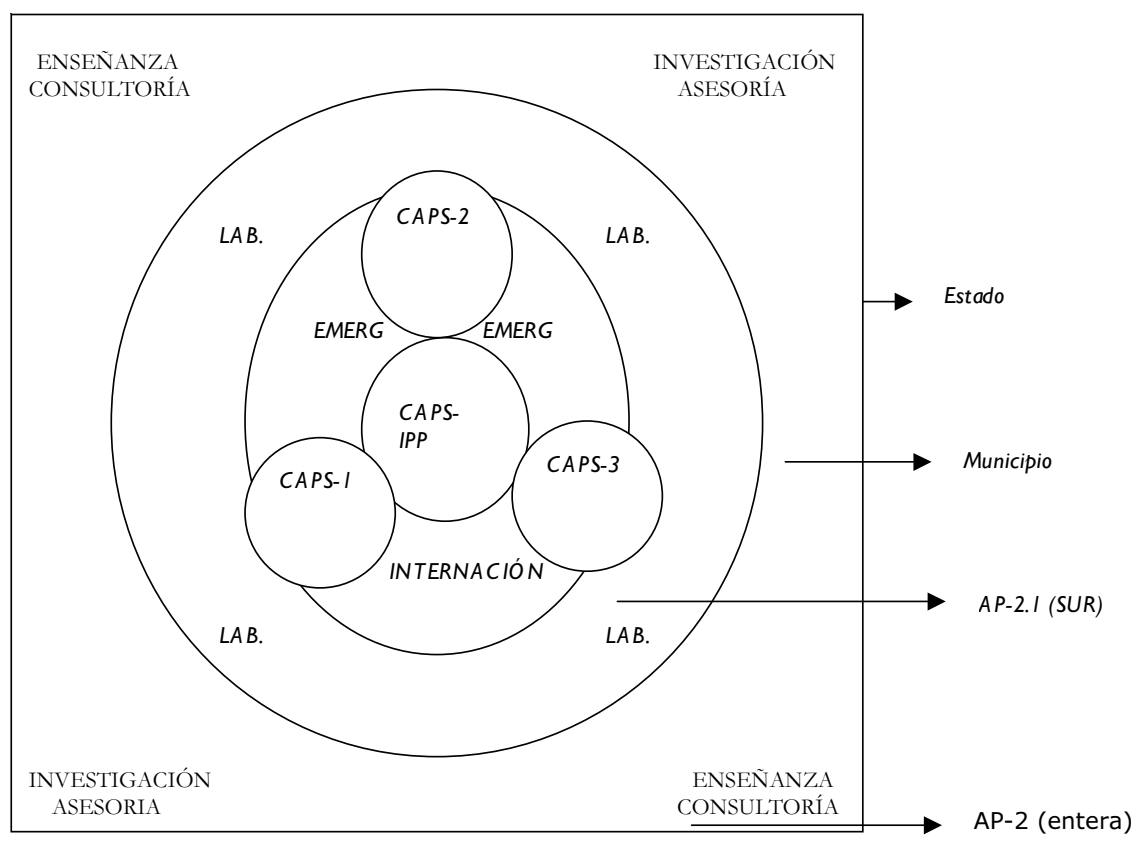

\section{Conclusiones}

No es tarea fácil realizar el cierre de un trabajo como este, con un verdadero manantial de datos para ser analizados y de posibilidades en la aplicación de los resultados obtenidos. En función de esto, dejamos de lado la pretensión de agotar todas estas posibilidades y decidimos concentrarnos en algunas que consideramos más importantes para el momento actual vivido por la Institución, el cual se presenta repleto de desafíos:

- Completar las modificaciones organizacionales necesarias para la adaptación plena de las acciones institucionales al ideario de la reforma psiquiátrica incluido en su misión y directrices básicas.

- Modernizar gerencialmente la Institución para que pueda no solo responder a las nuevas exigencias de funcionamiento en red y de adaptación a nuevos modelos de gestión sino, sobre todo, para que pueda mejorar la eficacia y la eficiencia de sus acciones actuales.

- Consolidar el rol de liderazgo importante de la Institución, en el proceso de reforma psiquiátrica producido actualmente en el país (una de las reformas más avanzadas del mundo). 
Intentamos responder sintéticamente a estos desafíos con nuestra macroestrategia de creación de un Centro de Atención Diaria en el Instituto (Caps-IPP), pero somos conscientes de que aún queda mucho por hacer en términos de acciones concretas - políticas, gerenciales y técnicas - para llegar a la implementación exitosa de esta propuesta. Sabemos que la propuesta es buena, pero también entendemos que su implementación requerirá de un trabajo gerencial importante en la Institución, para lograr obtener la adhesión del cuerpo institucional a esta estrategia.

Este trabajo deja a la vista varias puntas de bilos de las que aún se puede tirar para sacarlas del enredo de informaciones producidas. Esperamos que la Institución pueda utilizarlas y desarrollarlas en el proceso continuo de perfeccionamiento de sus acciones.

Por otro lado, reconocemos que hay aspectos del trabajo, principalmente los que se refieren al desarrollo del método de la démarche, relacionados con el meta-análisis, con los ejercicios proyectivos y con las innovaciones gráficas, que no fueron presentados aquí, pero que merecen un tratamiento especial y detallado que debe, necesariamente, ser realizado en un trabajo específico.

\section{Referencia Bibliográfica}

CRÉMADEZ, M. \& GRATEAU, F. Le Management Stratégique Hospitalier. 2. ed. Paris: InterÉditions, 1997. 



\section{Análisis estratégico y prospectiva EN SALUD: el enfoque de Godet y simulaciones de escenarios para el Programa de Salud Familiar (PSF)}

Francisco Javier Uribe Rivera

Desde el siglo XVI, el término Prospectiva (retomado por Gaston Berger en 1957) corresponde al acto de mirar desde lejos, de distinguir alguna cosa que está frente a nosotros (Godet, 1993). Se entiende aquí la construcción de escenarios como la rama más formalizada de la Prospectiva, por basarse en métodos y técnicas de análisis del futuro.

El concepto de escenario fue introducido en la década del 60 por la Rand Corporation y popularizado por Herman Khan (1969) en sus trabajos pioneros en el campo militar y de seguridad nacional, extendiéndose más tarde a la política.

La palabra escenario proviene del teatro. Representa la creación de un entorno adecuado y pertinente para representar o situar una obra. Indica el lugar y las circunstancias en que se desarrolla el tema. El tema es el texto y el escenario es el contexto que lo determina. Algo semejante ocurre con el plan. El contenido propositivo del plan es el texto, pero ese texto es ambiguo sin las condiciones explícitas de su contexto o escenario. De este modo, el escenario es el conjunto de condiciones y presuposiciones en que se sitúa el plan (Matus, 1994).

El enfoque de escenarios se desarrolla simultáneamente en EE.UU. y en Francia, avanzando hacia un cierto consenso metodológico. Los investigadores americanos Gordon, Elmer, Dalkey, etc., desarrollan diferentes métodos relativamente formalizados de construcción de escenarios, basados, en su mayoría, en reuniones de expertos: Delphi, matrices de impactos cruzados, etc. (Godet, 1993). El método de los impactos cruzados fue idealizado originalmente por Gordon en el Instituto para el Futuro (Roubelat, 1993) y posteriormente utilizado por los franceses. En Francia, los trabajos pertinentes reciben la influencia del gran pensador estratégico Michel Godet, y se materializan inicialmente en estudios de prospectiva geográfica implementados por la Delegación para el Ordenamiento del Territorio y la Acción Regional (Datar). 
El objetivo general de la técnica de escenarios es, según Schwartz (2000), permitir la formulación de planes para todas las alternativas de futuro posibles o imaginadas, o sea, ampliar las posibilidades de intervención, teniendo como referentes, diferentes escenarios alternativos.

El objetivo de este trabajo es presentar la metodología de Godet (1998), con las adaptaciones propuestas por nosotros, introduciendo también la lógica del software de probabilidades de escenarios que compone el método original: el SMIC Prob-Expert, en su versión revisada de 1998. Como ejemplos de aplicación de la metodología, presentamos algunas simulaciones del escenario del Programa de Salud Familiar (PSF), desarrolladas por diferentes grupos de alumnos del curso de Planificación de Salud de la Maestría de Salud Pública de la Ensp. Reflexionamos, además, sobre la utilidad de la técnica de escenarios según otros enfoques, especialmente el de aprendizaje organizacional.

\section{Algunas Definiciones Teóricas Previas a la Presentación del Enfoque}

\section{Diferentes definiciones de escenario}

- Una mirada hacia el futuro orientada a esclarecer, iluminar la acción presente (Godet, 1985).

- La descripción de las características esenciales (en relación a las alternativas estratégicas adoptadas) del contexto futuro dentro del cual estas alternativas deberán ser implementadas (Quade, 1993).

- La prospectiva es un panorama de los futuros posibles de un sistema destinado a iluminar las consecuencias de las estrategias de acción proyectadas.

- Conjunto coherente formado por la descripción de una situación futura y del camino que permite pasar de la situación original a la situación futura.

- Configuración de imágenes de futuro basada en juegos coherentes de hipótesis relacionadas a las variables centrales del objeto de análisis y de su ambiente y de las estrategias y alianzas de los actores (Buarque, 1993) 


\section{Objetivos de la construcción de escenarios}

- Seleccionar, entre la infinidad de combinaciones de hipótesis proyectadas, un pequeño número que presente el mayor grado de coherencia, de verosimilitud, y sobre todo, de interés por esclarecer las decisiones a tomar (Araújo, 1984; École Nationale de Santé Publique, 1997)

- Ayudar a situar, a elegir el tipo de plan o de acción estratégica más adecuado.

\section{Tipos de escenarios (Hatem et al., 1993)}

- Normativos (backcasting): se parte del punto de llegada para reconstruir el camino o la trayectoria que es necesario seguir desde la situación presente (de un futuro normativo hacia el presente).

- Exploraciones (forecasting): exploración de las trayectorias posibles a partir del presente (del presente hacia el futuro).

- Literarios: sin formalismo lógico, cualitativos.

- Formalizados: aplicación de métodos matemáticos (cálculo de probabilidades).

- Sin sorpresa: no plantea rupturas significativas en ningún dominio y tiene una probabilidad subjetiva bastante elevada.

- Contrastados: exploran las consecuencias de una ruptura importante, de probabilidad eventualmente baja, pero cuyo impacto es potencialmente importante.

El enfoque que presentamos aquí es un enfoque combinado, que conjuga un tipo de análisis estratégico cualitativo, basado en el juego de los actores, y un análisis formalizado, que plantea el cálculo de las probabilidades de los escenarios, a partir de la definición de las probabilidades aisladas y condicionales (cruzadas) de las hipótesis de comportamiento de las variables clave del sistema en análisis. Este enfoque permite, por otro lado, la construcción de escenarios exploratorios asociada a un esfuerzo de backcasting posterior.

El núcleo básico del enfoque está definido por el análisis estratégico de actores cara a cara con las variables del sistema y con el método de los impactos cruzados, consustanciado en el software pertinente, que permite cruzar las hipótesis de comportamiento de un sistema en proceso de prospección, probabilizando sus relaciones recíprocas o combinaciones. 


\section{Síntesis del Enfoque Formalizado de Previsión de Escenarios de Godet (adaptado)}

El método comprende los siguientes procedimientos relacionados:

\section{Delimitación del sistema o del dominio problemático}

Definición del tema, del área, de la organización o del problema que se pretende investigar.

Identificación de las variables externas e internas del sistema (hasta 15) y reducción de variedad

La primera cuestión que se plantea cuando se desea explorar el listado de los futuros posibles, es identificar los elementos que serán fundamentales para el futuro de la organización/situación estudiada, los cuales tendrán que ser jerarquizados por motivos operacionales.

El principal método de reducción recomendado, corresponde al análisis estructural (Roubelat, 1993; Bourse, 1992; Jouvenel, 1993) que consiste en analizar, a través de un cuadro de doble entrada, la influencia que cada variable ejerce sobre las otras ${ }^{1}$, ponderada en términos de ninguna (0), baja (1), media (2) y alta (3) intensidad. El cuadro del análisis estructural (Figura 1) permite establecer la distinción entre variables internas y externas. Este tipo de análisis posibilita detectar el grado de determinación y de dependencia de las variables entre sí. Las variables de mayor poder de determinación (en términos del número de variables que influyen y de la intensidad del impacto) son las variables motrices, cuya evolución futura marcará de manera decisiva el sistema global. Además de las variables predominantemente motrices, adquieren una gran importancia para la construcción de escenarios, las variables de vinculación, que son aquellas que presentan simultáneamente una alta motricidad y un alto nivel de dependencia, $\mathrm{o}$ sea, contribuyen a determinar un buen número de otras variables y son, simultáneamente determinadas por un buen número de otras. Estas últimas son consideradas dimensiones de incertidumbre particularmente significativas.

1 Como la matriz de análisis estructural de base permite detectar tan solo las relaciones directas entre variables, pero no las indirectas, el método sugiere la utilización de un procedimiento matemático que consiste en multiplicar la matriz de base por si misma, tantas veces como sea necesario, hasta que la jerarquía de las variables alcance una estabilidad (en general a partir de M7 o M8). De este modo, una relación de orden 2 entre A e B significa que A ejerce una influencia sobre un tercer componente $\mathrm{C}$, que a su vez actua sobre B. 
Las variables de vinculación corresponderían a las "incertidumbres críticas", en oposición a los "elementos predeterminados", que serían variables de alta predicción o de progresión lenta o conocida. La elección de las variables clave del escenario implica jerarquizar las propias variables sistémicas motrices, privilegiando algunas incertidumbres críticas, que establecerán la diferencia entre los escenarios, dado que los elementos predeterminados tienden a comportarse de forma homogénea en los diferentes escenarios, debiendo por lo tanto, ser ubicados en un segundo plano (Schwartz, 2000).

Esto equivale a privilegiar como variables clave, a aquellas que tienen un alto impacto sobre el sistema prospectado y un alto nivel de incertidumbre (Grupo Artur D. Little, 2002)

Figura 1 - Matriz de análisis estructural.

\begin{tabular}{|c|c|c|c|c|c|}
\hline \multirow{2}{*}{ Acción de/sobre } & \multicolumn{2}{|c|}{ Variables internas } & \multicolumn{2}{|c|}{ Variables externas } & \multirow{2}{*}{ Total Filas } \\
\cline { 2 - 5 } & $\mathrm{A}$ & $\mathrm{B}$ & $\mathrm{C}$ & $\mathrm{D}$ & \\
\hline $\mathrm{A}$ & 0 & 3 & 2 & 3 & 8 \\
\hline B & 1 & 0 & 1 & 1 & 3 \\
\hline C & 0 & 2 & 0 & 1 & 3 \\
\hline D & 0 & 1 & 0 & 0 & 1 \\
\hline Total Columnas & 1 & 6 & 3 & 5 & \\
\hline
\end{tabular}

Fuente: Rivera, 2003.

En esta matriz de análisis estructural, el resultado observado en el total de las filas, muestra la influencia de una variable sobre las otras (grado de determinación o motricidad). En el resultado total de las columnas, se puede evaluar en qué medida una variable está siendo influenciada por otras (grado de dependencia). Se observa que la variable A presenta una mayor motricidad y la variable B una mayor dependencia. La variable D presenta una bajísima motricidad y una alta dependencia. Estas últimas variables prácticamente podrían ser descartadas del análisis del escenario respectivo dado que son más resultados que causas o fuerzas motrices.

Los valores del análisis estructural pueden ser expresados en un gráfico de influencia/dependencia como el siguiente (Gráfico 1): 
Gráfico 1 - Grado de motricidad y dependencia de las variables del sistema.

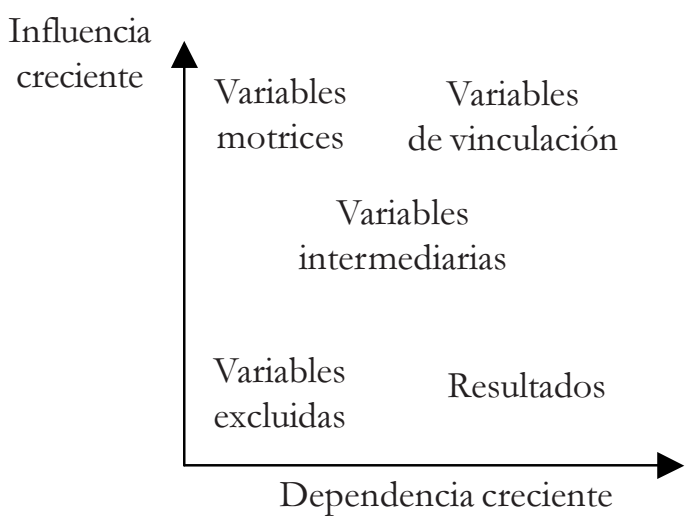

Fuente: Godet, 1993.

En función de la distribución de las variables, el sistema puede ser clasificado como estable o inestable (Gráfico 2).

Gráfico 2 - Dos tipos de distribución de las variables.

entradas

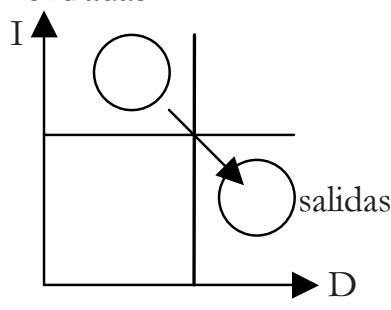

Sistema estable

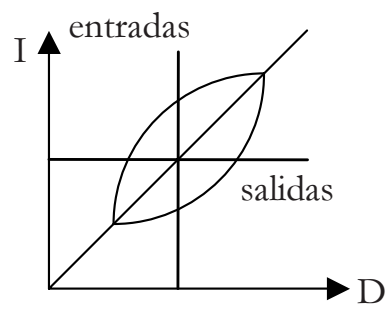

Sistema inestable

Fuente: Godet, 1993.

En el caso de un sistema estable, existe un predominio de las variables motrices. Si predominan las internas o dominadas por la organización, se podría pensar en una forma de actuación bastante similar a la planificación tradicional en un universo de riesgo, con posterioridad a la construcción de algunos escenarios sobre el ambiente.

En el caso de un sistema inestable, predominan las variables de vinculación. Este caso estaría en general asociado a una reflexión en términos del juego de 
los actores, dado que la dialéctica de los actores involucrados sería determinante en la construcción de los escenarios.

Por ende, si los desafíos son en su mayoría externos, el análisis prospectivo en términos del juego de los actores, es delicado y debe dar lugar al establecimiento de un sistema de vigilancia prospectiva compartido. A veces, la posición extremadamente dependiente de los factores típicos de la organización lleva a la necesidad de ampliar la reflexión hacia otras organizaciones.

Dicho de un modo más general, las características del sistema y la posición en el gráfico de influencia/dependencia de los factores internos y externos, permitirían orientar la elección de los instrumentos de análisis y de construcción de los escenarios.

El resultado del análisis estructural es reducir notoriamente la variedad de la información inicial, excluyendo del análisis posterior una serie de variables. Se considera que las variables seleccionadas en esta etapa representaría el listado casi definitivo de las variables clave o de las fuerzas motrices del escenario.

Pero el análisis estructural aislado, es un análisis desabrido, sin vida. Es necesario, por lo tanto, ingresar a una etapa más explicativa de las variables, que tenga en cuenta su evolución en el tiempo y a los actores involucrados. Esta etapa consiste en un análisis retrospectivo y presente de las variables seleccionadas, procurando identificar las tendencias pesadas (variables que tienen un comportamiento bastante previsible, de cambios lentos), las tendencias insinuantes o hechos generadores de futuro (variables que, no siendo tan decisivas en la actualidad, insinúan una importancia creciente a futuro) y el juego de los actores (Hatem et al., 1993; Bourse, 1992; Jouvenel, 1993).

\section{El análisis de los actores, de sus estrategias frente a las variables clave y la formulación de los eventos posibles}

El análisis del juego de los actores es extremadamente importante para la simulación del comportamiento futuro de las variables clave. En esta etapa, se procede a la exploración de las estrategias de los actores cara a cara con las variables del sistema, para a partir de allí definir sus principales posibles tendencias. A continuación será necesario elegir entre las diferentes tendencias posibles de cada variable clave, las tendencias centrales, o sea, las hipótesis de comportamiento futuro con mayor probabilidad de que ocurran o simplemente los eventos centrales.

Godet (1993), recomienda identificar hasta cinco actores capaces de influir sobre las variables preseleccionadas, explorando sus proyectos o sus estrategias 
de influencia sobre el sistema objeto y sus relaciones de influencia recíproca, en términos de poder. En relación a esta sugerencia de la elección de los actores realmente más relevantes, pensamos que el número cinco debe ser tomado con flexibilidad, aunque es válido en el sentido de reducir la variedad al máximo posible, para que el proceso sea más operativo.

El modelo de análisis de los actores de Godet, intitulado modelo MACTOR, está basado en el tratamiento informatizado de la información considerada como necesaria. En este modelo, el autor procura sistematizar los enfoques de teoría del juego o del Conflict Analysis desarrollado por Frazer y Hippel (1986 apud Godet, 1993).

Preferimos realizar una adaptación cualitativa de ese modelo, incorporando el raciocinio y algunas herramientas del modelo de análisis estratégico de la Planificación Estratégica Situacional de Matus (1994).

Existen dos matrices de cálculo que nos parecen extremadamente útiles: a) una matriz que revelaría el poder de influencia, el grado de control o la gobernabilidad de los actores sobre las variables más determinantes, ponderando ese control en términos de alto $(\mathrm{A})$, medio(M), bajo(B) y ningún control(0) (Figura 2); b) una matriz que contemplaría las estrategias de actuación potenciales (posición) de los actores con mayor gobernabilidad sobre las variables clave seleccionadas, considerando la información del análisis estructural (las otras variables que actúan sobre cada variable), y las principales posibilidades de comportamiento de las mismas en función de la posición de los actores (objetivos posiblemente asociados al cuadro de las estrategias) (Figura 3).

Figura 2 - Matriz de influencia de los actores/variables determinantes.

\begin{tabular}{|c|c|c|c|c|}
\hline & V 1 & V2 & V3 & V4 \\
\hline Actor 1 & 0 & B & A & M \\
\hline Actor 2 & B & A & M & 0 \\
\hline Actor 3 & A & 0 & M & A \\
\hline
\end{tabular}

La matriz del control de las variables por los actores (a) nos da una idea de la gobernabilidad que los actores tendrían sobre las variables, de modo de poder circunscribir a los actores de mayor poder de influencia sobre el comportamiento futuro de cada variable. Este comportamiento dependería del juego interactivo de los proyectos o de las estrategias de los actores respectivos. 
Figura 3 - Matriz de las estrategias de los actores y de los objetivos posibles pertinentes a la variable $\mathrm{x}$.

\begin{tabular}{|c|c|c|c|}
\hline Actores & Variables influyentes & $\begin{array}{c}\text { Estrategias de } \\
\text { actuación }\end{array}$ & $\begin{array}{c}\text { Tendencias o } \\
\text { objetivos posibles }\end{array}$ \\
\cline { 1 - 2 } A1 & V1 & & a) \\
& V2 & & b) \\
c)
\end{tabular}

La matriz de las estrategias posibles y de los objetivos para cada variableclave (b) permitiría relacionar o narrar las estrategias de actuación potencial de los actores de mayor gobernabilidad y deducir de las mismas las posibilidades de comportamiento posible de cada variable. Distinguir los comportamientos futuros de cada variable, supondría un cálculo estratégico más riguroso en los casos de las variables controladas por actores divergentes. Para la definición de esas tendencias, puede ser de utilidad, explorar alguna variante del análisis de las relaciones de influencia entre los actores (2 a 2), recomendada por Godet, o realizar un balance de las relaciones de poder o de fuerza inherentes a esos actores, en la línea del PES. Puede ser útil también para distinguir las tendencias más probables, el uso de la lógica de la matriz de motivación del momento estratégico del PES. En este caso, la motivación de los diferentes actores sería registrada (independientemente de la gobernabilidad) frente a los objetivos asociados a cada variable, objetivos asociados que corresponden a las tendencias o a los eventos más probables en función de las estrategias identificadas para los actores de mayor gobernabilidad.

En la simulación de las estrategias, la consulta a los actores o a sus conocidos es fuertemente recomendada. A veces, los actores no hablan de sus estrategias, sino que hablan de las estrategias de los otros. A través de la superposición de las informaciones, se puede montar un cuadro bastante aproximado de las estrategias.

Una variación interesante de la matriz de las estrategias de los actores frente a las variables del sistema, fue confeccionada en una clase de la maestría de Salud Pública de la Escuela Nacional de Salud Pública de la Fiocruz (Ensp/ Fiocruz, cohorte 2001); referida al análisis de las estrategias de los actores frente a las variables clave del Programa de Salud Familiar (PSF) e incluye algunas tendencias (Figura 4). 
Figura 4 - Estrategias de los actores cara a cara con las variables clave del PSF y los principales eventos simulados.

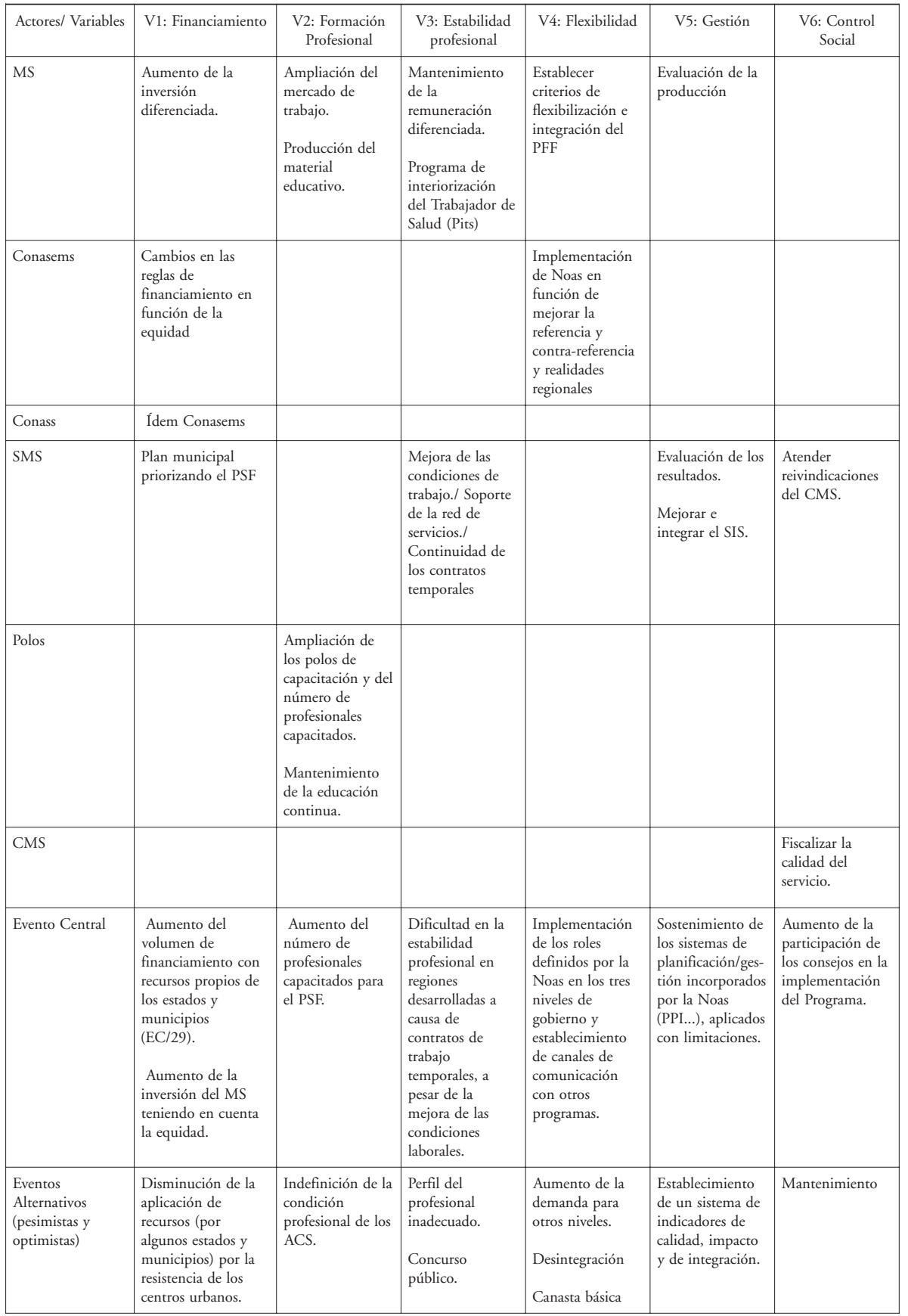


Es importante señalar, que algunos de los actores estudiados pueden ser considerados directamente como variables o dimensiones de incertidumbre, por ejemplo: un determinado actor cuyo comportamiento de futuro es considerado altamente incierto, un actor altamente influyente o el desenlace del conflicto entre 2 actores estratégicos. De esta manera, se estaría completando el cuadro de las variables clave.

El establecimiento definitivo de las variables clave y de las hipótesis fundamentales sobre la evolución de las variables (a partir de las estrategias de los actores) no es tarea fácil. Como el método de probabilidades de Godet supone el uso de no más de 6 hipótesis de comportamiento, se impone aquí un formidable esfuerzo de reducción en la variedad, tanto con relación a las variables clave como a sus hipótesis de comportamiento. Restricciones de exclusión y de preferencia deberán ser aplicadas a las configuraciones posibles de las variables; los comportamientos con posibilidad nula o baja deberán ser excluidos; el criterio representatividad de la variable (de un número mayor de otras) deberá ser considerado en la elección de las definitivas; se deberán realizar combinaciones de comportamientos (subescenarios) con el objetivo de reunir un número menor de hipótesis; se deberán adoptar las hipótesis con mayor probabilidad media como hipótesis centrales (Benassouli \& Monti, 1995).

Cuando el listado de eventos supera una cantidad, considerada como más operativa, se puede realizar una consulta a especialistas, los cuales serían convocados para opinar sobre la probabilidad estimada para cada evento enumerado, en términos de ninguna (0), baja (B), media (M) y alta probabilidad (A), y además sobre la pertinencia o grado de importancia de cada evento para el sistema o problema en análisis ( $0, \mathrm{~A}, \mathrm{M}, \mathrm{B})$. De este modo, serían elegidos los eventos de mayor probabilidad relativa y de mayor pertinencia.

\section{Definición de las probabilidades de comportamiento individual de las hipótesis de comportamiento y de las probabilidades condicionadas 2 a 2}

Esta etapa se caracteriza por la aplicación del método de los impactos cruzados, a la probabilidad de las tendencias. Aquí, se puede actuar de dos formas: a través de la consulta a especialistas y del posterior uso del software (para procesamiento de la información) o de la obtención de un consenso argumentativo dentro de un grupo operativo.

La consulta a especialistas: un cuestionario es confeccionado para que los especialistas opinen sobre dos items: la probabilidad de acontecimiento aislado de las hipótesis de comportamiento o eventos centrales y las probabilidades condi- 
cionadas 2 a 2. En este último caso, se pregunta cuál es la probabilidad de que ocurra $\mathrm{H} 1$ en el caso que se realice $\mathrm{H} 2$ y cuál es la probabilidad de $\mathrm{H} 1$ en el caso que no se realice $\mathrm{H} 2$ y así sucesivamente ( $\mathrm{H} 1$ con relación a H3, H4, H5 y H6, cuando los eventos son seis). Las preguntas específicas son respondidas de manera cualitativa según una escala de grados de realización de las hipótesis, con los valores siguientes: 1 (probabilidad casi nula, muy pequeña); 2 (improbable); 3 (probabilidad media); 4 (probable); 5 (alta probabilidad); y 6 (eventos independientes). Se podrá realizar un histograma con la distribución de las respuestas a cada pregunta formulada. Los grados de realización de las hipótesis, son transformados en probabilidades cuantitativas (de 0 a 1), en función de una escala convencional. Las probabilidades cuantitativas globales por evento corresponderán a las respuestas medias de los especialistas.

Por Consenso Argumentativo: es necesario señalar que la lógica del método de los impactos cruzados puede ser aplicada sin la necesidad de una probabilidad formalizada o informatizada de los escenarios, apoyada en una amplia consulta a especialistas. En este caso, una matriz de interdependencias (Figura 5) podrá ser útil. Se trata de una adaptación de la matriz presentada por Ortigueira (1978). Esta matriz podrá ser construida al interior del taller de prospectiva, basada en el consenso argumentativo alcanzado por los participantes.

Figura 5 - Matriz de impactos cruzados.

\begin{tabular}{|c|c|c|c|}
\hline Eventos & E1 & E2 & E3 \\
\hline E1 & No & $2+$ & $5-$ \\
\hline E2 & $1+$ & No & $=$ \\
\hline E3 & $2-$ & $=$ & No \\
\hline
\end{tabular}

Fuente: Adaptado de Ortigueira, 1978.

En el caso de la utilización de esta matriz, sugerimos simular los grados de correlación positiva o negativa eventualmente existentes, pudiéndose trabajar con valores de 0 (igual a la independencia o al signo $=$ ) hasta más o menos 5 , según la escala anterior de grados de realización de los eventos (usada en el cuestionario del método SMIC Prob Expert). A título ilustrativo, podríamos decir que en una correlación E31 siendo igual a 5- significaría que, si E1 ocurre, la probabilidad de que E3 no ocurra es muy alta. En el ejemplo anterior, dado el efecto de exclusión de E1 y E3, el escenario relativamente más probable seria 110. Esto va a depender definitivamente, de la probabilidad aislada de los eventos. De ser así, se sugiere que en el taller los participantes también establezcan por consenso las probabilidades aisladas de acontecimiento de los eventos, considerando los parámetros anteriores. 


\section{Identificación de las combinaciones de hipótesis de mayor probabilidad de acontecimiento y elección de los escenarios definitivamente obtenidos (Godet, 1998)}

Los resultados de los cuestionarios, traducidos en probabilidades cuantitativas, son transferidos a las matrices ad-hoc del software. A partir de las matrices cuantitativas y contemplando una serie de correcciones estadísticas, el Smic ProbExpert permite estimar las probabilidades de los escenarios o combinaciones de hipótesis posibles. El método permite una estimación de probabilidad de todas las combinaciones posibles (en el caso de 6 hipótesis, las combinaciones posibles serían 64; en el caso de 3, serían 8). Cada escenario posible admite la posibilidad de realización de cada hipótesis (1) o la posibilidad de no realización (0). En el caso de 3 eventos, la combinación de posibilidades sería:

111100110000001011010101 (cada escenario tendrá una probabilidad).

Cuando el listado de combinaciones es grande (64 a partir de 6 hipótesis por ejemplo), serán rescatadas las combinaciones de mayor probabilidad (que cubran un campo mayor de posibilidades), pudiendo ser reagrupadas en tipos de escenarios coherentes o conexos, considerando las combinaciones de dos, luego de tres hipótesis, que permitan tal reagrupamiento.

Además de la estimación de probabilidad de los escenarios, el SMIC ProbExpert permite en esta etapa analizar la sensibilidad de una variable (hipótesis de comportamiento) en relación a otra, a través del cálculo de los coeficientes de elasticidad relativos. Este análisis permite saber en qué medida varía una hipótesis cuando ocurre un delta $\times(10 \%)$ de variación de otra (y saber si esa influencia es positiva o negativa). Esto posibilita el conocimiento de las hipótesis más determinantes y las más dependientes, lo cual ayudaría a tener una idea de qué hipótesis sería necesario estimular y qué hipótesis sería necesario frenar a fin de alcanzar una determinada situación deseada.

Es importante señalar, que en el manejo del SMIC Prob-Expert, el autor utiliza más de un artificio, que consiste en analizar las respuestas de los diferentes especialistas y los agrupa según la homogeneidad de las respuestas. De esta forma, se busca compensar la dispersión o la variedad de respuestas recibidas (Ortigueira, 1978). De este modo, el software permite la estimación de probabilidades de escenarios para cada grupo de especialistas y para el conjunto de los grupos. 


\section{Definición del plan de acción en relación a los escenarios centrales}

El sistema que recomendamos aquí, junto con Matus, que concuerda en general con la perspectiva francesa, es profundizar el diseño del Plan, en relación al escenario central definido por la mayor probabilidad de realización, formulando simultáneamente dos alternativas de opciones menos detalladas: una para la hipótesis de un escenario más optimista; otra para la alternativa de un escenario más pesimista. El monitoreo del escenario indicará en el futuro, la necesidad virtual de una reconstrucción del escenario y de las opciones, de la posibilidad de detallar más las opciones marginales relacionadas al escenario central, o la reafirmación de la construcción originaria.

Godet (1993) considera que el plan de acción debería considerar los requisitos básicos siguientes:

- Trabajar, de ser posible, para estimular la realización de los escenarios más favorables a los objetivos de una organización.

- Limitar las consecuencias nefastas de la evolución de un escenario pesimista.

- Facilitar la inserción de la actividad futura de una organización, en una envolvente en constante evolución.

\section{Caso: el Programa de Salud Familiar (PSF)}

\section{Simulación I}

Dentro de la disciplina de Planificación de Salud de la Ensp (año 1999), un grupo de alumnos de la Posgraduación, realizó una simulación de los escenarios más probables del Programa. Doce alumnos, divididos en cuatro grupos, aplicaron las etapas del método de Godet y actuaron como especialistas, opinando sobre la probabilidad de las tendencias enumeradas.

En un primer momento, el grupo relacionó las siguientes variables de más alto impacto sobre la evolución del PSF:

- Remuneración médica.

- Reglas de financiamiento a nivel federal.

- Continuidad administrativa del Ministerio de Salud.

- Existencia de una red de referencia y contra-referencia eficaz.

- Integración del Programa con la red básica tradicional. 
- Control social.

- Formación profesional/enseñanza universitaria.

- Factores de estabilidad profesional.

- Impacto sobre la salud de la población.

- Comprometimiento de la política municipal de Salud/nivel de adhesión de los secretarios.

- Disponibilidad de instancias técnicas de control de calidad.

- Deología profesional.

Luego de analizar las relaciones de causa-efecto que se establecerían entre las variables (análisis estructural implícito, no completamente formalizado), y un intento de agrupamiento de las mismas y de la búsqueda de las más representativas, se optó por seleccionar las siguientes variables de mayor motricidad:

- V1: continuidad administrativa de la política actual del Ministerio de Salud y de las reglas Subsecuentes de financiamiento valorizando el PSF.

- V2: formación universitaria y profesional que actualmente estimula la especialización.

- V3: capacidad de integración del PSF con el resto del sistema, con los niveles secundario y terciario.

- V4: capacidad de estabilidad del profesional, incluyendo estímulos materiales e ideológicos.

- V5: control social y técnico de calidad.

- V6: nivel de compromiso de las secretarías municipales de salud, evidenciado por la política municipal de salud.

A continuación, el grupo realizó un análisis estratégico del juego de los actores, en relación a su interacción con las variables anteriores. Fueron definidos los actores, la gobernabilidad de los actores sobre las variables clave y la influencia de los actores entre sí.

\section{Actores sociales y políticos}

- A1: Ministerio de Salud

- A2: Consejo Nacional de Secretarios Municipales de Salud (Conasems)

- A3: MEC

- A4: Consejos profesionales 
- A5: Consejos Municipales de Salud

- A6: Consejo Nacional de los Secretarios de Salud (Conass) (Ver Figuras 6 y 7 )

Figura 6 - Gobernabilidad de los actores sobre las variables clave.

\begin{tabular}{|c|c|c|c|c|c|c|}
\hline & Financiam. & Form. Univ. & Integración & Estabilidad & Control & PMS \\
\hline MS & $\mathrm{A}$ & $\mathrm{B} / \mathrm{M}$ & $\mathrm{B} / \mathrm{M}$ & $\mathrm{B}$ & $\mathrm{B} / \mathrm{M}$ & $\mathrm{M}$ \\
\hline Conasems & $\mathrm{M}$ & $\mathrm{B}$ & $\mathrm{M} / \mathrm{A}$ & $\mathrm{A}$ & $\mathrm{A}$ & $\mathrm{A}$ \\
\hline MEC & 0/B & $\mathrm{A}$ & $0 / \mathrm{B}$ & $\mathrm{B} / \mathrm{M}$ & $0 / \mathrm{B}$ & $0 / \mathrm{B}$ \\
\hline Cons. Prof. & $\mathrm{B} / \mathrm{M}$ & $\mathrm{M}$ & $0 / \mathrm{B}$ & $\mathrm{B} / \mathrm{M}$ & $\mathrm{M}$ & $\mathrm{B}$ \\
\hline C.M.S. & $\mathrm{B} / \mathrm{M}$ & $0 / \mathrm{B}$ & $\mathrm{M}$ & $\mathrm{M}$ & $\mathrm{M} / \mathrm{A}$ & $\mathrm{A}$ \\
\hline Conass & $\mathrm{M} / \mathrm{B}$ & 0/B & $\mathrm{M} / \mathrm{A}$ & $\mathrm{M}$ & $\mathrm{B} / \mathrm{M}$ & $\mathrm{M}$ \\
\hline
\end{tabular}

Quién controla qué, grado de control en términos bajo (B), medio (M) y alto $(\mathrm{A})$

Por argumentar que los Consejos Municipales de Salud podrían estar bien representados por el Conasems, el grupo pasó a considerar a partir de este momento solo a este último.

Figura 7 - Influencia de un actor sobre otro (2 a 2)

\begin{tabular}{|c|c|c|c|c|c|c|}
\hline & MS & Conasems & MEC & Cons. prof. & Conass & Motricidad \\
\hline MS & & 2 & 1 & 1 & 2 & 6 \\
\hline Conasems & 2 & & 0 & 0 & 2 & 4 \\
\hline MEC & 0 & 0 & & 1 & 0 & 1 \\
\hline Cons. prof. & 1 & 0 & 1 & & 0 & 2 \\
\hline Conass & 1 & 1 & 0 & 0 & & 2 \\
\hline Dependencia & 4 & 4 & 2 & 2 & 5 & \\
\hline
\end{tabular}

A partir de este análisis, se llegó a algunas conclusiones en relación a los actores que controlan prioritariamente las variables enumeradas (relacionados por orden de importancia) y a la influencia recíproca de los actores:

- La variable 1 (reglas de financiamiento) dependería fundamentalmente del Ministerio de Salud (en primer lugar) y del Conasems (en segundo lugar). Estos actores tienen una influencia recíproca e intensa, y representarían en general a las fuerzas de mayor motricidad. 
- La variable 2 (formación profesional) dependería principalmente del MEC y de los Consejos Profesionales, aunque se registre particularmente una pequeña influencia del MS sobre el MEC, que contribuye a la conformación del mercado de trabajo profesional.

- Las variables 3 (integración), 4 (estabilidad profesional) y 5 (control social) dependerían fundamentalmente de los Secretarios Municipales y Estatales de Salud.

- La variable 6 (política municipal de salud y compromiso de la gestión) dependería, por orden de importancia de: Conasems; Consejos de Salud (con una alta influencia sobre el Conasems y sobre la PMS); MS; Conass.

El grupo simuló, de manera informal (sin usar la matriz ad-hoc), los principales objetivos asociados a las estrategias de los actores de mayor gobernabilidad sobre las variables clave y reflexionó sobre la viabilidad de los mismos.

Considerando toda la información producida, el grupo estableció las siguientes hipótesis de comportamiento, eventos o tendencias centrales:

- E1: continuidad del privilegio financiero al PSF, previendo la continuidad del equipo o de la política actual del MS (y por el apoyo del Conasems) y por ser la propuesta defendida programáticamente también por la oposición. La cobertura podrá eventualmente ser expandida de forma más significativa.

- E2: pocos cambios y muy lentos en la graduación y aumento más significativo del espacio del Programa en la Posgraduación a título de especialidad (véase polos de formación regional de las equipos involucrando Universidades y Municipios).

- E3: previsión de importantes problemas de integración por presiones financieras relativos a los niveles más complejos, los cuales no acompañarían las crecientes demandas planteadas por el Programa en expansión.

- E4: previsión de mantener los estímulos materiales a la estabilidad profesional a través de una remuneración diferenciada.

- E5: expansión discreta de la importancia de los Consejos de Salud en el control de calidad del sistema y de las instancias técnico-profesionales creadas a nivel local, para tal fin.

- E6: expansión importante del compromiso de los gestores de salud debido a la creciente importancia del nivel municipal, al bajo costo y a la resolutividad del programa.

A continuación el grupo, subdividido, procedió a estimar las probabilidades de realización de las variables (aisladas y cruzadas), completando cuestionarios ad-hoc, y utilizando el software, calculó las probabilidades de los escenarios y las tasas de sensibilidad. Algunos de los resultados obtenidos serán expuestos aquí. 
Sobre los eventos de mayor motricidad y dependencia (Figuras 8 y 9 , respectivamente).

Figura 8 - Coeficiente de motricidad de los eventos de mayor motricidad del sistema.

\begin{tabular}{|c|c|c|c|}
\hline Grupo & $\begin{array}{c}\text { Coeficiente } \\
\text { (valor global motricidad) }\end{array}$ & Evento & Descriptor evento \\
\hline 1 & 2.122 & 5 & Control social \\
\hline 2 & 1.595 & 1 & Financiamiento MS \\
\hline 3 & 1.179 & 6 & Compromiso del gestor \\
\hline 4 & 0.774 & 5 & Control social \\
\hline
\end{tabular}

Figura 9 - Coeficiente de dependencia de los eventos más dependientes del sistema.

\begin{tabular}{|c|c|c|c|}
\hline Grupo & Coeficiente & Evento & Descriptor Evento \\
\hline 1 & 1.248 & 2 & Formación Profesional \\
\hline 2 & 1.206 & 3 & Presión financiera niveles complejos \\
\hline 3 & 1.012 & 3 & Ídem \\
\hline 4 & 0.215 & 3 & Ídem \\
\hline
\end{tabular}

El Evento 5 tendería a ser más motriz y el E3 sería el más dependiente. Se destacan también por la motricidad, los eventos 1 y 6 .

Las mayores tasas de elasticidad específicas por grupo serían las siguientes (Figura 10):

Figura 10 - Mayores tasas de elasticidad observadas.

\begin{tabular}{|c|c|c|c|c|}
\hline Grupo & \multicolumn{1}{|c|}{1} & \multicolumn{1}{c|}{2} & \multicolumn{1}{c|}{3} & \multicolumn{1}{c|}{4} \\
\hline Mayor tasa & E 25 $=7,9$ & \multicolumn{1}{|c|}{ E41=6,2 } & E46=6,0 & E31=-2,2 \\
\hline Descripción & $\begin{array}{l}\text { Variación del 10\% } \\
\text { en el control social } \\
\text { altera positivamente } \\
\text { la formación } \\
\text { profesional en 7,9\% }\end{array}$ & $\begin{array}{l}\text { Variación del 10\% en } \\
\text { el financiamiento del } \\
\begin{array}{l}\text { MS altera en 6,2 la } \\
\text { estabilidad } \\
\text { profesional }\end{array}\end{array}$ & $\begin{array}{l}\text { El compromiso del } \\
\text { gestor variando } \\
10 \% \text { altera 6,0\% la } \\
\text { estabilidad } \\
\text { profesional }\end{array}$ & $\begin{array}{l}\text { El aumento en 10\% } \\
\text { de E1 inhibe en } \\
2,2 \% \text { el evento } \\
\text { problemas de } \\
\text { integración }\end{array}$ \\
\hline
\end{tabular}


Para presentar los resultados correspondientes al tema 2 en adelante, es necesario exponer aquí la probabilidad de los 5 escenarios más probables por grupo y para el conjunto (responsables por el 60,7\% de las probabilidades) (Figura 11).

Figura 11 - Escenarios de mayor probabilidad según los grupos de trabajo.

\begin{tabular}{|c|c|c|c|c|c|c|}
\hline No escenario & Índice & Grupo 1 & Grupo 2 & Grupo 3 & Grupo 4 & Media general \\
\hline 1 & 111111 & 0.367 & 0.417 & 0.000 & 0.336 & 0.280 \\
\hline 5 & 110111 & 0.000 & 0.181 & 0.221 & 0.168 & 0.143 \\
\hline 3 & 101111 & 0.189 & 0.032 & 0.000 & 0.037 & 0.064 \\
\hline 64 & 000000 & 0.071 & 0.151 & 0.021 & 0.000 & 0.061 \\
\hline 17 & 111101 & 0.000 & 0.000 & 0.089 & 0.146 & 0.059 \\
\hline
\end{tabular}

Analizando las diferencias observadas entre los grupos, podemos concluir que tres eventos materializas desacuerdos en relación a su realización o no. Estos eventos, según el orden de importancia, son: la capacidad de integración, comprometida por el déficit financiero de los niveles más complejos (el grupo 3 cuestiona ese evento); el grado de cambios en la formación profesional (el grupo 1 atribuye 10\% de probabilidad al escenario 3, que no prevé cambios formativos) y el propio control social (el grupo 4 atribuye $14 \%$ de probabilidad a un escenario (17) donde no figura el evento 5 de controle social.)

El escenario central o más probable es el 1: se mantienen los niveles actuales de financiamiento del PSF y hay una eventual expansión de la cobertura del programa; se prevé problemas de integración por un déficit financiero relativo a los niveles más complejos, el cual significaría una incapacidad de atender a toda la demanda adicional producto del aumento de los esfuerzos de captación del PSF, redundando en problemas de calidad de la atención; se esperan cambios muy pequeños en la graduación profesional, aunque se pueda prever un esfuerzo importante de preparación de cursos de especialización en PSF; se espera un compromiso cada vez mayor del municipio y una discreta expansión del control social y técnico de la calidad del programa.

El escenario ideal es el 5, donde no existirían problemas de integración del PSF con el resto del sistema. El grupo 3 que defiende este escenario, cree que es posible superar la tendencia negativa, a través de una buena administración de los recursos financieros, un control estricto de la demanda derivada a través del programa y una mejora de la resolutividad del mismo (todas estas medidas serían incluidas en plan de acción), variables que dependen en parte de un buen control técnico-social de la calidad. 
La posibilidad de los otros 4 escenarios más probables, de transitar hacia el ideal (el 110111), define parámetros para la formulación de una estrategia de actuación. Habría dos eventos de expansión discreta, por debajo de lo deseable, que expresarían fenómenos en torno de los cuales se verifican desacuerdos importantes en relación a su probabilidad de realización, que serían el E2 (pocos cambios en la formación) y el E5 (expansión discreta de la importancia de los Consejos). Es interesante reparar que el E5 es uno de los de mayor motricidad. Sobre esos dos eventos de característica entre negativa, neutra o discretamente positiva, sería imperativo actuar. El evento 3 (integración) configura un problema de alta probabilidad, aunque exista desacuerdo en relación al mismo. La superación de ese problema constituiría un objeto privilegiado de intervención, apuntando al escenario ideal. La intensificación de variables de mayor motricidad en relación a las tendencias críticas mencionadas y a la intervención junto a los actores que más controlan los eventos motrices pertinentes, configuran una parte importante del manejo estratégico exigido por la situación. El plan estratégico deberá consistir en la multiplicación de acciones procurando impactar principalmente E2, E3 y E5. Específicamente en relación a E2, se plantea la necesidad de intensificar la presión de los Consejos profesionales y de las Secretarías sobre el MEC, las instituciones responsables por la currícula médica y por la formación profesional, y sobre los profesionales, de modo de estimular cambios curriculares en la enseñanza médica, incentivar cursos de posgraduación en salud familiar y lograr que los profesionales entiendan que se está creando una nueva especialidad en salud con campo para todos los profesionales, lo cual ya estaría siendo confirmado a través de la evolución de un mercado de trabajo fuertemente inducido por el MS. Dada la motricidad referida por los grupos para el E5, el control técnico y social de la calidad del programa debería ser intensificado con acciones concretas, de modo de impactar sobre otros fenómenos dependientes.

En este ejercicio, solicitamos a los grupos que identifiquen los principales modelos mentales (creencias, preconceptos, presuposiciones arraigadas) que los otros grupos hayan utilizado en la construcción de sus "narrativas de futuro".

Los principales modelos mentales planteados en esta simulación fueron:

- Falta de resolutividad del PSF, expresada a través del aumento de la demanda para los niveles complejos (cuando debería ser lo contrario).

- Falta de disposición organizativa para el control de flujos de demanda y de cobertura.

- Valorización excesiva de la dependencia de recursos y no de la organización de fondos y gastos.

- Algunos grupos no creen en el MEC, por considerar que los profesionales ven en la especialización una fuente adicional de ingresos con piso salarial 
definido y que la formación profesional no es prioridad del Programa.

- El control social es aún un deseo o utopía, actualmente es muy débil y está menos direccionado por la evaluación y más por el interés político-corporativo de unos pocos.

En esta simulación surgió un dato nuevo: la posibilidad de explorar las diferencias de opinión en el proceso de discusión de diferentes formas de intervención. De un modo semejante, los modelos mentales implícitos en la apreciación de probabilidades de eventos, revelan una importancia singular en el momento de la formulación de estrategias. Tenemos la sensación de que ayudan a comprender acciones y a cuestionar la probabilidad de algunos eventos, ayudando a cristalizar un mayor consenso sobre el futuro y sobre el proyecto de acción.

Una indagación de los modelos mentales implícitos y su uso bajo la forma de un diálogo crítico puede considerar la técnica de escenarios como "recuerdo del futuro", lo cual corresponde en la visión de Senge (1995), dentro de la corriente del aprendizaje organizacional, al uso de la técnica como posibilidad de sacar a luz y cuestionar modelos mentales con la finalidad de tejer un acuerdo sobre proyectos futuros o de alinear la visión de los sujetos organizacionales.

\section{Simulación 2 - Revisión del PSF}

Estos resultados son el producto de la discusión y reflexión realizada por un grupo de la disciplina de Planificación de Salud de la Maestría de la Ensp de 2000 .

A continuación presentaremos paso a paso el análisis realizado, discutiendo la elección de las variables, el empleo de las herramientas y la selección de los escenarios probables.

\section{Paso I: selección de variables}

A partir de las características del PSF fueron definidas algunas variables que proporcionen los ejes básicos para el análisis del escenario. Cabe señalar que estas variables son profundamente interdependientes.

V1: capacidad de estabilidad profesional, destacando la remuneración diferenciada. Principal estrategia observada para asegurar el horario integral y la dedicación exclusiva del médico.

V2: reglas de financiamiento condicionando el compromiso del gestor: la diseminación de módulos de PSF por Brasil ha sido estimulada, en gran medida, por la política ministerial que proporciona el traspaso de fondos correspondiente 
a la cuota variable del Piso de la Atención Básica, instituida en la NOB-96 y alterada por la disposición 1882 de 18/12/97 (Brasil. Ministerio de Salud, 1998:53):

El incentivo al Programa de Agentes Comunitarios de Salud y Programa de Salud familiar consiste en el montante de recursos financieros destinado a incentivar la implantación de equipos de salud familiar y agentes comunitarios de salud, reorientando prácticas, con énfasis en las acciones de prevención de enfermedades y promoción de la salud (Art. $5 \int 1^{\circ}$ ).

V3: Articulación con los programas de salud viabilizando el sistema efectivo de referencia y contra-referencia: la resolutividad del Programa dependerá en gran medida del redimensionamiento de la red, y de su capacidad de integración.

V4: control social y evaluación permanente: el control social a través de los Consejos de Salud debería ser la clave de las actividades de evaluación, ajustando las políticas a las necesidades e intereses de las comunidades. Esta variable es, aún, importante, dado que está fuertemente asociada al desarrollo y conquista de los derechos y prerrogativas de ciudadanía, reflejando el desarrollo de otros sectores, como educación, empleo, desarrollo social en general.

V5: incentivo a la formación profesional adecuada al Programa: formación generalista en relación a la atención médica y basada en la salud colectiva, a través del componente de promoción de la salud que el profesional debería ejercer.V6: impacto sobre la salud de la población: este impacto deberá ser medido a través de los indicadores epidemiológicos comúnmente utilizados y otros indicadores capaces de evidenciar cambios en la calidad de vida.

V7: flexibilidad y adaptación a la realidad local: esta variable tiene un significado clave en el análisis. La experiencia revela que, en la práctica, toda estrategia bien urdida tiene un margen de autonomía e independencia en su forma de evolución. Esto se debe a la existencia de factores imprevisibles y/o imponderables en el cálculo estratégico. De esta forma, aunque la flexibilidad no esté planteada en el proyecto original (el programa es concebido como un paquete único para todo el país, sin considerar las diferencias regionales y locales), un cierto grado de flexibilización local es inevitable.

\section{Paso 2: análisis estructural}

Através del análisis estrutural es posible mendir el impacto de cada una de las variables sobre cada una de las restantes. De esta forma se establecen las que tienen características motrices y las que tienen características dependientes.

En la matriz de análisis estructural (Figura 12) se observa que las variables V4 (control social y evaluación permanente) y V7 (flexibilidad y adaptación a la 
realidad local) son las de mayor fuerza motriz, o sea, tienen capacidad de influir sobre los eventos relacionadas a las demás variables. Las de mayor dependencia son V6 (impacto sobre la salud de la población), V3 (articulación con los programas de salud viabilizando el sistema efectivo de referencia y contra-referencia) y V7 (flexibilidad y adaptación a la realidad local). La variable V7 funciona como variable de vinculación, dado que es al mismo tiempo motriz y dependiente.

Figura 12 - Matriz de análisis estructural.

\begin{tabular}{|c|c|c|c|c|c|c|c|c|}
\hline & V1 & V2 & V3 & V4 & V5 & V6 & V7 & Total \\
\hline V1 & & 0 & 2 & 0 & 3 & 2 & 2 & 9 \\
\hline V2 & 2 & & 2 & 1 & 1 & 2 & 0 & 8 \\
\hline V3 & 0 & 0 & & 1 & 1 & 3 & 3 & 8 \\
\hline V4 & 2 & 2 & 2 & & 1 & 3 & 3 & 13 \\
\hline V5 & 1 & 0 & 2 & 1 & & 3 & 2 & 9 \\
\hline V6 & 1 & 1 & 1 & 1 & 1 & & 1 & 6 \\
\hline V7 & 2 & 0 & 3 & 3 & 0 & 3 & & 11 \\
\hline Total & 8 & 3 & 13 & 9 & 8 & 16 & 12 & \\
\hline
\end{tabular}

A través del cruzamiento de motricidad y dependencia (Gráfico 3), observamos que el sistema representado por estas variables muestra en general, un sistema inestable, o sea, predominan las variables de vinculación (cuadrante superior derecho del gráfico), en detrimento de las variables motrices (cuadrante superior izquierdo) y de resultados.

Gráfico 1 - Distribución de las variables según motricidad y dependencia.

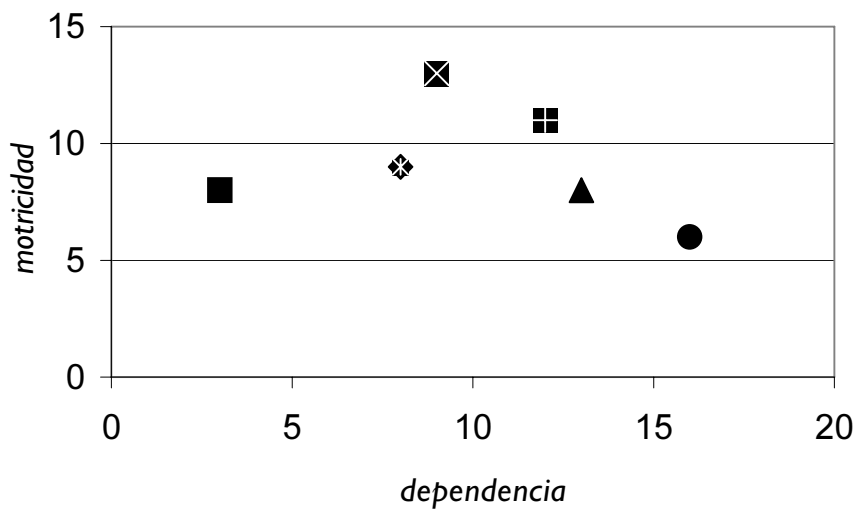

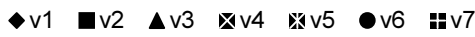


Por considerar V6 (impacto sobre la salud de la población) la variable más dependiente y menos motriz, el grupo optó por excluírla como variable clave. V6 corresponde de aqui en adelante, a la flexibilidad y adequación a la realidad local.

\section{Paso 3: análisis de gobernabilidad de los actores sobre las variables}

A partir de las características de instabilidad descriptas anteriormente, se recurrió a este análisis con el objetivo de aumentar la precisión al momento de definir los eventos y las tendencias centrales del escenario. Cabe señalar que la mirada sobre este trabajo está dirigida al nivel local del sistema de salud, o sea, aquel en que las políticas y programas se traducen en acciones, y no hacia el nivel central, donde se formulan las políticas y programas.

Selección de los actores con interés e influencia en el PSF:

Ministerio de Salud (MS)

Consejo Municipal de Salud (CMS)

Gestor Municipal (GM)

Consejos profesionales (CP)

Secretarías Estatales de Salud (SES)

Agencias de Financiamiento Internacional (AFI)

Escuelas de Formación de Profesionales de Salud (EFPS)

Figura 13 - Matriz de influencia de los actores sobre las variables.

\begin{tabular}{|c|c|c|c|c|c|c|}
\hline & V1 & V2 & V3 & V4 & V5 & V6 \\
\hline MS & A & A & B & 0 & M & B \\
\hline CMS & B & B & M & A & M & A \\
\hline GM & A & A & A & A & A & A \\
\hline CP & M & 0 & 0 & M & A & 0 \\
\hline SES & M & M & A & M & A & M \\
\hline AFI & A & A & 0 & M & A & B \\
\hline EFPS & 0 & 0 & M & B & A & A \\
\hline
\end{tabular}

Se observa que el Gestor Municipal tiene una importancia capital, seguido por las agencias de financiamiento internacional y del Ministerio de Salud y de las Secretarías Estatales de Salud. Lamentablemente constatamos que los Consejos Municipales de Salud tienen una influencia muy por debajo de lo deseado. 


\section{Paso 4: definición de los eventos de tendencia central}

Los eventos constituyen hipótesis de comportamiento de las variables y son definidos a partir del análisis efectuado hasta este punto.

V1 - E1: considerando los intereses de los diversos actores la tendencia es que se produzca una expansión del programa como política diferenciada.

V2 - E2: existe una tendencia de mantenimiento de normas de financiamiento favorables al PSF

V3-E3: existe una tendencia a restringir la atención básica (primaria) generando conflicto en relación a la referencia para niveles complejos.

V4 - E4: la consolidación del control social efectivo y la asimilación de una sistematización de evaluación suceden muy lentamente y de manera poco efectiva.

V5 - E5: tendencia a la expansión de los programas de capacitación a través de financiamientos propios para este fin.

V6 - E6: tendencia a que surjan aperturas en el sentido de una mayor flexibilidad e adaptación a las realidades locales.

El grupo evaluó la probabilidad de realización de cada evento aisladamente (Figura 14) como también la probabilidad de realización en el cruzamiento dos a dos (Figura 15).

Figura 14 - Probabilidad de realización aislada.

\begin{tabular}{|l|c|c|c|c|c|c|}
\hline Evento & E1 & E2 & E3 & E4 & E5 & E6 \\
\hline Probabilidad aislada & 0.8 & 0.8 & 0.9 & 0.8 & 0.6 & 0.6 \\
\hline
\end{tabular}

La probabilidad de realización aislada de cada evento fue estimada utilizando una escala de 0 la 1.

Figura 15 - Matriz de impactos cruzados.

\begin{tabular}{|c|c|c|c|c|c|c|}
\hline & E1 & E2 & E3 & E4 & E5 & E6 \\
\hline E1 & & +2 & +3 & 0 & +3 & +2 \\
\hline E2 & +3 & & +1 & 0 & +3 & 0 \\
\hline E3 & -1 & 0 & & 0 & -2 & -2 \\
\hline E4 & -1 & -3 & -3 & & 0 & +3 \\
\hline E5 & +3 & +1 & +1 & 0 & & +2 \\
\hline E7 & +3 & +1 & -2 & +2 & +2 & \\
\hline
\end{tabular}


El impacto cruzado de las variables fue estimado utilizando una escala de -3 a +3 . El valor de cada célula representa la probabilidad de que el evento de la columna se realice, en el caso de que se realice el evento de la línea correspondiente. El impacto puede representar un estímulo (sinal +) o de inhibición (sinal -).

\section{Paso 5: definición de los escenarios más probables}

El enunciado de los eventos representa, en la visión del grupo, la tendencia de desarrollo de las variables seleccionadas. Por lo tanto, no existiendo en la matriz de impactos cruzados ningún efecto de inibición significativo sobre ningún evento, y considerando la probabilidad de realización aislada de las variables, se eligió como escenario central, aquel en que todos los eventos formulados se realizan (escenario 111111). Aunque basado en la estimación de realización aislada de los eventos y en la matriz de impactos cruzados, el grupo definió un escenario pesimista y un escenario optimista en torno al escenario central, contribuyendo a una visualización más clara de las acciones necesarias para el desarrollo del PSF.

\section{Escenario central: |||||| $\mid$}

A partir de los intereses de los diversos actores, la tendencia es que exista una expansión del programa como política diferenciada y el mantenimiento de normas de financiamento favorables al PSF.

Por otro lado, al haber una mayor apertura en la puerta de entrada del sistema, es previsible que exista una presión en la demanda para niveles más complejos del sistema. Sin embargo, las propuestas del programa se han concentrado en los temas pertinentes a la atención básica, sin una preocupación explícita sobre la resolutividad y la garantía de mecanismos de referencia y contrarreferencia. Los actores con mayor interés en concretizar una atención más efectiva -por ejemplo el CMS- cuentan con un bajo nivel de organización y gobernabilidad, comparado con los demás. La hipótesis del grupo es que el control social y la asimilación de prácticas sistemáticas de evaluación se efectivizarán muy lentamente, lo que contribuiría para el mantenimiento del PSF dentro de los límites de la propuesta de canasta básica de salud. Con relación a la capacitación profesional, se observa la introducción de nuevas líneas de financiamiento apuntando a la instalación de cursos de especialización y residencia para profesionales de nivel superior, además de la formación de polos de capacitación en los estados, apuntando al entrenamiento y a la rotación de agentes de 
salud y otros profesionales. Pesar de toda la dificultad con respecto al desarrollo de un control social efectivo, se observa que existe una importante tendencia de flexibilidad y adaptación local determinada por el propio hecho de que la implantación del programa se realice al interior de la comunidad.

En este escenario, el plan de acciones debería explorar esta potencialidad de adaptación local, estableciendo entrenamientos y programas de capacitación que enfaticen las habilidades de interacción y escucha del profesional, teniendo como objetivo el aumento de la resolutividad de la atención del PSF. El sistema de referencia/contra referencia también debería ser aquí una parte central de la estrategia de acción, comprometiéndose en la articulación del programa con la atención básica y alta complejidad. Finalmente, el controle social debería ser objeto de atención particular debido a su motricidad y a su impacto potencial específico sobre el montaje del sistema y sobre la resolutividad de las prácticas.

\section{Escenario pesimista: I I I I I0}

En el escenario central intentamos definir con bastante realismo, las tendencias centrales del PSF. Se observó que el espacio a ser explorado en el sentido de mejorar el desempeño del programa, consiste en la posibilidad de flexibilización local debido a la propia presión ejercida en el nivel de implantación de los módulos. Sin embargo, la probabilidad estimada de realización aislada de este evento es de apenas 0,6 dado que el programa tiene importantes trazos de centralización y padronización a nivel nacional.

Si la flexibilización local no se expande, tendremos un PSF sin grandes oportunidades de transformarse en un programa resolutivo e impactante, tendiendo a transformarse tan solo en una política focalizada.

\section{Escenario optimista: I I00 I I}

En la descripción del escenario central se observa que los dos puntos más críticos del PSF, en la evaluación del grupo, residen en la debilidad del control social en tanto fuente de evaluación permanente del programa, y el bajo nivel de articulación de la red de salud con vistas a una atención resolutiva. De esta forma el escenario optimista es aquel en que estos eventos no ocurren, o sea, en donde el futuro nos aporte la consolidación del control social y una red jerarquizada de servicios de salud, capaz de responder en forma adecuada a la necesidad de atención. En este escenario, el PSF no tendría dificultades de producir los impactos deseados en el cuadro de salud de la población. 
El grupo considera, finalmente, que el PSF enfrentará diferentes escenarios y realidades nacionales. Por ejemplo, en los grandes centros urbanos, donde ya existe una red básica bien estructurada (bien o mal estructurada), a nuestro criterio el PSF enfrentará en un primer momento, el surgimiento de conflitos relativos a las diferencias entre el nivel salarial de los profesionales del PSF y los de los puestos o centros de salud, así como una factible sobreposición de roles, lo que probablemente no sucederá en las regiones más pobres del país, donde aún no existe una estructura mínima de salud. Por lo tanto, el PSF necesita por lo menos de dos enfoques estratégicos: uno para ajustarse a la realidad de las áreas urbanas donde ya existe una red establecida, de modo a dar respuesta a los potenciales conflictos financieros, de responsabilidades y culturales y otro para adaptarse a la realidad de áreas rurales totalmente desprovistas de cobertura sanitaria. En la primera situación, una de las formas de dar respuesta a esos conflictos sería aprovechar los propios profesionales de los puestos y centros de salud de la red, para actuar como profesionales del programa, buscando transformar el perfil estático de un puesto de salud, que solo espera la demanda, en un perfil dinámico donde la demanda puede ser provocada, a través de visitas y acciones educativas a la comunidad a la cual da cobertura. Para la segunda situación, los estímulos que favorezcan la derivación de profesionales y de recursos serán la gran estrategia inicial, para abastecer las regiones más carentes del país.

\section{Simulación 3 - Análisis crítico de las construcciones anteriores}

En el 2002, los grupos de alumnos se sumergen en los escenarios del PSF construidos en años anteriores, y aportan nuevos elementos de análisis:

- Existe una mayor valorización del rol del MS, lo cual le permite ejercer influencia sobre la formación profesional a través de la creación de un mercado de trabajo y del incentivo a los polos regionales de formación. En este sentido, se relativiza la influencia anteriormente aceptada del MEC y de los Consejos profesionales. Existe un reconocimiento de la formación profesional, la cual de forma gradual da cuenta del nuevo modelo, estimulada por el nuevo mercado laboral, cursos de posgraduación, expansión de los polos de capacitación y el Programa de Incentivo a los cambios curriculares de las Escuelas Médicas (PROMED), apunta a apoyar a las escuelas que voluntariamente quieran adaptar sus procesos de enseñanza/producción de conocimientos y de servicios, a las necesidades epidemiológicas de la mayoría de la población brasileña, teniendo en cuenta la excelencia técnica y la relevancia social. 
- El evento crítico que señalan los grupos se relaciona a la estabilidad profesional. Una forma de contratación del profesional, que estimule su adhesión y permanencia en el programa, continua siendo un gran obstáculo, especialmente en regiones más desarrolladas. Los municipios son cautelosos a la hora de realizar contrataciones permanentes, principalmente debido a la Ley de Responsabilidad Fiscal.

- Aunque el Programa de Expansión de Salud Familiar en grandes centros urbanos (Prodesf) ya cuenta con fondos suficientes para los cuatro próximos años e incentivo financiero del Banco Mundial, hay grandes dudas en relación al nivel de apoyo financiero que estados y municipios puedan ofrecer en términos de recursos propios, debido a la resistencia que el Programa ocasiona, en la medida en que se sobrepone a una red de atención básica más densa.

- Los grupos reconocen como evento positivo, que el aumento de la demanda en los servicios provocará presiones en cadena para la organización de los otros niveles, favoreciendo la creación de un sistema de referencia/ contrarreferencia. Esto estaría facilitado por la estrategia de la NOAS (2002).

- Un grupo adicionó, a las tradicionales variables de financiamiento, formación profesional, estabilidad profesional, flexibilidad e integración sistémica y control social, la variable gestión del programa, no considerada anteriormente.

Los escenarios confeccionados obedecen a la construcción de una tabla de las estrategias de los actores, que incluye la definición de eventos centrales y alternativos (Figura 4). Los tres escenarios más probables serían los siguientes:

\section{Escenario central}

- Aumento de financiamiento teniendo en cuenta la equidad (Aumento del volumen de financiamiento con recursos propios de los estados y municipios (EC/29). Aumento de la inversión del MS teniendo en cuenta la equidad).

- Aumento de los profesionales capacitados para el PSF.

- Dificultad de estabilidad profesional en regiones desarrolladas.

- Implementación de roles definidos por la NOAS y de vías de comunicación del PSF con otros programas.

- Aumento de la participación de los CMS en la implementación del programa. 


\section{Escenario optimista}

- El MS creará indicadores de información de calidad de gestión para un mayor monitoreo de los municipios y dispondrá formas de divulgación de las informaciones.

- El monitoreo será articulado junto a la SES, que debido a la implementación de la Noas asumirá con más énfasis su rol de gestora.

- El MS retomará la NOB/98 de Recursos Humanos donde se discute el Plan de Cargos y Carreras (PCC).

- La creación del concurso público posibilitará la inserción en la carrera pública del PSF posibilitando una mayor estabilidad profesional.

\section{Escenario pesimista}

- El financiamiento será mantenido.

- Podrá surgir cierta resistencia a la expansión del PSF en los centros urbanos y como consecuencia disminuir la aplicación de los recursos de estos centros.

- La indefinición de la condición profesional del agente comunitario de salud (¿auxiliar de enfermería o promotor de la salud?) puede perjudicar la relación del mismo con el programa y con la comunidad.

- El MS y las SMS no invierten en estrategias de estabilidad profesional produciendo una mayor rotatividad y una menor demanda.

- El tratamiento diferencial del PSF proporcionará el mantenimiento del mismo como sistema paralelo de salud.

Se observa, en el caso de la simulación del año 2002, un desvío de los escenarios en relación a la simulación anterior. El escenario pesimista de este año correspondería al escenario central de la simulación anterior. El escenario optimista sería un escenario marcado por el intento de estabilizar profesionales a través de concursos públicos y por la búsqueda de una mayor responsabilización a través de un monitoreo de la calidad. Podríamos bautizar este escenario como "búsqueda de la calidad". El escenario central se distingue por los esfuerzos en el plano de la integración regional y presentaría como único evento ocasionalmente negativo, la dificultad de estabilidad profesional en regiones desarrolladas. Podemos bautizar este escenario como "expansión con integración". El pesimista es un escenario con dificultades de integración, de mantenimiento. Es el escenario de un "programa aún paralelo". 
A partir de este análisis prospectivo surgen grandes temas de planificación: el desarrollo de un sistema de indicadores de calidad de la gestión y de impacto, incluyendo indicadores de integración; disponibilidad y padronización de formas de divulgación de informaciones; mayor flexibilización del PSF y avances en la integración a través de la implementación de la Noas; nuevos planes de carreras y concursos públicos; delimitación clara de la condición profesional de los agentes comunitarios de salud; incentivo a la participación comunitaria a través del soporte de los medios de comunicación masivos y de la divulgación de información, etc. La cuestión de la resolutividad del programa es aún un tema para ser explorado en forma permanente. Finalizamos esta parte, poniendo en discusión una polémica relacionada con este tema, como un llamado de atención a la necesidad de que el Programa de Salud familiar no pierda la característica fundamental del Programa de Médico de Familia, o sea, la existencia de un soporte importante de supervisión médica especializada al médico de familia, capaz de potencializar la capacidad de resolución de la estrategia en general.

\section{Consideraciones finales}

El objetivo de este trabajo, que simplifica didácticamente el enfoque de la prospectiva de Godet, es intentar poner al alcance del público académico y de los gerentes una herramienta poderosa de auxilio en la toma de decisiones.

En el desarrollo del mismo, nos vimos en la obligación de confrontar diferentes autores "godetianos" y otros latinoamericanos, buscando establecer una lógica de síntesis. La lectura que realizamos de la escuela de Godet es situacional. Representa un esfuerzo de adaptación a nuestra cultura.

Es importante que no se tenga la idea, de que este enfoque de prospectiva, es de naturaleza puramente matemática. Es bueno volver a señalar, como lo hicimos anteriormente, el hecho de que la probabilística matemática de los escenarios, de la que nosotros presentamos un simple ejemplo, es apenas una parte infinitesimal de un enfoque más amplio, donde el juzgamiento estratégico, la reflexión de naturaleza cualitativa, literaria, histórica y cultural, ocupan un espacio mucho mayor. El componente matemático puede, eso sí, ayudar como un medio y no como un fin en si mismo.

Como ilustramos a través de algunos casos trabajados con los alumnos de diferentes líneas de posgraduación, el nivel de formalización puede ser dosificado. En algunos casos, no se trabaja tanto con especialistas externos y con la lógica de utilización de un programa de computación. El análisis es más interno 
y cualitativo, respetando sí, la idea general del protocolo. Uno de los items menos explorados, que podría sustituir la consulta a especialistas, se relaciona con la necesidad de procurar a los actores que controlan variables y consultarlos respecto a sus estrategias frente a esas variables. Estas entrevistas son ineludibles y requieren de un tiempo que nosotros no tuvimos. Por esta razón, tuvimos que realizar simulaciones, lo cual no es deseable. La construcción del mapa de las estrategias de los actores constituye uno de los mayores desafíos de la prospectiva, pues de esto depende la buena formulación de los eventos.

Es importante recordar aquí, que el rigor de la prospectiva puede ser relativizado cuando esta técnica es asumida como el conjunto de las narrativas más abiertas de los actores, cuyo objetivo es el de evidenciar las creencias o preconceptos que sustentan esa lectura del futuro. La discusión sobre esos fundamentos cognitivos y emocionales sobre la mirada hacia el futuro puede ser crucial para alinear posiciones prácticas con relación al mismo. La prospectiva como recuerdo del futuro implica poner en evidencia la tradición defendida por los individuos para distanciarse de ella a través del diálogo crítico.

La importancia de la prospectiva puede ser evaluada en diferentes dimensiones. La más importante es el intento de quebrar la rigidez de posiciones, aprendiendo a trabajar con posibilidades. Es la lógica del raciocinio condicional: si sucede tal escenario, actúo de tal modo. Si cambia, actúo de otra forma. Aprender a aprender a cambiar es el objetivo. Del mismo modo, como fue dicho anteriormente, el mérito de la prospectiva es aprender del futuro, es decir la creación de un ambiente que posibilite un distanciamiento crítico de los determinantes rígidos de la cultura.

Para terminar, diríamos que la construcción de escenarios es un proceso que debe ser lo más colectivo posible, para que se reduzca la subjetividad inexorable del arte de lidiar con lo desestructurado. No deja de ser un diálogo, que a veces asume caminos indirectos, como el de la consulta a especialistas, cuyo objetivo mayor es anticipar la acción más acertada, la cual seria fruto del consenso posible entre actores que reflexionan sobre algo complejo como el futuro. La dificultad inmanente no puede excluir la reflexión, en nombre de la espontaneidad.

\section{Referencias Bibliográficas}

ARAÚJO, J. L. de. Cenários e modelos para a análise de alternativas energéticas. In: Seminário sobre Matrizes e Balanços Energéticos Estaduais. Planejamento Energético Estadual. Cenergs. Porto Alegre, 1984. 
BENASSOULI, P. \& MONTI, R. La planification par scénarios: le cas AXA France 2005. Revue Futuribles, 1(1), nov. 1995.

BRASIL. MINISTÉRIO DA SAÚDE. Norma Operacional Básica - SUS 1996. Gestão plena com responsabilidade pela saúde do cidadão. Brasília: Diário Oficial da União, 22 de abril de 1996.

BRASIL. MINISTÉRIO DA SAÚDE. Portaria no 1882 . Dispõe sobre o Piso de Atenção Básica. Brasília: Diário Oficial da União, 18 de dezembro de 1997.

BRASIL. MINISTÉRIO DA SAÚDE. Regionaliração da Assistência à Saúde: aprofundando a descentralização com equidade no acesso. Norma Operacional da Assistência à Saúde NOAS-SUS 01/02 (Portaria MS/GM nº 373, de 27/01/ 2002). Brasília.

BOURSE, F. Prospective et Systémique: de l'analyse structurelle aux jeux d'acteurs. AFCET/ UAS. Deuxième École Européene de Systemique. Paris, 1992. (Mimeo.)

BUARQUE, S. C. Planejamento Estratégico e Cenários. Cendec/Brasília/Caderno de Transparências, 1993. (Mimeo.)

ÉCOLE NATIONALE DE SANTÉ PUBLIQUE (ENSP)/Rennes/França. Introduction à la Méthodologie de la Prospective et des Scénarios. Dossier documentaire et pédagogique. Département MATISS., février-mars 1997. (Mimeo.)

GODET, M. Prospective et Planification Stratégique. Paris: CPE, 1985

GODET, M. Manual de Prospectiva Estratégica: da antecipação à ação. Lisboa: Publicações Dom Quixote, 1993.

GODET, M. SMIC Prob Expert. Méthode de Probabilisation des Scénarios. Manuel d'utilisation. Paris: Heurisco, 1998.

GRUPO DE ESTUDO ARTUR D. LITTLE. A ambição move o mundo. In: HSM Mangement. Estratégia e Planejamento: autores e conceitos imprescindíveis. São Paulo: PubliFolha, 2002.

HATEM, F. et al. La Prospective: pratiques et méthodes. Paris: Economica, 1993.

JOUVENNEL, H. Sur la démarche prospective: un bref guide méthodologique. Revue Futuribles, 3(2), p.75-89, Paris, Septembre 1993.

KLAN, H. El año 2000. Rev. del Occidente, Madri, 1969.

ORTIGUEIRA, M. La Corporación Cibernética. Granada: Publicaciones del Sur, 1978.

MATUS, C. Política, Planejamento e Governo, 2 vol. Brasília: Ipea, 1994. (Série Ipea). 
REVUE FUTURIBLES. Volume Prospective et Stratégie, 1(18), nov. 1989. (Toda a coleção).

ROUBELAT, F. Les Méthodes de consultation d'experts. In: HATEM, F. et al. La Prospective: pratiques et méthodes. Paris: Economica, 1993.

SENGE, P. et al. La Quinta Disciplina en la Práctica: estrategias y herramientas para construir la organización abierta al aprendizaje. Barcelona: Granica S.A., 1995.

SCHWARTZ, P. A Arte da Visão de Longo Prazo: planejando o futuro em um mundo de incertezas. São Paulo: Zumble/Best Seller, 2000. 


\section{Cultura y liderazgo comunicativo}

Francisco Javier Uribe Rivera

La necesidad de un nuevo paradigma organizativo obedecería, según Crozier (1989), a algunos elementos básicos:

- En un sistema de producción de evolución acelerada, la capacidad de innovar se transforma en la primera cualidad que se enfrenta a la capacidad de racionalización.

- La nueva lógica de los servicios está mucho más relacionada a la calidad que a la cantidad, y en este sentido, la idea de una atención cada vez más personalizada del cliente se hace imperativa.

- El recurso humano adquiere una importancia extrema, en la medida en que los esquemas de racionalización productiva y de producción en masa son superados relativamente.

- Existe una marcada expansión de la importancia de la inversión inmaterial, o sea, de la inversión en las personas, en el sistema de relaciones, y en la cultura, que se desarrolla paralelamente a una visión de la organización como una sociedad de aprendizaje.

Ese nuevo paradigma estaría basado en el principio de simplicidad de las estructuras organizativas, relativizando la importancia de las estructuras y de los procedimientos como factores integradores; en el principio de autonomía de las personas y de las unidades, facilitando la creatividad y el hacer frente a los problemas; y, en el principio de gobierno de la cultura, según el cual la organización dejaría de ser regida predominantemente por las reglas de procedimiento y/o por las órdenes jerárquicas, buscando un mínimo de restricciones indispensables para la coordinación de esfuerzos en la cultura que produce todo grupo humano con una comunidad de objetivos.

La gerencia participativa, las prácticas de delegar y de descentralización, la informalización de las estructuras, pasan a ser los ejes del nuevo estilo de gerencia- 
miento. La profesionalización o el desafío de estructurar la organización a partir del conocimiento, pasa a ser más importante que las estructuras y procedimientos.

En el contexto de este modelo propuesto, la escucha o auscultación organizacional son obligatorias. La necesidad de apoyar el proyecto de empresa en una escucha de la cultura impone nuevos desafíos metodológicos y organizativos. Por otro lado, la escucha de los otros, como base del nuevo paradigma, se articula a un proyecto de comunicación dentro del cual el surgimiento de un nuevo patrón de liderazgo es fundamental. Parece que el ideal de liderazgo fuerte, carismático, deja de ser funcional, en pro de un tipo de liderazgo más volcado a la movilización.

$\mathrm{Al}$ asumir aquí la gestión de la escucha organizacional como regla básica, nos proponemos: presentar y analizar algunos elementos de la auscultación o auditoría de la cultura, de modo a orientar la construcción metodológica de un modelo de análisis cultural; discutir a grandes rasgos la cuestión del cambio cultural, especialmente el aspecto de la evolución cultural vinculada al enfoque de la gestión estratégica hospitalaria que trabajamos en este libro; y discernir algunas características del denominado liderazgo comunicativo a la luz de algunas contribuciones de la sociología organizacional, de la gestión de calidad y del modelo de la organización que aprende a aprender.

La hipótesis básica que orienta esta reflexión es que, más allá de la importancia de las metodologías racionalistas de gestión (planificación estratégica y gestión de calidad), que no es negada, crece la importancia de la comprensión de factores como la cultura, la negociación y el liderazgo, considerados los pilares de una nueva forma de conducción basada en la escucha.

\section{Cultura y cambio organizacional}

Autores como Matus (1994) y Crozier \& Friedberg (1977) adoptan la metáfora del juego social para caracterizar las organizaciones. Según esta perspectiva, las organizaciones son reguladas sistémicamente por reglas fácticas y/o legales, las cuales son observadas por todos los actores organizacionales. Estos producen sus jugadas o desarrollan sus estrategias particulares, en función de intereses parciales, sin alterar o sobrepasar el modelo de las reglas generales (por lo menos, a corto plazo).

En la concepción de Crozier \& Friedberg (1977), conviven conflictivamente dos tipos de racionalidad: la racionalidad sistémica, definida por las reglas de juego organizacional, y la racionalidad estratégica de los actores. La primera conlleva una lógica deductiva, actúa desde lo global hacia lo particular, 
focaliza la organización como un conjunto que transciende a los actores en particular. La segunda está centrada en la idea de la organización como construcción social, conlleva una lógica inductiva que implica la búsqueda de la totalidad a partir de lo particular. Ambas racionalidades chocan y se juzgan mutuamente. Entre las reglas y los actores existe una relación circular de causalidad.

Matus (1994), aplicando su teoría de la producción social al campo organizacional, establece que las organizaciones tienen reglas, acumulación y flujos de producción social. Las reglas del sistema determinan en última instancia el poder de los actores, o sea, la acumulación de recursos organizacionales y de producción técnica, lo cual determina la variedad posible de productos o acciones. Las reglas pueden, por ende, ser transformadas a largo plazo por los actores, dependiendo del grado de acumulación de recursos de poder. En el campo organizacional se destacan tres reglas interrelacionadas: la direccionalidad o la misión, la gobernabilidad o el grado de centralización/descentralización, y la responsabilidad o el nivel de rendición de cuentas.

Estas reglas, especialmente las de responsabilidad, determinan para el autor, la calidad de la gestión (tipo de acumulación institucional). Cuando predomina una baja responsabilidad, no se exige cumplimiento al dirigente, quien no siente la necesidad de una planificación estratégica de sus problemas y compromisos fundamentales. De este modo, su agenda es improvisada, irracional y acumula todo tipo de problemas, de alto y bajo valor relativo. El dirigente tiende a concentrar problemas y decisiones, no delega y el tipo de gestión pertinente es una gestión tradicional, donde no hay una preocupación por los productos y resultados finales de la organización en relación a su ámbito externo. La dinámica inversa actuaría en organizaciones de alta responsabilidad. La gestión por objetivos finales y la planificación estratégica surgirían como resultado de la exigencia, del control social.

Cambiar la calidad de la acumulación organizativa implica alterar tendencialmente las reglas del juego organizacional, sobre todo en lo referente a la responsabilidad. Este es uno de los principales desafíos de la administración pública latinoamericana.

Thévenet (1986), teórico organizacional francés, plantea a su vez, que el sistema de reglas organizacionales está condicionado por la cultura. La cultura determina las reglas, y estas determinan los sistemas de gestión y la lógica de los actores. En el modelo de este autor, la relación es unívoca. Está ausente allí el efecto inverso de los actores sobre las reglas. Este énfasis en la cultura como fundamento de las reglas del juego organizacional parece ser compartido por Matus (1994), cuando destaca una sobredeterminación de la responsabilidad sobre el conjunto de las reglas y asume que la base de la responsabilidad es la cultura como conjunto de estructuras mentales. 
La cultura es vista por Thévenet como el conjunto de referencias compartidas organizacionalmente y producidas históricamente en los procesos de aprendizaje inmanentes al enfrentamiento continuo de problemas. Las configuraciones simbólicas típicas de la cultura son fuentes de comportamientos y se desarrollan en procesos interactivos de intervención sobre la doble problemática macro de las organizaciones: la relación con el ambiente y la cohesión interna.

Para Schein, autor del célebre trabajo Organizational Culture and Leadership (apud Fischer \& Fleury, 1996), la cultura organizacional es el conjunto de conceptos básicos que un grupo inventó, descubrió o desarrolló al aprender cómo lidiar con los problemas de adaptación externa e integración interna y que funcionaron lo suficientemente bien como para ser considerados válidos y enseñados a nuevos miembros como la forma correcta de percibir, pensar y sentir, en relación a esos problemas. La similitud de este concepto con la definición de Thévenet es notable.

Thévenet (1993) visualiza la cultura como las reglas fácticas del juego organizacional. Del mismo modo que Matus, el autor señala la importancia de la responsabilidad en el conjunto de las configuraciones culturales. Se trataría de la conciencia del deber y de la concepción del individuo que predomina en la organización, esta última reflejada en los sistemas de remuneración y de evaluación.

Varios elementos componen la cultura organizacional. A partir de una lectura crítica de Thévenet y de Matus (mentor de la Planificación EstratégicaSituacional, PES) y de un modelo teórico habermasiano, Rivera (1996) señala la posible correlación entre el concepto de mundo de la vida de Habermas (1987), los componentes culturales enunciados por el autor francés y las reglas del juego organizacional de la teoría de las macroorganizaciones del PES.

La primera área de correlación estaría representada por la intersección entre el concepto de direccionalidad del PES y el concepto de cultura como componente estructural del mundo de la vida organizacional. Formarían parte de este campo simbólico, elementos como la percepción del oficio por los agentes organizacionales, el saber técnico o el saber del oficio, el tipo de percepción del ambiente externo (como recurso o amenaza) y el proyecto real de empresa, visto como el ser (o el debe ser) históricamente estructurado de la organización (misión). Esta área se relacionaría a la "cultura técnica" o a la simbología vinculada al proyecto tecnológico de la organización.

Otra área de correlación está dada por el concepto de gobernabilidad del PES y por el concepto de sociedad en tanto estructura normativa del mundo de la vida organizacional. El campo simbólico pertinente incorporaría las representaciones sociales vinculadas al tipo de estructura de poder y de conducción de la organización, al grado de centralización/descentralización de la misma, a las formas de regulación de las interacciones entre los agentes 
organizacionales. El enfrentamiento del problema de la cohesión interna es inherente a este campo simbólico.

La tercera área de correlación que se establece es aquella que corresponde al concepto de personalidad (o de socialización de los sujetos) en la estructura del mundo de la vida organizacional y a las reglas de responsabilidad de Matus (1994). En este campo simbólico predominan actitudes y representaciones vinculadas al ejercicio del liderazgo, a la concepción de la rendición de cuentas y a la capacidad de socialización de los agentes organizacionales, incluyendo los procesos educativos. La responsabilidad es tomada aquí como una conducta interiorizada por los individuos en el sentido de solicitar y rendir cuentas.

Aunque esta correlación pueda parecer forzada, resulta útil para ordenar el pensamiento y contribuir a un esclarecimiento de las principales categorías de la cultura, que es necesario levantar en un proceso de auditoría apuntando al cambio organizacional. Es importante aclarar que estas 3 categorizaciones constituyen estructuras o procesos interdependientes, que se nutren recíprocamente, lo que contribuye a una noción más integradora del concepto general de cultura, tal como el adoptado aquí.

La adopción del concepto de mundo de la vida organizacional por Rivera está sustentada en gran medida en la lectura de Flores (1989). Este autor formula una concepción lingüística de las organizaciones, en la cual incorpora el concepto de mundo organizacional. Este concepto "de mundo de la escucha y de la relevancia" (Flores, 1989:18) está fundamentado en una lectura heiddegeriana y corresponde a la tradición organizacional, a la estructura simbólica que predetermina el conjunto de compromisos institucionales. El concepto de mundo de la vida organizacional definido por Rivera, señala al conjunto de configuraciones simbólicas que son acordadas históricamente y que se constituyen en el telón de fondo que regula sistémicamente una institución, más allá de los mundos de la vida de los actores por separado.

Dos ideas centrales están implícitas en esta visión de la cultura organizacional, como mundo de la vida compartido. La primera idea, es que la cultura se constituye a partir del accionar comunicativo de los agentes organizacionales, en procesos de aprendizaje donde se destaca el componente búsqueda del consenso como fundamento del accionar. De acuerdo con la segunda idea, la cultura no es inmutable, sus configuraciones simbólicas pueden ser cuestionadas a nivel discursivo cuando son disfuncionales para el accionar teleológico y normativo.

De este modo, el tratamiento dado al concepto de mundo organizacional de Flores, es dialéctico, habermasiano, en el sentido de que, si bien el habla y la acción se constituyen a partir del mundo de la vida, de la tradición cultural, esta tradición también puede ser reformulada a partir de una postura crítica, discursiva. 


\section{El Método de Análisis Cultural}

La propuesta de Thévenet es importante para la gerencia por dos motivos. En primer lugar, el autor proporciona un enfoque de análisis cultural, de auditoría de cultura. En segundo lugar, el autor sugiere una concepción de trabajo cultural. De este modo, Thévenet procura operativizar un poco más la discusión sobre cultura, ayudando a superar el campo de las generalidades del tipo "es muy difícil trabajar con cultura" o "la cultura no es instrumentable", muy comunes en este campo discursivo.

En relación al primer punto, Thévenet establece una marcada distinción entre análisis de cultura y análisis de clima social. Este último corresponde a un relevamiento instantáneo, fotográfico, de las percepciones de los agentes organizacionales en relación a los sistemas de gestión organizacional. El resultado del mismo es un promedio cuantitativo de opiniones. El análisis de cultura, en cambio, presupone un relevamiento histórico, longitudinal, de las representaciones sociales compartidas subyacentes a los sistemas de gestión y situaciones reales. El autor afirma que, a medida que el análisis de clima social se interesa por lo que las personas piensan, el análisis de cultura se preocupa por lo que la gente hace y por las referencias que presuponen su acción. La cultura no es transparente, no se evidencia de un modo claro. El análisis cultural implica una metodología compleja que, a diferencia de investigar de un modo directo la cultura, la cual no es abordable en una primera aproximación, su intención es registrar los hechos, informaciones y eventos orientados a representarla, o sea, aquellos sobre los cuales se supone que deja una marca. Todo el problema se reduce a saber dónde se sitúan estas marcas; o cuáles serían los dominios analizables. Por otra parte, el análisis dinámico de la marcas, señales e indicios de la cultura, supone la organización de estas informaciones en hipótesis sobre la cultura, hipótesis que requieren una validación permanente (buscando la confirmación concreta de estas hipótesis, procurando alternativas a partir de la observación de empresas comparables o de la competencia, buscando hechos que puedan cuestionar su validez u obligar a una mayor precisión de las mismas). Podría decirse que el análisis cultural supone una metodología "indiciativa" e hipotética, de naturaleza falible en el sentido de un permanente proceso de cuestionamiento.

Thévenet $(1986,1991,1993)$ delimita los ejes centrales, categorías o dominios de una auditoria de cultura:

- Un análisis longitudinal de los fundadores y de los liderazgos distintivos de la organización, que procure captar las especificidades, diferencias y negaciones (en relación al contexto de la época) de su proyecto y personalidad: es indispensable indagar sobre la formación y las características ideológicas 
del fundador o de sus líderes, sobre las características de su personalidad, su lugar de origen, sus actos y gestos, su nivel de compromiso con la comunidad, los principios que sustenta, y fundamentalmente, la caracterización del grado de ruptura o de desvío que tal figura produce en relación al contexto de la época.

- Un análisis histórico de las tecnologías o de los proyectos tecnológicos de la empresa, procurando captar discontinuidades e incrementos, abarcando el tema crucial de la percepción del ámbito externo y la identificación de los factores que estructuran las actividades o productos organizacionales (la razón de ser).

- Un análisis de la importancia relativa de las diferentes estructuras productivas de la empresa, realizada de forma longitudinal, para poder captar, por ejemplo, la relación entre administración-medio y estructura de producción final, entre producción y ventas, entre investigación y producción, etc. De lo que se trata, en este caso, es de identificar qué funciones o áreas organizacionales son más valorizadas dentro de la división de poderes.

- Un análisis de los sistemas de gestión, apuntando a captar los valores esenciales o que actúan de modo subyacente a los mismos, el tipo de toma de decisiones, el nivel de participación, el nivel de responsabilidad característico: se entiende, en este caso, que los sistemas de gestión, específicamente los de gestión de personal y de evaluación en general, presuponen un código de valores sobre lo que es ser un buen o un mal funcionario, un buen o un mal producto o resultado (se pueden orientar investigaciones sobre el tema, a través de muestreo)

- Un análisis histórico de las estructuras de poder, de los organigramas, de las convenciones, de las formas de comunicación y de socialización (destacando estas últimas), de los símbolos de diferenciación de status social, de la disposición del espacio, de las historias y leyendas organizacionales, etc., apuntando a captar las señales y símbolos del poder y de los esquemas de interacción social, de los hábitos y ritos sociales.

Un análisis de este tipo no parece distanciarse de un tipo de análisis convencional organizacional. Su especificidad es el intento de revelar las representaciones sociales compartidas organizacionalmente, o sea, las lógicas subyacentes a la acumulación de hechos, a las regularidades, repeticiones y redundancias observables en cada una de las categorías de información anteriores, que definen las hipótesis culturales propiamente dichas. La presencia reiterada de trazos de una categoría de información (del fundador, por ejemplo) en otras (tales como el análisis histórico de las capacidades y/o de los valores implícitos en los sistemas de gestión), define la posibilidad de considerar esas hipótesis como más serias. Esto no significa que algún aspecto que esté incluido en una única categoría de 
información no sea representativo de la cultura, sino que se prefiere tomar aquellos aspectos que tienen una chance mayor de ser una hipótesis seria.

Es importante destacar, que lo que interesa en el análisis histórico no es la sucesión detallada de eventos, sino la apropiación de las lógicas fundamentales; y subrayar que este análisis - en el caso por ejemplo de los fundadores y de otras categorías- es un tipo de abordaje simbólico que se preocupa por aquello que es recordado, ponderado por el cuerpo social como significativo (que es diferente a que el fundador sea esencialmente asî́.

En el artículo nuestro ya mencionado (Rivera, 1996), se mencionan las dimensiones más específicas del relevamiento de cultura sugeridas por Thévenet:

- La percepción del oficio, de la misión, como un rol social específico o un valor egocéntrico.

- La percepción de los productos, como positivos y de gran valor o como negativos y de valor escaso.

- El conocimiento de la identidad del oficio.

- La importancia concedida a la capacitación.

- La relación entre la percepción del entorno, la estructura de poder y la dinámica organizacional: un entorno amenazador crea introspección en el sentido de la jerarquía interna, de estar a la defensiva, de la lucha por la competencia, de un tipo de comunicación controlada; un entorno ecológico o percibido como lleno de oportunidades estimula la búsqueda activa, creativa, de recursos, acompañado, en general, por formas más democráticas y flexibles, y por un énfasis en la innovación.

- El grado de equilibrio entre los imperativos económicos, sociales, éticos y morales: cómo se vivencian los beneficios implícitos en la misión; si este beneficio está restricto al lucro económico o incorpora alguna dimensión ecológica, como el respeto ambiental; cómo es vivenciado el orden interno, si es como autoritarismo o democracia; cómo es percibido el equilibrio entre os grupos, si es como relación de fuerza o contrato social.

La metodología de análisis cultural de Schein (2000) presupone como punto de partida, el análisis de los signos observables de la forma de ser de la organización (artefactos). Las siguientes preguntas pueden ayudar a precisar esos artefactos: Cuando entró a esta organización, ¿qué detalles le llamaron la atención?, ¿qué aspectos del ambiente de trabajo resumen para usted, "la manera en que hacemos las cosas aquíl?, ¿qué reglas?, ¿qué procedimientos?, ¿qué hábitos? A continuación, el autor propone establecer la lógica subyacente a los artefactos: ¿qué llevó a las personas de esa organización a hacer las cosas de esa forma? Esta pregunta ayudaría a diferenciar las estrategias, metas y filosofías que actúan como justificaciones adoptadas para los artefactos. El paso 
definitivo consistiría en buscar los preconceptos culturales subyacentes: las creencias, percepciones, pensamientos y sentimientos tomados como naturales (la gran fuente de valores y acciones).

Schein señala la existencia de valores asumidos y valores en uso, que corresponderían al segundo nivel del análisis cultural. Esto generaría una inconsistencia entre los artefactos y los valores asumidos. Uno de los puntos de partida de la búsqueda de los preconceptos culturales subyacentes reales, consistiría en explorar esa eventual inconsistencia. En este sentido, el discurso oficial pasa a ser un importante material de análisis, no tanto por lo que revela, sino por lo que intenta ocultar. Fleury y otros autores (1997), asumen que por su naturaleza inconsciente, los preconceptos básicos de la cultura no se entregan a la observación directa y sus significados se escabullen por entre los dobleces del discurso manifiesto de los actores organizacionales. Para revelar su verdadero significado, es preciso ir más allá de las apariencias y de las primeras impresiones. Es necesario visualizar los actos fallidos de los discursos, los lapsus de memoria y las contradicciones entre el discurso y la práctica. En estos eventos sorpresivos, es donde surgirían los contenidos básicos. El método de abordaje clínico de Schein, sería capaz de revelar los significados de eventos aparentemente misteriosos, irracionales o ingenuos, relacionándolos con los preconceptos básicos de la cultura.

A medida que las contradicciones detectadas son examinadas minuciosamente, algunas preguntas relativas a los diferentes dominios de análisis serían cruciales para la distinción de los preconceptos básicos que constituyen la cultura (Fischer \& Fleury, 1996):

- La relación con la naturaleza: la relación con el ambiente ¿es de dominación, sumisión, o armonía?

- La naturaleza de la realidad y de la verdad: las reglas de lingüística y de comportamiento que diferencian lo que es real de lo que no lo es; si la "verdad" de la organización es revelada o descubierta; si el criterio de verdad es la argumentación, la credibilidad científica o de otro tipo.

- La naturaleza humana: la naturaleza humana ¿es buena, mala o neutra?

- La naturaleza de la actividad humana: aquello que es considerado "correcto", en el modo de actuar del ser humano frente a los preconceptos sobre el ambiente, sobre la realidad, sobre la naturaleza humana: ¿ser activo, pasivo, o desarrollarse por si mismo?

- La naturaleza de las relaciones humanas: ¿cómo es distribuido el poder y el amor?, ¿la vida es cooperativa o competitiva, individualista o cooperativa, basada en la autoridad, en la tradición o en el carisma?

La comprensión del nivel más profundo de la cultura presupone pensar en las organizaciones desde un punto de vista histórico, respondiendo a la pre- 
gunta: en toda la historia de la empresa, ¿cuáles fueron los valores, creencias y certezas de los fundadores y de los líderes que la transformaron en una empresa exitosa? (Schein, 1999). En este sentido, los cuestionamientos anteriores tendrían que estar dirigidos preferentemente al liderazgo histórico de la organización.

Para profundizar la delimitación del item naturaleza de la actividad (como categoría teórica articuladora de prejuicios básicos o dominio analítico particular), podemos citar la clasificación establecida por Kluckhohn y Murry (Fleury et al., 1997) sobre la modalidad u orientación (de valor) de la actividad humana. Habría tres orientaciones básicas de valor:

- La orientación del sujeto por el ser: la acción es orientada por el deseo existente en el individuo;

- La orientación del devenir del ser: se preocupa por lo que es "dado" en la personalidad del ser humano y también por lo que puede llegar a realizar, rescatando la idea de desarrollo;

- La orientación hacia el hacer: está focalizada en la tarea, en la eficiencia y en el descubrimiento, su característica principal es la demanda de acción, teniendo en cuenta la realización, de acuerdo con patrones externos al individuo que actúa;

En relación a la Identidad de una Empresa, el grupo Strategor (1997) reflexiona sobre la existencia de tres posibilidades: focalización de la empresa en la actividad o tarea (bajo las características citadas en el párrafo anterior), en el carisma (o estructuración en torno del liderazgo) o en un comportamiento (de tipo planificado, por ejemplo).

En cuanto a la perspectiva metodológica a ser utilizada para captar las categorías teóricas anteriores, Schein propone otras categorías para ser investigadas (Fischer \& Fleury, 1996):

- Analizar el tenor y el proceso de socialización de los nuevos miembros.

- Analizar las respuestas a incidentes críticos de la historia organizacional. Para cada crisis es preciso identificar lo que fue hecho, decidido, y los principales temas asociados a los motivos alegados para tomar esas decisiones.

- Analizar las creencias, valores y convicciones de los creadores o portadores de cultura.

- Analizar y explorar junto a las personas que integran la organización, las sorpresivas observaciones que fueron descubiertas durante las entrevistas.

Es significativo el grado de complementación entre las perspectivas de Schein y de Thévenet. La importancia de considerar los incidentes o crisis más notables de la organización a efectos de sumergirse en el simbolismo que sustentó el enfrentamiento de los mismos y de analizar las estrategias de socialización o de adaptación de los nuevos miembros a la empresa (como elementos evidenciados 
por Schein que pueden enriquecer la perspectiva del autor francés). En relación al segundo aspecto, el desarrollo realizado por Maanen (1996) sobre el tema de la socialización de los sujetos, según el tipo de entrenamiento privilegiado (y en consecuencia la posibilidad de ascenso funcional) es particularmente motivante. Nos referimos al trabajo Procesando a las Personas - Estrategias de Socialización Organizacional, incluido en la coletánea organizada por Fischer \& Fleury (1996) donde este autor describe las principales estrategias de adaptación usadas por las empresas en términos polares: formales/informales; fijas/variables; secuenciales/no secuenciales; en serie/aisladas; por competición/concurso; por investidura/por despojo, etc. Haremos una pequeña descripción del contenido de estas estrategias. Una estrategia de entrenamiento formal realza el rol de objeto del novato, establece una marcada diferencia (entre quien entrena y aquel que es entrenado) cuyo objetivo es inculcar nuevos roles sociales. Una estrategia informal, es un tipo de aprendizaje más solidario en el propio trabajo, al servicio del desarrollo de destrezas dentro de un nuevo rol. La primera es más "cosificante" que la segunda, contribuyendo a una mayor similitud. La similitud es, por otra parte, una consecuencia muy probable de una estrategia de formación seriada (inculcación de patrones a un grupo), fija (concatenación de pasos o requisitos predeterminados para alcanzar una posición, generando menor movilidad), y por despojo (exposición del novato a un test degradante para acceder a una nueva posición, generando una tendencia hacia la domesticación, similar a un entrenamiento militar). Si el objetivo es una mayor diversidad y creatividad, el conjunto de las estrategias polares sería más funcional.

A partir de la información anterior, se puede construir el siguiente cuadro de análisis cultural (Figura 1):

La metodología de relevamiento propuesta por el autor francés se asemeja bastante al modelo presentado por Fleury, Shinyashiki, \& Stevenato (1997), en el trabajo Arqueología Teórica y Dilemas Metodológicos de los Estudios sobre Cultura. Este modelo del Triángulo Metodológico para el estudio de la cultura, plantea la necesidad de tener varios observadores de un mismo objeto, la aplicación de varias teorías y la implementación de varios métodos o técnicas, en función de identificar la congruencia y consistencia de los mismos, la capacidad de generar datos comparables, la complementariedad, la validez externa de los enfoques.

La "triangulación” es definida como la combinación de métodos para estudiar un mismo fenómeno. La metáfora proviene de la navegación y de la estrategia militar que utiliza múltiples puntos de referencia para localizar la posición exacta de un objeto. Esta perspectiva, basada en Duncan (apud Fleury, Shinyashiki, \& Stevenato, 1997), implica el uso de cuestionarios, de entrevistas cualitativas y de la observación participativa o libre de los alrededores, considerando tanto la mirada nativa como la externa y las dimensiones cualitativa y cuantitativa. Por medio de esta "triangulación" se procura compensar las deficiencias de un método a través del uso de otros. 
Figura 1 - Componentes básicos de la cultura organizada.

\begin{tabular}{|c|c|}
\hline Categoría & Tipo de Información Posible \\
\hline $\begin{array}{l}\text { Cultura Técnica } \\
\text { (Proyecto Tecnológico) }\end{array}$ & $\begin{array}{l}\text { - Relación con el ambiente: dominador, pasivo, armonía } \\
\text { tecnologías } \\
\text { - Tipo de relación con la actividad: Orientación a partir } \\
\text { de la persona o de la tarea } \\
\text { - Identidad empresarial: Focalización en la actividad, en } \\
\text { el liderazgo o en el comportamiento } \\
\text { - Razón de ser de las actividades (factores estructurantes): } \\
\text { el leit motiv argumentativo que explica la decisión sobre } \\
\text { las mismas (especialmente en situaciones de crisis y de } \\
\text { cambio) } \\
\text { - Valorización diferencial de las áreas de actividades } \\
\text { - Vivencia o percepción valorativa de los } \\
\text { productos/beneficios de la actividad } \\
\text { - Conocimiento de la identidad del oficio }\end{array}$ \\
\hline Normatividad o Gobernabilidad & $\begin{array}{l}\text { - Tipo de comunicación/formas de coordinación } \\
\text { - Vivencia del orden interno - grado de autoritarismo o } \\
\text { de participación del sistema de conducción/orientación } \\
\text { relacional predominante: individualismo (el bienestar } \\
\text { personal predomina sobre el del grupo), orientación } \\
\text { colateral (el grupo predomina), jerárquica o lineal } \\
\text { (relación colateral con mayor énfasis en la continuidad } \\
\text { temporal)/orden basado en la tradición, autoridad legal o } \\
\text { carisma } \\
\text { - Percepción de la relación entre los actores: ¿contrato } \\
\text { social o relación de fuerza? }\end{array}$ \\
\hline Socialización de los Sujetos & $\begin{array}{l}\text { - Importancia de la capacitación } \\
\text { (de adaptación social) } \\
\text { - Responsabilización: nivel de formalidad y grado de } \\
\text { creencia en la rendición de cuentas. /Concepciones } \\
\text { valorativas predominantes en la evaluación: ¿qué es un } \\
\text { buen producto, un buen resultado, un buen } \\
\text { funcionario?/ y percepción de los deberes y derechos de } \\
\text { las personas y de la empresa } \\
\text { Tipo de liderazgo de los portadores de cultura - análisis } \\
\text { de la especificidad de los Fundadores en Relación al } \\
\text { Contexto }\end{array}$ \\
\hline
\end{tabular}


Es pertinente señalar aún la afirmación de Schein (1999), referente a la metodología: la cultura no se captura a través de cuestionarios (o tan solo a partir de), sino que supone el recurso de grupo, el debate con el grupo, dado que la naturaleza de la cultural es grupal.

En relación a la elaboración de hipótesis, Thévenet (1993) postula la necesidad de trabajar la información relevada, en relación a algunas categorías de análisis que suelen ser más frecuentes, según su experiencia: la actividad, la persona, el ambiente, la vivencia o uso del tiempo, el futuro, el cambio, los servicios públicos, etc. Ilustra la actividad presentando tres instituciones financieras con percepciones diferentes del sentido de la actividad: predominio de la relación con el cliente y la obtención de lucro en el primero; visión de la actividad como tecnicidad financiera en el segundo; y percepción del banco como instrumento de apoyo financiero para una red de agentes económicos, industriales por ejemplo, en el tercero. En relación a la visión de los derechos y deberes de la persona frente a la empresa y viceversa, el autor ilustra dos situaciones: una, en donde el énfasis está colocado en el desarrollo y formación de la persona, en su promoción material y de sus habilidades, junto con la exigencia de un compromiso total; otra, en donde la empresa espera de sus empleados el respeto a las reglas y a la jerarquía, hay poca participación, pero cada uno dentro de la empresa, tiene la posibilidad de conservar grandes márgenes de libertad. El ambiente, también está diferenciado a través de la presentación de tres empresas con hipótesis de comportamiento o de percepción específicas: el ambiente como terreno a ser conquistado, dentro de la visión de la empresa como líder; el ambiente como conjunto de amenazas de las cuales es necesario protegerse; el ambiente como no existente, como simple prolongación o consecuencia de la actividad o producto-base.

Thévenet recomienda que la auditoria de cultura sea participativa. Una de las contribuciones más importantes e inmediatas que una auditoria puede ensayar (y que implica un cambio) es la posibilidad de que los agentes refuercen su capacidad de comprensión de la organización y el nivel de visiones y representaciones compartidas existentes.

\section{Gestión Cultural y Cambio}

En relación a la cuestión del trabajo cultural, Thévenet formula la siguiente proposición: mucho más estratégico (en el sentido productivo) que afrontar una cultura determinada, que procurar cambiarla o debilitarla, es utilizarla como recurso para el proyecto de cambio. La idea de cultura como recurso conlleva la 
necesidad de discernir al interior de la cultura, aquellos trazos positivos que pueden ser funcionales al cambio. La recomendación estratégica es procurar apoyarse en la cultura para el cambio. Esto no significa que la cultura sea inmutable. La cultura, según el autor, cambia y no cambia. Esto quiere decir que la cultura es de difícil manipulación en el sentido de un cambio directo. El autor señala que es extremadamente difícil diagnosticar un determinado estado $A$ de la cultura, en la medida en que esta no se evidencia claramente (especialmente cuando nos situamos desde el interior de la misma). A través de una metodología "indiciativa" e hipotética solo captamos señales.

Por ende, es mucho más difícil afirmar que con el proyecto $x$ podremos llevar a la cultura del estado $A$ hacia el $B$. La cultura, según Thévenet, cambia a largo plazo, siempre cambia en función del proyecto de empresa, pero este cambio es indeterminado, en el sentido que tanto puede ir hacia $B$, como para $C$ o $D$. Dada esta dificultad de lidiar directamente con la cultura, apuntando al cambio, el autor plantea la necesidad de captar los aspectos positivos de un trazo cultural, que pueden ayudar al cambio, o que pueden ser movilizados positivamente al enfrentar un problema determinado. La cuestión es más compleja de lo que se supone, dado que un mismo trazo cultural puede contener aspectos positivos y negativos desde la perspectiva del abordaje de una situación problemática. En este caso, lo más estratégico es fortalecer los aspectos positivos, de modo que potencialicen la perspectiva de cambio, debilitando simultáneamente los aspectos negativos. Es conocido el ejemplo de la autonomía médica como trazo cultural, que contiene una positividad desde el punto de vista de una mejor adaptación de sus productos y de un mayor dinamismo, y una negatividad desde el punto de vista de la dificultad de evaluación del trabajo médico. Un proyecto que apunte a una mayor eficiencia y competitividad, tendría que apoyarse en el principio de autonomía de los procesos de producción y de la centralidad médica, promoviendo la participación privilegiada del recurso médico como requisito, y negociando la responsabilización, de modo de debilitar paulatinamente la dificultad del control del trabajo médico.

La visión planteada aquí es más enfática aún: la idea de cultura como recurso, se centra más en el discernimiento de los valores clave relacionados con un problema determinado que es importante fortalecer, para favorecer la ingerencia positiva sobre el mismo. La auditoría de cultura ayudaría a esta tarea de discernimiento. De esta manera, la cuestión de la cultura pasa a formar parte del mundo operacional del enfrentamiento de problemas. La relación cultura-problemas pasa a un primer plano. La cultura deja de ser vista tan sólo como obstáculo, para ser visualizada como recurso. Una recomendación simple del modelo de análisis de Thévenet que debe destacarse por ser de gran valor, es la estrategia de procurar actuar siempre sobre lo que es más fácil. 
Dos posibilidades se abren inicialmente al abordaje cultural como recurso: la adaptación de los proyectos organizacionales, su modulación o regulación, en función de la cultura (en este caso, la cultura actúa como factor de condicionamiento de la viabilidad operacional de los proyectos, como factor limitante); y el empleo de valores clave de la cultura que pueden potencializar un proyecto de cambio, lo cual implica comunicar sobre cultura, reflotando y explorando propositivamente el mensaje profundo de los buenos valores culturales de la tradición compleja de una organización.

Se debe retomar el tema del cambio de la cultura, por ser una cuestión extremadamente importante. La difícil ingerencia sobre la cultura no puede significar el abandono de la reflexión sobre estrategias de cambio cultural. Desde nuestro punto de vista, que coincide en gran parte con el de Thévenet, una actuación directa sobre cultura es posible, aunque limitada. Puede dar frutos a largo plazo a través de la teoría y del entrenamiento. Este factor, largamente defendido por Matus, como la capacidad de cambiar estructuras mentales, es sin duda de singular importancia. Por ende, el cambio cultural puede acaecer como resultado de un abordaje indirecto, correspondiente a la implantación progresiva y negociada de un proyecto gerencial que se apoye en la democratización de las estructuras de poder, en el fortalecimiento de la comunicación interna, y en el desarrollo de formas de evaluación y de rendición de cuentas. Esto quiere decir que el montaje de sistemas gerenciales, como agrupamientos, puede actuar retrospectivamente sobre las reglas de juego organizacional y sus bases culturales, contribuyendo a cambiarlas, a pesar de la imprecisión de los plazos. Alcanzar nuevos resultados positivos al enfrentar los problemas derivados de una mejora de la gestión, puede cristalizar nuevas representaciones culturales en relación a las reglas organizacionales.

Dada la imposibilidad de una fórmula de cambio cultural, lo que se propone es algo coherente con el principio habermasiano de la correlación entre el mundo de la vida y el accionar comunicativo. La apertura de canales de comunicación ampliada, propiciados por reformulaciones gerenciales, crea las condiciones y la oportunidad para el cuestionamiento cultural y su reformulación, de ser necesario. En este sentido, las formas de tomar el control deben ser consensuadas colectivamente bajo el supuesto de que a lo que se apunta es a una mayor transparencia y participación. Más comunicación es la estrategia general de cambio cultural, dado que la comunicación y la cultura se interrelacionan constantemente, una depende de la otra.

Afirmamos anteriormente que de cualquier modo la cultura cambia en función del proyecto de empresa. Esto quiere decir, entre otras cosas, que habría una determinada relación dialéctica entre cultura y tecnologías, según la cual la evolución de tecnologías podría hacer caducar determinados valores 
culturales y nuevos valores culturales pueden ayudar a desatar el surgimiento de tecnologías (Habermas, 1997). Este es más un argumento a favor de una visión más pragmática de la cultura, que presenta una evolución inexorable, aunque indeterminada, inducida por la propia razón técnica. Esta evolución nunca es radical, en el sentido de lo nuevo substituyendo a lo viejo. La cultura presenta incoherencias, trazos a veces contradictorios o diferentes, conviviendo en una tensión dialéctica, algunos perdiendo consistencia, otros en cierne anunciando su expansión. Apoyar el cambio cultural supone un rodeo estratégico caracterizado por el intento de reforzar lo nuevo que surge a partir de lo viejo. Es diferente a la negación pura y simple. Es buscar acompañar el cambio cultural desde el interior de la cultura. Si elementos del ambiente externo y la tecnología contribuyen para inducir evoluciones culturales, esas evoluciones respetan, inspirados en Maturana (1998), el determinismo de la propia cultura, su condición profunda de saber legitimado por la comunicación.

Un aspecto fundamental en la creación de bases para el cambio cultural es el tipo de liderazgo. Pensar un liderazgo comunicativo implica ver el liderazgo ya no vinculado a la supervisión, sino a la viabilización de los procesos de interacción necesarios para el desarrollo de la organización. Este liderazgo, definido a grandes rasgos por Crozier \& Sérieyx (1994) y Covey (1994), debería ser un liderazgo preocupado con la motivación de los agentes, con capacidad de negociación dentro de la línea de "ganar-ganar", un liderazgo capaz de incentivar la participación, capaz de promover intercambios entre los agentes, un liderazgo con visión estratégica de los grandes objetivos, proactivo, con cualidades humanas destacadas en el campo de la socialización y de la comunicación, etc. La capacidad de movilización y de integración social son piezas clave de una propuesta de liderazgo constructivo. La preocupación por el liderazgo conforma un área fuertemente vinculada a la constitución de la cultura, según Thévenet y Shein.

Pettigrew (1996), en el trabajo ¿La Cultura de las Organizaciones es Administrable?, confirma la importancia del liderazgo en la cambio cultural y sustenta que el cambio es difícil, pero posible. Entre los factores que facilitarían ese cambio el autor destaca: el cambio de creencias en la administración central; un contexto externo favorable, receptivo al cambio; la creación de espacios que favorezcan la transformación de una situación de divisionismo en la administración central en una condición de mayor cohesión; la implementación de cambios estructurales más o menos drásticos con posterioridad a los cambios en las creencias, para reforzarlos, y la utilización de sistemas de premiación de la organización para fortalecer la tendencia general; un aprovechamiento inteligente de las situaciones de crisis importante; el uso intensivo de la comunicación, a través de la exploración de modelos de desempeño y búsqueda de una profundización de los mensajes valorativos del cambio, priorizando el entrenamiento y desarrollo del personal. 
Concluiremos este debate sobre el cambio cultural con Schein (1999). En base a los trabajos de Kurt Lewin, Schein explora un mecanismo de naturaleza psicológica inherente al cambio, planteándolo como un aprendizaje. Para el autor, el cambio es transformador porque es preciso desprenderse de alguna cosa antes de aprender algo de nuevo. La motivación para desaprender y aprender algo nuevo surge de la percepción de que si las cosas continuaran del modo que están, los objetivos no serán alcanzados. Esto genera ansiedad por la supervivencia (por la culpa). Pero, la percepción de lo que puede estar involucrado en el proceso de aprendizaje causa "ansiedad del aprendizaje", dado que las personas pueden tornarse temporalmente incompetentes y perder su lugar en el grupo al hacer las cosas de otra manera. Para que ocurra el cambio, la ansiedad por la supervivencia debe ser mayor que la del aprendizaje. Esto se consigue a través de la reducción de esta última, proporcionándole al aprendiz la seguridad psicológica necesaria.

El abordaje del cambio cultural pone en juego la cuestión de la indeterminación. Si la cultura cambia, no se sabe con certeza hacia donde. Esta idea es un cuestionamiento importante al raciocinio de la planificación estratégica y de la calidad total. Aumentar la indeterminación del abordaje cultural en los enfoques racionalistas, puede significar la posibilidad de un gran enriquecimiento en el campo gerencial, a nivel explicativo y a nivel de la creación de posibilidades de intervención práctica. En sí, el abordaje de la cultura puede ayudar a explicar eventuales fracasos de los métodos que presuponen una previsibilidad elevada. Puede ayudar también a modelar proyectos elaborados en base a los grandes enfoques gerenciales. Nos enseña algo de humildad.

\section{Cultura y Poder}

Fleury \& Fischer (1996) plantean la relación entre poder y cultura. Para ellos, el poder moldea la cultura, sanciona la cultura permitida y puede transformar la cultura en encubrimiento y dominación, en ideología. Esta es una cuestión que no podemos eludir aquí; cuestiona la visión de la cultura como conjunto compartido de representaciones sociales. Los autores, sin embargo, admiten una doble posibilidad: la cultura como conjunto legítimo de valores y la cultura como dominación.

Este análisis realizado desde la perspectiva del poder como medio estratégico, nos obliga a una precisión conceptual del significado de compartir. Cultura en el sentido de compartir corresponde a un acuerdo circunstancial, a un acierto procesal, que no puede desconsiderar las restricciones objetivas de las temáticas representadas por los medios de regulación formal: el dinero y el poder. 
La cultura como valores y configuraciones compartidos es, por otro lado, una posibilidad, no un dato inexorable. Al igual que Thévenet, hablamos de cultura fuerte y débil. La auditoría de cultura tiene en el diagnóstico de su "fortaleza" un desafió instrumental. Una cultura fuerte es una cultura constituida en términos ideales, como un conjunto legítimo de valores, capaz de regular positivamente una organización, sobre todo cuando fracasan los mecanismos de regulación burocrática. Pero, una cultura fuerte es una posibilidad, con variaciones. Una cultura débil, por el contrario, es un tipo de cultura con baja capacidad de legitimación. Correspondería a una situación de fragmentación y de debilitamiento de los sistemas de ideas en tanto factores de regulación/legitimación. En este caso, la integración de la acción se daría por una vía plenamente estratégica.

Lo que es típico de una cultura fuerte es, por ende, el acto de compartir. Si debemos tener en cuenta el fenómeno del poder, lo más pragmático es debilitar nuestras posiciones y considerar la cultura como una metáfora organizacional entre otras, que se integran o no entre sí. Considerar la cultura como ideología, en el sentido de una cultura débil, no parece el camino más correcto. El concepto de cultura débil no es coherente con la visión moderna de cultura.

Habermas (1995), en una entrevista concedida a la Folha de São Paulo, hace una interesante distinción entre un sistema normativo factible y un sistema normativo válido, entre factibilidad y validez. Un sistema normativo, para él, puede ser legal y legítimo, o sea, factible, sin ser válido (está refiriéndose a los dispositivos normativos de orden nazi). El carácter de validez estaría dado por la participación del mayor número de agentes sociales en la génesis del orden normativo. Dispositivos relativos a los judíos no contaron, sin duda, con el apoyo de la población respectiva, lo que les resta validez.

En esta línea de pensamiento, podemos precisar con mayor claridad el concepto de acuerdo circunstancial o posible, inherente al hecho mismo de compartir referencias sociales como base de la cultura, como un sistema de legitimación factible, no necesariamente válido, o en camino a la validez. ¿Es posible hablar de cultura factible y cultura válida? ¿Algún tipo de cultura es completamente válida? ¿La validez es tan sólo una cuestión de orientación ideal, posible solamente en una situación de habla ideal?

Hablamos de cultura como cultura factible, con una mayor o menor orientación hacia la validez. Dado nuestro orden social, no existe una cultura completamente válida. La cultura es una forma de comprensión organizacional, entre otras, capaz de explicar o no situaciones concretas en relación a la dependencia de la especificidad y, definitivamente, del nivel de legitimación del conjunto cultural. Si es una metáfora organizacional posible, la cultura fuerte es también una proposición, que se fundamenta en un programa deliberado que apunta a un tipo de organización cuya dinámica teleológica obedece a los designios nor- 
mativos que se cristalizan en el cruzamiento con el mundo de la vida de los actores organizacionales.

Hablar de cultura, de este modo, implica considerar los procesos de cristalización de configuraciones simbólicas vinculadas comunicativamente. La lógica de la cultura no es la lógica de la integración típica de los sistemas de acción racional. La cultura se relaciona, sin embargo, con esos sistemas. El tipo de cultura que corresponde a la ideología forma parte del proceso que Habermas (1997) denomina como colonización del mundo de la vida por el sistema. Aquí no hay asimilación por parte del mundo de la vida de los actores de una lógica sistémica. Hay una invasión de lógicas. Por el contrario, se pretende que los mecanismos de acción racional pasen a obedecer a los imperativos del mundo de la vida. Esto supone una inversión del orden de importancia de los tres medios que regirían el orden social: el poder, el dinero y la solidaridad, en favor de la última.

\section{Evolución Cultural y Gestión Estratégica}

En el capítulo 2, presentamos las premisas generales, de orden teóricoconceptual del enfoque de la Démarche Stratégique. Estas ayudan a entender el tipo de movimiento de evolución cultural que el enfoque pretende concretizar. Crémadez \& Grateau (1992; 1997), haciendo una lectura de las características de las organizaciones profesionales de salud, en los modelos de Mintzberg (1982), definen las características del patrón tradicional de identidad hospitalaria, de las cuales presentaremos sintéticamente algunas de ellas: incremento de toma de decisiones; atomización profesional (jerarquías profesionales rígidas en disputa); falta de articulación de las especialidades; descentralización acentuada del poder, estructura organizacional achatada; doble comando: administrativo y asistencial; el tabú de la incompetencia del otro (escasa valorización de la evaluación y de la gestión); visión funcional del usuario y poca apertura hacia el ambiente externo; redes relacionales espontáneas, basadas en las identidades creadas en los procesos de formación/socialización anteriores; estilo liberal de la profesión.

Si bien los autores reconocen la presencia de este patrón tradicional, por otra parte también distinguen una crisis paradigmática de la medicina, del servicio público y de la formación profesional, que señala el surgimiento de características socioculturales contradictorias con aquel patrón. Ellos advierten nuevos trazos, tales como: una demanda creciente de gestión producto de la concentración tecnológica en grandes burocracias hospitalarias, que limita la concepción de medicina liberal; un crecimiento de la importancia de la racionalidad económica por una 
mayor interpenetración de lo técnico con lo tecnológico; la necesidad de un enfoque de red, de colaboraciones externas, de trabajo en equipo, que cuestiona la fragmentación de las especialidades y de las instituciones; un mayor grado de interdependencia entre sectores y servicios en la fundamentación de diagnósticos y conductas terapéuticas; una mayor concentración de diversos especialistas en torno a nuevas tecnologías de uso común; nuevas modalidades de atención que agrupan diversas especialidades favoreciendo la comunicación entre si, etc. De este modo, los autores reconocen un cuadro cultural contradictorio, en transición.

Dentro de este contexto, la gestión estratégica actuaría como un refuerzo indirecto de los aspectos positivos de aquellos trazos culturales en evolución, trazos aún "en cierne", a través de los siguientes elementos analizados: refuerzo de la capacidad explícita en la determinación de prioridades, dentro de una perspectiva de totalización de la organización que supere el incrementalismo; visión predominante de la perspectiva de la contribución y no de la atribución: la visión de costo-oportunidad obliga a comparar los beneficios alternativos de una aplicación, priorizándose los usos de mayor beneficio para la organización como un todo, en detrimento del negociado indiscriminado de recursos; sentido de red, de la creación de transversalidades; formalización de la planificación y de la evaluación, contribuyendo a una clara apropiación de la organización por parte de los actores (a través de un lenguaje común); creación de lugares de encuentro, de comunicación; mayor relacionamiento entre gestores y operadores; énfasis en la negociación, en la evaluación de la capacidad global de los servicios frente a los usuarios; fortalecimiento del sentido colectivo de la actividad.

\section{El Liderazgo Comunicativo}

Crozier \& Sérieyx reúnen, en el libro Du Management Panique à l'Entreprise du XXI Siécle (1994) la síntesis de los trabajos de la conferencia internacional "En busca de la organización del mañana”, organizada por el grupo canadiense Innovación. En esta conferencia que contó con grandes pensadores del área del gerenciamiento, se constata críticamente los contratiempos con que se depara esta área. Los autores participantes defienden profundos cambios en el estilo de gerenciamiento y en las formas de organización del trabajo, de modo que las instituciones puedan adaptarse mejor a los desafíos del futuro. Un tema recurrente en el texto, es la necesidad de un nuevo patrón de liderazgo, cuyo surgimiento representaría una de las condiciones favorables al cambio organizacional deseado.

El panelista que da cuerpo a la discusión sobre liderazgo en el libro mencionado es Warren Bennis, tradicional especialista en el tema. 
Dentro de la conceptualización del liderazgo, Bennis afirma que el poder debe ser la energía fundamental necesaria para lanzar y sustentar una acción o, dicho de otro modo, la capacidad para traducir la intención en realidad y de sustentar la acción. El liderazgo es el uso juicioso de este poder.

Un liderazgo eficaz y bien ejercido podría lograr que las organizaciones pasen de un estado presente a un estado futuro, creen perspectivas potenciales y inspiren en los trabajadores la voluntad de cambiar e introducir nuevas filosofías y estrategias, de modo la movilizar y focalizar las energías y los recursos existentes.

Las organizaciones sufrirían de una saturación de gestión "procedimental" y de una ausencia evidente de liderazgo. En función de esta ausencia, las organizaciones habrían concentrado sus energías en los instrumentos de gestión, creando muchas veces monstruos burocráticos.

Para Bennis habría una diferencia básica entre el gerente y el líder: el liderazgo sabe lo que es necesario hacer, mientras que el gestor sabe como hacerlo bien.

El autor relaciona diferentes roles esenciales para distinguir la gestión del liderazgo. La gestión es definida como hacer bien las cosas, el liderazgo como hacer lo acertado. La gestión cuidaría de la administración, el líder de la innovación; la gestión del mantenimiento, el liderazgo del desarrollo; la gestión se centraría en el sistema y la estructura, la liderazgo en las personas; la gestión pensaría a corto plazo, el liderazgo a largo plazo; la gestión se preocuparía con el cómo, el liderazgo con el qué y el porqué; la gestión trabajaría con la obediencia, el liderazgo con el compromiso; la gestión con el control, el liderazgo con el poder. El líder se preocuparía por canalizar la atención sobre una visión, explorando los recursos emocionales y espirituales de la organización, sus valores, su compromiso y sus aspiraciones; mientras el gerente exploraría los recursos físicos de la organización, su capital, sus capacidades, sus materias primas y su tecnología (Figura 2)

Figura 2 - Distinción entre gestión y liderazgo.

\begin{tabular}{|l|l|}
\hline Gestión (hacer bien las cosas) & Liderazgo (hacer lo correcto) \\
\hline$\cdot$ administración & - mantenimiento \\
- sistema /estructura & - corto plazo \\
$\cdot$ ¿cómo? & - obediencia \\
$\cdot$ control & - innovación \\
$\cdot$ desarrollo & - gente/confianza \\
$\cdot$ largo plazo & ¿qué? ¿por qué? \\
- compromiso & - poder \\
\hline
\end{tabular}


El líder estaría centrado exclusivamente en el aspecto humano, mientras que el gerente no, sin embargo el secreto estaría, tal vez, en un equilibrio entre gestión y liderazgo, variando esta dosis de acuerdo a las circunstancias.

El verdadero líder incentivaría y valorizaría una práctica mucho más direccionada hacia proyectos dinámicos que hacia comités. Para Bennis (2001), los equipos de estos proyectos se caracterizarían por privilegiar al cliente, por poseer objetivos precisos y trabajar en un clima de autonomía, de apertura hacia el exterior y de responsabilidad. Dentro de una perspectiva de refuerzo del equipo o del grupo, el liderazgo parecería ser más la exploración de las capacidades presentes en una mayoría que el poner en evidencia las capacidades de una minoría.

El liderazgo dependería del aprendizaje y podría ser visto como un proceso profundamente humano, marcado por ensayos y errores, victorias y derrotas, cálculos e imprevistos, intuición y perspicacia. Aprender a ser un líder depende de los valores fundamentales y de los modelos de roles provistos por la infancia y por la adolescencia, pero todo el resto se adquiere con el transcurso de los años y de las experiencias personales (Bennis \& Nanus apud Crozier \& Seriéis, 1994).

En este proceso de aprendizaje, el desarrollo del liderazgo se inspira en modelos que "dan el ejemplo". Bennis (2001) afirma que, si desde el comienzo tenemos líderes fuertes, crearán actitudes y un ambiente en el cual el liderazgo podrá desarrollarse. Esta sería una de las curiosas paradojas del éxito y del fracaso: el fracaso lleva a un mayor fracaso y el éxito a un mayor éxito.

El liderazgo, sin embargo, no se relacionaría con la posición jerárquica o con la función ejercida; en las organizaciones modernas, cada trabajador debería ser el líder de alguien, sobro todo de sí mismo. Esa comprensión coincide con el cuestionamiento teórico realizado por el autor a cinco grandes mitos: el liderazgo es un don raro; los líderes son natos, no se hacen; son carismáticos; sólo existe liderazgo en la escala más alto de la organización (o más importante); el líder controla, dirige, estimula, manipula (Bennis \& Nanas, 1985). Esto contradice la utilización de una semántica por parte del autor con relación a líderes fuertes y vigorosos. Por ejemplo, la afirmación categórica de que todo gran grupo tiene un líder vigoroso (Bennis \& Biederman, 1999).

Bennis llegó a la conclusión de que las cualidades de un buen líder (o de un "liderazgo transformador") se corresponde frecuentemente con aquello que los empleados esperan de él. Estos esperarían que sus líderes les indiquen una dirección, les inspiren confianza y les ofrezcan esperanza. Para responder a las expectativas de los empleados, los líderes tendrían que ser resolutivos, tener un buen caracter y ser optimistas o estar convencidos de su eficacia personal.

Luego de analizar los trazos de los "grandes líderes", Bennis identifica los requisitos de un líder en orden de prioridad: comunicar su opinión sobre su 
visión de la organización; articular comprensión y desempeño; estar frecuentemente en contacto con sus empleados; poner énfasis en la ética; planificar la sucesión administrativa; comunicarse regularmente con los clientes; despedir empleados cuyo rendimiento es insatisfatorio; recompensar la lealtad; tomar todas las decisiones importantes; adoptar una posición conservadora (en el plano de las costumbres y de la conducta jerárquica).

Enfatiza especialmente la necesidad de conjugar capacidad visionaria y capacidad gerencial y la capacidad de obtener, de presentar resultados (Bennis, 2001). El autor señala también dos características que se repiten en los líderes que enfrentan fracasos: Una combinación de falta de perspectiva, arrogancia y el no saber escuchar, como así también la falta de inteligencia emocional o interpersonal (Bennis, 2001).

La primera calidad positiva resaltada corresponde a la determinación por buscar y alcanzar sus objetivos, para formular y luchar por una visión. Para Crozier \& Seriéis, frente a los grandes desafíos, la visión es la que despierta la capacidad colectiva. Los líderes, según Bennis, generan la movilización gracias a una potente visión capaz de provocar el descubrimiento de otros horizontes que les eran desconocidos hasta el momento.

Determinar y marcar una dirección correspondería también a adoptar un punto de vista, compartiendo "su sueño" con el conjunto de la organización para que esta pueda comprometerse por un largo tiempo. Para obtener esa adhesión el líder debería ser capaz de lograr la aceptación de la argumentación bien fundada sobre su visión.

Bennis (2001) destaca, en lo relativo a esta visión, la necesidad de desarrollar una perspectiva, señalando que es fundamental colocarse un paso adelante y tener alguna perspectiva sobre lo que está sucediendo, especialmente cuando los escenarios de las empresas se tornan más complejos.

En relación a la visión, que depende del desarrollo de la perspectiva y la pasión, el autor plantea además como factor fundamental del ejercicio del liderazgo, la capacidad de atribuir a la acción un significado particular. En otras palabras, es necesario percibir la existencia de algún propósito de trabajo, que está por encima de las personas. Este hecho supone que el ambiente sienta que está realizando un trabajo que marca una diferencia.

Para Crozier \& Sérieyx, interpretando a Bennis, la motivación sería un concepto infantilizante, que no tendría ningún efecto sobre las personas altamente escolarizadas; si las personas están movilizadas, ellas se motivarían por sí mismas. Esto daría a entender que la motivación no es inducida externamente, sino que surge como resultado personal cuando es movilizada a participar de los destinos de la organización y a desarrollar sus potencialidades individuales. 
Para movilizar la inteligencia de los individuos, y no sólo su obediencia, sería necesario un elemento nuevo, no previsto hasta entonces por la gestión de recursos humanos y la administración tradicional: que el empleado lo quiera auténticamente, personalmente. Y para esto, le son necesarias razones válidas desde su punto de vista. Ni la manipulación, ni la seducción, ni el terror (amenaza de recortes) han tenido éxito en este campo, como se puede apreciar perfectamente en nuestros días (Crozier \& Serieyx, 1994).

El mejor camino hacia la movilización libremente consensuada, pasaría por la comunicación; en una época donde el poder de la función se desgasta, la comunicación sería un elemento esencial del liderazgo, y se constituiría en un elemento integrador de prácticas y de nuevos comportamientos en la gestión. Significaría convencer a los demás de la justicia de su visión.

Para que la movilización en torno a una visión pueda ser efectiva, el líder debería además inspirar confianza, la cual estaría relacionada no sólo a la ejemplaridad, sino también a la constancia y a la coherencia. El mejor modo de demostrar coherencia, más allá de su propio comportamiento, sería pasar de las intenciones a los hechos concretos, modificando, por ejemplo, los procesos de gestión y la estructura organizacional (Bennis apud Crozier \& Sérieyx, 1994).

La confianza resultaría de un equilibrio sutil entre tres elementos fundamentales: audacia, competencia e integridad. El liderazgo valorizado, seria aquel que disipa las sorpresas, que está impregnado de una visión que emana por sus poros y estaría relacionado a una visión optimista y motivante del futuro.

El liderazgo transformador de Bennis, sería como una puesta en escena en tres actos: el primer acto correspondería a reconocer la necesidad de revitalización de la organización; el segundo seria crear una nueva visión; y el tercero, institucionalizar el cambio.

Esa visión da una interpretación un tanto personalista al liderazgo, al depositar en la persona del líder, plenas posibilidades de conducir al conjunto organizacional hacia el cambio, en detrimento aparente de una construcción colectiva. Las condiciones resultantes de restricciones sistémicas y de complejas interacciones entre los sujetos organizacionales quedan sometidas a su interpretación y dirección.

En términos críticos, podemos sostener que los aspectos comunicativos sobradamente presentes en el modelo de Bennis, pueden ser empobrecidos por la búsqueda de la adhesión del colectivo a una visión predeterminada por el líder, lo cual daría a este privilegio de la formulación y comunicación de la visión, un carácter un tanto inductista, estratégico. En realidad, observamos en el autor algunas incoherencias: además de las ya mencionadas, observamos un cierto énfasis en la necesidad del modelo jerárquico (aunque adaptable, flexible) 
y afirmaciones de índole estratégica como, por ejemplo, que la creatividad de un gran grupo supone la presencia o la invención de un enemigo externo (Bennis \& Bicderman, 1999).

Sin embargo, en nuestra visión, su concepción tiene aspectos extremadamente relevantes ha ser resaltados. Merece destacarse, en la visión de Bennis, la valorización del trabajo en equipo, la capacidad de precisar los objetivos de los colectivos, la búsqueda por parte de los mismos de autonomía y de apertura hacia el exterior, requisitos que, a nuestro modo de ver, contribuyen a la socialización y la responsabilización de los individuos. Es extremadamente pertinente, también, su visión del liderazgo, el cual depende de un proceso de aprendizaje que se realiza a través de la experiencia histórica y personal de cada uno, en la interacción con los otros. La valorización del aspecto humano por sobre el tecnológico y procedimental, contribuye a un liderazgo no manipulador, sino que busca agregar los valores y motivaciones fundamentales de cada individuo que integra la organización. A diferencia de la lógica del control inherente a la gestión tecnoburocrática clásica, el fenómeno del liderazgo actuaría como el ejercicio del poder en función del desarrollo de dinámicas de equipo y de interacción disciplinaria que favorecerían la innovación y el cambio. La promoción del liderazgo dependería en gran medida de un tipo de aprendizaje caracterizado por el tránsito cultural entre disciplinas diferenciadas e informaciones aparentemente distantes. Esta línea de pensamiento refuerza, por lo tanto, la idea del liderazgo como proceso de aprendizaje y como instancia de movilización de las capacidades individuales e intersubjetivas de la organización. Es importante remarcar aquí, que el autor opina que la conquista de ventajas competitivas depende, en gran medida, de la creación de un clima abierto de interacción de ideas, de la capacidad para crear un modelo organizacional y la arquitectura social que permitan generar capital intelectual, de la posibilidad de liberar el poder cerebral de cada persona de un equipo (Bennis, 2001).

La relevancia dada a las personas, en la gestión, pone en segundo plano el aspecto de mecanismo. Realza los valores presentes en los individuos, valoriza la autonomía, la responsabilidad y la apertura de la organización hacia su entorno. Se resaltan los aspectos éticos, de carácter y la capacidad del líder para movilizar al equipo. Capacidad del líder para la movilización e integración que destaca la inversión en la comunicación, como forma de "argumentar" su visión y sus actos.

Estos son elementos, que a nuestro modo de ver, resaltan aspectos capaces de construir una ética volcada hacia la comunicación y hacia la responsabilización con los objetivos de la misión organizacional. Sin embargo, un liderazgo que pretenda volcarse hacia la democratización de las decisiones y hacia el entendimiento intersubjetivo, más que argumentar su visión, necesita ofrecer a todos 
los involucrados en los procesos de trabajo de la organización, la posibilidad de la argumentación discursiva, y la toma de decisiones basadas en consensos derivados de estas.

La calidad de ser líder, en una reconstrucción volcada hacia el diálogo, se relaciona fundamentalmente con su capacidad de movilizar los sujetos organizacionales y de promover la argumentación entre los sujetos sobre sus visiones de la misión, de los objetivos acciones necesarias para lograrlo. Este seria un liderazgo afirmado en la ética y en la capacidad de buscar el alcance de la misión a través de la capacidad cognitiva y relacional, fundada en la promoción de la integración de los sujetos a fin de lograr un adecuado desempeño organizacional. Este seria un liderazgo volcada hacia la responsabilización y hacia la socialización de los sujetos organizacionales.

Para Covey (1994), el rol del liderazgo es el sustrato básico sobre el cual estaría asentado el movimiento por la calidad total, y el alcance del éxito en su implementación estaría basado, más que en sus procedimientos, en la implementación de principios y prácticas esenciales, desarrollados en su libro Liderazgo Basado en Principios (1994). Los fundamentos del liderazgo estarían basados en la idea que la búsqueda de la calidad prioriza una orientación orientada hacia las necesidades y exigencias del cliente, y que la calidad como resultado o producto, es una función de la calidad, como proceso de producción. Esta última meta general de calidad dependería del grado de compromiso de los actores organizacionales derivado del ejercicio del liderazgo.

El requisito más importante para la "transformación del modo occidental de administrar" estaría en el principio de que "la tarea del administrador es liderar y no supervisar" (Deming apud Covey, 1994).

Si el modo tradicional de realizar administración percibiría a las personas como productos o "cosas", sería tarea de los líderes orientarse hacia la valorización de sus actitudes y valores básicos, despertando en ellas sus motivaciones intrínsecas y desarrollando sus capacidades, como ideas y creatividad, prestableciendo un liderazgo fundado en la delegación de poderes.

La realización de un cambio cultural profundo, para Covey (1994), partiría del cambio personal hacia el cambio organizacional. Un liderazgo proactivo, volcado hacia las personas, sus comportamientos e interacciones, partiría del compromiso con principios que serían "estables e inmutables", correspondientes al desarrollo de siete hábitos basados en los 14 principios de Deming, uno de los mayores ideólogos de la calidad.

El primer hábito se relacionaría a la proatividad. Significa la toma de iniciativa por parte de las personas, como respuesta a los estímulos externos, basada en el ejercicio de sus propios principios. Estas estarían menos sujetas al control de fuerzas y condicionamientos externos y asumirían su capacidad y responsabi- 
lidad para cambiar a sí mismas, al ambiente e influir sobre los otros. La proactividad estaría asentada en el hábito de tomar decisiones y en un accionar basado en principios y valores.

El hábito que focaliza la relación entre liderazgo y misión, representaría una mayor preocupación por al desarrollo de relacionamientos, que por la gerencia de equipamientos; por los valores y principios más que por las actividades; tendría más en cuenta la misión, los objetivos organizacionales y su dirección que los métodos, las técnicas y la velocidad. La declaración de la misión personal y organizacional seria su punto clave.

El tercer hábito se refiere al principio de administrar el tiempo y las prioridades en torno a roles y objetivos. Abarcaría el desarrollo de un cronograma de prioridades a partir de la evaluación de los objetivos personales y organizacionales. El desarrollo de la capacidad de la organización para la "calidad total", seria mayor cuando las actividades tienen un alto significado y prioridad para las personas.

Otro hábito, el cuarto, se basa en el principio del beneficio mutuo que defiende relacionamientos del tipo ganar-ganar entre todas las partes involucradas en cualquiera de los emprendimientos, aún entre los competidores, necesarios para alcanzar la eficacia a largo plazo.

El principio de la comunicación empática seria la base del hábito cinco: implicaría buscar comprender sinceramente a las otras personas, establecer una comunicación entre ellas, compartiendo no sólo palabras, ideas e informaciones sino también sentimientos, emociones y sensibilidad.

El hábito seis estaría relacionado con la cooperación creativa, donde los integrantes de la organización, al estar conscientes de las relaciones de interdependencia entre las partes, tendrían la posibilidad de generar creatividad, mejoras e innovación.

Por otro lado, el hábito siete "afine el instrumento" se refiere al principio de mejora continua. Las personas y las organizaciones poseerían cuatro grandes necesidades o características: 1) físicas o económicas; 2) intelectuales o psicológicas; 3) sociales o emocionales y 4) espirituales u holísticas. La capacidad de las personas para comprometerse con la mejora implicaría una inversión del liderazgo en el desarrollo de estas cuatro áreas, y resultaría en la "organización del aprendizaje, base de la mejora continua de sistemas, procesos y resultados".

Estos principios de Deming sistematizados por Covey, son afines con una perspectiva no personalista del liderazgo. Sus fundamentos armonizarían a priori con la noción de valores compartidos, entendimiento entre las personas y aprendizaje colectivo, y con la noción de que la coordinación de la acción debe implicar ganancias para todos los involucrados. 
Limerick, Passfield \& Cunnugton (1994), interpretando el paradigma de la organización que aprende, resumen con extremada claridad los trazos de un liderazgo comunicativo, cuando se refieren a uno de los mentores ideológicos del movimiento, Peter Senge: En una organización que aprende, el rol del liderazgo difiere dramáticamente de la visión del decisor carismático; es el responsable de construir organizaciones donde las personas están continuamente expandiendo sus capacidades para moldear el futuro, o sea, el liderazgo es responsable del aprendizaje.

Sustentando la defensa del cambio incremental (progresivo y basado en el aprendizaje colectivo) en oposición a la corriente del cambio transformacional (modificaciones más abruptas basadas en liderazgos fuertes), los autores cuestionan algunas creencias referentes al líder transformacional, tales como: son necesarios líderes fuertes para el cambio (no sólo buenos ejecutivos sino líderes fuertes); la imposibilidad de delegar funciones estratégicas a gerentes subordinados, como la definición de la misión principal, la definición de los valores de la corporación, la especificación de la demanda del ambiente deseable y, de las respuestas del sistema, etc.; la visión del líder como un sujeto solitario, capaz de movilizar emociones, absorbido por ideales, carismático.

La concepción de una organización en permanente proceso de aprendizaje de la experiencia, de ensayo y error, de generación de la información y de las capacidades necesarias para un cuestionamiento sistemático de su performance y para una evolución continua de sus habilidades, no se conjuga, según el autor, con una visión que plantea al liderazgo siempre en la cima de la institución.

Para Dionne \& Roger (1997), el verdadero estratega del siglo XXI, es aquel que concibe la organización como el conjunto de personas que la modelan, y que se asume como un negociador del cotidiano, capaz de incluir ese conjunto en un proceso de aprendizaje y de cambio permanentes. Dotado de una visión clara de su proyecto de empresa, este estratega debería ser capaz de animar su organización, compartiendo su visión y favoreciendo el libre desarrollo del potencial humano.

Peter Senge, ha cobrado notoriedad por sus análisis sobre el liderazgo. En El Nuevo Trabajo del Lider (Starkey, 1997), el autor caracteriza los requisitos del liderazgo de la organización que aprende, las nuevas habilidades que debería incorporar, refiriéndose además, a algunas herramientas de desarrollo del liderazgo.

El líder debería ser encarado, según el autor, como arquitecto, profesor y director. En el ejercicio del primer rol, el líder se involucra desde la arquitectura de los ideales y propósitos de la organización, y de la traducción práctica de las políticas y estrategias, construidas colectivamente. Si la responsabilidad fundamental del liderazgo se relaciona con la planificación, esto no significa que este acto sea solitario. El término construcción colectiva sugiere concebir el 
proceso de planificación de las políticas y estrategias como un proceso de aprendizaje organizacional ampliado. Citando a Mintzberg (1982), Senge asume que esta planificación no puede ser vista como un esquema racional, elaborado en el plano abstracto e implementado a todo el ámbito de la organización, sino como un fenómeno emergente. Organizaciones exitosas "fabrican su estrategia", una vez que logran estar continuamente aprendiendo de los constantes cambios de la condiciones de sus negocios, ponderando lo deseable y lo factible. El secreto no está en obtener la estrategia acertada, sino en promover el pensamiento estratégico. La elección de la acción individual es tan sólo una parte de la necesidad del creador de la política. Lo más importante es la necesidad de poder visualizar la complejidad y formular conceptos $\mathrm{y}$ visiones del mundo para lidiar con esa complejidad. Promover un ambiente de aprendizaje a través de la difusión del pensamiento estratégico seria una de las funciones esenciales del liderazgo.

El líder como profesor corresponde a la visión del mentor, del guía, del facilitador. Los objetivos fundamentales de este profesor serían poner en discusión y ayudar a reestructurar los modelos mentales y visiones de la realidad de las personas y promover el pensamiento sistémico, relacionado a las causas estructurales o profundas de los fenómenos.

El líder como director de las personas y de la misión organizacional es una instancia que se compenetra de los ideales de gran responsabilidad que caracterizan a una organización que aprende y que se coloca al servicio de los intereses superiores de la organización. El concepto de un liderazgo que presta servicios (servant leadership) es lo opuesto al liderazgo egocéntrico.

Entre las habilidades que el liderazgo debería desarrollar, Senge cita:

- La construcción de visiones compartidas, lo cual implica algunos requisitos: el líder debe saber comunicar su visión y pedir apoyo, en el sentido de corroborar si merece el compromiso de los otros y de cuestionar su punto de vista, asumiendo una construcción interactiva; las visiones personales deben ser estimuladas y no anuladas; la construcción de la visión es un proceso continuo, que no se deja aprehender por la figura de la "declaración de la misión" en reuniones especiales, sino que implica la difusión del pensamiento estratégico capaz de apoyar el cuestionamiento cotidiano de lo que realmente queremos conseguir en cada instancia práctica; el liderazgo debe poder combinar visiones extrínsecas (del tipo "derrotar al oponente") con visiones intrínsecas (crear un nuevo producto, un nuevo patrón de satisfacción de necesidades); el liderazgo debe saber distinguir visiones positivas (fundadas en aspiraciones) y negativas (basadas en el miedo), fortaleciendo las primeras. 
- Traer a la superficie y testar modelos mentales, lo cual implica: la posibilidad de percibir y cuestionar "saltos de abstracción" (que serían generalizaciones precipitadas realizadas a partir de determinados datos sin un testeo adequado de los mismos); equilibrar indagación y argumentación, asumiendo que las situaciones complejas exigen un aprendizaje cooperativo; distinguir la teoría comprometida (qué se debe hacer) de la teoría en uso, asumiendo que la distancia entre lo declarado y lo real en uso implícito, es crítica para el aprendizaje; reconocer y disipar rutinas defensivas, concebidas como acciones que previenen a las personas y unidades de vivenciar perturbaciones o amenazas y de identificar y modificar las causas de esas amenazas (Argyris, 1992).

- Desarrollar el pensamiento sistémico, que corresponde a: visualizar interrelaciones, no cosas, procesos, no fotos instantáneas; ir más allá de las acusaciones, asumiendo que el origen de las fallas no son las personas, sino los sistemas; concentrarse en la complejidad dinámica (saber relacionar causas y efectos distantes en el tiempo y espacio y distinguir consecuencias remotas) y no en la complejidad de detalles; concentrarse, en términos de la acción, en áreas de alta potencialidad; evitar soluciones sintomáticas.

- Crear una red de protección para la reflexión individual y colectiva, capaz de sustentar la posibilidad de innovación y de cambio. Aquí, la capacidad de garantizar un tiempo libre para la reflexión de los sujetos organizacionales es fundamental.

Senge, también, cita algunas herramientas de desarrollo del liderazgo que pasaron a ser relevantes dentro de las organizaciones que aprenden:

- El descubrimiento del prototipo de sistema predominante: Senge sustenta que habría una relación general precisa y más o menos recurrente de prototipos de sistema (estructuras sistémicas repetitivas o formas de comportamiento repetitivo que configuran patrones genéricos) y que la identificación del tipo característico de cada empresa en particular, es un ejercicio de análisis importante capaz de apuntar hacia cambios organizacionales significativos. A título de ilustrativo, señalaremos un prototipo bastante difundido que es el de la transferencia de responsabilidad, el cual lleva a postergar soluciones estructurales en pro de un tratamiento sintomático, que sólo profundiza a lo largo del tiempo la crisis de una organización, (para quien le interese profundizar el conocimiento de los prototipos, puede consultar La Quinta Disciplina, Senge, 1998).

- Definir dilemas estratégicos: este nivel del ejercicio se refiere a la capacidad de evocar los dilemas o de distinguir valores distintos y a veces aparentemente conflictivos por detrás de las decisiones (por ejemplo costo y calidad). El objetivo del ejercicio consiste en mapear donde los gerentes se ven 
(más cercanos a qué valor) y donde ven la organización, y en buscar una sinergia posible entre valores, mediante una simulación que implica usar un valor como contexto posible del otro, pensando en términos de secuencia y no de instantes, de modo dinámico, etc.

- La columna de la izquierda de Chris Argyris: es un ejercicio construido a partir de la elección de una situación específica, que configura una interacción con los otros que funciona mal, en el sentido de no generar un aprendizaje. De esta situación específica, cada participante registra lo dicho o declarado formalmente (en la columna de la derecha) y el modelo mental real (o nuestro diálogo interno) en la columna izquierda. La confrontación de los ejercicios genera un tipo de cuestionamiento que puede ayudar a mejorar las interacciones desde el punto de vista del aprendizaje. Esta herramienta ayudaría a identificar y cuestionar "saltos de abstracción" y a traer a la superficie y discutir críticamente las premisas de nuestras posiciones y comportamientos.

- Laboratorios de aprendizaje: Senge se refiere a la necesidad de combinar en estos laboratorios, temas profesionales con dinámicas interpersonales significativas, dado que el aprendizaje es un fenómeno individuo-individuo e individuo-sistema, y concede gran importancia al desarrollo de juegos de simulación de la dinámica de sistemas, que corresponden a ejercicios de prospectiva, y a determinados insights de estructuras profundas que causan problemas organizacionales (capacidad de problematización).

Concluiremos esta parte haciendo alusión a un autor nacional. Motta (1991) destaca tres dimensiones de habilidades y cualidades del liderazgo: organizacional, interpersonal e individual.

Sobre las habilidades organizacionales, el autor señala:

- El buen conocimiento de la misión y de los objetivos internos, para que estos puedan ser comunicados, y de las características del ámbito externo, de modo de facilitar la adaptación de la empresa a la realidad existente.

- La capacidad de un continuo descubrimiento y procesamiento de problemas y soluciones.

- La capacidad de articular, agregar y procesar continuamente ideas y alternativas de acción para redefinir el sistema de autoridad y de responsabilidad, a partir de valores compartidos

- La capacidad de tener una visión (intuición sobre el futuro) y de orientarse en términos prospectivos.

En relación a las habilidades interpersonales, el autor destaca:

- La capacidad de aprender a aceptar a las personas como realmente son y de reconocer el valor positivo que ellas tienen. 
- Estimular el contacto directo permanente con las personas, aumentando la confianza en las mismas.

- Desarrollar las capacidades de comunicación y de negociación, reforzando compartir la información, la interacción permanente y la participación.

- Practicar un tipo de gestión ambulante, diminuyendo la distancia social.

En relación a las habilidades individuales, el autor considera que deben ser encaradas de manera flexible, por ser factibles de ser adquiridas o no necesariamente innatas. Destaca además, algunas habilidades básicas como: el buen conocimiento de sí mismo (antes que nada), de sus potencialidades y limitaciones; la iniciativa; el optimismo; la persistencia; la integridad y la autenticidad. Reforzando la dimensión subjetiva, el autor se detiene en la importancia de lo ilógico y de la intuición en la gestión administrativa, que explican el carácter a veces poco coherente y racional de la misma. Plantea que la intuición combina elementos de racionalidad formal e informal y que se apoya fuertemente en la experiencia acumulada por el liderazgo. Esta importancia otorgada a la dimensión subjetiva no formal o racional del liderazgo actúa aquí como un argumento importante para no omitir la naturaleza individual de la misma.

Este autor sintetiza las cualidades del liderazgo, a través de la siguiente figura:

Figura 3 - Mitos y realidades sobre el liderazgo.

\begin{tabular}{|c|c|}
\hline Liderazgo no es & Liderazgo es \\
\hline 1. Magia o misterio. & 1. Habilidad humana y gerencial. \\
\hline 2. Propiedad de personas eminentes. & 2. Alcanzable por personas comunes. \\
\hline $\begin{array}{l}\text { 3. Fruto de cualidades especiales } \\
\text { innatas. }\end{array}$ & $\begin{array}{l}\text { 3. Producto de habilidades y } \\
\text { conocimientos aprendidos. }\end{array}$ \\
\hline $\begin{array}{l}\text { 4. Panacea para la solución de todos los } \\
\text { problemas. }\end{array}$ & $\begin{array}{l}\text { 4. Forma de comunicación y articulación } \\
\text { de una misión y de futuros alternativos. }\end{array}$ \\
\hline $\begin{array}{l}\text { 5. Uso del poder personal para } \\
\text { garantizar seguidores o propósitos } \\
\text { personales. }\end{array}$ & $\begin{array}{l}\text { 5. Uso del poder existente para garantizar } \\
\text { el alcance de propósitos comunes. }\end{array}$ \\
\hline
\end{tabular}

Fuente: Motta, 1991.

De estas líneas se desprende que el nuevo paradigma de liderazgo acentúa la necesidad de que este tenga una clara visión estratégica y atributos de comunicación y de negociación que lo faculten a actuar más como factor de movilización que de imposición. Como insinuamos anteriormente, es importante resaltar, que esta disponibilidad de una visión privilegiada para el cambio (como 
varios autores culturalistas reafirman) no puede ser entendida como una visión personalista y manipuladora del liderazgo, sino como una mirada puesta al servicio de la argumentación crítica (más allá de la persuasión de base emocional) y construida en base a la escucha activa de los otros y, principalmente, de la cultura.

\section{Referencias Bibliográficas}

ARGYRIS, C. Enfrentando Defesas Empresariais: facilitando o aprendizado organizacional. Rio de Janeiro: Campus, 1992.

BENNIS, W. A Nova liderança. In: Grupo HSM Management (Orgs.) Liderança e Gestão de Pessoas: autores e conceitos imprescindiveis. São Paulo: Publifolha, 2001.

BENNIS, W. \& BIEDERMAN, P. W. Os Gênios da Organização: as forças que impulsionam a criatividade das equipes de sucesso. Rio de Janeiro: Campus, 1999.

BENNIS, W. \& NANNUS, B. Diriger. Paris: InterÉditions, 1985.

COVEY, S. R. Liderança Baseada em Princípios. Rio de Janeiro: Campus, 1994.

CRÉMADEZ, M. \& GRATEAU, F. Le Management Stratégique Hospitalier. Paris: InterÉditions, [1992] 1997.

CROZIER, M. L'Entreprise à l'Ecoute. Paris: InterÉditions, 1989.

CROZIER, M. \& FRIEDBERG, E. L'Acteur et le Système. Paris: Éditions du Seuil, 1977.

CROZIER, M. \& SÉRIEYX, H. Du Management Panique à l'Entreprise du XXI Siècle. Quebec: Maxima, 1994.

DIONNE, P. \& ROGER, J. Le Stratège du XXI Siècle: vers une organization apprenante. Montreal/Paris/Casablanca: Gaetan Morin, 1997.

FISCHER, R. M. \& FLEURY, M .T. (Orgs.) Cultura e Poder nas Organizações. São Paulo: Atlas, 1996.

FLEURY, M. T. L. et al. Arqueologia teórica e dilemas metodológicos dos estudo sobre cultura organizacional. In: MOTTA, F. P. C. \& CALDAS, M. (Orgs.) Cultura Organizacional e Cultura Brasileira. São Paulo: Atlas, 1997.

FLORES, F. Inventando la Empresa del Siglo XXI. Santiago: Hataché, 1989.

HABERMAS, J. Entrevista à Folha de S. Paulo (17/05/1995). Folha de S.Paulo, Ilustrada, p. 54-55. São Paulo, 17/05/1995.

HABERMAS, J. Teoria de la Acción Comunicativa. Madri: Taurus, 1997. 
LIMERICK, D.; PASSFIELD, R. \& CUNNINGTON, B. The Learning Organiration, 1(2), MCB University Press, 1994.

MAANEN, V. V. Processando as pessoas: estratégias de socialização organizacional. In: FISCHER, R. M. \& FLEURY, M .T. (Orgs.) Cultura e Poder nas Organizações. São Paulo: Atlas, 1996.

MATURANA, H. Emocões e Linguagem na Educação e na Política. Belo Horizonte: Editora UFMG, 1998.

MATUS, C. Sobre la teoría de las macroorganizaciones. Revista PES, n. 3, Santafé de Bogotá, 1994.

MINTZBERG, H. Structure et Dynamique des Organisations. Paris: Éditions d'Organisation, 1982.

MOTTA, F. P. C. \& CALDAS, M. Cultura Organizacional e Cultura Brasileira. São Paulo: Atlas, 1997.

MOTTA, P. R. Gestão Contemporânea: a ciência e a arte de ser dirigente. Rio de Janeiro: Record, 1991.

PETTIGREW, M. A cultura das organizações é administrável? In: FISCHER, R. M. \& FLEURY, M .T. (Orgs.) Cultura e Poder nas Organizaçoes. São Paulo: Atlas, 1996.

RIVERA, F. J. U. A gestão situacional em saúde e a organização comunicante. Cadernos de Saúde Pública, 12(3): 357-372, jul-set, 1996.

SCHEIN, E. Guia de Sobrevivência da Cultura Corporativa. Rio de Janeiro: José Olympio, 1999.

SENGE, P. A Quinta Disciplina: arte e prática da organização que aprende. São Paulo: Best Seller, 1998.

SENGE, P. et al. A Dança das Mudanças: os desafios de manter o crescimento e o sucesso em organizações que aprendem. Rio de Janeiro: Zumble/Campus, 2000.

STARKEY, K. Como as Organizações Aprendem: relatos de sucessos das grandes empresas. São Paulo: Zumble/Futura, 1997.

STRATEGOR. Stratégie, Structure, Décision, Identité: politique générale d'entreprise. Paris: Dunod, 1997.

THÉVENET, M. Audit de la Culture d'Entreprise. Paris: Les Éditions d'Organisation, 1986.

THÉVENET, M. La Culture d'Entreprise. Paris: Presses Universitaires de France, 1993.

THÉVENET, M. A cultura de empresa hoje em dia. Revista de Administração, 26, (2):32-39, abril/junho 1991. 


\section{Comunicación y negociación GERENCIAL}

Francisco Javier Uribe Rivera

$L a$ necesidad de gerenciar organizaciones profesionales, dentro de las cuales se sitúan las de salud, obliga a pensar los términos comunicación y negociación como elementos decisivos de un determinado modelo de gestión. Usamos el término organización profesional, en el sentido que le fue dado por Mintzberg (1982), como característico de un tipo organizacional dominado, desde el punto de vista de la posibilidad de control de los procesos de trabajo y de las decisiones administrativas, a través de centros operativos (con una gran dosis de autonomía), y donde la padronización productiva y las formas de coordinación son dependientes, en gran parte, de conocimientos, habilidades y formas de status adquiridos fuera de la organización, en las asociaciones respectivas y en las universidades.

En un trabajo anterior (Rivera, 1995), analizando las características de esas organizaciones, tales como la falta absoluta de padronización de muchas relaciones de insumo-producto y la imprecisión de sus resultados, desechamos la posibilidad de una gerencia tradicional, de una normatización "mecanisista" de procesos.

Considerando: a) el encierro en un tejido intrincado y variable de una amplia gama de servicios y de categorías profesionales, vinculados a procesos en permanente diversificación; b) el corporativismo de esas categorías que conspira contra la idea de equipo, de gran valor en la prestación de servicios sanitarios; c) la necesidad de definir colectivamente mecanismos de evaluación de resultados (y de responsabilidades); d) el carácter interactivo del trabajo final etc., adherimos a un tipo de modelo de gestión comunicativo, negociativo, consensual.

Entender a la administración pública como un circo de intereses de actores variados, en disputa por una hegemonía determinada, refuerza, aún más, la idea de mejorar la comunicación interna como medio para la cristalización de pactos 
normativos, capaces de cohesionar esas organizaciones. La característica básica del poder en las organizaciones profesionales, no concentrado, sino fuertemente compartido o distribuido por los diferentes núcleos profesionales y operativos, refuerza un sistema de gestión que encuentra en la adaptación mutua y en la negociación de intereses sus trazos más importantes.

En este contexto, la necesidad de una discusión sobre formas de mejorar la comunicación y la capacidad de negociación de los agentes organizacionales adquiere una clara relevancia.

Presentaremos algunas de las bases del modelo de negociación de la Harvard Law School y adelantaremos algunas posibilidades de complementación del mismo a partir de enfoques lingüísticos o comunicativos. Precedemos este análisis de una revisión concisa de las formas de negociación y de negociador, dado que este análisis ayuda a circunscribir mejor el tipo de modelo específico que sustentamos.

\section{Tipos de Negociación y de Negociador}

Matus (1994), distingue 3 tipos de negociación:

- Cooperativa: basada en intereses distintos y objetivos comunes, dando lugar a un juego de suma positiva.

- Conflictiva, basada en intereses opuestos, dando lugar a un juego de suma 0 .

- Mixta, basada en intereses opuestos combinados con intereses distintos, dando lugar a una negociación mixta.

Para este autor, la elección del tipo de negociación está determinada por el tipo de objeto de la negociación. De este modo, por ejemplo, las cuestiones que involucran a una comunidad económica, suscitan en general, formas mixtas de negociación; las cooperativas económicas son más proclives a formas cooperativas de negociación; por otra parte, la negociación de la compra de un inmueble involucra formas más conflictivas, donde mantener en secreto cierta información vital es una estrategia natural.

Es importante señalar que Matus sitúa la negociación como una posibilidad o un medio estratégico, junto a la autoridad, a la persuasión y al conflicto.

Chalvin (1997), distingue la negociación del entendimiento y de la autoridad. La autoridad correspondería, como plantea Matus, a la imposición jerárquica de directrices, presuponiendo la legitimidad de la jerarquía y poderes desiguales. La autoridad podría, sin embargo, deslizarse hacia la violencia coercitiva. 
El entendimiento supondría poderes iguales y una comunidad absoluta de intereses. Para este autor, la negociación permitiría un proceso crítico de articulación de poderes diferentes y complementarios, basado en la tolerancia y en la pluralidad. Situada entre la autoridad y el entendimiento natural, la negociación tipifica un universo de poder fluctuante.

Chalvin identifica diferentes enfoques de negociación:

- El enfoque persuasivo: el negociador aquí aprecia la competencia y las negociaciones difíciles. Defiende su punto de vista con fuerza, le gusta ganar. Establece plazos para la negociación, su discurso es avasallador apuntando a someter al otro. Siempre pide más para obtener un poco menos. Existe, en este caso, un sentido de manipulación. Este estilo puede comprometer claramente la relación interpersonal involucrada en la negociación.

- El enfoque cooperativo: el negociador pertinente se preocupa por su interlocutor y busca encontrar un objetivo común, elaborando en conjunto una solución nueva. Es un juego del tipo ganar-ganar. Se opta por la comunicación, en detrimento de la agresividad y de la disputa. Existe una predisposición a compartir el poder. La preservación de la relación es el objetivo supremo, pudiendo hasta comprometer la obtención de ganancias.

- El enfoque considerado ideal: en esta alternativa, se persigue la resolución de problemas, la adhesión completa de las dos partes a una alternativa de solución duradera, construida a lo largo de una discusión profunda. Esta opción difícilmente se diferencia de la anterior, a no ser por la idealización de una solución perfecta, que implique el máximo de ganancia y de relación, posibilidades a veces conflictivas.

- El enfoque a través de la conciliación: es un estilo adaptativo, lento, realista, de sumatoria progresiva de intereses, dentro de la línea de los arreglos provisorios. Es un estilo camaleónico de articulación, preocupado por la obtención de pequeños resultados. Se trata de una política pragmática de resultados, que no produce soluciones perfectas ni duraderas.

- El enfoque procedimental: corresponde a un enfoque burocrático, ritualístico, de producción de acuerdos básicamente formales, considerando procedimientos y no contenidos substantivos.

Para este autor, lo que existe en la práctica es una combinación de enfoques de negociación, donde algunos presentan una mayor capacidad de convergencia. Al igual que Matus, el autor sustenta que es necesario dosificar o combinar, de manera adecuada a la realidad, las estrategias de mayor autoridad, entendimiento y negociación.

Zajdsznajder (1988), establece una discusión sumamente interesante sobre dos formas básicas de negociación: la negociación basada en la argumentación y 
aquella basada en la persuasión. Para este autor, la base de la argumentación es la comunicación crítica. Esta implicaría la presentación de razones o de una serie de pruebas para las tesis defendidas y la obtención de un convencimiento legítimo en relación a estas razones, que podrán ser posteriores.

En la persuasión habría un tipo de convencimiento no crítico, no basado en razones. El acuerdo podría ser obtenido sencillamente en base a la adhesión a un político poderoso capaz de ofrecer seguridad; caracterizado por un discurso agresivo o manipulador, hipnótico, que se adapta a cada público; y que explora las emociones. Esta caracterización coincide con la de Matus, quien diferencia la negociación de la persuasión teniendo en cuenta que en la primera habría una disposición a hacer concesiones, en circunstancias que en la segunda habría una total cooptación.

El modelo elegido en este trabajo como opción más prometedora, es el de la negociación cooperativa que apunta, dentro de lo posible, al ideal, y este modelo estaría basado prioritariamente en la argumentación crítica. El modelo de Negociación de Harvard estaría situado en esta línea. Según Zapiola (1992), es necesario realizar una salvedad importante al método en relación a su denominación: Cómo Llegar al Sí: la negociación de acuerdos sin concesiones. Un método argumentativo al estilo ganar-ganar no admitiría como característica propia, la no realización de concesiones.

Se considera aquí, la inevitable interacción argumentativa-persuasiva, tal como fue reconocida por Zajdsznajder. En este sentido, se recomienda la subordinación de un componente persuasivo de la negociación, difícil de apartar, a la argumentación crítica. Por último, se sustenta la idea de que la determinación de la situación en juego, sobre el tipo de enfoque negociativo no es absoluta, de modo que podremos priorizar voluntariamente la búsqueda permanente de un ideal de enfoque cooperativo.

\section{Una relectura del Modelo de Negociación de Harvard}

Este modelo, consustanciado con Cómo Llegar al Si: la negociación de acuerdos sin concesiones (Fisher \& Ury, 1985) y en Cómo Llegar a un Acuerdo (Fisher \& Brown, 1990), también es conocido como el método de negociación que parte de principios o en función del mérito. Es visto como una alternativa a la negociación suave, donde el negociador, para evitar el conflicto, se limita a concesiones unilaterales, y/ o a la negociación áspera, donde el negociador exacerba el conflicto, defendiendo posiciones extremas, con la expectativa de derrotar al interlocutor. 
El modelo consta de cuatro elementos básicos:

- Separar el relacionamiento de la esencia del problema, trabajando el relacionamiento interpersonal como un interés particular del proceso de negociación;

- Negociar a partir de los intereses y no de posiciones;

- Buscar variadas opciones de ganancia mutua a través de un proceso creativo; Negociar antes que nada los principios o patrones objetivos a partir de los cuales la negociación puede ser posible.

\section{La cuestión del relacionamiento}

Trabajar el aspecto del relacionamiento interpersonal implica prestar atención a tres dimensiones: la percepción, la emoción y la comunicación.

En relación a la percepción, el método hace una serie de recomendaciones, que relacionaremos a continuación:

- Considerando que la percepción es situacional, que no existe una verdad absoluta, que tendemos a ver solo aquello que queremos ver en función de nuestra tradición, es indispensable intentar ver, como el otro ve. Esto implica ponerse en el lugar del otro. El modelo del "como si" es una técnica necesaria: ¿cómo veríamos una determinada situación si estuviésemos en el lugar del otro?

- Es importante no deducir las intenciones de los otros, a partir de nuestros propios miedos. Esto significa la necesidad de no atribuir a priori, la peor de las interpretaciones, a lo que el otro dice o hace. Este tipo de "ceguera situacional", puede llevar a desplazar ideas nuevas e interesantes, en el sentido de un acuerdo, y a ignorar cambios sutiles de posición.

- Es fundamental no culpar al otro por su problema. La atribución directa de culpa, aún siendo justificada, es generalmente contraproducente. Aquí existe un problema de comunicación. A título ilustrativo, mostraremos dos enunciados diferentes: (a) "Su compañía es totalmente indigna de confianza. Todas las veces que ustedes realizan el mantenimiento de nuestro generador giratorio aquí en la fábrica, hacen un trabajo de pésima calidad y vuelve a romperse"; y, (b) "Nuestro generador giratorio, cuyo mantenimiento habitualmente realizan ustedes, volvió a romperse. Esta situación se reiteró tres veces en el mes pasado. La primera vez, quedó parado por una semana entera. La fábrica necesita de un generador que funcione. Quiero su opinión sobre cómo podemos minimizar el riesgo de fallas en el generador. Quizás debamos cambiar de empresa de mantenimiento, o lo que ustedes nos sugieran". Atribuir culpa involucra fuertemente a las personas 
con el problema, genera una resistencia en el plano interpersonal que compromete la negociación del problema. Está claro que el segundo enunciado es mucho más positivo.

- Es importante considerar todas las percepciones de cada uno de los integrantes de la otra parte involucrada. Algunos intereses tratados como sin importancia, en el sentido de no ser obstáculos para un acuerdo, si son bien explorados, pueden crear áreas de afinidad o de acuerdo capaces de ayudar a un compromiso más amplio.

- Actuar, en determinadas oportunidades, de manera contradictoria a las expectativas del otro, puede contribuir a atenuar conflictos y abrir espacios para acuerdos. La inesperada visita de Anwar Sadat, presidente de Egipto, a Jerusalén, en 1977, es un buen ejemplo de esto. En vez de actuar como un enemigo declarado, Sadat actúa como un colaborador. Este paso dramático, contribuyó, sin duda, para la firma de un tratado de paz entre Egipto e Israel.

- En la realización de cualquier acuerdo, se sobrentiende la participación del otro desde el inicio do proceso. Es importante otorgarle interés al resultado, certificándose de que el otro participa del proceso. Por ejemplo, gran parte de la legislación anti-apartheid, formulada tan solo por legisladores blancos, fue desacreditada, porque estas medidas fueron entendidas por los negros como una reafirmación de la "opresión" del hombre blanco". La mejor manera de caracterizar esta recomendación es asumir que el proceso en sí, es el real producto de la negociación.

- Es fundamental, además, preparar los términos de un acuerdo, sobre todo de aquello que implique desventajas para el otro, de un modo tal que no violente los valores, los principios y la auto-imagen de los otros negociadores. Redactar la esencia del acuerdo, de tal modo que el resultado parezca ser justo, ayudará a la posición de los otros, en la defensa de esa posición frente a eventuales reclamos de sus superiores. Esto corresponde al consejo: "guardar las apariencias: haga que sus propuestas sean compatibles con los valores del otro". Tal preocupación, fortalece la posibilidad de un relacionamiento futuro positivo.

En relación al aspecto emocional, el método, además de destacar la importancia crucial de los sentimientos en relación a las palabras, en el sentido de que puedan comprometer significativamente el proceso de acuerdo, aconseja una absoluta transparencia.

Explicitar las emociones y reconocerles su legitimidad es absolutamente normal y necesario. Liberarse del peso de las emociones contenidas, aumenta significativamente la probabilidad de trabajar en el problema. Para ello es nece- 
sario dejar que el otro se desahogue, creando un clima propicio para que esto suceda. Una regla de oro se aplica a los casos de una reacción agresiva: escuchar en silencio, no reaccionar, pedir que el otro prosiga; sólo una persona por vez tendría el derecho de "sacarse".

La utilización de gestos simbólicos que expresen cariño, solidariedad, preocupación por el otro, minimizan la posibilidad de un clima hostil.

En situaciones en las que impere un estado emocional negativo, la utilización de técnicas de visualización puede ser útil. Colocarse en "estado de recurso" corresponde a visualizar escenas de una negociación anterior en las que hayamos sentido plenamente realizados, motivados, involucrados en procesos positivos. Del mismo modo, podríamos concentrarnos en el estado emocional, en el que nos gustaría que nuestro par estuviese, adoptando ese estado. El otro puede seguir nuestro ejemplo, contagiarse, buscar recursos positivos.

Una variante de la técnica del "como si" es la disociación visual-sinestética. Se aplica a situaciones en que el par de la negociación está acorralado en un estado interno negativo o en un proceso de auto-convencimiento negativo, en posiciones cerradas, sin poder avanzar. La idea implícita es desconectarlo de ese estado de concentración en sentimientos y diálogos internos, a nivel de la representación sinestética, a través del recurso de la visualización. Colocar al interlocutor como observador de la situación, cambiando su forma de representación sensorial, es una forma de cambiar su estado. Este desvío de la atención, le permitiría a la persona tomar distancia en relación a su problema -asumir una meta-posición-. Pedir que la persona involucrada, imagine lo que vería en esa situación que está viviendo, si estuviese en el lugar del otro, es uno de los recursos. En general, se trata de formular preguntas que hagan con que esa persona observe la situación, y diga lo que ve realmente. Explorar la representación visual del objetivo de esa persona, e inducirla a construir una imagen del mismo, es parte de esta lógica que actúa como una técnica sencilla de creatividad. Esto se corresponde en general, con la idea de asumir al otro no como un enemigo, sino como un par, un socio en el proceso de negociación.

El aspecto de la comunicación es el tercer elemento del trabajo vinculado al relacionamiento. Sin comunicación no hay negociación. Habría 3 grandes problemas de comunicación:

- No hablar para otro interlocutor, sino para una platea.

- No escuchar, por estar concentrado pensando las próximas jugadas.

- Los malentendidos de la comunicación, considerando una comprensión diferente de ciertos términos (por motivos culturales) o un tipo de comunicación discursiva indirecta, imprecisa.

Las recomendaciones pertinentes son las siguientes: 
- Escuchar y registrar activamente lo que está siendo dicho. Preguntar, solicitar la aclaración frente a una posición ambigua, es fundamental, como así también reproducir positivamente, en forma resumida, los términos de la presentación del otro. El otro, al percibir que su propuesta está siendo entendida, quedará muy satisfecho. Lo ideal es reproducir la propuesta del otro, en mejores términos do que a formulación originaria, ayudar a especificarla mejor. En esta operación, no se emitirían juicios, ni comentarios críticos. Posteriormente, resulta mucho más fácil, cuestionar la presentación del otro, cuando se obtiene un acuerdo inicial constructivo sobre lo que el otro está queriendo decir. La utilización de los mismos términos que el otro emplea crea una sintonía sutil, un rapport, una aproximación casi "fisiológica". El back tracking o reproducción resumida de la propuesta del otro, utilizando el mismo tipo de términos utilizados por él, es una técnica bastante utilizada en el campo de la psicología, ayudando a armonizar, a comunicar. La Psicología Comportamental parte de la hipótesis de que en la representación sensorial de la experiencia, las personas utilizan predominantemente una determinada forma de representación, que es el sistema sensorial que estaría bajo el foco de la concientización. De este modo, habla de personas predominantemente visuales o auditivas o sinestéticas. El lenguaje de los seres humanos reflejaría esa tendencia. Las personas visuales utilizarían gran cantidad de términos visuales (a primera vista, aclarar, ilustrar, visiblemente, evidentemente, etc.) y así sucesivamente. Presentarían, además, determinadas características de comportamiento no verbal o una determinada fisiología. Los sinestéticos, por ejemplo, tendrían una respiración profunda, amplia; sus movimientos se mimetizarían con sus palabras; la voz sería grave, el ritmo lento con muchas pausas, etc. Esta construcción es utilizada en ventas. Intentar vender un producto a través de sus cualidades visuales a una persona sinestética es una pésima estrategia. Una persona de este tipo podría sensibilizarse ante cualidades como la textura, el confort, etc. La aplicación de esta técnica al campo de la negociación es obvia. Convencer resulta más fácil si utilizamos el tipo de términos, adecuados a la forma de representación primaria de nuestro par en la negociación. Por lo tanto, es absolutamente necesario traducir nuestros argumentos al lenguaje del otro. Esta técnica puede ser reforzada a través de espejar al otro, esto consiste en reflejar el comportamiento no verbal de los participantes de una negociación de modo de crear una sintonía, una aproximación inconsciente (voz, gestos, postura, respiración, etc.). Además de ayudar a crear una relación más armoniosa, el espejo está considerado como un instrumento que precede a la posibilidad de conducir al otro (leading).

- Es importante hablar para ser entendido. Se recomienda emplear medios privados y confidenciales de comunicación, grupos relativamente pequeños, 
para evitar la situación de tener que afirmarse frente a terceros, y utilizar una comunicación directa, concisa, no excesiva. En esto último se sobrentiende la necesidad de hablar con objetivos claros, saber lo que se quiere comunicar.

- Hable sobre usted y no sobre el otro. Condenar las motivaciones del otro lleva a inevitables cuestionamientos. Es más conveniente describir el impacto de un problema sobre usted, que analizar el problema desde el punto de vista de la responsabilidad del otro. Decir: "nos sentimos discriminados", en lugar de "usted es racista", hace una gran diferencia.

\section{Negociar intereses y no posiciones}

El segundo paso decisivo de este modelo, consiste en evitar el intercambio posicional, dado que este pone en conflicto la relación con la esencia del problema. Concentrarse en las posiciones o en las respuestas específicas que usted quiere obtener, de un modo egocéntrico, lleva a situaciones extremas, de asfixia (de la propia relación). Antes que eso, es necesario conciliar intereses, en cuanto a los fundamentos (o causas) de una posición (deseos, necesidades, temores, valores).

Fisher \& Ertel (1997) ilustran la diferencia existente entre posiciones e intereses. Si estamos inseguros sobre si algo es una posición o un interés, debemos determinar si existe más de una forma de satisfacer ese planteo. Si no la hay, como en el caso de "yo exijo un automóvil de la empresa", se trata de una posición. Por el contrario, si existen varias formas de satisfacer una exigencia (como en el caso de "quiero algún transporte para el trabajo" o "quiero más status en la empresa") es probable que sea un interés.

Para descubrir los intereses subyacentes, es necesario aplicar a sí mismo y/ o al interlocutor, la técnica del porqué: ¿por qué el otro asume una determinada posición? o ¿por qué el interlocutor no asumiría una determinada posición? (correspondiente a la posición que nosotros esperaríamos o nos gustaría que él tomase). Las decisiones o motivaciones que se originan en el uso sistemático del porqué pueden ser jerarquizadas, a través de sucesivas preguntas que van develando nuevas motivaciones que surgen como consecuencia de las primeras. Las últimas motivaciones en general son las más decisivas.

En algunos modelos de negociación (Kluczny, 1993), más vinculadas a la mediación, al arbitraje, el punto de partida consiste en la definición de un metaobjetivo que una las partes, de un objetivo compartido, de lo que se denomina la base de resultados de un acuerdo.

Este punto presupone que ambas partes definan su objetivo en el proceso de negociación. La definición del meta-objetivo común, se obtiene a partir de 
consultar a cada parte acerca del beneficio a ser alcanzado por el objetivo específico. Sucesivas preguntas en el sentido de "¿con qué finalidad”? pueden llevar a la definición de la llamada base de resultados.

En general, los meta-objetivos corresponden lingüísticamente a nominalizaciones. Las nominalizaciones son palabras que reemplazan a un sustantivo en una sentencia, pero no pueden ser tocadas, sentidas, ni oídas. No son tangibles. Palabras como amor, felicidad, curiosidad son algunos ejemplos. Son palabras abstractas, genéricas, sin especificidad en términos de contenido. Se prestan subjetivamente a múltiples interpretaciones y no suscitan oposición. Por esta razón facilitan acuerdos generales. Son fenómenos lingüísticos que transforman un proceso dinámico en un acontecimiento abstracto, (amar en amor, por ejemplo). Estos nos impiden saber el contenido concreto, la forma concreta del acaecer de un acontecimiento determinado. Por tal razón, son considerados fenómenos de distorsión de la experiencia o de substitución de datos sensoriales.

Una vez determinado el meta-objetivo y definidas algunas condiciones básicas para ser decididas en el proceso de negociación, se recomienda la aplicación sistemática de la técnica del "desafío de relevancias". Esto significa recordar todo el tiempo, en qué medida una determinada discusión, es relevante desde el punto de vista de la base de resultados de la negociación. De este modo, se economiza tiempo, evitando "irse por las ramas" y se organiza el proceso de alcanzar objetivos concretos.

La premisa implícita en la posibilidad de negociar intereses, es que por detrás de posiciones opuestas, además de intereses conflictivos, habría intereses comunes y divergentes, no necesariamente incompatibles.

La idea sería, entonces, ampliar la franja de acuerdo en torno a los intereses comunes y explorar en profundidad la posibilidad de conciliar o armonizar con aquellos intereses divergentes, creando afinidades que allanen el camino para una negociación más amplia. Es necesario considerar, además, que una de las partes puede tener múltiples intereses, ofreciendo la posibilidad de acuerdos con segmentos de la otra parte involucrada. Algunas necesidades humanas básicas pueden ser consideradas intereses, como: la seguridad, el bienestar económico, el sentimiento de pertenencia, el reconocimiento, el control sobre la propia vida.

A título ilustrativo, citamos el tratado de paz egipcio-israelí elaborado en Camp David en 1978. Israel ocupó la península de Sinai durante la Guerra de los 6 días en 1967 y no desistía de obtener una parte del Sinai. Egipto, quería su devolución completa. En innumerables oportunidades, las 2 partes mantuvieron sus posiciones sin concesiones. Se diseñaron mapas y mapas mostrando posibles fronteras que dividían el Sinai, sin éxito. El análisis de los intereses posibilitó el acuerdo. Israel quería la seguridad, no quería tanques egipcios en su frontera. Egipto quería la soberanía, teniendo en cuenta que después de años de 
ocupación colonial por sucesivos pueblos, esa república había conquistado finalmente su soberanía, transformándose en un valor político incalculable para su población. Sadat y Begin llegaron a un acuerdo en base a un plan que restituiría el Sinai a la soberanía egipcia y que desmilitarizaría grandes áreas garantizando la seguridad de Israel. La bandera egipcia flamearía en todo el territorio, pero no habría tanques egipcios cerca de la frontera israelí.

Otra situación que ilustra las posibilidades de negociación de intereses, más allá del intercambio posicional, es la negociación del precio del alquiler de un inmueble. Aquí existirían intereses opuestos: maximizar/minimizar el precio del alquiler. La posibilidad de un acuerdo sobre el problema dependería en gran medida de una negociación basada en otros intereses. Habría ejemplos de intereses comunes, a explorar: ambos quieren estabilidad (una relación de inquilinato duradera); ambos desearían que el inmueble estuviese bien conservado; ambos podrían estar interesados en un buen relacionamiento mutuo. Es posible que tengan intereses no conflictivos, sino simplemente diferentes, por ejemplo: el inquilino tal vez no quiera lidiar con pintura fresca y el propietario no quiera asumir el costo de la pintura; el propietario quisiera tener la seguridad de un pago anticipado por el primer mes de alquiler y tal vez quiera que ese pago se efectúe mañana, mientras el inquilino, sabiendo que el departamento vale la pena, tal vez no tenga problema ante una condición de ese tipo. Los intereses conflictivos tal vez puedan acotarse más, si existiera un acuerdo en relación a los intereses comunes y divergentes. Por ejemplo, la disposición del inquilino a asumir el costo de la pintura, en el caso que el propietario se haga responsable de pintar el departamento, junto con la aceptación, por parte del inquilino, de un pago anticipado. Ellos pueden estar de acuerdo, antes que nada, en relación a la necesidad de una buena conservación del inmueble, admitiendo un esfuerzo compartido, y la necesidad de sostener una buena relación a futuro.

En relación a este paso, la transparencia es un imperativo. Es necesario dar vida a los intereses, ser explícito. El acto de declinar los intereses propios debe ser acompañado por la búsqueda de su reconocimiento por parte del otro. Dar legitimidad a los propios intereses es una búsqueda permanente y necesaria, sobre todo cuando esos intereses son considerados extremamente pertinentes. El reconocimiento de los intereses del otro como parte del problema, sería lo opuesto a la situación anterior. Reconocer los intereses del otro explícitamente, puede ser el primer paso hacia el reconocimiento de los propios. El relato o el reconocimiento de los intereses del otro puede ser precedido del enunciado "corríjame si estoy equivocado", lo que caracteriza una posición abierta. Si el otro no corrige el relato de sus motivaciones, significa que acepta su descripción de la situación. Esta sería un área más de acuerdo; una forma más de "fisiología del sín". 
Algunas otras recomendaciones son interesantes.

- Plantear el problema antes que la solución. En el caso de una obra en construcción, cuyos camiones ponen en riesgo la vida de los niños de la localidad, la mejor forma de comunicar esta situación no sería por ejemplo: "creemos que ustedes deberían levantar una cerca alrededor del área en construcción dentro de 48 horas y limitar, inmediatamente, la velocidad de sus camiones a $25 \mathrm{Km}$. por hora y le digo porqué”. De esta manera, el interlocutor seguramente no escuchará sus razones. Hablar en primer lugar de los riesgos para los niños pequeños, procurando que el constructor se coloque en su situación, reconociendo el valor de la vida humana, es una forma más efectiva de promover una escucha constructiva.

- Olvidar situaciones negativas del pasado y concentrarse en el futuro, ayuda a crear un relacionamiento más constructivo, como también reencuadrar el pasado, procurando y comunicando los aspectos positivos de situaciones de negociación anteriores de carácter crítico.

- Tener una mente abierta a diferentes opciones y no a una única opción, es otro imperativo obvio.

- El ser riguroso con el problema y amable con las personas, crea el fenómeno de la "disonancia cognitiva", a partir del cual las personas tienden a eliminar la incoherencia - de efectos desagradables-promoviendo una mayor interacción.

\section{Buscar opciones creativas de ganancia mutua}

El tercer paso del método se refiere a la necesidad de buscar primero soluciones creativas y después decidir (no confundir el proceso de la invención con la decisión misma).

Existirían una serie de obstáculos para desarrollar la creatividad necesaria en una negociación:

- El juzgamiento crítico, prematuro, exacerbado, mata la creatividad, la imaginación.

- Las personas creen que su tarea es estrechar las distancias entre las posiciones y no ampliar las opciones disponibles. Esto se corresponde con la búsqueda de una respuesta única.

- Existe, en general, un preconcepto equivocado de una "torta fija". La historia de la división de la naranja, de dos criaturas que disputan la misma naranja y que acuerdan en partirla al medio, una quedándose tan solo con la 
cáscara, tirando el jugo, y la otra haciendo lo contrario, desmitifica la idea de que toda negociación es un proceso que supone una "torta fija" (que implica soluciones del tipo ganar/perder).

- A veces, predomina la idea de que "resolver el problema de los otros es problema de ellos". El abordaje unilateral del problema de la negociación es otro obstáculo frente a la posibilidad de diferentes opciones de ganancias mutuas. Este abordaje lleva al encierro egocéntrico, obstaculiza y compromete la posibilidad de la diversidad.

Frente a este cuadro de obstáculos, surgen algunas recomendaciones:

\section{Separar la invención de las decisiones}

La realización de sesiones de sugerencias libres (brainstorming session) con el actor que negocia y/o con los interlocutores, es el método básico para estimular la creatividad. Algunas reglas son básicas: cambiar el ambiente de la sesión; crear una atmósfera informal; elegir un moderador que garantice la simetría y la riqueza del debate; trabajar con grupos no muy grandes, para estimular la participación individual, ni muy pequeños, para proporcionar un intercambio estimulante; hacer que los participantes se sienten uno al lado del otro (en semicírculo), frente al problema (rodeándolo, dado que lo físico refuerza el psicológico), que en este caso sería, la búsqueda cooperativa de opciones; esclarecer las reglas básicas, especialmente la regla de desterrar las críticas negativas; sugerir libremente; registrar las ideas a la vista de todos, reforzando el sentimiento de construcción colectiva. A partir de allí, se sugiere relajar la regla de la ausencia de críticas, destacando las ideas más prometedoras, tomar una idea prometedora y perfeccionarla y estipular un plazo para evaluar las ideas y decidir. Para "romper el hielo" en una reunión con los interlocutores, es muy útil proponer por lo menos dos alternativas al mismo tiempo, para no crear la sensación de compromiso con una única idea, o presentar antes del relato de opciones alternativas, ideas contradictorias de las cuales usted visiblemente está en desacuerdo.

\section{Ampliar las opciones es esencial}

Para ampliar las opciones se sugiere una metodología que consiste en un desvío de las opciones entre lo particular y lo general. El punto de partida consistiría en procurar procesar (describir y explicar) un problema y posibles alternativas de solución. En este punto, se puede intentar una extrapolación que permita identificar el abordaje general o la teoría general que subyacen a una idea particular (una opción) o a la propia explicación del problema. A continua- 
ción, se podrían discutir otras alternativas inherentes a la misma forma de abordaje general. Una buena manera de estimular la creatividad es observar problemas y propuestas a través de la mirada de diferentes especialistas.

Se pueden intentar técnicas de disociación del interlocutor, apuntando a apartarlo de afirmaciones categóricas, que expresa con firmeza en relación a algo en particular. Se aplica a situaciones críticas donde el interlocutor se aferra a formulaciones rígidas de carácter negativo. La lógica de esta técnica consistiría en asumir nuevos roles, a través de una simulación basada en la pregunta: “¿qué pensaría yo de esta cuestión si fuese...?”. Las nuevas dimensiones positivas derivadas de los nuevos roles asumidos, serían introducidas sorpresivamente al diálogo, ayudando de este modo a fijar la asociación con tal o cual dimensión (el elemento sorpresa actuaría como ancla). Se estima que la tendencia natural de las personas a escapar de las situaciones desagradables, facilitaría este proceso de ampliación de opciones o de reencuadramiento positivo de la situación, que no deja de ser una autosimulación de un encuentro multidisciplinario.

La relación de opciones posibles puede aumentar, si son consideradas "versiones más leves" de enfrentar un problema, en el caso que el acuerdo buscado se muestre inalcanzable. La recomendación implícita es buscar acuerdos de pesos diferentes. Si no pudieran ponerse de acuerdo en cuanto a la esencia, tal vez concuerden en cuanto al procedimiento (por ejemplo la necesidad de un arbitraje). Del mismo modo cuando no sea posible llegar a un acuerdo permanente, tal vez puedan llegar a un acuerdo provisorio. Si no es posible llegar a un acuerdo de primera línea, tal vez sea posible un acuerdo de segunda línea -acordando aquello sobre lo que desacuerdan.

El condicional close o modelo del "como si" puede ser útil en la definición de acuerdos de pesos diferentes. Esta técnica se aplica a situaciones en que hay objeciones que dificultan el acuerdo. La idea es buscar un acuerdo condicional que puede ser sucesivo. Se le pregunta a la parte que objeta, si estaría de acuerdo con una determinada propuesta, en el caso que las objeciones que manifiesta fuesen tenidas en cuenta o aceptadas. El objetivo es reforzar la "fisiología del sî", dado que esta facilita un acuerdo.

Modificar el alcance del acuerdo propuesto, parcializando o recortando la esencia del problema, puede permitir, aún, acuerdos parciales, con un menor número de partes involucradas o abarcando solo algunos aspectos.

\section{Procurar ganancias mutuas}

Esta cuestión está directamente ligada al paso dos del método, que recomienda explorar los intereses comunes y armonizar los diferentes (no incompa- 
tibles). Llegar a un acuerdo a través de las diferencias, supone la existencia de intereses que pueden ser armonizados. Esto puede quedar claro si consideramos que hay situaciones en que:

Una de las partes se preocupa más con: La otra parte se preocupa más con:

- la forma

- la esencia

- las condiciones económicas

- las opiniones políticas

- el futuro inmediato

- el futuro lejano

- los antecedentes

- este caso

- el prestigio, la reputación

- los resultados

- el equipamiento pesado

- la ideología, etc.

La existencia de diferentes creencias puede ser aprovechada, por ejemplo, para convocar a un arbitraje. La valorización diferente del tiempo entre vendedor y comprador posibilita acuerdos que impliquen planes de financiamiento. El comprador paga más caro por el auto, si puede pagar más tarde. El vendedor se dispone a postergar el pago, si puede obtener un precio mayor. De este mismo modo existen diversas situaciones de diferencias, que en vez de distanciar pueden ser capitalizadas en términos de un acuerdo basado en el análisis de intereses.

\section{Facilitar la decisión del otro}

Facilitar la decisión del otro se inscribe, en la misma línea de razonamiento de la premisa "guardar las apariencias del acuerdo". Pero también quiere decir que la negociación debe evitar el espíritu de manipulación de los incrementos deliberados con el fin de "crear más espacio de negociación" y que debe considerar las consecuencias de un acuerdo X para el otro, procurando mejorarlas.

\section{Definir patrones para la negociación}

El cuarto paso decisivo consiste en buscar e insistir en criterios objetivos, en acordar patrones justos e independientes de la voluntad, que puedan determinar un acuerdo. El punto de partida de la negociación debería ser este acuerdo. Dentro de estos patrones, podemos citar: el valor de mercado, los antecedentes, la opinión científica, los costos, un tribunal, patrones morales, la tradición, etc. 
La búsqueda de criterios justos puede referirse a un conjunto de patrones que ayuden a dirimir la cuestión substantiva o a procedimientos justos para resolver los intereses conflictivos. La antiquísima forma de dividir un pedazo de torta entre dos niños: una corta y la otra elige, es un ejemplo de procedimiento.

Una variación de la técnica "uno corta, el otro elige" consiste en que las partes negocien lo que creen que es un acuerdo justo, antes de decidir sus respectivos roles. Esto se aplica a los casos de divorcio. Alternar las posiciones, echar la suerte, dejar la decisión a cargo de un tercero, son otros ejemplos interesantes. Lo importante es resaltar que el punto de partida, es formular cada cuestión como la búsqueda de criterios objetivos, procurando un acuerdo en función de esos criterios.

A veces, un patrón de legitimidad no excluye la existencia de otros. Es importante considerar los patrones sugeridos por el socio de la negociación y, porqué no, eventualmente asumirlos. La mejor manera de dirimir diferencias sobre el mejor criterio es involucrar a más personas, identificar cuál es el patrón de mayor aceptación social. Comprometer o compartir las diferencias es una solución aconsejable cuando existen dos criterios diferentes (precio de mercado y costo devaluado). El patrón usado por las partes en el pasado puede ser, también, una alternativa de resolución de diferencias.

Concluiremos esta parte, haciendo algunos pequeños comentarios (a partir del Cómo Llegar al Sì) acerca de cómo negociar con aquel que no quiera jugar dentro de las reglas de la negociación por principios. El "jiu-jitsu" de la negociación es una forma de abordaje que se aplica en estos casos, y que consiste en evitar lanzar la fuerza directamente contra la del otro, utilizando habilidades para esquivar los ataques y redireccionar la fuerza del otro a partir de sus propios intereses. El objetivo es intentar traer al otro hacia el campo de la exploración de los intereses. Las reglas básicas de este abordaje serían:

- No contraatacar.

- No atacar la posición del otro. Es mejor aceptarla como una opción, procurando los intereses y principios subyacentes y pensar el modo de mejorarlos. Por lo tanto, siempre mire por detrás de la posición del otro.

- Logre que el otro discuta hipotéticamente las consecuencias para ustedes de la imposición de una propuesta defendida por él. No defienda sus ideas. Pida al otro, críticas y consejos sobre una idea sustentada por usted. En vez de pedirle que acepte o rechace una idea, pregúntele lo que hay de malo en ella: “¿Qué intereses de esta propuesta no tendría en cuenta?”. Examine los juicios negativos del otro para descubrir los intereses subyacentes y mejorar sus ideas desde el punto de vista de él. Reelabore sus ideas en base a lo que ha descubierto, logrando que la crítica, antes que un obstáculo al proceso 
de trabajar en pos de la obtención de un acuerdo, se transforme en un ingrediente esencial de ese proceso.

- Coloque al otro en su posición y pregunte lo que él haría en este caso. Es una forma de canalizar críticas en un sentido constructivo.

- Reformule los ataques hacia usted como ataques al problema. Ejemplo: "Cuando usted dice que la huelga demuestra que no nos interesan los chicos, percibo su interés por la educación de ellos. Compartimos este interés, ellos son nuestros hijos. Queremos que la huelga termine para poder volver a educarlos. ¿Qué es lo que ambos podemos hacer?”

- Las personas empeñadas en este abordaje usan dos instrumentos claves: la pregunta y el silencio. Las afirmaciones generan resistencias, mientras que las preguntas generan respuestas. Además de ayudar a discernir mejor los intereses de los otros, distienden el ambiente (minimizan el conflicto) y promueven la creatividad. El silencio genera cierta incomodidad en el otro, especialmente cuando tiene dudas. Lleva a la necesidad de hablar más, de completar afirmaciones que culminarán en un "callejón sin salida". Genera desafíos.

Es importante citar que, Ury posteriormente profundiza esta estrategia en Supere el No: negociando con personas difíciles (1991). En este trabajo, el autor reafirma la necesidad de traer al interlocutor al campo de la discusión de intereses o hacia una actitud de solucionar problemas (desviándolo de la postura ofensiva). Más que saber afirmar, lo esencial aquí es saber hacer preguntas vinculadas a la solución de los problemas, priorizando las preguntas abiertas (que son aquellas que no pueden ser respondidas con un no). Corresponden a este tipo preguntas: "¿Por qué usted quiere esto?”, “¿Por qué usted cree que esto sería justo?”, “¿Por qué no hacerlo de este modo?”, “¿Qué es lo que estaría mal en este abordaje?”, “¿y si aceptáramos esa exigencia...?”, (condicional), “¿Cuál es el propósito de esta política?”, “¿Cómo me aconseja proceder?”, “¿Quién podría establecer una excepción?”.

Una última técnica interesante de la metodología de negociación por principios, es la técnica del texto único. Un mediador elabora un anteproyecto a partir de los intereses de ambas partes de la negociación y discute este anteproyecto con cada parte por separado, alternativamente, reformulándolo sucesivamente en función de los aportes de cada lado, hasta que surge una versión que más agrade a los dos.

Fisher y Ertel (1997), interesados en la aplicación práctica del enfoque de negociación por principios, proponen una verdadera "caja de herramientas para la preparación de una negociación", que condensa la propuesta en términos de formatos, lo cual puede ser de mucha utilidad. A partir de la misma, proponemos el siguiente protocolo de preparación de la negociación: 
- Relacionar los actores de nuestro lado y del otro afectados con el resultado de la negociación.

- Enumerar, a través de la técnica ad-hoc, los intereses de ambos lados, procurando darles un orden de prioridad. Distinguir los intereses eventualmente comunes y distintos.

- Relacionar patrones "justos" de negociación en torno a la cuestión substancial específica a la que se debe dar respuesta en esta negociación (criterios legítimos), procurando identificar en qué medida pueden favorecer o no a nuestra posición.

- Identificar algunas opciones iniciales de ganancia mutua examinando los intereses y los criterios legítimos de negociación.

- Identificar las alternativas de ambos lados, en el caso que no se llegue a ningún acuerdo. Ver los pros y contras. Explorar la posibilidad de mejorar mi(s) alternativa(s) y transformar la(s) del interlocutor en menos atractiva(s).

- Usar la imparcialidad del proceso para persuadir. En este caso, (cuando no se llega a un acuerdo substancial) se busca identificar en qué medida pueden ser aplicados procesos persuasivos de obtención de acuerdos sobre el proceso (por ejemplo: yo corto, usted elige; lanzar la moneda; llamar a un especialista; dejar decidir a un árbitro). Intentar además, identificar situaciones donde el interlocutor se encuentre en nuestra situación, rescatando sus argumentos y viendo la posibilidad de aplicación a una situación concreta (test de reciprocidad).

- En relación a la comunicación y al relacionamiento:

- Enumerar los problemas de relacionamiento y sus posibles soluciones. - Enumerar nuestras suposiciones acerca de las intenciones y percepciones del otro y lo que podemos llegar a escuchar (o de lo que los otros pueden llegar a decir) que pueda cuestionar esas suposiciones.

- Enumerar las declaraciones que puedan expresar nuestros intereses y las respuestas posibles de la contraparte, apuntando a reencuadrar o redeclarar nuestros intereses de modo que ellos los escuchen mejor.

- Simular a situación en términos de un teatro lúdico de negociación, cuantas veces sea necesario, distribuyendo los roles (usar los elementos acumulados analíticamente).

- Enunciar finalmente un mínimo de 3 opciones consideradas de ganancia mutua. 


\section{Comunicación, creatividad y ejercicio de la influencia}

El modelo lingüístico de la gramática transformacional de Chomsky (1965) plantea que entre la representación sensorial primaria de la experiencia y la representación lingüística actúan tres formas de moldear la realidad de carácter universal (filtros): la generalización, la distorsión y la omisión. La generalización consiste en absolutizar una experiencia singular. La omisión es una forma de negación de la experiencia, de silenciamiento. La distorsión es una nueva disposición o una nueva organización de los conceptos, ideas u objetos. Es una forma de substitución de datos sensoriales. Este metamodelo asume que estas formas universales actúan habitualmente en la realidad (aún como formas de adaptación y de defensa de los seres humanos), pero que pueden llegar a límites patológicos o generar situaciones patológicas (cuando se tornan muy persistentes o se aplican a contextos inapropiados).

Para el autor, las expresiones lingüísticas reflejan estas formas universales del modelo experiencial. Por ejemplo, hay personas que utilizan muchos operadores modales de posibilidad o de necesidad. Son expresiones del tipo: "es imposible que", "no puedo hacer tal cosa"; "no son capaces...", (de posibilidad) o "es necesario..."; "tenemos que hacer", (de necesidad), etc. Son expresiones que marcan un límite o una imposibilidad, pero no dan informaciones precisas sobre cómo actúa este límite. En la práctica, denotan una extrema rigidez y creencias arraigadas. Los operadores modales se encuadran en la clase de las omisiones. Ejemplos de generalizaciones son las expresiones que se utilizan como cuantificadores universales del tipo nunca, todos, nadie, etc., o aquellas sin datos referenciales como "no quisieron dejarme hablar". Las relaciones de causaefecto son consideradas formas de distorsión, dado que en este caso, por lo general, se comete el error de atribuir una única causa a un efecto, como también las nominalizaciones que transforman algo dinámico en un dato fijo, absoluto. La taxonomía general es mucho más abarcativa; el objetivo aquí es dar apenas algunos ejemplos.

La idea implícita es que las expresiones lingüísticas configuran una forma de lenguaje superficial, que no da cuenta del contexto global de las representaciones básicas, que corresponden a un nivel más profundo del lenguaje. Si yo digo: "Juan compró un auto", se trata de una estructura superficial; la estructura profunda correspondiente podría ser: "Juan le compró a alguien, en tal día, en tal lugar, un auto de tal marca por determinado valor". De este modo, la estructura profunda abarcaría los elementos lingüísticos que representan la experiencia, no necesariamente todos, porque los modelos universales intervendrían en primer lugar entre la experiencia y la estructura profunda del lenguaje, y en segundo lugar entre esta última y la estructura superficial. En una situación pato- 
lógica, una eventual tarea terapéutica consistiría en acceder a los niveles más profundos, relacionando nuevamente al paciente con la experiencia negada, distorsionada o generalizada, de modo de ampliar sus posibilidades. El uso sistemático de expresiones clasificables de las formas universales, limita el modelo de mundo de los seres humanos.

Comunicadores ligados a escuelas de la psicología comportamental (Bandler \& Grinder, 1981) plantean un modelo de cuestionamiento simple (modelo de precisión) que ayudaría a "profundizar" el lenguaje, a disminuir la ambigüedad virtual. Por ejemplo:

- En el caso de utilizar operadores modales serían pertinentes dos preguntas: "¿qué es lo que le impide de...?” (cuando la afirmación es: "no puedo hacer tal cosa”); “¿qué sucedería si no ocurriese X?” (en el caso de la afirmación: "debo hacer tal cosa").

- En el caso de una utilización excesiva de cuantificadores universales, del tipo "nadie me comprende", se puede utilizar en tono interrogativo el cuantificador universal: “¿nadie?” o exagerar la afirmación incrementándole otro cuantificador universal o inclusive el término "¿verdaderamente?”.

- En relación a expresiones sin datos referenciales, como la anteriormente citada, puede ser utilizada la interrogación: “¿quién?”.

- En relación a la utilización de vínculos de causa-efecto del tipo: “yo me iría de vacaciones, pero no tengo auto", la conexión podría ser cuestionada transformándose en afirmación de la siguiente forma: "o sea, si usted tuviera un auto, saldría de vacaciones"; la modificación de la forma de la afirmación permitiría verificar la existencia del vínculo o dejar abierta la posibilidad de una réplica (otras formas específicas de quebrantar vínculos de este tipo serán presentadas más adelante).

- En cuando a la utilización de nominalizaciones, como por ejemplo: "yo tengo esperanza", usar: "¿qué es lo que usted espera?”, o "el dolor me oprime”, usar: “¿cómo específicamente te oprime?”, (las preguntas qué o cómo posibilitarían transformar substantivos abstractos en dimensiones del proceso).

Se considera, por lo tanto, que el lenguaje presenta "zonas de sombras" que seria preciso iluminar a través de un cuestionamiento efectivo y oportuno. Esto implica la búsqueda de una "objetivización" del lenguaje que facilite el entendimiento de los enunciados, que ayude a la comprensión de lo que se formula, que permita un mayor esclarecimiento de lo que el otro dice. Es la búsqueda de un habla verdadera.

Pero considerándose la creatividad y el ejercicio de la influencia, el uso deliberado del lenguaje "con zonas de sombra", del lenguaje impreciso, de enunciados ad-hoc, paradójicamente sería aconsejable, dado que esa forma le exige al 
oyente que active su propia vivencia interna, ya que en las deliberaciones están ausentes casi todas las informaciones específicas. Dicho de otro modo, el lenguaje impreciso estimula la imaginación del oyente, contribuye a desencadenar un movimiento interno en busca de respuestas o expresiones más precisas y concretas. En este sentido, el uso de nominalizaciones ayudaría al ejercicio de la creatividad y de la expansión de posibilidades. Un habla imprecisa debería encaminarse rápidamente hacia un tipo de habla verdadera, para rescatar el contenido preciso de los productos de la imaginación. (Cudicio, 1992). El habla imprecisa y otras formas, enumeradas a continuación, corresponden a la utilización invertida del metamodelo lingüístico, al denominado modelo Milton, en alusión al americano Milton Erickson, tal vez el mayor psiquiatra hipnótico de la época moderna.

El lenguaje para el modelo Milton permite innumerables posibilidades (Bandler/Grinder, 1981), como por ejemplo:

- La utilización principalmente de nominalizaciones, que se prestan a una diversidad de contenidos subjetivos, brinda la posibilidad de despertar la creatividad del interlocutor.

- El uso de presuposiciones del tipo "no se cuál de los dos aparatos vas a comprar" (la suposición es la compra), consideradas uno de los más poderosos patrones lingüísticos, cuando son empleados por un comunicador que presupone aquello que no quiere que sea cuestionado. Un principio general es presentar a la persona muchas otras alternativas de elección siendo que, a pesar de esto, todas ellas presuponen la respuesta que usted desea.

- El uso de vínculos de causa-efecto del tipo "mientras dudamos, nuestros competidores comienzan a ocupar puntos estratégicos" (es un vínculo propiciado por el conector mientras). En estos casos, el comunicador procura vincular algo que está ocurriendo, con algo que él quiere que ocurra, invitando al oyente a responder como si una de esas cosas ocurriese en realidad a "causa" de la otra. Estos vínculos se apoyan en la tendencia reconfortante que las personas tienen de hacer asociaciones, de atribuir una causalidad tranquila, acrítica a determinadas cosas (sobre todo cuando una parte de la sentencia es un hecho que ocurre en la realidad). Una interpretación posible de la sentencia anterior puede ser la de un llamado para evitar la indefinición, la división, como causa posible de la pérdida de posiciones.

- La posibilidad de órdenes encubiertas. En vez de dar abiertamente las instrucciones, el comunicador encubre directivas dentro de una estructura más amplia de la sentencia, que puede ser un relato. Esta técnica puede ser reforzada por la "marcación análoga" que consiste en dar énfasis a determinadas partes de la frase con la ayuda de comportamientos no verbales 
(pausas, entonaciones, gestos, calidad de la voz, etc.) para estimular la atención consciente e inconsciente del oyente.

- Citar a otras personas para presentar indirectamente mensajes, así como metáforas, es otro de los recursos que ayudan a disminuir o a quebrar las eventuales resistencias del oyente, facilitando la transmisión de contenidos. Elaborar una metáfora implica construir un texto que tenga una estructura isomorfa en base a la situación inicial, pero cuyo desenlace se modifica en el sentido en que se pretende transitar.

Citamos tan solo estas posibilidades, con la intención de ilustrar de qué modo la técnica de la comunicación hipnótica puede ser explorada en el campo de la persuasión. Podemos enriquecer esta narrativa citando otras alternativas que son muy útiles:

- El uso de órdenes negativas en personas resistentes o contestatarias, en el sentido inverso de aquello en que son instruidas. Ejemplo: "no quiero que usted tenga una sensación de relajamiento y confort". Una respuesta por oposición puede ser el relajamiento efectivo.

- Evitar en el caso de personas rígidas y contradictorias la utilización exagerada del "sí, pero..." y de los contra-ejemplos, dado que esto puede contribuir a reforzar una posición determinada. Seria mejor seguirle la corriente al oyente, exagerando o enfatizando adrede la problemática o la posición del mismo, dando lugar a que el propio oyente pueda dar los contra-ejemplos necesarios a la reformulación de una posición determinada que insista en mantener. De este modo reaccionará con una alternativa por oposición.

- Anunciar las consecuencias negativas de un no-acuerdo va en dirección de aquella tendencia natural -enunciada anteriormente- de escapar de lo desagradable, pudiendo abrir espacio para posibilidades de acuerdo.

- La modificación intencional del sistema de representación consciente del otro (implícito por ejemplo en las técnicas de disociación) crearía estados alterados de conciencia, que son estados que se caracterizan por una menor resistencia a la posibilidad de nuevos aprendizajes, de un cambio.

- La interrupción brusca (a través de diferentes recursos) de patrones arraigados de comportamiento del otro permitiría a misma lógica anterior y es uno de los recursos más importantes de los procesos de inducción hipnótica. Interrumpir sorpresivamente una conversación monótona, es una interrupción de patrón que genera un estado alterado de conciencia, de confusión, que puede ser explorado a efectos de producir nuevos significados.

Finalizaremos esta parte, haciendo referencia a algunos medios de influencia citados por Cudicio (1992) cuya finalidad seria quebrantar o cuestionar relaciones de causa-efecto implícitas en los enunciados del otro. Estas técnicas pre- 
tenden reorientar la discusión en dirección a nuevas opciones frente a una afirmación perentoria que refleja el "callejón sin salida" al que llegó un conflicto. Servirían por lo tanto para manejar el conflicto de manera creativa y para influir sobre los otros (dando lugar a la modificación de las opiniones).

Veamos un ejemplo: "siempre llegas tarde, esto demuestra que no te importa el trabajo" es un vínculo de causa-efecto y de igualdad. El criterio implícito es la puntualidad para el autor de la afirmación.

Frente a afirmaciones de esta naturaleza, el "menú de influencia" contiene generalmente tres alternativas: desviar, evitar o dar contra-ejemplos. Veamos algunas posibilidades:

\section{Alargar o comprimir el debate}

\section{Alargar}

La técnica consiste en alargar el debate ascendiendo hacia niveles lógicos superiores. Se hablásemos de un gato, podríamos alargar pasando a la categoría felino, luego mamífero, y después animal. Una posible respuesta seria: "¿Qué significa "llegar tarde" considerando que la empresa dispone de toda mi vida activa futura?".

\section{Comprimir}

Inversamente, ahora podemos descender hacia niveles lógicos inferiores: "solo me atrasé exactamente 10 minutos".

\section{Utilizar la jerarquía de criterios}

La técnica consiste en sumar criterios cada vez más importantes: "Para mi lo más importante es la productividad efectiva, no la demora"

\section{Modificar el marco del debate}

Se trata de modificar el marco, o sea el contexto. Podemos modificar su tamaño, su duración o cualquier otro elemento. Por ejemplo: "pareces ignorar lo que ocurrió hoy"; o bien: "¿qué te hace pensar que mi atraso se relaciona con un estado de ánimo? 


\section{Los contra-ejemplos}

Es el "sí, pero...", útil también en el caso de las presuposiciones. Ejemplos: "Si llegaras tarde, significaría que no te importa el trabajo", o "Fulano de tal siempre llegaba tarde, pero su dedicación y su producción desmentían críticas como la tuya".

\section{Refutar}

Es posible refutar el comportamiento externo, el criterio o la causa-efecto.

- El comportamiento: "Usted no lo percibe, pero, en realidad, me importa".

- El criterio: “¿Entonces lo que cuenta para usted es la hora? ¿En qué me transformé aquí adentro? ¿Mi rendimiento no interesa?"

- Causa-efecto: “¿Si no llegase tarde, creerías que me importa el trabajo?”

\section{Reformular, redefinir}

Se puede reformular la frase pero bajo la forma de una interrogación o redefinirla para verificar su exactitud. Cuando afirmamos algo de mala fe difícilmente conseguimos repetir por segunda vez la afirmación con la misma convicción. Ejemplo: "si entendí bien, ¿el hecho de llegar atrasado, significa que no me importa el trabajo?

\section{La estrategia de realidad}

Este trazo distintivo plantea la siguiente pregunta: ¿Cómo sabe una persona lo que sabe, y qué elementos necesita para verificar su experiencia? Ejemplo: “¿Cómo puedes saber que no me importa nuestro trabajo?"

\section{El objetivo}

Interrogamos sobre el objetivo de la persona o sobre su afirmación. Ejemplo: “¿qué ganas preguntando esto?”; “¿qué piensas hacer para solucionar el problema?"; y así sucesivamente.

Se trata de un conjunto de técnicas simples de influencia que buscan desviar la atención del problema o el foco de concentración del otro, desarticular el 
nivel de análisis implícito o enumerar argumentos contrarios a determinadas afirmaciones. De esta manera se pretende suavizar una situación conflictiva o remover a otros de sus posiciones.

En relación al probable sentido manipulador de estas técnicas, se podría afirmar que ninguna técnica es neutra, dependiendo de quién las utiliza. Así como pueden ser utilizadas para inducir posiciones en los otros, pueden también ayudar a detectar esta intención en los interlocutores y a desarticularla. Pueden ayudar, además, a modificar posiciones que hayan sido pensadas equivocadamente como negativas. Ahora, en relación al habla imprecisa, se debe subrayar que esta forma no puede ser absolutizada, sino que presupone un desvío constante hacia el habla verdadera, y que, en ese caso, no se trata de la transmisión de mensajes específicos, sino de generalizaciones que pueden intensificar la creación de ideas nuevas y variadas, útiles para la negociación. Dicho de otro modo, ningún mensaje contrario al punto de vista del interlocutor es transferido; la respuesta está en el propio oyente. Lo importante es rescatar que una estrategia inteligente de combinación de hablas, debe estar subordinada a la búsqueda de un entendimiento duradero, que no signifique la negación absoluta de ninguna de las partes en juego.

\section{Consideraciones finales}

En este trabajo, buscamos plasmar la idea de que la negociación es un proceso de creatividad y de comunicación intensiva. La cuestión central es conseguir generar la mayor cantidad de ideas u opciones, capaces de permitir acuerdos de variado alcance, más que la búsqueda de una única forma o de la fijación en un único tipo de respuesta.

El modelo de negociación es altamente desestructurado, de difícil planificación y control. Depende de las situaciones en juego, de los tipos de negociador y de innumerables variables subjetivas y objetivas. Pero puede realizarse un esfuerzo en el sentido de un mínimo de planificación, cuyo objetivo sea el de llegar a la negociación con alternativas.

En el desarrollo de la presentación del modelo cooperativo, procuramos aportar al gerente los instrumentos de acción para el ejercicio del mismo, convencidos de que a pesar de que la dinámica de la negociación implica asumir diferentes formas entrelazadas y evolutivas, la posibilidad de un acuerdo duradero, superior, se inserta en la perspectiva de ganar-ganar.

Planificar la negociación significa un mínimo de previsión de posibilidades. La simulación de las mismas puede ser facilitada por una guía como la que 
presentamos en el anexo 1, cuyo único objetivo es generar información que puede ser útil, de acuerdo con cada caso real.

Finalizamos aquí, reafirmando la necesidad de un enfoque pragmático que combine argumentación y persuasión, donde esta ultima esté subordinada. Idealizamos, sin embargo, un enfoque argumentativo donde el libre e irrestricto ejercicio de la comunicación crítica sea la tónica. No deja de ser una buena causa.

\section{Referencias Bibliográficas}

BANDLER, R. \& GRINDER, J. Atravessando: passagens em psicoterapia. São Paulo: Summus, 1981. (Anexo final sobre o modelo Milton)

CHALVIN, D. L'Entreprise Négociatrice. Paris: Dunod, 1997.

CHOMSKY, N. Aspects of the Theory of Sintax. Cambridge: MIT Press, 1965.

CUDÍCIO, C. Cómo Compreender la P.N.L.: introducción a la programación neurolinguística. Argentina: Granica, 1992. (Série Alternativa Management)

FISHER, R. \& URY, W. Como Chegar ao Sim: a negociação de acordos sem concessões. Rio de Janeiro: Imago, 1982.

FISHER, R. \& BROWN, S. Como Chegar a um Acordo: a construção do relacionamento que leva ao sim. Porto Alegre: Imago, 1990.

FISHER,R. \& ERTEL, D. Estratégias de Negociação: um guia passo a passo para chegar ao sucesso em qualquer situação. Rio de Janeiro: Ediouro, 1997.

KLUCZNY, J. NLP: practitioner training manual. Seminário NLP in Rio, jan. 1993. (Mimeo.)

MATUS, C. PES: guía de análisis teórico. Venezuela: Fundación Altadir, 1994. (Mimeo.)

MINTZBERG, H. Structure et Dinamique des Organisations. Paris: Les Éditions d'Organisation, 1982.

RIVERA, F. J. U. Por um Contraponto Teórico-metodológico entre o Planejamento Estratégico-Situacional (PES) e o Controle da Qualidade Total (TQC) na Saúde Pública. Rio de Janeiro: ENSP/Fiocruz, 1995. (Mimeo.)

URY ,W. L. Supere o Não: negociando com pessoas difíceis. São Paulo: Best Seller, 1991.

ZAJDSZNAJDER, L. Teoria e Prática da Negociação: política de negociação. Rio de Janeiro: José Olympio, 1988.

ZAPIOLA, C. La Negociación: un enfoque integral con especificas referencias a la negociación laboral. Bogotá: Macchi, 1992. 


\section{(INTER)SUBJETIVIDAD, APRENDIZAJE ORGANIZACIONAL Y CAMBIO: algunas herramientas lúdico-pragmáticas}

Francisco Javier Uribe Rivera

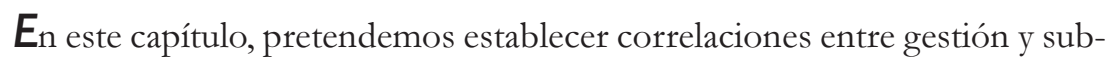
jetividad, y lo hacemos a través del aprendizaje. La determinación de correlacionar nos permite presentar a grandes rasgos, entendimientos teóricos y proposiciones instrumentales típicas del paradigma gerencial de la organización que aprende, correspondientes a una significativa metáfora organizacional.

Aportamos aquí, datos sobre la visión más actualizada de aquel paradigma de liderazgo, entendiendo que el liderazgo es una categoría básica de la gestión y de los procesos de cambio organizacional que acentúa el dilema entre el carácter subjetivo (o individual) y el carácter social de la conducción de esos procesos.

Nuestro objetivo no es negar la subjetividad inherente al campo administrativo, sino cuestionar su uso analítico como categoría o instancia separada de los procesos de interacción comunicativa que definen, desde nuestro punto de vista, la esencia de la gestión administrativa.

Presentamos, también, algunas herramientas utilizadas por la organización que aprende, que se constituyen en instrumentos de reflexión, de diálogo y de negociación, de cuestionamiento de los fundamentos cognitivos y emocionales de la propia percepción y del propio accionar (en general ocultos).

Por último, presentamos estrategias referentes a cómo encaminar procesos de cambio organizacional, fruto de desarrollos recientes de los autores más destacados de la learning organization.

\section{Aprendizaje, Subjetividad y Planificación}

La subjetividad en la gestión es un tema que está al orden del día en función de una relativa crisis de la gestión procedimental y del surgimiento de una nueva 
visión que destaca la importancia de la cultura (en la formulación de los objetivos organizacionales), del liderazgo comunicativo y del aprendizaje organizacional. La organización pasa a ser concebida como una sociedad que aprende a aprender.

El aprendizaje, para los teóricos de la learning organization, debe ser vista como un proceso continuo con las siguientes etapas: aprender a percibir o a reinterpretar una situación, aprender cómo aplicar esta percepción en la formulación de una política y especificación de una acción, aprender como implementar estas políticas y acciones pretendidas, y aprender cómo mantener estos tres últimos items activos, vivos, y abiertos a una constante revisión (http:// www.zumble.com.br;2001)

Esta definición es importante, porque se aproxima significativamente al objetivo de la planificación, área de trabajo dentro de la cual desarrollamos nuestra reflexión desde una perspectiva situacional y comunicativa. La coincidencia que se presenta básicamente entre nuestro enfoque y el de la organización que aprende, tiene que ver con la percepción de la realidad como un proceso mediatizado por nuestro propio recorte situacional, privilegiando aquí el ángulo de nuestra cultura, de nuestros valores y creencias. Esta percepción interesada de la realidad, que extrajimos de Matus (1993), no se distingue de la visión de la realidad como proceso que supone el filtro de nuestros propios modelos mentales, término tan apreciado por los teóricos de la organización que aprende. Los modelos mentales son definidos por Senge y otros autores (1995) como preconceptos profundamente arraigados, generalizaciones o imágenes que tenemos, que influyen sobre el modo como percibimos el mundo y actuamos sobre él.

Maturana (1998) asume que la racionalidad es un plano constituido de premisas que aceptamos porque nos agradan (idea que refuerza el predominio de las emociones sobre lo racional) y que el camino que lleva a la percepción es el de la objetividad entre paréntesis, que significa que el acto de conocer depende del observador y se estructura en tanto uno invite al otro a un tipo de diálogo sobre la validez de las coherencias operacionales del propio conocimiento. Esta posición refuerza la idea matusiana de que existen diferentes formas de explicar una misma realidad, de acuerdo con la perspectiva específica del observador.

Mitroff (1999) es otro autor que señala la existencia de una profunda relación entre la forma de analizar problemas y determinados tipos psicológicos derivados de una interpretación del ser humano basada en Jung. De acuerdo con estos tipos, una misma realidad podrá ser aprehendida de manera más sistemática o de una manera fragmentada y detallista, más volcada a tecnicismos o hacia aspectos humanos y sociales. La particular subjetividad de los individuos contribuirá a la creación de explicaciones y soluciones diferentes que no com- 
portarían el criterio de la solución "correcta". Todas podrán ser encaradas como correctas. De este modo, el acto de analizar problemas implica la necesidad de incorporar a la mayor parte de los implicados en los mismos y de experimentar diferentes enunciados y explicaciones. Dentro de esta línea de complejidad del análisis de problemas, Mitroff formula, además, la idea de que hoy en día la paradoja es una parte esencial de la administración, dado que la realidad reconoce innumerables situaciones "donde más puede llevar a menos", como por ejemplo, la corrida armamentista. La capacidad de lidiar con paradojas sería otro de los atributos fundamentales del arte del liderazgo. Llama la atención, en este autor, que manifiesta la misma preocupación que Maturana acerca de la influencia de las emociones y de la espiritualidad en la posibilidad de lidiar con los fenómenos administrativos y lo cognitivo en general.

No existiendo, por lo tanto, un conocimiento absoluto, independiente del observador, la primera etapa del aprendizaje (interpretativo) se constituye como la posibilidad de interacción lingüística dirigida al cuestionamiento de los modelos mentales que presiden la percepción de los distintos observadores. En este caso en particular, nos referimos al aprendizaje como proceso colectivo u organizacional, que corresponde según Kim (1996), al proceso de transferencia de los contenidos del aprendizaje individual, que redunda en un saber consensual, cristalizado como memoria social tácita o cultura. Es este proceso de socialización del saber que fundamenta, habermasianamente, la validez relativa a contextos concretos del saber como racionalidad.

Resulta extremadamente interesante percibir, que entre los teóricos de la learning organization, la planificación es un proceso de aprendizaje que permite el afloramiento y el cuestionamiento de los modelos mentales de los agentes teniendo en cuenta la posibilidad de una visión compartida. Arie P. de Geus (1997) sustenta así que el verdadero propósito de la planificación eficaz no es hacer planes, sino cambiar el microcosmos, los modelos mentales que los responsables de tomar las decisiones cargan en sus mentes.

En esta perspectiva, la idea burocrática de gabinetes de planificación cede el lugar a una concepción dinámica de laboratorios de aprendizaje, de talleres de planificación donde lo que interesa es más el proceso que el resultado.

Para Kim (1996) el aprendizaje supone un ciclo que se inicia con la captación de nuevos datos, referentes a reacciones del ambiente a una acción implementada, que prosigue considerando los recuerdos de experiencias pasadas, en un proceso de atribuirle significado o de concluir algo sobre este nuevo fragmento de información (aprendizaje individual) y que culmina con el almacenamiento de esos significados bajo la forma de modelos mentales individuales. Este autor destaca la existencia de dos formas de aprendizaje: el operacional, relativo a cómo implementar procesos de trabajo y rutinas (a las habilidades), y 
el conceptual, relativo al porqué de estos procesos o habilidades (al conocimiento). Este último tipo de aprendizaje sería el responsable de introducir nuevas realidades al desafiar la naturaleza propia de los procesos existentes. El aprendizaje efectivo exigiría la presencia de ambas formas.

El mismo autor señala la existencia de ciclos incompletos de aprendizaje. El aprendizaje situacional correspondería a una situación donde los cambios en el plano de la percepción y de la acción sucederían en contextos de mucha especificidad, sin modificar los modelos mentales individuales (administración de crisis). El aprendizaje fragmentado, que llevaría a la pérdida de conocimientos, correspondería a una ruptura entre el aprendizaje individual y el colectivo. El aprendizaje oportunista, correspondería a un tipo de orientación de la acción que rompe el vínculo con la memoria organizacional.

La efectividad del aprendizaje dependería, de ir más allá del aprendizaje situacional y fragmentado y de utilizarse el aprendizaje oportunista. Corregir el aprendizaje situacional implicaría transferir las nuevas percepciones específicas hacia mapas más genéricos de la realidad, situar estos nuevos datos en contextos de mayor complejidad, caracterizados por un elenco más abarcativo y dinámico de relaciones de causalidad (para el autor, los prototipos sistémicos de Senge pueden ser de utilidad aquí). La superación del aprendizaje fragmentado señala la necesidad de laboratorios de aprendizaje, donde se practique el diálogo, la simulación colectiva, la argumentación y la indagación. La utilización del aprendizaje oportunista correspondería a un apelo a la planificación a través de escenarios, entendido como una posibilidad de ampliación de horizontes capaz de superar relativamente el determinismo de la cultura previa.

Dada nuestra formación cultural, pensamos que la aplicación creativa, flexible y simplificada del raciocinio de la planificación estratégica-situacional suple en gran medida las exigencias implícitas en el pensamiento sistémico de Jay Forrester y Peter Senge. Nos referimos, como enunciamos anteriormente, a la idea de una explicación causal totalizadora (más que a la compartimentación del saber) y rigurosa, en el sentido de señalar causas subyacentes y esenciales. Vemos también en la operatividad de los talleres de trabajo de planificación, procesos o laboratorios de aprendizaje donde la búsqueda de un consenso a partir de las diferencias situacionales contribuye a superar el aprendizaje fragmentado y a generar cultura o una comunidad de ideas.

Pensamos, por otro lado, que la planificación situacional matusiana debería enfatizar una importante opinión de Kim (1996), según la cual el modelo administrativo predominante de problema-solución, puede llevar a opacar la pertinencia o no del/los problema(s) seleccionado(s). Para Kim, mucho más importante que la propia problematización, es la capacidad de articulación del problema, entendiéndolo como dependiente de nuestras premisas más pro- 
fundas o modelos mentales. De este modo, descomponer un problema y descubrir el medio de rearticularlo puede proveer mejores condiciones, que solo intentar redoblar los esfuerzos para solucionarlo en la forma en que se presenta inicialmente.

Una de las ideas que más nos impresiona de los teóricos de la learning organization, plantea la relativa fragilidad de la experiencia para proveer elementos para el aprendizaje. Esto se relaciona, como señalamos anteriormente, con el concepto de complejidad dinámica, que profundizaremos más adelante. Aquí plantearemos simplemente que en la actualidad es extremadamente difícil prever con algún grado de precisión las consecuencias de actos que practicamos hoy a partir de determinadas informaciones obtenidas sobre problemas. Estas consecuencias pueden ser remotas o distantes en el tiempo y en el espacio, debido a la intermediación en un determinado ciclo información-acción-resultados, de muchos otros ciclos y agentes. Dada esta difícil previsibilidad de los fenómenos a partir de la experiencia pasada, surge la necesidad de aprender del futuro, entendiendo la técnica de escenarios como un diálogo-narrativa del futuro que en el fondo seria un diálogo sobre los modelos mentales o los filtros que aplicamos en la percepción del futuro (técnica de escenarios como "recuerdo del futuro"). Ese diálogo puede ayudar a redireccionar la visión. No interesa tanto la probabilidad de una narrativa determinada. Ella podrá constituirse, como aprendimos de un alumno de uno de nuestros cursos, en una especie de "profecía autorrealizable", a través de la fuerza de la convicción representada por el compartir.

Nos gustaría terminar esta parte con algunas consideraciones sobre el aprendizaje como fenómeno individual, que depende de la socialización y de una interacción más amplia con el medio, y sobre el aprendizaje como cambio orientado hacia la acción.

Maturana (1998) asume el aprendizaje como un proceso continuo de cambios de comportamiento inducido por la necesidad de una interconexión estructural entre individuo y medio. El aprendizaje corresponde a los cambios ocurridos a lo largo de la vida, en función de una red de interacciones con los otros y el medio, orientado hacia la adaptación frente a las demandas recurrentes. En este proceso histórico se da tanto la (re)producción del individuo como del medio. El aprendizaje, desde lo cognitivo, está orientado hacia el hacer. Aprender es cambiar para hacer. Aprender es hacer. En este contexto interpretativo, nuestro discurso sobre planificación como aprendizaje remite a la necesidad continua de repercepción de situaciones para la delimitación de acciones. Como Matus afirma el fenómeno de la planificación es la mediación entre el conocimiento y la acción. 
Piaget (apud Freitag, 1985), al referirse al desarrollo ontogénico del individuo, sustenta la idea de que esa evolución estaría caracterizada por el fenómeno de la "descentración". A "descentración" constituye un proceso de socialización que llevaría al niño del monólogo (autista) al diálogo, de la acción e interacción a las actuaciones hipotético-deductivas, de la premoralidad a la autonomía moral. En este trayecto el niño realiza un aprendizaje en el cual pasa a distinguir el mundo externo del mundo interno y consecuentemente el mundo externo de los objetos del mundo social. La "descentración" reuniría dos movimientos concomitantes y complementarios: el creciente interés del individuo por el grupo (socialización), traducido en su pensamiento y su lenguaje socializado, y el distanciamiento consciente del individuo en relación a su grupo y a las normas que reglamentan su interacción, traducido en una creciente individualización y autonomía (concientización).

El aprendizaje, aunque básicamente individual, presupone, de este modo, una relación permanente hacia afuera, una intersubjetividad y una relación con el objeto en general, en situaciones de praxis. Dicho de otro modo, las capacidades cognitivas y de socialización que tipifican el mundo subjetivo o de la personalidad constituyen estructuras que se alimentan principalmente de la dinámica de las estructuras del mundo social, de las normas y de los hechos sociales (Habermas, 1987)

La subjetividad, entonces, es indisociable de la intersubjetividad. El dilema que pesa sobre el aprendizaje es la posibilidad de superación del aprendizaje fragmentado y situacional por la ingerencia del diálogo o de la argumentación crítica. Si el aprendizaje es inicialmente individual, aunque ocurra en contextos de interconexión, la posibilidad de que se convierta en usos sistémicos, depende de su transformación en concepciones de mundo o en sistemas de ideas dotados de legitimidad.

\section{Las Corrientes de la Learning Organization}

Actualmente, se identifican tres corrientes (Boyett, 1999):

- Un abordaje que considera que el principal obstáculo del aprendizaje individual y organizacional correspondería a la dificultad de explicitar y cuestionar ("desafiar") libremente los modelos mentales de los participantes de una organización. Este enfoque estaría representado por el trabajo de los profesores Christopher Argyris (especialista en educación y comportamiento organizacional de Harvard) y Donald Schön del Massachutess Institute of Technology (MIT). 
- Un abordaje que se concentra en los problemas de aprendizaje que ocurren cuando los modelos mentales del tipo "sí-pero" están incorrectos por dos razones diferentes: en primer lugar porque atribuyen un relacionamiento causal a algunos eventos y ese relacionamiento no existe y, en segundo lugar, porque no reconocen ese relacionamiento causal cuando está presente. Este abordaje está más asociado al trabajo de Peter Senge, Jay W. Forrester y del Center for Organizational Learning del MIT.

- Un abordaje más cultural, representado por el trabajo del profesor del MIT, Edgard Schein, que explora las relaciones entre las posibilidades de aprendizaje organizacional y las condiciones necesarias desde el punto de vista de la cultura organizacional.

El primer enfoque subraya la necesidad de desacelerar nuestros procesos mentales de modo de poder ser concientes de nuestros modelos mentales, a través de la reflexión, y a adquirir habilidades de indagación y de argumentación que colaboren con el cuestionamiento de nuestros modelos y de los modelos de los otros. Argyris sustenta que las personas tienen la predisposición a sacar conclusiones precipitadas acerca de la conducta de los otros (a "subir la escalera de inferencias"), debido a una lectura parcial de los datos de la experiencia y a una interpretación sesgada de esos datos en función de preconceptos o creencias culturales arraigadas. Por otro lado, el autor señala que el clima organizacional se caracteriza en general por la presencia de rutinas defensivas, que forman parte de un modelo denominado como "incompetencia calificada" (Argyris, 1977) o Modelo 1, que presenta ciertas características:

- Intentar gerenciar el ambiente de trabajo apuntando al mayor control posible de los factores que lo afectan.

- Aprobar y elogiar a los otros. Decir siempre aquello que usted cree que hará sentir bien a las otras personas en relación a sí mismas. No herir sus sentimientos. Decir siempre cuánto se preocupa por ellas y, de ser posible, conciliar cuando dicen que otras personas actuaron inadecuadamente.

- Nunca confrontar las razones o acciones de los otros.

- Defender su posición para vencer. Mantener su posición siempre. Sentirse vulnerable a una franqueza.

- Nunca decirle a los otros todo lo que usted piensa o siente.

- Mantener sus principios, valores y creencias.

Este autor sugiere una serie de técnicas que apuntan a poner en discusión y cuestionar aquello que no se está diciendo en situaciones de interacción que no tienen éxito; e inserir en situaciones de diálogo, un espíritu de indagación, de autocrítica autentica, que posibilite aumentar la capacidad de evaluación del comportamiento defensivo y de las consecuencias negativas no reconocidas. 
Estas técnicas ayudarían a promover una evolución hacia el llamado Modelo 2, definido por Amatucci (1999), como un modelo caracterizado:

- por la búsqueda y elaboración de información válida, testada, ratificada discursivamente;

- por la exploración de ese material en la fundamentación del proceso de toma de decisiones, libre e informada;

- por el compromiso interno con la decisión y monitoreo constante de la implementación.

Si el Modelo 1, es un modelo de comunicación manipuladora, donde predomina la persuasión y la inducción estratégica, marcado por un supuesto racionalismo y por intentar una protección unilateral del otro, el Modelo 2 es un modelo de raciocinio productivo, donde no se trata de salvarle "el pellejo" a nadie, sino de promover un diálogo crítico que no ahogue sentimientos y emociones, que persiga la verdad y la autenticidad, la protección bilateral de sí mismo y del otro (reciprocidad).

Es notorio el parentesco de la Ciencia de la Acción de Argyris, enfatizada por Amatucci en la Teoría Crítica de la Sociedad, y más específicamente con el modelo de la Teoría del Accionar Comunicativo de Habermas. De este modo, surge una conexión interesante entre una metateoría filosófica y una escuela de educación y comportamiento organizacional que solidifica la metáfora de las organizaciones que aprenden.

Senge es el autor que ejerce el liderazgo más fuerte dentro del campo de la “organización que aprende”. En el libro A Quinta Disciplina (Senge et al., 1995), el autor condensa la contribución de diferentes miembros del movimiento, proponiendo a los lectores un conjunto de técnicas pragmáticas ligadas a la posibilidad del aprendizaje. Este autor realiza aportes específicos, en dos áreas importantes de análisis: la dinámica de sistemas y la teoría del liderazgo.

Para Senge (et al., 1995), la dificultad de reconocer los relacionamientos de causalidad sistémica, se debe al hecho de que nuestros modelos mentales trazan la imagen de un mundo unidireccional, en el cual un problema lleva a una acción que lleva a una solución. Nuestros modelos mentales implican una estructura

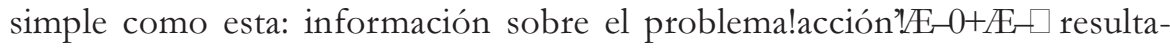
do. Sin embargo, vivimos en un ambiente circular continuo, donde cada acción se basa en las condiciones actuales. Estas acciones afectan las condiciones, y las condiciones alteradas, se transforman en la base de las acciones futuras. El proceso no tiene comienzo ni fin. Las personas están interconectadas. Muchos de esos loops están interrelacionados. A través de largas cadenas de acciones en cascada, cada persona reacciona continuamente al eco de sus propias acciones anteriores, así como de las acciones de los otros. El mundo es un gran espiral de 
causalidad donde causa y efecto giran continuamente. Este espiral puede girar de forma ordenada o estirarse azarosamente, con grandes lapsos de tiempo entre acción y resultado. En los sistemas compuestos de feedbacks en interacción y largos intervalos de tiempo, las causas de un síntoma observado pueden ser provenientes de una sector totalmente diferente del sistema, y muy distante en el tiempo. Para confundir aún más las cosas, tales sistemas presentan indicios, que fuimos condicionados a esperar. Pero, en general, esos síntomas coincidentes o causas aparentes surgen de una causa distante. Las personas son de este modo atraídas por acciones que no son relevantes al problema en cuestión.

Los autores proponen un entrenamiento dentro del pensamiento sistémico, capaz de ayudar a mejorar las percepciones de esos relacionamientos de causalidad. Los principales elementos de ese entrenamiento serían:

- El modelado dinámico de sistemas, que consiste en crear sistemas o modelos en el computador, simular su comportamiento, explorar cómo reaccionan los modelos a los cambios en la estructura y en las políticas y comparar el comportamiento del modelo con los sistemas reales que están siendo presentados. El modelado de sistemas es una actividad participativa, en la cual se aprende por prueba y error y a través de la práctica. Es el aprendizaje a través de la sorpresa de los errores cometidos.

- El uso de los llamados "prototipos sistémicos" (ver anexo do capítulo), término acuñado por Senge para denotar ciertas regularidades o patrones de comportamiento sistémicos que se verifican continuamente en las situaciones de negocios. El reconocimiento del prototipo en particular, que corresponde a una determinada situación problemática, así como el ejercicio de una estrategia de cuestionamiento adecuada a ese patrón de conducta, podrían mejorar el raciocinio sistémico y proveer eventuales alternativas de acción.

- El uso de juegos de negocios, como los "micromundos" y "simumundos" (de Senge), que consisten en verdaderos simuladores de vuelo, donde los participantes toman decisiones y evalúan los resultados de las mismas en situaciones que no ofrecen riesgo y que comprimen las dimensiones de tiempo y espacio. Estos juegos ayudarían a valorizar la interconexión de los eventos, a testear modelos mentales y a percibir el comportamiento dinámico de sistemas.

Como adelantamos anteriormente (Rivera, 2000b), tenemos cierta resistencia a la adopción de patrones interpretativos que no correspondan a nuestros referenciales culturales. El desconocimiento de los elementos del pensamiento sistémico según la matriz de Forrester, puede explicar esta reticencia. La idea de que unos pocos prototipos son capaces de contemplar la diversidad de situaciones problemáticas vividas, nos genera cierta incomodidad. Esa idea nos sugiere un cierto reduccionismo. 
Sin embargo, adherimos a las ideas de fondo del análisis de Senge, que darían, según nuestra lectura, la posibilidad de:

- Desarrollar explicaciones complejas de la realidad, capaces de señalar las causas esenciales de los fenómenos y la relación dinámica de las causas en general. El modelo de una explicación situacional al estilo matusiano, de naturaleza autorreferencial, policéntrica, totalizadora y rigurosa, puede suplir la necesidad de un enfoque de causalidad como el aconsejado por Senge.

- Establecer prácticas de simulación que ejerciten el raciocinio del tipo "sípero". En este caso, nos referimos a la planificación estratégica de escenarios, que nos permite simular la construcción de situaciones futuras, como consecuencia de la interconexión del comportamiento de diferentes variables clave y de la dinámica de los actores sociales que controlan esas variables, y que nos ayuda a pensar qué hacer en situaciones alternativas de futuro. Este raciocinio condicional sería un elemento del aprendizaje organizacional de extrema importancia, pues nos ayudaría a desarrollar la capacidad de cambio en función de la circunstancia real futura que pretendemos simular "ex ante" con nuestro modelo. En esta perspectiva, confrontar las diferentes posibilidades de futuro ejercería una tensión contraria a la rigidez de posiciones. Dado su carácter reduccionista, preso a lo esencial o motriz, la planificación de escenarios sería también una herramienta auxiliar poderosa en el desarrollo de un tipo de pensamiento dirigido hacia la complejidad dinámica, que definimos como una narrativa que relativiza la extensividad del detalle y que se vincula al movimiento evolutivo de variables, tendencias y relacionamientos realmente relevantes. Por último, pensar el escenario futuro nos permitiría crear una perspectiva opuesta al determinismo de nuestra cultura, al obligarnos a pensar en nuevas posibilidades no previstas con claridad, en función de nuestra tradición.

- Establecer dinámicas dialógicas que ayuden a discernir y a cuestionar los modelos de pensamiento que subyacen en las diferentes explicaciones posibles de una realidad. La radicalización de la idea de una explicación situacional, que acentúe el policentrismo y la necesidad de descubrir las premisas y los intereses valorativos que condicionan las diferentes lecturas, se inscribe dentro de esta perspectiva.

Schein (2001) es el tercer autor del movimiento citado como formulador del enfoque cultural. La cuestión central de su planteo es qué tipo de cultura sería necesaria para el aprendizaje y cómo crearla. La cultura necesaria para el aprendizaje presentaría algunas características:

- Equilibra los intereses de todos los involucrados: ningún grupo domina el pensamiento de la gerencia, dado que es sabido que cualquiera de estos grupos (clientes, empleados, proveedores, etc.) puede retardar y destruir la organización. 
- Se concentra en las personas, no en los sistemas: se cree en la capacidad de aprender de las personas, valorizando el aprendizaje y el cambio.

- Logra que las personas crean en la posibilidad de cambiar su ambiente: el autor se plantea la siguiente pregunta: si creemos que el mundo que nos rodea no puede ser modificado, ¿de qué sirve aprender a aprender? Relájese y no intervenga sobre algo predestinado.

- Encuentra tiempo para el aprendizaje: Un cierto tiempo de "descanso" es deseable para ser usado para el aprendizaje. Como dice el autor: ser seco y malo no es una buena receta para el aprendizaje organizacional.

- Adopta un abordaje holístico de los problemas: estos presentan múltiples dimensiones interconectadas y mecanismos de causalidad complejos.

- Estimula la comunicación abierta: Existe un compromiso con una comunicación total y con la verdad. Desarrolla un vocabulario común que permite la comunicación.

- Apuesta al trabajo en equipo: la competición individualista no es vista como la respuesta para todos los problemas.

- Tiene líderes accesibles, que reconocen su vulnerabilidad e incertidumbre, que se piensan a sí mismos como profesores y agentes de cambios y no como carismáticos responsables por la decisión.

Schein (2001) reconoce que la cultura que predomina en las organizaciones es lo opuesto y que, en general, a causa de las inducciones de esa cultura y de un modelo escéptico de la naturaleza humana, no habría espacio suficiente para el desarrollo libre del aprendizaje colectivo. Por tales razones, el autor sugiere la necesidad de creación de "puertos psicológicamente seguros" para el aprendizaje o de sistemas paralelos (dentro o fuera de la organización) donde las personas tendrían la oportunidad de un entrenamiento y práctica, apoyo y estímulo para superar el miedo y la vergüenza de cometer errores, entrenamiento y recompensas por los esfuerzos en la dirección correcta, y normas que recompensen la innovación y la experimentación. Schein desiste del núcleo de la organización como posibilidad de un ambiente seguro que actúe como cuna del aprendizaje para el cambio, y plantea que ese sistema paralelo debería ser creado en la cima de la organización, teniendo al ejecutivo como principal alumno y representado por su entorno.

En este punto, se observa una importante contradicción entre Schein y Senge. Para Senge la idea de que todo cambio importante viene de arriba, es un mito que debe ser combatido y sustenta una visión ecológica del liderazgo, que sobrentiende la necesidad de encarar toda la organización, como la posibilidad de un ambiente seguro para el ejercicio del aprendizaje hacia la transformación. De cualquier modo, subsiste la duda: ¿cómo crear un ambiente seguro para el 
aprendizaje rompiendo con el condicionamiento de una cultura impositiva, sin apelar a inducciones externas?

Se nos ocurre que: buscar formas de distanciarse de la cultura, observándola desde afuera (a través de un cambio ambiental y de un diálogo interdisciplinario); intensificar los procesos comunicativos dirigidos hacia el procesamiento de aspectos disfuncionales de la cultura, para encaminar pragmáticamente los problemas reales; como así también la afirmación de las diferencias, representadas por los aspectos individuales o subjetivos, encubiertos por la noción de cultura, pueden representar pistas generales para responder positivamente a la cuestión anterior. Señalamos nuevamente la importancia de la planificación a partir de escenarios, como forma de distanciamiento de la tradición y de la experiencia acumulada.

\section{¿Liderazgo Individual o Colectivo?}

En el capítulo anterior, analizamos las habilidades básicas y las formas de desarrollo del liderazgo, según Senge. Recalcamos la capacidad del liderazgo de constituirse en un proceso de construcción interactivo de la visión, sin anular los puntos de vista personales. El liderazgo, entendido de este modo, debería saber administrar la diversidad dentro de una misma perspectiva y lidiar creativamente con las antinomias y paradojas. Destacamos también el papel educativo del liderazgo que consistiría en propiciar un ambiente de discernimiento y de análisis crítico de los modelos mentales individuales y sociales de los participantes de una organización. Esta capacidad de posibilitar sumergirse en las estructuras interiores, profundas, de las personas organizacionales es una forma de rescatar la importancia de lo subjetivo dentro de los procesos administrativos.

En el libro La Danza del Cambio (1999), Senge desarrolla la versión más actualizada de su concepción de liderazgo. A partir de la metáfora del jardín, el autor confronta la imagen del liderazgo-héroe. El liderazgo "jardinero" no es aquel tipo que postrado sobre las plantas implora: "Crezcan plantas, crezcan con ahinco". Este liderazgo, por el contrario, reconoce que el crecimiento depende de su potencial y se decide a acompañar su ciclo natural, preocupándose por las condiciones que refuerzan y que limitan su crecimiento (agua, suelo, nutrientes, sol, otros árboles...). Por detrás de esta imagen está la idea de que las organizaciones deben ser vistas como sistemas biológicos y no como máquinas. En el caso de una concepción mecanicista de la organización, cuando surge un problema, es asimilado bajo la condición de una pieza defectuosa que debe ser cambiada. En la concepción biológica organizacional, lidiamos con gente, con personas, que al igual que las plantas, no pueden ser tratadas como piezas de un 
engranaje maquinal. En el caso del jardín, una planta no muere para ser reemplazada simplemente por otra. Lo que sucede es que una nueva va creciendo y acaba tomando el lugar de la vieja. Lo mismo ocurre con el comportamiento. Si un comportamiento nuevo es más eficaz que el antiguo, entonces el nuevo acaba conquistando espacio. De este modo, el líder-jardinero sería aquel que intenta actuar sobre las condiciones limitadoras y promotoras del desarrollo potencial de las personas organizacionales, especialmente sobre las condiciones básicas para un aprendizaje colectivo y solidario. Estas condiciones de aprendizaje, serían los factores propulsores o realizadores del potencial de crecimiento de las personas, potencial que podría ser inhibido en contextos impositivos y objetivantes.

El liderazgo para Senge, no sería un factor individual; o solamente individual. Dentro de su visión ecológica, el liderazgo corresponde a la capacidad colectiva para moldear los cambios. En una organización habría diferentes líderes, en diferentes niveles, no necesariamente ejecutivos. Entre ellos se destacan los "que portan la semilla", esto significa aquellos que tienen la capacidad de establecer redes más o menos informales de comunicación; de impulsar, en todos los niveles, en relaciones de transversalidad, la posibilidad de transferencia de habilidades y de conocimientos. Estos líderes construirían su potencial, a través de su capacidad de establecer interconexiones entre innovadores.

Para el autor, los grandes problemas que enfrenta el cambio son de tipo gerencial. Se relacionan a la incapacidad de generar una dinámica de negociación a partir de una visión compartida; a la dificultad de poner en discusión temas "indiscutibles" mediante el desarrollo de habilidades de reflexión e indagación; a la tendencia de evitar enfrentar las causas más complejas de los problemas en pro de un tratamiento sintomático; a un tipo de conducta defensiva que escatima medidas que puedan afectar intereses, etc.

Estas restricciones, típicas de la despreocupación de los dirigentes por el aprendizaje colectivo, pueden ser compensadas a través de estrategias de aprendizaje. Pero esto no es suficiente. El cambio exigiría una mayor concentración sobre los aspectos limitadores del crecimiento, entendiendo el cambio no como reemplazo o substitución, o producción de algo absolutamente nuevo, sino como crecimiento (como evolución de lo nuevo a partir de lo antiguo). La referencia de Senge a Maturana: "la historia es la transformación para la conservación", o dicho de otro modo: "cada movimiento está siendo inhibido a medida que ocurre", corresponde al reconocimiento de tendencias naturales de compensación o de limitación del crecimiento, que deberían ser el blanco privilegiado de una reflexión estratégica sobre cómo actuar para debilitar o atenuar esas tendencias, y para prolongar los momentos de inflexión compensadora. Toda esta reflexión apunta a la necesidad de pensar, no en términos de imponer cambios, sino de cultivar cambios. 
Esta perspectiva no pretende afirmar que el liderazgo no sea individual, sino que plantea las relaciones entre capacidades individuales y sociales. Intenta reforzar la idea de que el líder es quien fomenta los procesos de aprendizaje que pueden generar un liderazgo diseminado, de que el desarrollo del liderazgo como instancia individual depende de interacciones típicas del fenómeno social del aprendizaje.

Como vimos anteriormente, Motta (1991) formula que la esencia del liderazgo consiste en la capacidad de dominar el contexto (capacidad de análisis estratégico del ambiente y de los problemas organizacionales, de intuición del futuro y de formulación de la visión), capacidad de manejo intersubjetivo (comunicación y negociación) e individuales (como un gran conocimiento de sî mismo, la capacidad de socialización y la autenticidad). Reforzando la dimensión subjetiva, el autor se detiene en la importancia de lo ilógico y de la intuición en la gestión administrativa, que explican el carácter a veces poco coherente e irracional de las decisiones tomadas. Motta plantea además, que la intuición mezcla elementos de racionalidad formal e informal y que esta se apoya fuertemente en la experiencia acumulada a través del liderazgo. El destacar la dimensión subjetiva, en cuanto a lo formal o racional del liderazgo actúa aquí como un argumento importante para no omitir la naturaleza individual de la misma.

En Bennis, otro autor ya citado, encontramos finalmente, ideas importantes sobre el liderazgo como un fenómeno vinculado prioritariamente a la movilización de las personas (y no necesariamente a la inducción de la motivación), a la reflexión futurista de la gran visión en detrimento del detalle operacional y al desarrollo de la innovación. De un modo diferente a la lógica del control, inherente a la gestión tecno-burocrática clásica, el fenómeno del liderazgo actuaría como el ejercicio del poder para el desarrollo de dinámicas de equipo y de interacción disciplinaria que favorecerían la innovación y el cambio. La promoción del liderazgo dependería mucho, de un tipo de aprendizaje caracterizado por el tránsito cultural entre disciplinas diferenciadas e informaciones aparentemente distantes. Esta línea de pensamiento refuerza, por lo tanto, la idea del liderazgo como proceso de aprendizaje y como instancia de movilización de las capacidades individuales e intersubjetivas de la organización.

\section{Consideraciones Intermediarias a Título de Recapitulación}

El nexo que establecemos entre subjetividad y gestión, corresponde al entendimiento de la organización como sociedad que aprende, y de la planificación como comunicación dirigida hacia la discusión crítica de los diferentes modelos mentales (a nivel individual) involucrados en el análisis de problemas. 
El aprendizaje es entendido como proceso individual de adquisición de conocimientos y habilidades, dependiente de la socialización y de procesos de interconexión con el medio, en el sentido de lo trabajado por Maturana y por Piaget en relación al proceso cognitivo en general.

El aprendizaje como proceso social correspondería a la superación del aprendizaje fragmentado, que ocurre cuando el aprendizaje individual no se preocupa por una transferencia de contenidos hacia los grupos y organizaciones (o por compartir).

La subjetividad es por lo tanto indisociable de la intersubjetividad, y se expresa en la gestión a través de ella. Esto no implica su disolución o anulación en o por el patrimonio social o cultural. La diferencia no puede ser negada, debe ser afirmada cuando sea necesario.

La cuestión del liderazgo ofrece un campo interesante para la reflexión sobre cómo características subjetivas y sociales ligadas a la gestión organizacional se atacan mutuamente. Liderazgo es tanto una capacidad individual como social, entendido tanto como resultado, como posibilidad del aprendizaje organizacional.

Las capacidades de reflexión y de diálogo, de argumentación y de indagación, la capacidad de poner en discusión lo no dicho que condiciona el habla de los sujetos organizacionales y de cuestionar algo indiscutible en una organización, el uso de la planificación de escenarios como "recuerdo del futuro" (análisis de los filtros mentales que condicionan nuestro modo de mirar hacia el futuro) y aprendizaje de la capacidad de cambio, el análisis de problemas como posibilidad de cuestionamiento de nuestras creencias, son, entre otras, capacidades de aprendizaje que pueden redundar en visiones compartidas, superando el aprendizaje fragmentado, y generando un saber común que alimenta la cultura de una organización.

La afirmación de la individualidad y el distanciamiento en relación a la cultura pueden significar, por ende, la posibilidad de la diferencia innovadora.

\section{Algunas Técnicas de la V Disciplina}

\section{La columna de la izquierda}

El objetivo de esta técnica es tomar conciencia de las suposiciones básicas que orientan nuestra conversación y que contribuyen a crear obstáculos en situaciones cotidianas, y desarrollar una forma más clara de hablar sobre estas suposiciones.

Consta de los siguientes pasos: 


\section{Primer paso: elegir un problema}

Seleccione un problema difícil que haya abordado recientemente, esas dificultades interpersonales que muchos procuramos ignorar:

- No consigue llegar a un acuerdo con un colega.

- Otra persona no se empeña lo suficiente.

- Usted se considera víctima de un trato injusto.

- Cree que nadie considera su punto de vista.

- La organización resiste (o cree que resistirá) a un cambio que usted pretende implementar.

- Cree que su equipe no presta atención al problema fundamental.

Escriba un párrafo breve describiendo la situación. ¿Cuál es su objetivo?, ¿quién pone obstáculos?, ¿qué podría suceder?

Segundo paso: la columna derecha (lo que fue dicho)

Ahora recuerde una conversación frustrante que tuvo, o imagine la conversación que hubiera tenido si hubiese tocado el tema.

En un papel o en varios haga un cuadro con dos columnas.

En la columna derecha, escriba el diálogo tal como fue; o anótelo tal como cree que sería se plantease el problema. El diálogo puede continuar por varias páginas. Deje la columna izquierda en blanco hasta terminar.

Tercer paso: la columna izquierda (lo que usted pensaba o sentía)

Ahora, en la columna izquierda, escriba lo que pensaba y sentía, sin decirlo.

Cuarto paso: reflexión (utilización de la columna izquierda como recurso)

Podemos aprender mucho al registrar una situación por escrito, guardarla por una semana y luego analizarla. El caso se transforma en un instrumento que nos permite examinar nuestros pensamientos como se fuesen de otros.

$\mathrm{Al}$ reflexionar, pregúntese:

- ¿Qué me indujo a pensar y sentir de esa manera?

- ¿Cuál era mi intención?, ¿qué pretendía alcanzar?

- ¿Alcancé los resultados que buscaba? 
- ¿Cómo influirían mis comentarios sobre las dificultades?

- ¿Por qué no dije lo que estaba en la columna de la izquierda?

- ¿Qué prejuicios tenía sobre la otra persona?

- ¿Cuál fue el precio de actuar de esa manera? ¿Cuáles fueron los frutos?

- ¿Qué me impidió actuar de otra manera?

- ¿Cómo puedo usar mi columna de la izquierda como recurso para mejorar nuestras comunicaciones?

Imaginé mi interacción con un colega, Bill, luego de que él hizo una presentación extensa para nuestro jefe, relativa a un proyecto en que estamos trabajando juntos. No pude asistir a la presentación, pero oí decir que fue mal recibida.

\section{Lo que estoy pensando}

Todo el mundo está diciendo que la presentación fue una bomba. ¿Será que él sabe que fue tan mala?

¿O será que él no está dispuesto a enfrentarlo?

Él está realmente con miedo de enfrentar la verdad. Si él tuviese más auto-confianza, probablemente aprendería algo de una situación como esta

No puedo creer que él no perciba que la presentación fue desastrosa para la continuidad de nuestro trabajo.

Necesito encontrar el modo de lograr que este "tipo" despierte.

\section{Lo que es dicho}

Yo: ¿Cómo fue la presentación?

Bill: Bueno, no se. Es muy temprano aún para saberlo. Además, estamos pisando en terreno nuevo

Yo: Bueno, ¿qué crees que debemos hacer? Creo que las cuestiones que planteaste son importantes.

Bill: No estoy tan seguro. Vamos a esperar a ver qué sucede.

Yo: Tal vez tengas razón, pero creo que tal vez necesitemos hacer algo más que simplemente esperar.

Fuente: ejemplo no problematizado presentado por Senge et al., 1995. 


\section{Lo indiscutible}

Este ejercicio tiene como objetivo, aprender a partir de temas tabú, tan indiscutibles que ni siquiera se discute el hecho de que sean indiscutibles.

Los pasos son los siguientes:

\section{Primer paso: compilando datos}

Cada participante del equipo recibe tres tarjetas y lapiceras del mismo color. Sin discusión ni colaboración, cada persona anota un problema indiscutible en cada tarjeta, describiéndolo detalladamente para que todo el mundo lo entienda. Si la conducta de alguien forma parte de lo indiscutible, debe hacerse referencia al cargo y no al nombre de la persona.

\section{Segundo paso: distribuyendo las tarjetas}

Primera opción: alguien junta las tarjetas, las mezcla y las distribuye, o bien, hace una pila y deja que la gente las tome. Los miembros del equipo colocan la tarjeta en la mesa, boca arriba, a medida que las extraen.

Segunda opción: después de cinco minutos, todos salen de la sala, llevando sus tarjetas. De a uno, los miembros del equipe entran en la sala de reunión y esconden sus tarjetas. Cuando todas hayan sido escondidas, las personas vuelven a sala y buscan encontrar tres tarjetas.

\section{Tercer paso: revelando temas comunes}

Cada persona lee en voz alta las tres tarjetas del paso 2 y las pega en la pared. Cuando todas hayan sido leídas, los miembros del equipo las agrupan temáticamente. El equipe debe decidir cuántos temas serán abordados durante la reunión, dejando los otros para después. Es aconsejable comenzar por los temas indiscutibles más fáciles.

Estas pregustas ayudan a orientar el diálogo:

- ¿Cuál es la amenaza que se esconde detrás de lo indiscutible?

- ¿Qué modelo mental permitió la persistencia de esta estructura oculta?

- ¿Qué impide que este tema sea discutido con seriedad?

- ¿Cuáles son las consecuencias indeseables del indiscutible, en el pasado, presente y futuro? 
- ¿En qué medida este indiscutible sustenta u obstaculiza nuestra capacidad para el aprendizaje en equipo?

- ¿Cómo se relaciona el indiscutible con la visión y los valores a los que suscribimos?

- ¿Qué deseamos hacer con este indiscutible?

\section{Perspectivas múltiples}

El objetivo de esta técnica es ampliar las perspectivas del equipo, los puntos de vista desde los cuales sus miembros examinan un problema. Se trata de estimular la rotación de roles de modo de permitir que los miembros de un equipo vean un tema importante desde la mayor cantidad de perspectivas posibles. En primer lugar, se debe definir el problema o el tema a ser analizado y escribir en tarjetas el cargo o la posición de los diferentes actores representados en este equipo. Deberían ser convocados los diferentes actores involucrados en el problema en cuestión.

Los participantes tomarían de a uno, una tarjeta de la pila que fue mezclada y se movilizarían hacia la posición representada en ella. Asumiendo esta nueva posición, harían comentarios sobre el problema, acerca de cómo analizar el mismo, y/ o sobre cómo abordarlo. Los comentarios deben ser necesariamente registrados.

En algún momento usted se deparará con descripciones completas de cada perspectiva. En ese momento, el equipo puede comentar la situación desde cada una de ellas. Podemos llegar a la conclusión, por ejemplo, que la perspectiva del representante de finanzas incluye tres puntos de vista o que la posición de las finanzas contiene tres perspectivas. Cada una de esas perspectivas podrá ser analizada por separado desde diferentes ópticas.

\section{Escribir siendo leal}

El ejercicio tiene dos objetivos: ayudar a identificar con mayor claridad sus propios modelos mentales en relación a las personas clave de su organización y abordar una dificultad desde diferentes perspectivas. También puede ayudar a adquirir habilidad política.

El ejercicio consiste en escribir tres versiones de un informe o memorándum y analizar a continuación las diferencias.

Usted tendría que elegir una situación difícil que se presenta inesperadamente, sobre la cual escribirá un informe. Enumere algunas personas con las 
que usted espera ser leal al momento de escribir ese informe. Algunas pueden ser simbólicas o hipotéticas. A continuación, elija dos personas o grupos de personas, que leerán el informe cuando este concluido. Elija también mentalmente su lealtad para con la verdad tal como usted la ve.

Escriba, inicialmente, una descripción de la situación como si su lealtad fuese únicamente con la verdad. Utilice preferentemente tres párrafos:

- Presentación: Imagine que las personas leerán su informe en un futuro lejano. ¿De qué manera desearía atraer su atención?, ¿qué podría decir, que resulte interesante para que ellas deseen continuar leyendo? ¿qué cree que les gustaría saber primero?

- Núcleo (párrafo central): Aquí debe constar el núcleo del relato: ¿qué ocurrió, a quién, dónde, cuándo, por qué y para qué? ¿Qué ocurrio, qué significa, quién participó?

- Cierre (párrafo final): ¿qué es lo que usted quiere que sientan las personas en un futuro, cuando hayan terminado de leer el relato? ¿Cómo espera que reaccionen? ¿Cuál es su mensaje? ¿qué le sugiere el informe? ¿Existe alguna moraleja o algún plan de acción implícitos?

Cuando haya terminado, olvide el informe por unos dos días. Este trabajo será su grupo testigo.

Escriba, ahora, los informes correspondientes a las dos personas elegidas, pensando en la imagen de estas personas al momento de la lectura de las palabras del memorándum. Haga de cuenta que no les mostrará los resultados. Se sugiere aquí también escribir tres párrafos, a partir de las preguntas anteriores.

Usted tiene ahora tres informes. Analícelos como se fuese la primera vez y responda estas preguntas:

Observe primero el informe "sinceramente":

- ¿Cuál es la impresión que le deja el autor del informe?

- ¿Qué datos (del texto) lo llevan a esta conclusión?

- ¿Cuál es la impresión que obtiene partiendo solamente del informe, de la historia y de los hechos respectivos? ¿Cuán importantes son estos hechos?

- ¿Qué frases específicas generarían esa impresión?

Ahora observe los otros dos informes (uno después de otro):

- ¿Cuál es la impresión que usted obtiene, a partir del primer informe, de la persona A?

- ¿Qué parte del texto le deja esa impresión? Por ejemplo, ¿qué elementos figuran aqui que no se incluyen en los otros?

- Observando el párrafo inicial, ¿Qué cree el autor que le interesará a A?

- ¿Qué es lo que el autor desea que A ignore? ¿Qué datos o detalles son omitidos? 
- ¿A qué conclusión quiere el autor que llegue A? ¿Cómo quiere que reaccione $A$ ?

- Ahora imagine que usted le muestra el resultado a A. ¿Aceptaría A el tipo de evaluación y las premisas? ¿se sentiría conforme o disconforme?

- ¿Es posible verificar las premisas que llevaron a esas respuestas? ¿Existe alguna razón por la cual puedan no ser ciertas?

Debe escribir aún un informe final a partir de las tres versiones iniciales, de las cuales extraerá los nuevos párrafos. Concéntrese en esas versiones y vea si es posible sintetizarlas. Revise la versión final teniendo en cuenta nuevas lealtades. Identifique los cambios que sean necesarios para que este informe sea digerible para todos.

Finalmente, entregue estas cuatro versiones a las personas A y B, preguntándoles qué versión preferirían, y qué material debería ser enfatizado en la versión definitiva.

\section{Proyector y Pantallas}

El objetivo de este ejercicio es observar la mente colectiva en acción; ver dos perspectivas polarizadas y aprender a tomar distancia de las posiciones rígidas tradicionales. Cada participante representa el papel de alguien que enfrenta un dilema y plantea dos puntos de vista sobre ese problema.

Un miembro de cada equipo se propone como proyector. Debe exponer su dilema y las dos alternativas. Este dilema debería ser real, inminente, a ser resuelto. El proyector elige qué persona representará cada aspecto del dilema, la cual actuará como pantalla sobre la cual proyectará sus pensamientos.

Las "pantallas" deben compenetrarse en el papel atribuido, procurando debatir el dilema no desde un punto de vista personal, sino a partir del punto de vista del papel que está representando (de la mejor forma posible). El proyector escucha en silencio, reflexionando.

El proyector comunica a las "pantallas" lo que sintió mientras escuchaba y los tres miembros de cada equipo comienzan a visualizar frente a ellos los preconceptos y pensamientos acerca del dilema.

Finalmente, los diferentes equipos se reúnen y hacen un resumen general.

\section{Protocolos de Discusión Especialista (Hábil)}

Es útil escribir los protocolos en tarjetas, para que los miembros del equipo de discusión los tengan a mano durante las reuniones. 
Sugerencias para los contenidos de las tarjetas:

- Preste atención a sus intenciones: ¿qué deseo de esta conversación? ¿Estoy dispuesto a recibir influencias?

- Equilibre la argumentación con el cuestionamiento: ¿qué la o lo llevó a ese punto de vista? ¿qué significa ese punto de vista?

- Elabore un sentido compartido: Cuando usamos la palabra ¿qué queremos decir?

- Sea conciente de sus reacciones: ¿qué estoy pensando? ¿qué estoy sintiendo? ¿qué es lo que quiero en este momento? ¿qué me impide buscar lo que quiero?

- Explore las presiones: ¿Cuáles son nuestros puntos de acuerdo y en qué disentimos?

Preparar el terreno para una discusión de este tipo significa:

- Procurar un terreno neutro para la discusión, donde no haya símbolos de poder y prestigio y los miembros del equipo se traten como colegas.

- Actuar de modo de crear un clima de confianza y sinceridad.

- Estimular y recompensar la introducción de nuevas perspectivas, incorporando eventualmente fuentes externas de nuevas perspectivas.

- Planifique bien los temas de discusión (divulgados con anticipación) y el contexto de la discusión, evitando distracciones y una jornada muy prolongada.

Para poder desarrollar la capacidad de escucha durante una reunión de este son necesarios algunos requisitos:

- Deje de hablar con los otros y consigo mismo. Aprenda a silenciar su voz interior.

- Imagine el punto de vista de otra persona. Colóquese en la posición del otro, en el contexto del otro.

- Preste real atención y demuestre interés.

- Observe la conducta no verbal para captar otros significados.

- No interrumpa. Aumente su nivel de tolerancia.

- Escuche "entre líneas". Tome en cuenta el sentido figurado del lenguaje. Capte las omisiones del discurso, las cosas que no son dichas que por lógica deberían estar presentes. Pregunte sobre ellas.

- No critique mientras escucha. Evite comentarios críticos e intempestivos en ese momento. Limítese a dar respuestas constructivas hasta que el contexto haya cambiado y las críticas puedan ser expuestas sin que parezcan acusaciones. 
- Escuche activamente, expresando con otras palabras lo que los otros han dicho durante la conversación.

- Deje de hablar. Haga un voto de silencio por un tiempo.

\section{Vivero}

El objetivo de esta técnica es perfeccionar nuestro estilo de comunicación en un ámbito de discusión especialista (hábil).

Descripción: la mitad del equipo (en un círculo interno) discute un tema, mientras la otra mitad (en un círculo externo) observa. La crítica se realiza de a dos personas, no con todo el grupo, de modo que las personas se sientan más cómodas para intercambiar comentarios.

Aborde un tema difícil: un problema recurrente, una racionalización, un fracaso, algo "indiscutible"....

Pasos:

\section{Primer paso: estableciendo una conexión}

Cada miembro del equipo elige un colaborador en quien confíe. Los colaboradores se sientan de a dos y se hacen las siguientes preguntas:

- ¿Qué opiniones contundentes tiene (como individuo) sobre este tema?

- ¿Qué datos observables (hechos, no opiniones) puede usted aportar para la discusión?

- ¿Está abierto a las influencias?

- ¿Cuál es su visión sobre un desenlace satisfactorio de la discusión?

El objetivo de esta descripción es garantizar que ambos colaboradores entiendan los conceptos, valores y aspiraciones del otro.

Segundo paso: grupo $A$, en el centro (20 minutos)

Ubique las sillas en dos círculos concéntricos, sin mesas. Un colaborador de cada grupo se integra al grupo A y el otro al B. Los grupos se alternarán en la conversación y observación. Los que se sienten en el círculo interior (grupo A) inician la conversación, siguiendo los protocolos de la discusión especializada, definiendo el tema y abordándolo del modo que consideren más conveniente. Los miembros del grupo B adoptan el papel de observadores/instructores. Se 
sientan al lado de los colaboradores, de modo que puedan verse y escucharse con facilidad. Cuando le toque el papel de observador/instructor, use estas preguntas como parámetros; tome nota sobre ejemplos específicos (incluyendo los comentarios) que ilustren su percepción de la destreza del colaborador.

Mientras su colaborador argumentaba, ¿cuántas veces...?

- Expuso sus opiniones e ideas con tanta claridad que quien escuchaba podía visualizarlas mentalmente?

- Expuso los preconceptos en los que se basaban sus opiniones e ideas?

- Aportó datos observables para sustentar y esclarecer un razonamiento?

- Pidió a los demás a enriquecer sus ideas?

- Se abstuvo de ser defensivo cuando lo cuestionaban?

Cuando su colaborador cuestionaba, ¿cuántas veces...?

- Hizo preguntas sobre las hipótesis y datos que los otros señalaban sin generar una actitud defensiva?

- Hizo preguntas que mejoraran la comprensión del grupo sobre las opiniones de alguien?

- Escuchó sin juzgar (atentamente y sin interrupciones) mientas otros hablaban?

Tercer paso: la primer crítica (5 minutos)

Al cabo de 20 minutos, disuelva el grupo y vuelva al trabajo de a dos. En 5 minutos, los observadores revisan sus notas con el integrante que habló. Al hacerle críticas, utilice los protocolos de la discusión especializada. Por ejemplo, en vez de decir "actuaste a la defensiva", diga "interpreté este comentario como defensivo".

Cuarto paso: perfeccionamiento y nueva crítica (de 25 a 30 minutos) crítica.

El grupo A regresa a la discusión y al finalizar el grupo B procede a la Quinto paso: Grupo B en el Centro (2 sesiones y 2 críticas)

El grupo B iniciará la conversación y el grupo A la observación. 
Sexto paso: auto-observación y definición con todo el grupo

Todo el grupo delibera (luego de un descanso que permita reflexionar sobre las reacciones de los participantes) sobre la capacidad del mismo para generar una comprensión más amplia de su propia conducta e intenta llegar a un consenso definitivo sobre la temática pautada.

\section{Protocolos de diálogo}

Exponga sus procesos mentales (suba lentamente la escalera de inferencias) (Figura 1).

Figura 1 - Protocolos para mejorar la argumentación.

\begin{tabular}{|c|c|}
\hline Qué hacer & Qué decir \\
\hline $\begin{array}{l}\text { Exponga sus premisas, y describa los datos } \\
\text { que lo condujeron a las mismas. }\end{array}$ & $\begin{array}{l}\text { "Yo pienso de la siguiente forma, y aquí está lo } \\
\text { que me llevó a pensar de este modo..." }\end{array}$ \\
\hline Explique sus premisas. & "Partí del concepto de que..." \\
\hline Haga explícito su razonamiento. & "Asumí esta posición porque..." \\
\hline $\begin{array}{l}\text { Explique el contexto del su punto de vista: } \\
\text { quién se verá afectado por sus propuestas, } \\
\text { cómo será afectado y porqué. } \\
\text { Aporte ejemplos de lo que usted propone, } \\
\text { aunque sean hipotéticos o metafóricos. } \\
\text { Cuando hable, intente imaginar la } \\
\text { perspectiva de los otros en relación a lo que } \\
\text { usted dice. }\end{array}$ & $\begin{array}{l}\text { "Para tener una imagen clara de lo que yo } \\
\text { digo, imaginen que ustedes son los clientes } \\
\text { que se verán afectados..." } \\
\text { "Aquí tienen algunos ejemplos del tipo de } \\
\text { cosas que yo tenía en mente cuando llegué a la } \\
\text { conclusión de que..." }\end{array}$ \\
\hline
\end{tabular}

Someta sus conclusiones y conceptos al juzgamiento de los otros.

\begin{tabular}{|l|l|}
\hline $\begin{array}{l}\text { Estimule a los demás a explorar su modelo, } \\
\text { sus premisas y sus datos. }\end{array}$ & $\begin{array}{l}\text { "¿Cuál es su opinión sobre lo que acabé de } \\
\text { decir?" } \\
\text { "¿Identificó alguna falla en mi razonamiento?" } \\
\text { "¿Les gustaría aportar algo más?" }\end{array}$ \\
\hline $\begin{array}{l}\text { Revele los detalles que le parezcan menos } \\
\text { claros. Esta actitud, en vez de debilitarlo, } \\
\text { desactiva la fuerza de los oponentes y es una } \\
\text { invitación a la superación. }\end{array}$ & $\begin{array}{l}\text { "Aquí hay un aspecto que podrían ayudarme a } \\
\text { resolver..." }\end{array}$ \\
\hline $\begin{array}{l}\text { Aún en el medio de su argumentación, } \\
\text { escuche con atención y estimule a los demás } \\
\text { a presentar sus perspectivas. }\end{array}$ & "¿Alguien ve la situación de otro modo?" \\
\hline
\end{tabular}

Fuente: Senge et al., 1995. 
Figura 2 - Protocolos para mejorar el cuestionamiento.

Pida a los otros que expongan sus modelos mentales.

\begin{tabular}{|l|l|}
\hline Qué hacer & Qué decir \\
\hline $\begin{array}{l}\text { Acompañe a los demás por la escalera de } \\
\text { inferencias y verifique qué datos utilizan. }\end{array}$ & $\begin{array}{l}\text { "¿Cómo llegó a esa conclusión?" } \\
\text { "¿Qué datos dispone para sustentar esa } \\
\text { conclusión?" } \\
\text { "¿Qué lo llevó a decir eso?" } \\
\text { "¿'De qué modo se relaciona esto con sus } \\
\text { intereses?" } \\
\text { "¿Hacia dónde va su razonamiento?" }\end{array}$ \\
\hline $\begin{array}{l}\text { No utilice un lenguaje agresivo con la gente } \\
\text { que no está familiarizada con esos métodos. } \\
\text { Sus preguntas no deben inducir a actitudes } \\
\text { defensivas. }\end{array}$ & $\begin{array}{l}\text { En vez de preguntar: "¿a qué se refiere?" o: } \\
\text { "¿qué pruebas tiene de eso?", pregunte "¿Puede } \\
\text { ayudarme a comprender sus ideas?" }\end{array}$ \\
\hline $\begin{array}{l}\text { Explique las razones de su cuestionamiento } \\
\text { y cómo se relaciona con sus propios } \\
\text { intereses, expectativas y necesidades }\end{array}$ & "Pregunto cuáles son sus premisas porque..." \\
\hline $\begin{array}{l}\text { Induzca a los demás a explayarse. Verifique } \\
\text { porqué dicen lo que dicen. }\end{array}$ & \\
\hline
\end{tabular}

Fuente: Senge et al., 1995.

Compare las propias premisas con las ajenas.

\begin{tabular}{|l|l|}
\hline $\begin{array}{l}\text { Verifique lo que los otros dicen, pidiendo } \\
\text { que contextualicen lo dicho y que aporten } \\
\text { ejemplos. }\end{array}$ & $\begin{array}{l}\text { "¿Esto es semejante a?" } \\
\text { "¿Cuáles serían las consecuencias de esta } \\
\text { propuesta?" } \\
\text { "¿Quién se vería afectado por ella, cómo y por } \\
\text { qué?" }\end{array}$ \\
\hline $\begin{array}{l}\text { Verifique si ustedes comprendieron lo que } \\
\text { los otros dijeron. }\end{array}$ & $\begin{array}{l}\text { "¿Será que entendí bien lo que usted dice?" } \\
\text { "Si entendí correctamente, usted está diciendo } \\
\text { que..." }\end{array}$ \\
\hline $\begin{array}{l}\text { Preste atención a la nueva comprensión que } \\
\text { puede surgir. No se empeñe en destruir la } \\
\text { argumentación del otro o en promover la } \\
\text { propia. }\end{array}$ & \\
\hline
\end{tabular}

Fuente: Senge et al., 1995. 
Figura 3 - Protocolos para lidiar con un punto de vista en desacuerdo.

\begin{tabular}{|l|l|}
\hline Qué hacer & Qué decir \\
\hline $\begin{array}{l}\text { Pregunte al otro nuevamente cómo llegó a } \\
\text { ese punto de vista. }\end{array}$ & "¿Cómo llegó a esa conclusión?" \\
\hline Corrobore si usted realmente comprendió & $\begin{array}{l}\text { "¿está tomando en cuenta datos que yo no } \\
\text { dispongo?" }\end{array}$ \\
\hline $\begin{array}{l}\text { Explore, escuche, presente sus opiniones } \\
\text { abiertamente. Esté alerta al sentido más } \\
\text { amplio que puede surgir de la exposición } \\
\text { sincera de otros modelos mentales. }\end{array}$ & "Veamos si comprendí ¿¿usted está diciéndome \\
que...?"
\end{tabular}

Fuente: Senge et al., 1995.

Figura 4 - Protocolos para momentos de "asfixia".

\begin{tabular}{|l|l|}
\hline Qué hacer & Qué decir \\
\hline $\begin{array}{l}\text { Admita que existe una crisis y procure } \\
\text { superarla con humor (la concentración en los } \\
\text { datos puede guiarlo por la escalera de } \\
\text { inferencias) }\end{array}$ & $\begin{array}{l}\text { "¿Qué sabemos con certeza?" ¿Existe algo que } \\
\text { nos parezca cierto, pero que no esté confirmado } \\
\text { por los datos?" }\end{array}$ \\
\hline Busque información que nos ayude a avanzar. & $\begin{array}{l}\text { "¿Qué cosas estamos ignorando?""¿Que es } \\
\text { imposible de conocer?" }\end{array}$ \\
\hline $\begin{array}{l}\text { Pregunte si no hay una forma de diseñar } \\
\text { juntos un experimento o un cuestionario que } \\
\text { proporcione nuevas informaciones. Escuche las } \\
\text { ideas como si fuese la primera vez. }\end{array}$ & $\begin{array}{l}\text { ¿¿En qué puntos concordamos y en qué puntos } \\
\text { estamos en desacuerdo?" }\end{array}$ \\
\hline $\begin{array}{l}\text { Considere el modelo mental de la otra persona } \\
\text { como un fragmento de un rompecabezas } \\
\text { mayor. }\end{array}$ & $\begin{array}{l}\text { "¿Estamos partiendo de dos conceptos muy } \\
\text { diferentes?" }\end{array}$ \\
\hline $\begin{array}{l}\text { Pregunte qué datos o qué lógica podrían } \\
\text { modificar esa perspectiva. }\end{array}$ & $\begin{array}{l}\text { ¿QQué tendría que suceder para que considere } \\
\text { otra alternativa?" }\end{array}$ \\
\hline $\begin{array}{l}\text { Pida ayuda al grupo para reelaborar la } \\
\text { situación. No permita que la conversación se } \\
\text { detenga con "un acuerdo sobre el desacuerdo". }\end{array}$ & $\begin{array}{l}\text { "Parece que llegamos a una situación sin salida y } \\
\text { temo que saldremos de aquí sin entendernos... } \\
\text { ¿Alguien tiene ideas que nos ayuden a esclarecer } \\
\text { nuestro pensamiento?" }\end{array}$ \\
\hline $\begin{array}{l}\text { Evite promover sus argumentos cuando } \\
\text { alguien habla desde otro punto de vista. }\end{array}$ & $\begin{array}{l}\text { "No comprendo el porqué de nuestra } \\
\text { desavenencia". }\end{array}$ \\
\hline
\end{tabular}

Fuente: Senge et al., 1995. 


\section{Estrategias para enfrentar desafios del cambio organizacional}

En el libro La Danza de los Cambios, Senge (2000), y otros autores asumen como objetivo presentar técnicas y estrategias que puedan ayudar a resolver una serie de desafíos que el proceso de transformación organizacional permitiría. Algunos de estos desafíos serían: la falta de tiempo de los dirigentes y gestores del cambio; la carencia de esquemas de ayuda o de tutoría de los grupos involucrados en el proceso; la dificultad de presentar el cambio como una cuestión relevante; los obstáculos en la difusión de las informaciones y de los resultados inherentes al proceso; un cierto aislamiento y espíritu de arrogancia de los grupos-piloto que lleva a una polarización entre fanáticos del cambio y disidentes; la incapacidad de actuar conforme al discurso; el miedo y la ansiedad inherentes a todo proceso de transformación; la dificultad de formular indicadores del proceso de apreciación y medición del cambio; el desafío de adquirir mayor autonomía como grupo piloto del cambio y de pasar a ser parte del esquema de poder reconocido por la organización (gobernabilidad); el desafío de posibilitar una constante definición crítica de la estrategia y del propósito organizacional.

Frente a estos desafios, algunos principios estratégicos pueden ser articulados:

\section{La necesidad de flexibilizar el tiempo}

La cuestión fundamental es cómo generar más tiempo para permitir una concentración mayor en los procesos innovadores y de cambio. Esto dependería de diferentes orientaciones:

- Delegar en las personas un mayor control del uso de su propio tiempo, como una condición que posibilite mayores niveles de confianza.

- Valorizar el tiempo no estructurado, un tiempo "libre" volcado a la reflexión y el diálogo, para el "soñar despierto" individual y colectivo, para la discusión de los aspectos ambiguos de la estrategia, del cambio y del aprendizaje informal, para la búsqueda de una mayor innovación y de una mayor cohesión organizacional.

- Procurar integrar varias iniciativas diferentes en una única, especialmente cuando estas demandan capacidades relacionadas para el cambio.

- Decir no a la "politiquería", al juego de poder y a la burocracia.

- Desarrollar una mayor concentración estratégica sobre aquellos aspectos vinculados a las iniciativas de cambio, generando la capacidad de decir no, 
a las cuestiones no esenciales y de eliminar tareas innecesarias. Esto implica una conformación racional de la agenda que supone algunas técnicas: examinar si los compromisos asumidos para los próximos meses, se relacionan con elementos de la visión organizacional (para usted mismo, para el grupo piloto del cambio y para la organización) o no; evaluar junto con los colaboradores más cercanos un listado de aspectos en los que el dirigente pone demasiada atención y de aspectos a los que no le pone la atención suficiente; cuestionarse sobre las tareas de las cuales no quisiera preocuparse, delegándolas, las tareas que usted no debería hacer, y las tareas con las cuales podría lidiar con mucha menos supervisión; clasificar las iniciativas o sugerencias de alternativas de acción de acuerdo con la facilidad de realización y el impacto sobre la organización.

- Esta capacidad de flexibilización implica poder parar algo antes de comenzar algo nuevo y en abandonar determinadas actividades consideradas relevantes (aún después de una depuración) por un cierto tiempo, para concentrarse en lo que sería relativamente más importante ("negligencia planificada")

\section{La necesidad de ser un ejemplo de apertura y de cultivar la moderación y el gradualismo para combatir el miedo y la ansiedad inherentes al cambio}

El miedo y la ansiedad derivarían de un "hiato de apertura", de una tensión entre las crecientes exigencias de sinceridad y de apertura del grupo involucrado y la capacidad real de las personas de toda la organización. Estos sentimientos podrían ser enfrentados con las siguientes estrategias:

- El dirigente tiene que ser un ejemplo de apertura, en el sentido de reconocer su vulnerabilidad, su capacidad de cometer errores que deben ser encarados como oportunidades. El compromiso con la verdad y la aceptación de la diversidad como algo valorado, dentro de un ambiente de escucha de las diferentes visiones, ayuda a aumentar la confianza de las personas y a estimular su propio liderazgo. Del mismo modo actúa la percepción de que la participación en procesos de cambio es una cuestión de elección y no de coerción.

- Es mejor comenzar de abajo y tomar impulso antes de confrontarse con situaciones difíciles. Es más eficaz ir de a poco, lidiando con pequeños miedos y ansiedades y construyendo la capacidad durante el largo recorrido en dirección a los grandes miedos y ansiedades.

- Evite "ataques frontales". El miedo no puede ser "expulsado" o domina- 
do. Lo que se puede hacer es crear condiciones favorables para el surgimiento gradual de la confianza, considerada un aspecto esencial de la dinámica organizacional. Tal situación depende de la conformación lenta de redes de ayuda entre las personas, basadas en el entendimiento interactivo y en la oferta por parte de la dirección de una red de contención psicológica.

- Como dirigente evite "disparar sobre sus propios pies" al pretender radicalizar el proceso de cambio ("ahora o nunca") y exigirle a las personas conductas avanzadas, absolutamente transparentes y dialógicas.

- Como dirigente debe dejar claro, que usted espera que exista un progreso continuo, pero que usted también sabe que habrá retrocesos y desventuras. Esto se condice con no querer disminuir la brecha entre "donde estamos" y "donde queremos estar" en un solo paso, sino poco a poco.

- Recordar permanentemente que el miedo y la ansiedad son respuestas naturales y que su inexistencia indica una falta de aprendizaje (ausencia de dudas) y de poco avance (o en dirección incorrecta) en el proceso de cambio.

\section{La necesidad de los gerentes clave de sensibilizar estratégicamente acerca de la importancia del cambio y de cons- truir la capacidad de ensamblarse a la organización como un todo desde el inicio}

La posibilidad de evitar una afiliación fanática que lleve al aislamiento frente a manifestaciones naturales de descrédito organizacional y la consolidación de la idea de la relevancia del "debe ser" del proceso de cambio dependen de diferentes estrategias:

- Buscar desde el inicio apoyo en los niveles gerenciales instituidos y trabajar en colaboración representan antídotos para la sensación de "falta de ayuda" que acomete los procesos de cambio

- Tornarse "bicultural": el liderazgo del cambio, debe saber proteger las iniciativas de cambio, conciente de que ellas precisan de "incubadoras" para desarrollarse, pero al mismo tiempo debe saber aprender de la experiencia, de la tradición. La eficacia del cambio depende en gran medida, de la posibilidad de transitar o de cruzar fronteras entre la subcultura emergente y la cultura preexistente. $\mathrm{O}$ de la posibilidad de comportarse bajo los términos definidos por la dirección y simultáneamente estimular en los grupos involucrados en el cambio, habilidades para desafiar verdades y creer.

- Desarrollar la negociación y la diplomacia de modo de incorporar en el proceso a los diferentes afectados y construir vínculos más estables con 
toda la organización. Los grupos innovadores exitosos son aquellos que desarrollan una "orientación hacia afuera", en vez de concentrarse exclusivamente en el desarrollo interno. Dentro de este espíritu, es importante tener paciencia con los chejes y lograr que las prioridades de los grupos ejecutivos formen parte del pensamiento creativo del grupo.

- Cultivar la franqueza reflexiva o la disposición para saber lidiar productivamente con el conflicto, en el sentido de posibilitar la creatividad, es una protección para la tendencia a la arrogancia. Del mismo modo que, asumir que usted no tiene que convencer a las personas, es un desafío que brinda la posibilidad de la coexistencia de "múltiples realidades" como estrategia de liderazgo.

\section{Saber cruzar fronteras}

La gobernabilidad depende esencialmente de la capacidad de saber cruzar estratégicamente fronteras, de la posibilidad de trabajar con grupos multifuncionales (y de transformar grupos temporarios en grupos con mayor permanencia en el poder), y del desarrollo de estructuras específicas que protejan contra "estar a merced" del autoritarismo.

La gobernabilidad depende de las cuestiones anteriores relativas a la relevancia del cambio y a cómo evitar el aislamiento, y de otras orientaciones, tales como:

- El liderazgo del cambio debe desarrollar la capacidad de percibir sus propias fronteras y programar una expansión gradual de su influencia en el sentido de encontrar vínculos con la estructura de gobernabilidad existente. Esta expansión depende en gran medida del desarrollo de un espíritu de investigación de los efectos que los proyectos innovadores, ocasionan en otras áreas, y de la disposición para convocar a esas áreas a problematizar esos efectos. Cuando se trabaja con un grupo multidimensional que abarca diferentes áreas de la organización, deberá realizarse un esfuerzo adicional en el sentido de responsabilizar a los gerentes de esas áreas. Saber atravesar fronteras delicadas depende de la capacidad de reconocimiento de las mismas, del diálogo y de la capacidad de responsabilizar a otras áreas

- La creación de colegiados de gestión y de comités de consulta, así como el desarrollo de la supervisión general de soporte al micro gerenciamiento, son estrategias permanentes de confrontación de las tendencias de retorno a la jerarquía.

- Es importante, en la búsqueda de una desconcentración de poder, realizar 
experiencias con grupos multifuncionales. Evite hablar sobre conexiones permanentes inicialmente; esto podría asustar. Primero muestre resultados, para luego negociar una transición del grupo temporario hacia algo permanente, patrocinado por los superiores.

- Nunca subestime el poder de pequeños cambios en situaciones complejas -si estos fuesen cambios acertados. Tanto las cuestiones de gobernabilidad, como las cuestiones de cambio social, son desalentadoras porque son complejas. Pequeñas ganancias, por ejemplo en cuanto al nivel de la autonomía local, pueden hacer una gran diferencia, de modo que esas cuestiones deben ser planteadas.

- La base de la gobernabilidad es prepararse para un largo viaje, no embarcando solo, sino desarrollando un proceso arduo de construcción de consenso. Debe formar parte de este proceso, la totalidad, o al menos una parte del sistema de poder ejecutivo vigente. La construcción del consenso no significa unanimidad, sino solidariedad, armonía, colaboración, para buscar soluciones comunes. El proceso es inevitablemente lento y lleno de concesiones al pasado, pues el autoritarismo es un rasgo fuerte y las diferencias entre los distintos grupos involucrados son muchas. Avanzar mentalmente rumbo al autocontrol es un proceso que requiere mucha madurez, que supone un cuestionamiento continuo de la idea simple de gobernabilidad como control externo. El desafío es establecer un proyecto de gobernabilidad que dificulte que alguien haga funcionar las cosas en beneficio propio. Esto implica proyectar sin tener una idea establecida de los futuros roles, apartando el autofavoritismo.

\section{Difusión de la importancia del proceso y de los resultados innovadores}

La eficacia del proceso de cambio depende, en gran parte, de la posibilidad de difundir a todos los sectores de la organización, el orden de importancia del proceso y los resultados innovadores presentados. El desafío de la difusión implica algunas estrategias, como:

- Reconocer y observar a los líderes de red, a los grupos de líderes que presentan alta capacidad de transferencia de conocimientos y habilidades, y de producción de ideas innovadoras.

- Desarrollar la capacidad de plantear "todo el sistema" en una sala, de movilizar todas las partes hacia un proceso de indagación colectiva, especialmente sobre cuestiones relacionadas a cómo están creando colectivamente situaciones en las cuales no hay vencedores. El objetivo de este proceso es 
ayudar a "consolidar" la percepción de que nuestras acciones dependen de las acciones de los otros, como también pueden causarle problemas a los otros.

- Aprender a divulgar informaciones sobre innovaciones con menos restricciones, buscando no estimular la competitividad, sino crear un "mercado abierto" para la innovación, sustentado en la colaboración.

- Hacer de la investigación y de la experimentación una responsabilidad ejecutiva, partiendo de la hipótesis de que la creación de conocimiento y de innovación representa una ventaja competitiva, en la medida en que las nuevas ideas sean implementables.

- Intentar vencer las fronteras organizacionales a través del desarrollo de un tipo de "indagación apreciativa", que del mismo modo que en el proceso de negociación, significa una aproximación a la problemática del otro, colocándose en la situación del otro, y en saber preguntar y cuestionar para permitir la evolución de la posición del otro.

- La difusión es también una cuestión de usar el lenguaje conscientemente, buscando ser comprendido por los demás.

\section{Hacer de la apreciación una prioridad}

El proceso de cambio exige el desarrollo de formas de medición del avance. Básicamente, el desafío de la medición implica la necesidad de hacer de la apreciación y del desarrollo de nuevas capacidades de apreciación, una prioridad entre los defensores del cambio. La cuestión central consiste en generar esta "cultura" a partir de la creación de un sentido de responsabilidad sobre la evaluación, lo cual sobrentiende definiciones participativas. La necesidad de aprender a reconocer y apreciar el progreso del cambio, está ligada a la presentación de resultados que ayuden a potenciar el mismo, creando nuevos niveles de motivación. Existe un desafío por producir consensualmente indicadores de apreciación diferentes de los tradicionales y de aprender a apreciar los defasajes de tiempo implícitos en un cambio profundo, dado que los resultados a veces no son inmediatos. La problematización que debería acompañar el reconocimiento de estos defasajes es un instrumento importante de aprendizaje del razonamiento sistémico. 


\section{Desarrollar la discusión de la estrategia y del propósito como posibilidad colectiva, entendiendo estrategia como conversación}

Algunas estrategias pueden ser visualizadas para enfrentar este desafío:

- Usar el "pensamiento por escenarios" para investigar "puntos ciegos" y señales de acontecimientos inesperados. Se recurre a este enfoque cuando existe la necesidad de crear en las personas una mayor apertura de posiciones. Al mostrar la posibilidad de varios futuros posibles, fundamentados en varias premisas diferentes, se crearía una tensión contraria a la defensa irrestricta, fija, de posiciones. En este sentido, los escenarios no serían encarados como previsiones.

- Combinar el pensamiento por escenarios con el análisis del propósito organizacional. Combinar la reflexión sobre escenarios (poniendo en discusión las fuerzas externas que pueden afectar el futuro) con la visión compartida (aspiraciones colectivas de las personas organizacionales) puede aliviar la tensión sobre las elecciones que la organización tiene que hacer y el impacto que estas elecciones puedan tener. El desafío consiste en mostrar un "camino hacia arriba" (el voluntarismo propositivo de la visión) y uno "para abajo" (de inducciones contextuales), contrastados, procurando hacer que las personas graviten en dirección al "camino hacia arriba", construyendo elecciones fundamentadas en el contexto y apoyadas en la intención de actuar sobre el mismo como condición para la producción de circunstancias favorables a la visión.

- Asumir que el objetivo consiste en mejorar la capacidad de pensamiento estratégico y pensamiento ético. El objetivo de la planificación no sería producir las mejores estrategias y planes, sino estimular que todos se involucren en procesos conversacionales que ayuden a desarrollar capacidades de aprendizaje y de raciocinio estratégico, y a construir elecciones apoyadas en el criterio de legitimidad.

- Asumir que lo más importante es exponer y testar las premisas subyacentes a las estrategias. Esto significa que las estrategias, como los escenarios, no pueden ser vistas como previsiones deterministas, sino como apuestas fundamentadas en una serie de argumentos sobre los actores aliados y oponentes, sobre las necesidades y problemas de la situación, sobre el impacto de las acciones, etc. La calidad del análisis de esos argumentos es de fundamental importancia para la elección de las estrategias. 


\section{Referencias Bibliográficas}

AMATUCCI, M. Aprendizado organizacional: encontro de tradições aponta para o futuro. In: LAS CASAS, A. Novos Rumos da Administração. Petrópolis: Vozes, 1999.

ARGYRIS, C. Double-loop learning in organizations. Harvard Business Review, 2(4), set./out.1977

BOYETT, J. O Guia dos Gurus: os melhores conceitos e práticas de negócios. Rio de Janeiro: Campus, 1999.

FREITAG, B. Piaget: encontros e desencontros. Rio de Janeiro: Tempo Brasileiro, 1985.

GEUS, A. P. Planejamento como aprendizado. In: STARKEY, K. (Org.) Como as Organizações Aprendem: relatos do sucesso das grandes empresas. São Paulo: Zumble/Futura, 1997.

GRUPO ZUMBLE CONSULTORIA. Seção aprendizagem organizacional. Disponível em <http://www.zumble.com.br>. Acesso em 18/06/2001.

HABERMAS, J. Teoria de la Acción Comunicativa. Madri: Taurus, 1987.

KIM, D. Administrando os ciclos de aprendizado organizacional. In: WARDMAN, K. T. (Org.) Criando Organizações que Aprendem. São Paulo: Zumble/Futura, 1996.

KIM, D. Loops de criação de paradigmas: como as percepções moldam a realidade. In: WARDMAN, K. T. (Org.) Criando Organizações que Aprendem. São Paulo: Zumble/Futura, 1996.

MATUS, C. Politica, Planejamento e Governo. Brasília: Ipea,1993.

MATURANA, H. Emoções e Linguagem na Educação e na Política. Belo Horizonte: Editora UFMG, 1998.

MITROFF, I.Tempos Dificieis.Soluções Inovadoras. A Arte de Fazer as Perguntas Certas e Resolver os Problemas Certos. Rio de Janeiro: Campus, 1999.

MOTTA, P. R. Gestão Contemporânea. A Ciência e a Arte de Ser Dirigente. Rio de Janeiro: Record, 1991.

SCHEIN, H. E. Guia de Sobrevivência da Cultura Corporativa. Rio de Janeiro: José Olympio, 2001.

SENGE, P. O novo trabalho do líder. In: STARKEY, K. (Org.) Como as Organizações Aprendem. São Paulo: Zumble/Futura, 1997.

SENGE, P. et al. La Quinta Disciplina en la Práctica: estrategias y herramientas para construir la organización abierta al aprendizaje. Barcelona: Granica, 1995. 
SENGE, P. et al. A Dança das Mudanças: os desafios de manter o crescimento e o sucesso em organizaçōes que aprendem. Rio de Janeiro: Campus/Zumble, 2000.

RIVERA, F. J. U. Cultura e Liderança Comunicativa: a gestão pela escuta 1. Ensp/ Fiocruz, 2000a. (Mimeo.)

RIVERA, F. J. U. Reflexões sobre a Organização que Aprende: a gestão pela escuta 3 algumas ferramentas lúdico-pragmáticas. Ensp/Fiocruz, 2000b. (Mimeo.)

\section{Anexo : Prototipos de sistemas de más amplia y difundida relevancia (Senge, 1997)}

- Equilibrando procesos atrasados. En este prototipo, los que toman decisiones dejan de considerar los atrasos involucrados a medida que se dirigen rumbo al objetivo. Como resultado, ellos sobrepasan el objetivo, pudiendo hasta generar ciclos recurrentes. Ejemplo clásico: constructoras que no paran de iniciar nuevos proyectos hasta que el mercado comienza a estabilizarse, momento en que los proyectos aún en construcción ya representan exceso de oferta.

- Limites al crecimiento. Un ciclo de refuerzo de crecimiento se detiene, pudiendo hasta revertirse, al aproximarse a los límites. Tales límites pueden ser de insuficiencia de recursos o repuestas externas o internas al crecimiento. Ejemplos clásicos: ciclos de vida de producto que alcanza prematuramente su límite máximo por baja calidad o servicio precario; el crecimiento y caída de la comunicación en un equipo gerencial, y la difusión de un nuevo movimiento.

- Transferencia de responsabilidad. Una "solución" a corto plazo es usada para corregir un problema, con resultados inmediatos aparentemente positivos. A medida que ese correctivo es usado otras veces, las medidas correctivas fundamentales a largo plazo son cada vez menos usadas. Con el tiempo, los mecanismos de solución fundamental pueden atrofiarse o perderse, intensificando aún más el uso de soluciones sintomáticas. Ejemplo clásico: usar personal de recursos humanos para resolver problemas locales de personal, impidiendo de este modo que los gerentes desarrollen habilidades interpersonales propias.

- Metas declinantes. Cuando no funciona más nada, disminuya sus patrones. Algo parecido a la "transferencia de responsabilidad", excepto por el hecho de que una solución inmediata implica dejar que un objetivo fundamental, tal como el patrón de calidad o el nivel de motivación de los em- 
pleados, se atrofie. Ejemplo clásico: empresa que responde a sus problemas de entrega, dilatando continuamente sus plazos de entrega estimados.

- Escalada. Dos personas o dos organizaciones, las cuales ven su bienestar propio como dependiente de una relativa ventaja sobre la otra, reaccionan continuamente a los avances de la otra. Siempre que uno de los lados avanza, el otro se siente amenazado, sendo llevado a actuar más agresivamente para reconquistar su ventaja, lo que provoca que el otro se sienta amenazado, y así sucesivamente. Ejemplos clásicos: corrida armamentista, guerras entre "patotas", guerras de precios.

- Tragedia de los comunes. Individuos que continúan intensificando el uso de un recurso comúnmente disponible por ende limitado, hasta que todos comienzan a tener retornos cada vez menores. Ejemplos clásicos: criadores que no paran de aumentar sus rebaños hasta que estos consumen todo el pasto compartido; divisiones de una empresa que comparten un mismo equipe de ventas y que compiten por el uso de los vendedores elevando sus metas de ventas, hasta que el equipo de ventas quede exhausto por sobrecarga.

- Crecimiento y subinversión. El crecimiento rápido se aproxima a un límite que podría ser eliminado o empurrado para el futuro, pero solamente a través de una importante inversión sin recursos físicos y humanos. Las metas o patrones declinantes ocasionan inversiones muy pequeñas, o muy lentas, y los clientes quedan cada vez más insatisfechos, desacelerando el crecimiento de la demanda, transformando la inversión requerida (aparentemente) en innecesaria o imposible. Ejemplo clásico: innumerables empresas, en momentos que pasaban por un exitoso crecimiento, permitieron la disminución de la calidad de los productos o servicios, y fueron incapaces de generar fondos suficientes para invertir en correctivos. 

Anexo:

\section{LA GESTIÓN ESTRATÉGICA HOSPITALARIA}

\section{Guía para el Análisis Estratégico del Perfil Asistencial de las Especialidades Médicas}

Este documento es un intento de adaptación y de simplificación de la guía de la démarche estratégica francesa, metodología de definición de la misión hospitalaria, idealizada por M. Cremadéz y F. Grateau y aplicada por el Centro Hospitalario Regional y Universitario de Lille (CHRU). Contiene una guía de aplicación de las principales matrices o formatos del enfoque y o conjunto de los formatos o instrumentos propiamente dichos. Los 14 formatos se refieren a las principales etapas del método:

- Análisis de lo existente.

- Segmentación estratégica.

- Análisis de la posición estratégica (valor y competitividad) de los segmentos.

- Portafolio de actividades y estrategia.

- Plan de acción.

\section{Análisis de lo Existente}

Es la primera etapa de la démarche estratégica. Es un diagnóstico que consiste de varios elementos:

- Una descripción de las patologías tratadas y de las tecnología actualmente utilizadas en la especialidad, así como de sus relaciones.

- Una descripción de las modalidades asistenciales de la oferta de actividades por especialidad. 
- Una descripción de la distribución de la oferta de actividades por especialidad y por segmento (cuando fuera necesario), considerando la red de servicios de salud del área.

- Una descripción de los colaboradores y de los competidores por segmento.

\section{Relevamiento de Patologías y Tecnologías}

\section{Patologías (Formato I)}

Este inventario permite conocer las actividades del servicio. Deben ser descriptas todas las patologías tratadas desde las más simples hasta las más complejas. Se puede indicar el tipo genérico de actividad involucrada para enfrentar las patologías. Por ejemplo: diagnóstico, seguimiento, tratamiento, actividad pedagógica, nivel de complejidad correspondiente, etc.

\section{Tecnologías (Formato 2)}

Este inventario incluye equipamientos, técnicas de apoyo diagnóstico y terapéutico, técnicas pedagógicas o actividades educativas, tecnologías de trabajo asistencial en equipo multiprofesional, la opinión de experts de otras especialidades, o también, para los servicios de Medicina, el savoir-faire de un cirujano cuya colaboración represente una capacidad distintiva dentro de la especialidad (soporte en conocimientos de otras especialidades).

\section{Distribución de la oferta de actividades por especialidad a través de la red de servicios}

Consiste en relacionar las actividades realizadas en la especialidad del hospital sede de la aplicación del enfoque: aquellas actividades realizadas fuera de la especialidad (aunque concernientes a la misma) pero realizadas dentro del hospital, aquellas realizadas fuera del hospital, y finalmente las actividades no disponibles en el área de referencia, que pueden ser necesarias. En esta guía fue realizada una adaptación de este item, teniendo en cuenta la aplicación del enfoque en la AP2.1 de la ciudad de Río de Janeiro, con la finalidad primordial de coordinar actividades entre los hospitales de la Lagoa y de Ipanema, sin perder de vista el conjunto. En este contexto, el formato específico de captación de información propuesto (Formato 3) consta de cuatro cuadrantes: uno referente 
al listado de los conjuntos de actividades agregadas, realizadas en la especialidad del hospital sede (Lagoa); otro referente al listado de las actividades del hospital de Ipanema; el tercero, referente a las actividades de los otros hospitales de la red (de ser necesario, diferenciar) y el cuarto, referente a las actividades no disponibles pero necesarias.

En relación a la distribución de la oferta, se propone otro formato adicional (Formato 4), que consiste en determinar las actividades típicas del hospital, las actividades típicas de la competencia, lo que es común y las actividades no disponibles en el área.

De ser necesario, se sugiere la realización del mismo tipo de relevamiento por segmento de actividad. Esto supone utilizar los formatos 3 y 4 luego de la segmentación estratégica, asumiendo como unidad de comparación, cada segmento de actividad.

\section{Cruzamiento entre patologías y tecnologías (Formato 5)}

Este cuadro establece la relación existente entre patologías y tecnologías a partir de los subconjuntos identificados en los cuadros anteriores, específicamente los formatos 1 y 2 .

Indicaremos aquí las tecnologías específicas para determinadas patologías dentro de la matriz correspondiente.

Para tanto utilizaremos la siguiente simbología:

- D - Tecnología utilizada en el diagnóstico y/o seguimiento.

- $\mathrm{T}$ - Tecnología utilizada en el tratamiento.

Podremos también representar la frecuencia de la utilización de la tecnología de la siguiente manera:

- $\mathrm{D}+/ \mathrm{T}+-$ Utilización casi sistemática.

- $\mathrm{D} \pm / \mathrm{T} \pm$ - Utilización frecuente (alrededor del 50\%).

- D-/T - Utilización excepcional.

\section{Análisis de las modalidades de atención}

Esta matriz está destinada a identificar las características asistenciales de las diferentes actividades de las tablas anteriores y definir subgrupos homogéneos de actividades en términos de la práctica médica. Los criterios del análisis de las modalidades son: 


\section{Programación}

- Electivo - Podemos considerar como electivo todo acto que pueda ser previsto con tres días de anticipación o articulado a un acto que pueda ser previsto con tres días de anticipación.

- No Electivo - Podemos considerar no electivo a todo acto que no pueda ser previsto o programado con tres días de anticipación.

\section{Necesidad de hospitalización}

- H - Hospitalización necesaria de uno o más días.

- $\mathrm{NH}-$ Hospitalización no necesaria.

\section{Duración de la hospitalización}

- D - Hospitalización igual o inferior a 24 horas.

- $\mathrm{S}$ - Hospitalización superior a 24 horas e inferior a 5 días.

- SS - Hospitalización superior a 5 e inferior a 15 días.

- P - Hospitalización superior a 15 días.

Necesidad de tecnología

- In - Tecnología disponible en el Servicio.

- $\mathrm{SH}$ - Tecnología disponible en otro servicio del Hospital.

- Ex - Tecnología no disponible en el Hospital, compartida con otros Servicios externos.

El análisis de las modalidades asistenciales implica completar en la práctica dos matrices:

- Matriz de segmentación de patologías (Formato 6).

- Matriz de segmentación de tecnologías (Formato 7).

Relacionar los Colaboradores y Competidores por Segmento (Formato 9)

Consiste en relacionar las instituciones que realizan actividades en común o específicas, referidas al segmento, clasificándolas en colaboradoras o competidoras. Es importante destacar que este item presupone la realización de la segmentación estratégica (etapa siguiente). 


\section{La Segmentación Estratégica (Formato 8)}

El objetivo de esta etapa es definir subgrupos homogéneos de actividad, llamados segmentos. Estos serían los productos básicos de una especialidad (Formato 6).

La segmentación es un análisis multicriterios, que apunta a evaluar las semejanzas y diferencias entre las actividades existentes en una especialidad. Cada uno de los subgrupos elegidos debe abarcar un grupo de actividades caracterizadas por las semejanzas en función de los criterios de análisis. Estos criterios, aunque numerosos a priori, son reducidos, en la práctica, a un número más limitado. Este recorte es situacional, o sea, depende del proyecto político de la dirección de cada hospital (y de la coordinación del Área Programática), de los proyectos y motivaciones de los profesionales de las especialidades involucradas, de las necesidades de diferenciación estratégica en función de dichos proyectos/objetivos y, también, de las demandas/necesidades que presente el área poblacional atendida por los hospitales.

Los criterios de segmentación son:

- Las patologías. Tipo y localización de la patología, nivel de complejidad, sobreposiciones.

- Las condiciones de atención. Necesidad de internación convencional o específica (camas de aislamiento), programación.

- Las tecnologias implementadas. Necesidad de disponer de una capacidad técnica específica.

- Las capacidades requeridas. Grado de sofisticación dentro de la especialidad, necesidad de recurrir a la capacidad de diversos especialistas.

- La competencia. Número de profesionales ejerciendo la actividad y medios a su disposición.

- El tipo de población involucrada (edad...).

- El lugar de la actividad en una red de cuidados. Emergencia, diagnóstico, tratamiento, seguimiento, educación y prevención.

Al final del proceso de segmentación, será necesario verificar que ningún elemento importante de heterogeneidad subsista dentro de cada segmento definido, y que, por el contrario, no exista una similitud muy evidente entre dos segmentos.

Un segmento estratégico validado estará compuesto de actividades que pueden ser evaluadas globalmente desde el punto de vista del interés que tienen para el hospital y desde el ángulo de las capacidades necesarias para obtener una posición de excelencia. 


\section{Análisis del Valor o de la Capacidad de Atracción del Seg- mento (Formato 10)}

El análisis del valor supone un análisis multicriterios, orientado por preguntas específicas. Los criterios valorados son:

\section{Posibilidad de Crecimiento (importancia social del segmento y capacidad de desarrollo tecnológico)}

La aplicación de este criterio supone la siguiente pregunta básica: ¿Cuáles son las posibilidades de progreso de la actividad a futuro...??

- ...en función de los factores de riesgo (edad, sexo, grupo social, situación epidemiológica...)?

- ...en función de la evolución tecnológica o del savoirfaire (nuevas terapéuticas)?

Aquí debe considerarse el potencial de crecimiento teórico en función de los escenarios epidemiológico y tecnológico que condicionan la demanda potencial. Las restricciones al crecimiento, como la capacidad instalada, los equipamientos y otros, deberían ser contempladas en relación a otros criterios.

Nota alta: fuerte crecimiento.

Nota baja: disminución importante.

\section{Intensidad de la Competencia}

En este caso, se trata de saber la cantidad de competidores existentes en el área de referencia. Para ello, se deben formular preguntas como: ¿Cuántas instituciones públicas y privadas ejercen una actividad similar en la zona de influencia del hospital?, ¿cuál es su contribución a la red de cuidados? (lo que hacen), ¿cuántos competidores están instalados actualmente?, ¿cuáles son sus medios materiales y financieros?, ¿se prevé la instalación de nuevos competidores?

Nota alta: pocos competidores.

Nota baja: muchos competidores. 


\section{Inversión (como barrera a la entrada)}

Aquí procuramos saber si la inversión necesaria (en instalaciones, equipamientos y capacidades médicas específicas) para ser competitivo en el segmento específico, constituye o no una barrera a nuestra entrada o a la entrada de eventuales competidores. Cuando el tamaño de la inversión necesaria es grande y no existe una previsión (o condiciones) de realizarla, se considera difícil penetrar en el segmento o continuar desarrollándolo. En el caso, de un no control de la inversión necesaria elevada, habría una desvalorización del segmento en lo que respecta a este criterio, por lo cual tendría que ser dada una nota baja al segmento. Cuando se considera que no habría barreras a nuestra entrada por el hecho de que controlamos la inversión necesaria elevada, la nota a ser dada tendría que ser alta. En este caso, la gran inversión realizada y que será complementada en el futuro, actúa como una ventaja competitiva nuestra y como eventual barrera a la entrada de competidores.

Nota alta: inversión necesaria elevada controlable.

Nota baja: inversión necesaria poco controlable.

Cuando la inversión necesaria no es considerable (no constituye una barrera) y está controlada, se prefiere una nota más intermedia, relativamente menor a la nota dada a un tipo de inversión necesaria elevada controlada. Esto se debe a que en ese caso, todos pueden realizar con facilidad la inversión necesaria, o sea que, el tamaño de la inversión necesaria no significa una barrera a la entrada de los otros, configurándose una situación en que nuestro nivel de inversión no representa una probable ventaja comparativa.

\section{Sinergias}

Se procura saber:

- $\quad$ Si existe, a nivel de la actividad, (o podría existir) alguna forma de integración o de política de colaboración con otros servicios del hospital (capacidades compartidas).

- $\quad$ Si es posible, a nivel de la actividad, la utilización en común de espacios y de medios logísticos con otros servicios (del hospital).

Nota alta: colaboración elevada / equipamientos e infraestructuras compartidos.

Nota baja: no existe colaboración / no hay utilización común. 


\section{Motivación Interna}

¿Les interesa a ustedes particularmente la actividad del segmento? ¿Están dispuestos a transferir recursos para desarrollar estas actividades? ¿Existe un nivel de compromiso razonable en relación al segmento?

Nota alta: motivación fuerte.

Nota baja: motivación débil.

\section{Posibilidades de Colaboración Externa}

¿La actividad permite establecer una red de colaboración con instituciones o profesionales externos o con otros especialistas de alguna disciplina específica? (incluir aquí los servicios que transfieren pacientes para el hospital)

Nota alta: potencial elevado.

Nota baja: no existe colaboración prevista.

\section{Potencial Regional}

¿Este segmento abarca una actividad importante de atracción de usuarios a nivel municipal?

Nota alta: poder de atracción municipal o estatal.

Nota baja: poder de atracción solamente local (área).

\section{Potencial Local}

¿El segmento desarrolla una actividad local importante (dentro del área programática)?

Nota alta: fuerte poder de atracción local.

Nota baja: bajo poder de atracción local.

\section{Potencial de Enseñanza e Investigación}

¿Este segmento abarca un volumen de actividad importante de enseñanza y de investigación? 
Nota alta: actividad de enseñanza e investigación.

Nota baja: rutina.

\section{Contribución para el Proyecto Político (o para el Proyecto de la Misión) del Hospital}

¿En qué medida el desarrollo del segmento es coherente con la definición general de la misión del hospital? ¿El desarrollo del segmento fue pensado como una prioridad para el proyecto general defendido para o hospital? En este caso, considerar la naturaleza del Hospital, si es general o especializado o una combinación específica.

Nota alta: segmento funcional al proyecto general de la misión.

Nota baja: segmento redundante, no prioritario.

\section{Contribución para la Imagen Externa}

¿Este segmento permite crear o desarrollar una imagen positiva frente al entorno (sistema de referencia, redacción de periódicos científicos, público en general, decisores locales....)?

Nota alta: contribución a la imagen fuerte.

Nota baja: sin impacto sobre la imagen.

Los técnicos franceses utilizan otros criterios posibles:

- Capacidad de transferir tecnología.

- Capacidad de incorporación tecnológica a través de colaboración externa con centros de punta.

- Capacidad de atraer recursos externos.

- Costo variable de la actividad (nota alta para un costo relativamente menor).

La inversión podría ser destinada a equipamientos/tecnología, recursos humanos especializados y capacidad instalada (lo que correspondería a trabajar con tres subcriterios).

El potencial de investigación y enseñanza también pueden ser separados.

Cada criterio tiene un peso porcentual (p) definido anteriormente. Este peso porcentual correspondería al grado de aplicabilidad, a la importancia o a la pertinencia de cada criterio en función de las características concretas de la Especialidad, tales como la naturaleza político-administrativa del hospital donde ésta inserta, el nivel de complejidad, el nivel de competencia del área, la visión 
política de la dirección estratégica, etc. Este peso es dado situacionalmente por el grupo en función de la Especialidad y es un peso uniforme para todos los Segmentos de la Especialidad. A cada criterio le corresponde una nota de 0/20 (n), dado a cada Segmento de la Especialidad. El valor global del segmento dependerá de los scores específicos, es la sumatoria de los mismos $(\mathrm{S}=\mathrm{p} \times \mathrm{n})$.

En la definición del peso (o distribución de 100 puntos por los criterios), pueden ser formuladas algunas preguntas:

- ¿Es el crecimiento un objetivo que forme parte de su proyecto de trabajo? ¿En qué medida se espera un crecimiento relevante o no de la especialidad a futuro?

- ¿En qué medida la competencia afecta a su especialidad? ¿Se aplica este criterio a su realidad? Cuando no hay mucha competencia, es indicado atribuir poco peso al criterio. Como consecuencia, el criterio posibilidad de crecimiento puede ganar importancia.

- ¿La inversión necesaria en su especialidad es elevada? (en teoría, no importa si usted lo controla o no). Priorice equipamientos y tecnologías. Cuando la especialidad no precisa de una inversión muy elevada (poco peso), puede ganar importancia relativa el factor motivación de los recursos humanos.

- ¿El potencial de sinergias y colaboraciones externas es elevado? ¿o a su especialidad prescinde o precisa pocas sinergias y colaboraciones?

- ¿Que tipo de potencial de atracción de clientes prioriza su especialidad?

- ¿En qué medida su especialidad es vista por la dirección estratégica como uno de los pilares del Hospital? ¿Contribuye de forma decisiva para mejorar la imagen externa del Hospital?

- Las actividades de enseñanza y de investigación ¿adquieren relevancia dentro de la especialidad?

\section{Análisis de la Posición Competitiva (definir los Factores Es- tratégicos de Éxito) del Segmento (Formato II)}

\section{Consiste en:}

- enumerar de 5 a 10 (sin rigidez) factores estratégicos de éxito del segmento analizado. Son ventajas, condiciones positivas que es necesario poseer para tener éxito en el desempeño de la actividad.

Ejemplos: la existencia de un buen sistema de emergencia que atienda a domicilio y en las calles, para Neurología, donde el factor tiempo es esencial en 
el traslado de pacientes; un buen relacionamiento con profesionales e instituciones de la red, capaces de derivar pacientes; un buen sistema de recepción, aumentando a calidad de atención; la disponibilidad de equipamientos, como un tomógrafo computadorizado; un buen sistema de laboratorio; etc.

Son condiciones, cuya posesión permite diferenciar establecimientos en términos de posición de vanguardia. En general, son capacidades profesionales, capacidades tecnológicas y financieras, relacionales, de efecto diferencial. Estas condiciones o recursos, no son necesariamente controlados por nosotros. Son factores necesarios idealmente al desarrollo de un tipo de atención de alto nivel de calidad, de punta.

- Evaluar, dando una nota (0/20), el grado de control de cada uno de estos factores por parte del hospital.

- Estimar el valor global de la posición competitiva del segmento, considerando que a cada factor debe ser atribuido un peso (\%) determinado.

- Hacer lo mismo en relación a los competidores.

\section{Portafolio de Actividades (Formato I2)}

Es un gráfico cuya abscisa corresponde a la posición competitiva y la ordenada, al valor de los segmentos. Los segmentos son posicionados en este gráfico, dividido en cuatro cuadrantes. A partir del análisis del portafolio debe ser definida la estrategia que consiste en establecer tres posibilidades de objetivos por segmento:

- Desarrollar, priorizar un segmento.

- Estabilizar un segmento.

- Disminuir la incorporación de usuarios a un segmento (Formato 13).

El portafolio permite una visión de conjunto de la especialidad, comparar la posición estratégica de los segmentos y establecer prioridades entre los mismos. Esto debería dar lugar a una reflexión sobre el plan de desarrollo específico de cada segmento, sobre el tipo de estrategia a ser seguida en cada caso: diferenciación; costos y/o focalización de actividades. 


\section{El Plan de Acción (Formato 14)}

Incluye las actividades visualizando el cumplimiento de la estrategia derivada del análisis del portafolio. Precisa recursos, productos, resultados e indicadores de seguimiento de las acciones.

Más consideraciones sobre Estrategia y Plan:

Tipos de estrategia:

- Desarrollar un segmento: identificar las actividades que deben ser expandidas, priorizadas, desarrolladas particularmente. Este objetivo en general se confunde con la estrategia de diferenciación o con el agregado de un plus de valor percibido como mejora de calidad, pudiendo implicar más costos, en inversiones específicas para enfrentar los puntos débiles típicos de los FCE. El desafío aquí sería buscar la estrategia de diferenciación que implique relativamente menos costos.

- Mantener o estabilizar un segmento: definir los segmentos que deben ser mantenidos en "baño maría", al mismo nivel de desarrollo histórico, de ser posible reduciendo costos. Aquí pueden constar segmentos de alta competitividad y valor, los cuales podrían ser apenas mantenidos en la actual posición, reduciendo costos y liberando recursos para otras actividades.

- Reducir la incorporación de usuarios a un segmento: definir qué tipo de usuario sería necesario recortar o focalizar, desestimular, disminuir, negociando la transferencia parcial o total de actividades para a red (se entiende por focalización privilegiar un determinado tipo de usuario o nosología).

Para Porter (1982), habría tres estrategias genéricas, mejor analizadas posteriormente a partir de la obra de Crémadez \& Grateau (1997): diferenciación, que implicaría definir una oferta única, exclusiva, diferenciada, percibida por todos como superior cualitativamente, cuyo acceso también podría ser diferenciado; liderazgo en costos, que representaría disminuir costos para liberar recursos hacia otros segmentos, sin comprometer la calidad; focalización (que puede cursar como estrategia de costos y/o diferenciación).

\section{Elaboración de los Planes de Acción}

Los planes incluyen los esfuerzos a ser realizados para actuar sobre la red de médicos de consultorio (que transfieren pacientes), para implementar asociaciones, para formar médicos y personal paramédico, para comunicar el savoir- 
faire controlado, para adquirir nuevas tecnologías, para implementar nuevos modos de atención, etc.

El Plan de Acción es "qué hacer" para implementar la Estrategia. Consistiría en un conjunto de actividades, tales como:

- Formas de apropiación/desarrollo de los Factores Clave de Éxito apuntando a enfrentar los puntos débiles identificados en el análisis: incorporación de tecnologías y de recursos humanos, entrenamientos, desarrollo de factores de calidad, etc.

- Acciones de negociación y de comunicación internas al hospital y con la red, incluyendo el establecimiento de sinergias y colaboraciones externas.

- Acciones que apunten a revalorizar un segmento, actuar sobre algún criterio del análisis del valor de bajo score, pasible de intervención (cuando la decisión política es buscar aumentar el valor).

- Acciones que apunten a modificar el modelo asistencial, las formas de atención que caracterizan un determinado segmento, el perfil de tecnologías utilizadas.

- Acciones de naturaleza social e intersectorial.

- Acciones que desarrollan objetivos típicamente médicos, como determinadas investigaciones.

La consolidación de un plan de acción implica retomar continuamente el análisis estratégica del valor y de la posición competitiva, apuntando a aumentar el control de los FCE, para mejorar la posición estratégica general.

El plan culmina con la definición de los indicadores de monitoreo de las acciones que permita la posibilidad de acompañar los cambios propuestos. 
Formato 1

Descripción de las Actividades

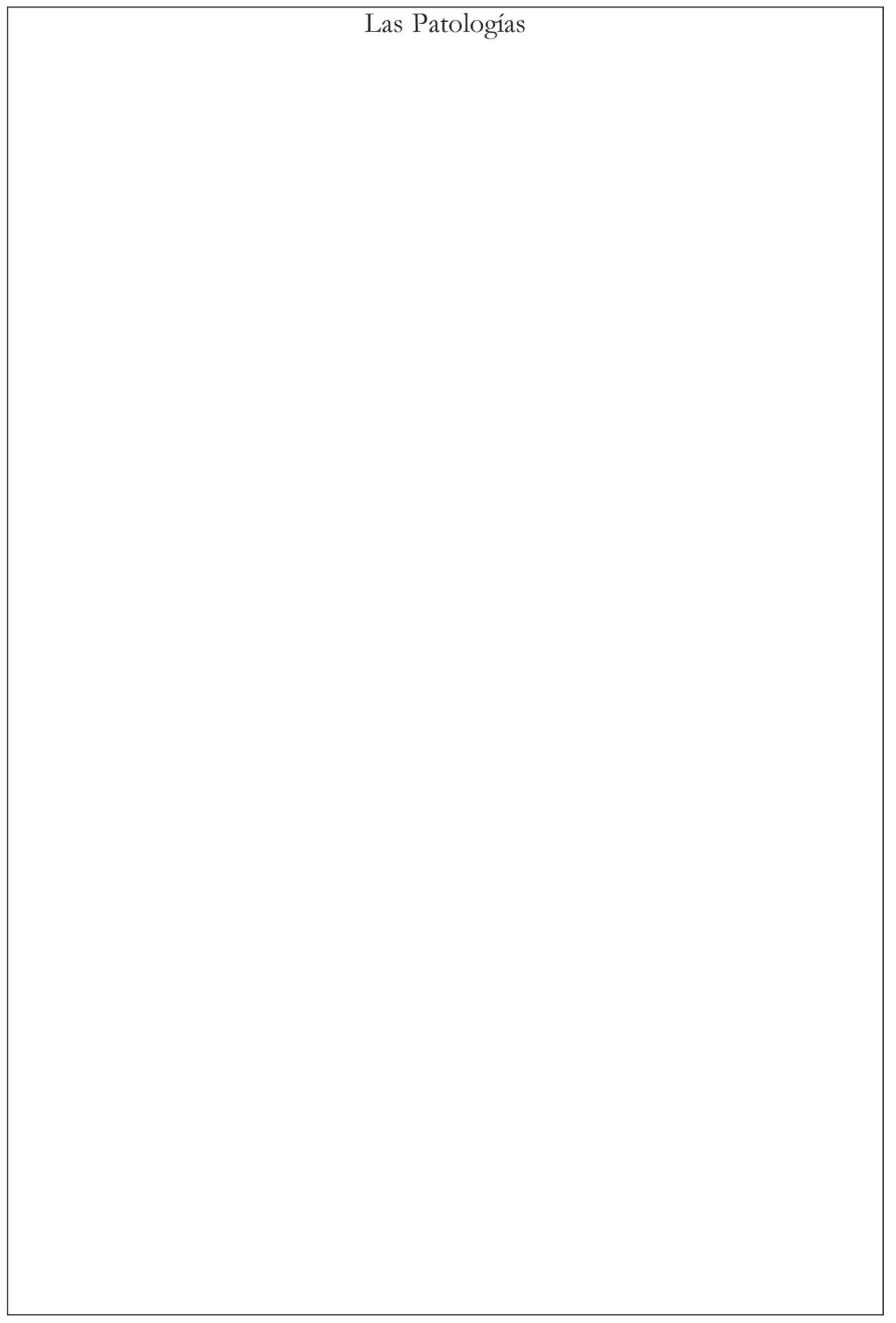


Formato 2

Descripción de las Actividades

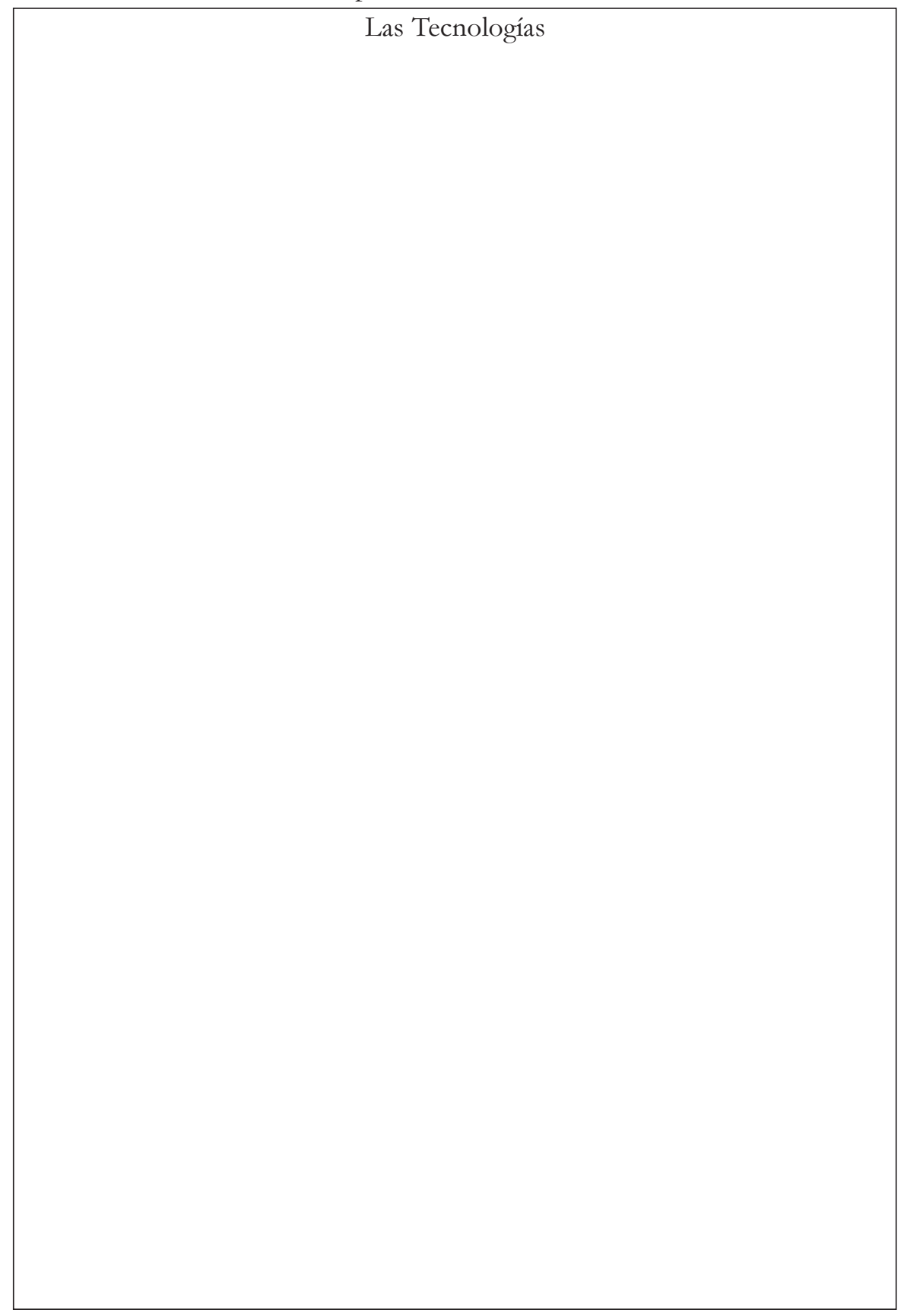


Formato 3

Cuadro de la Oferta de Actividades 1 (por especialidad)

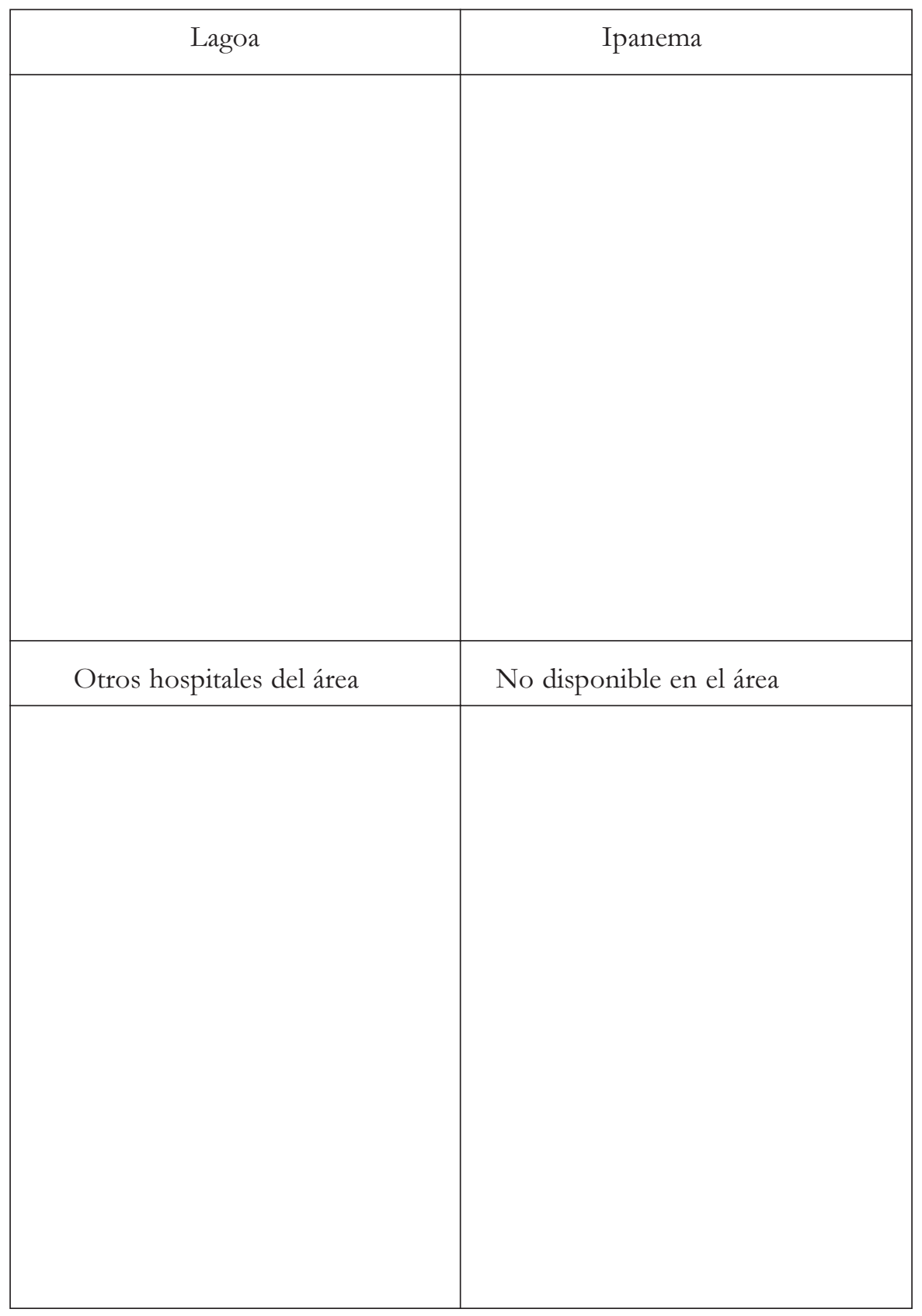


Formato 4

Cuadro de la Oferta de Actividades 2 (por especialidad)

\begin{tabular}{|l|l|}
\hline Común hospital / competencia & Específico a la competencia \\
\hline Específico al hospital & \\
\hline & \\
\hline & \\
\hline & \\
\hline
\end{tabular}


Formato 5

Matriz Patologías/Tecnologías

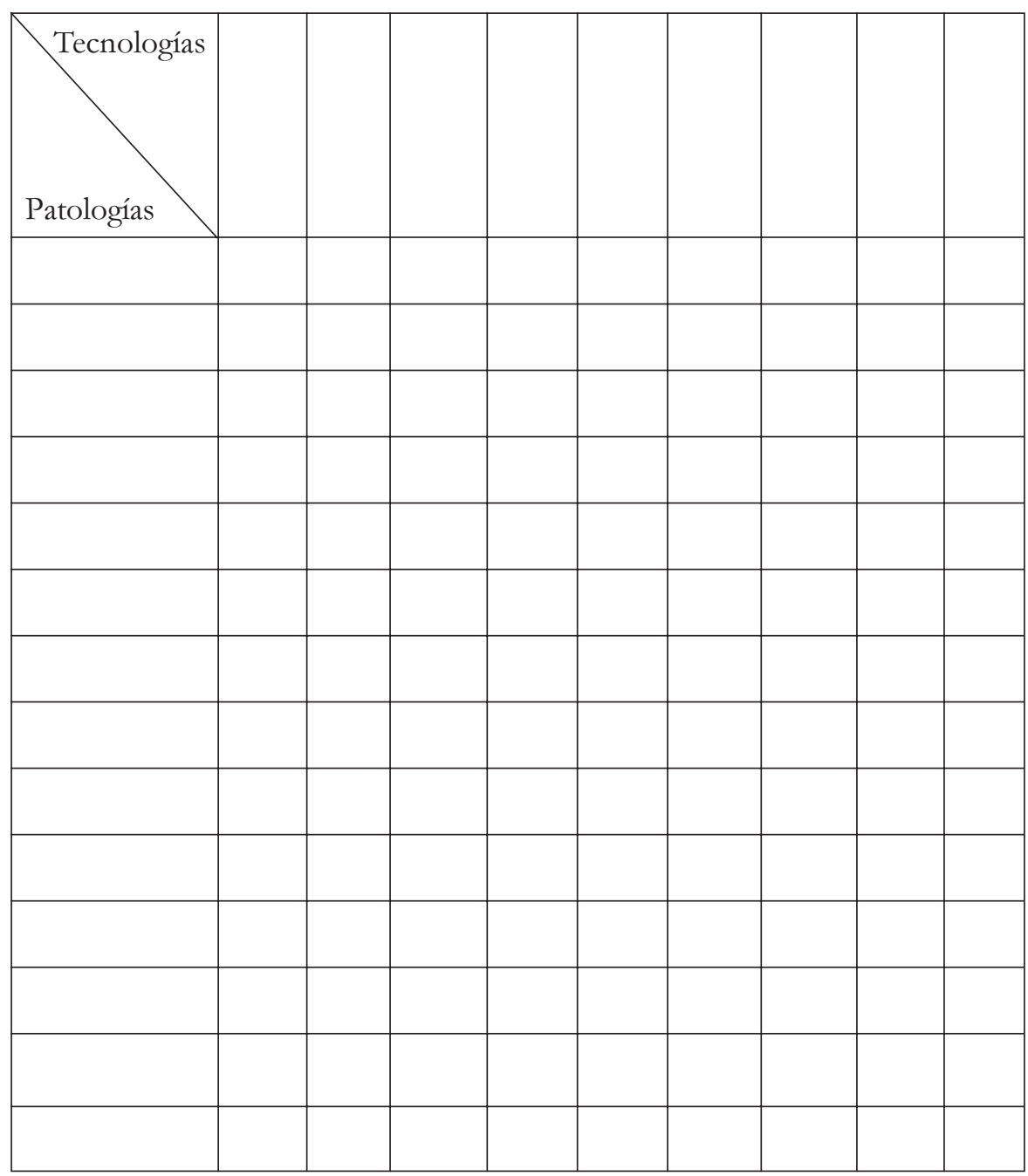

Clasificar las tecnologías, utilizando los siguientes símbolos:

D - Tecnología utilizada en el diagnóstico y/o en el seguimiento

$\mathrm{T}$ - Tecnología utilizada en el tratamiento

Podrá contemplarse también la frecuencia de la utilización de la tecnología

$\mathrm{D}+/ \mathrm{T}+$ Utilización casi sistemática

$\mathrm{D} \pm / \mathrm{T} \pm$ Utilización frecuente (alrededor del 50\%)

$\mathrm{D}-/ \mathrm{T}-$ Utilización excepcional 
Formato 6

Matriz de Segmentación de Patologías

\begin{tabular}{|c|c|c|c|c|}
\hline Componentes & 1) $\mathrm{E} / \mathrm{NE}$ & 2) $\mathrm{H} / \mathrm{NH}$ & 3) $\mathrm{D} / \mathrm{S} / \mathrm{SS} / \mathrm{P}$ & 4)IN/SH/EX \\
\hline & & & & \\
\hline & & & & \\
\hline & & & & \\
\hline & & & & \\
\hline & & & & \\
\hline & & & & \\
\hline & & & & \\
\hline & & & & \\
\hline & & & & \\
\hline & & & & \\
\hline & & & & \\
\hline
\end{tabular}

1) Electivo/No Electivo

2) Necesidad de Hospitalización (Hospitalización/No Hosp.)

3) Duración de la Hospitalización (día (D), semanal (S), hasta dos semanas (SS), prolongada (P)

4) Disponibilidad interna o externa (a la especialidad) de las tecnologías necesarias o implementadas. 
Formato 7

Matriz de Segmentación de Tecnologías

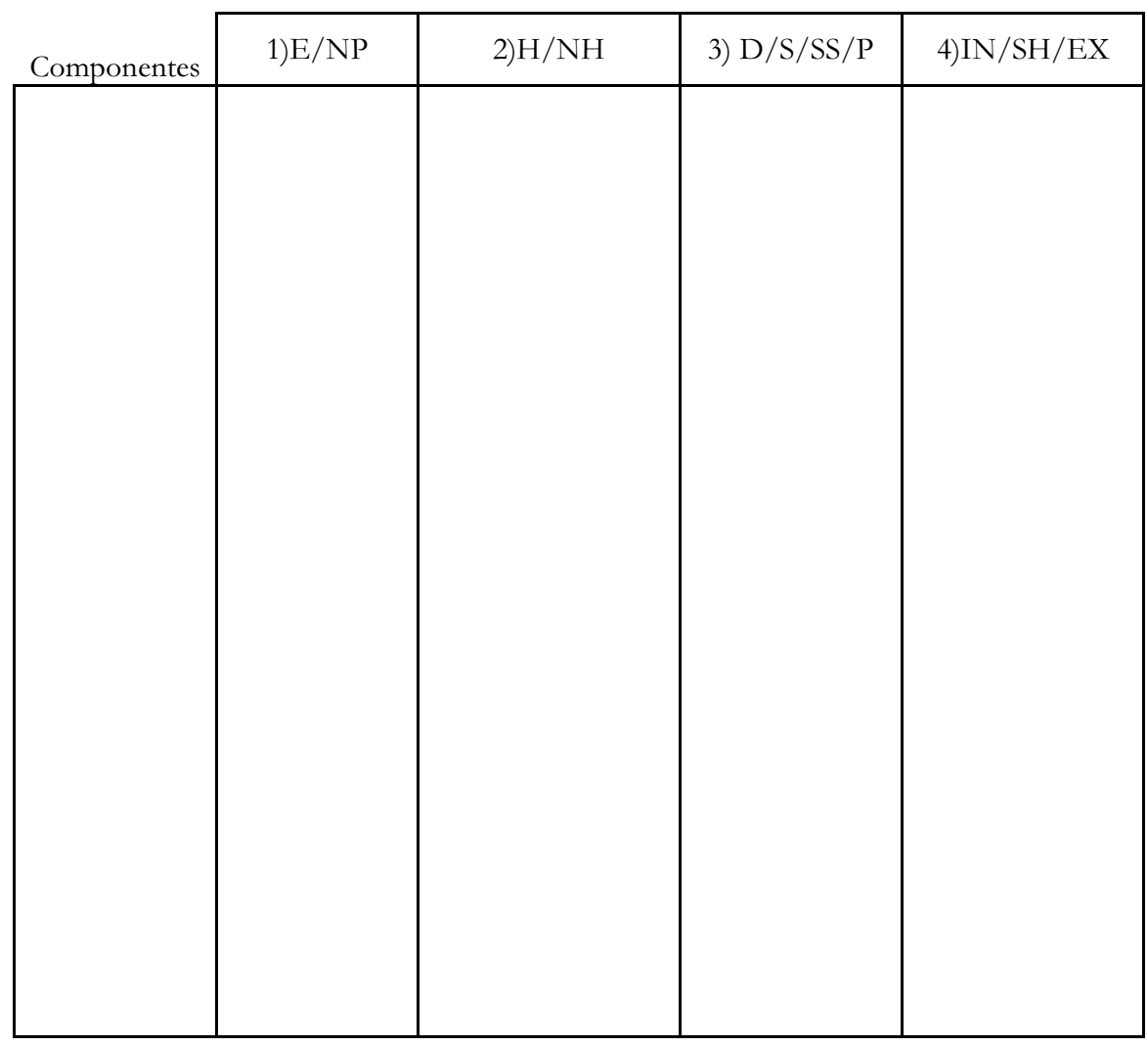

1) Electivo/No Electivo

2) Necesidad de Hospitalización (Hospitalización/No Hosp.)

3) Duración de la Hospitalización (día (D), semanal (S), hasta dos semanas (SS), prolongada (P)

4) Las tecnologías necesarias están disponibles en el Servicio (IN), en el Hospital (SH) o externamente (EX) 
Formato 8

Segmentación Estratégica

Servicio:

Segmentos:

1)

2)

3)

4) 
Formato 9

Cuadro de Colaboradores y Competidores (por segmento)

\begin{tabular}{|c|c|c|}
\hline Institución & $\mathrm{P}$ & C \\
\hline & & \\
\hline & & \\
\hline & & \\
\hline & & \\
\hline & & \\
\hline & & \\
\hline & & \\
\hline & & \\
\hline & & \\
\hline & & \\
\hline & & \\
\hline & & \\
\hline & & \\
\hline & & \\
\hline & & \\
\hline & & \\
\hline & & \\
\hline
\end{tabular}

Colaboradores Externos: CE

Competidores: C 
Formato 10

Evaluación del Valor (Capacidad de Atracción) del Segmento

\begin{tabular}{|l|c|c|c|}
\hline Criterios de evaluación & $\begin{array}{c}\text { Peso } \\
\%\end{array}$ & $\begin{array}{c}\text { Nota/ } \\
20\end{array}$ & $\begin{array}{c}\text { Score } \\
(=\text { PxN })\end{array}$ \\
\hline Posibilidades de Crecimiento & & & \\
\hline Intensidad de la Competencia & & & \\
\hline Inversión (barreras a la entrada) & & & \\
\hline $\begin{array}{l}\text { Sinergias (a nivel de capacidades e infraestructuras } \\
\text { compartidas) }\end{array}$ & & & \\
\hline Motivación Interna & & & \\
\hline Posibilidades de Colaboración Externa & & & \\
\hline Potencial Regional & & & \\
\hline Potencial Local & & & \\
\hline Potencial de Enseñanza e Investigación & & & \\
\hline $\begin{array}{l}\text { Contribución para el Proyecto Político General del } \\
\text { Hospital }\end{array}$ & & & \\
\hline Contribución para la Imagen Externa & & & \\
\hline Valor Segmento & & & \\
\hline
\end{tabular}




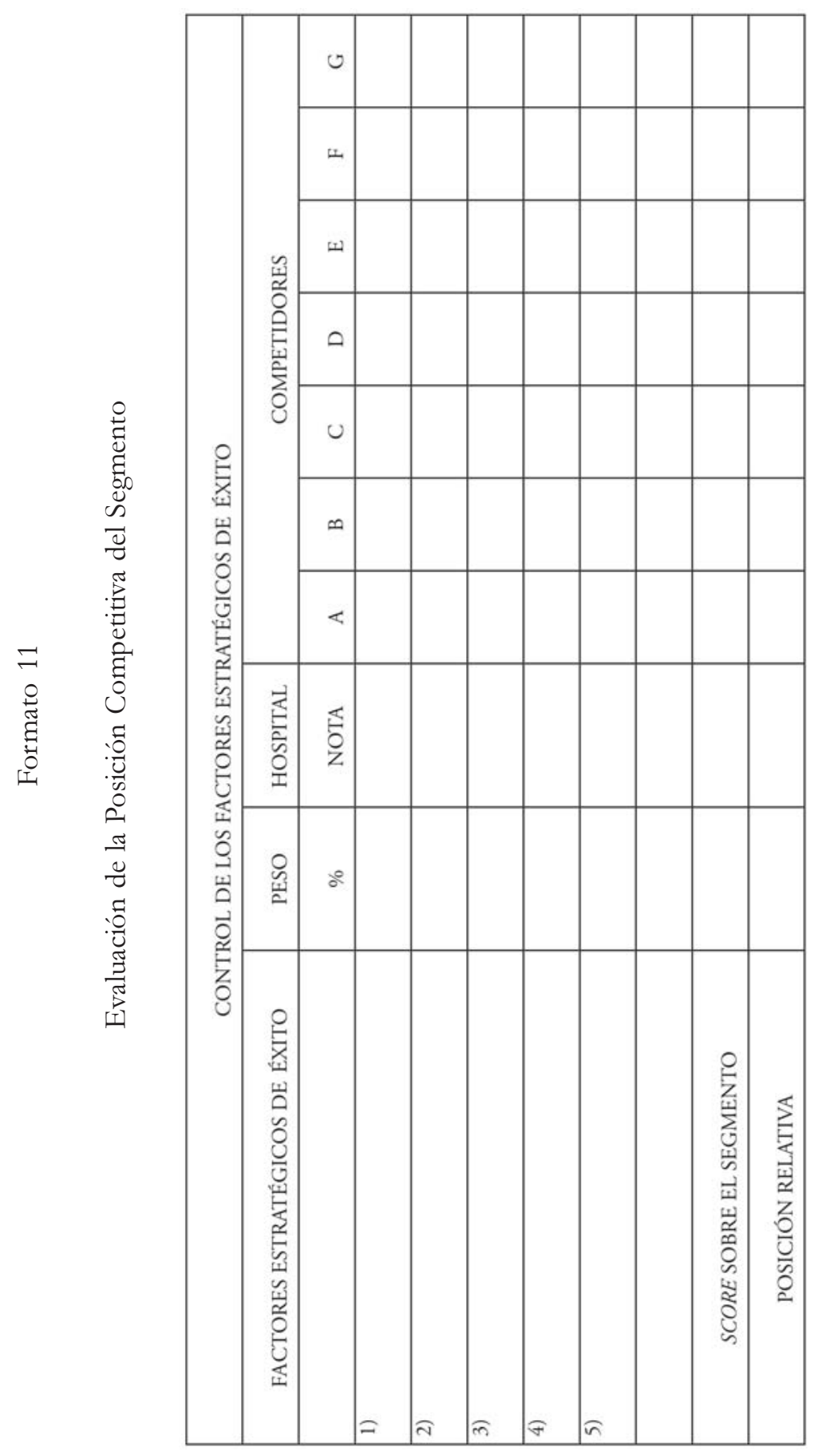

0
0
0
$:$
0
है
0 
Formato 12

Portafolio de Actividades

Servicio o Especialidad

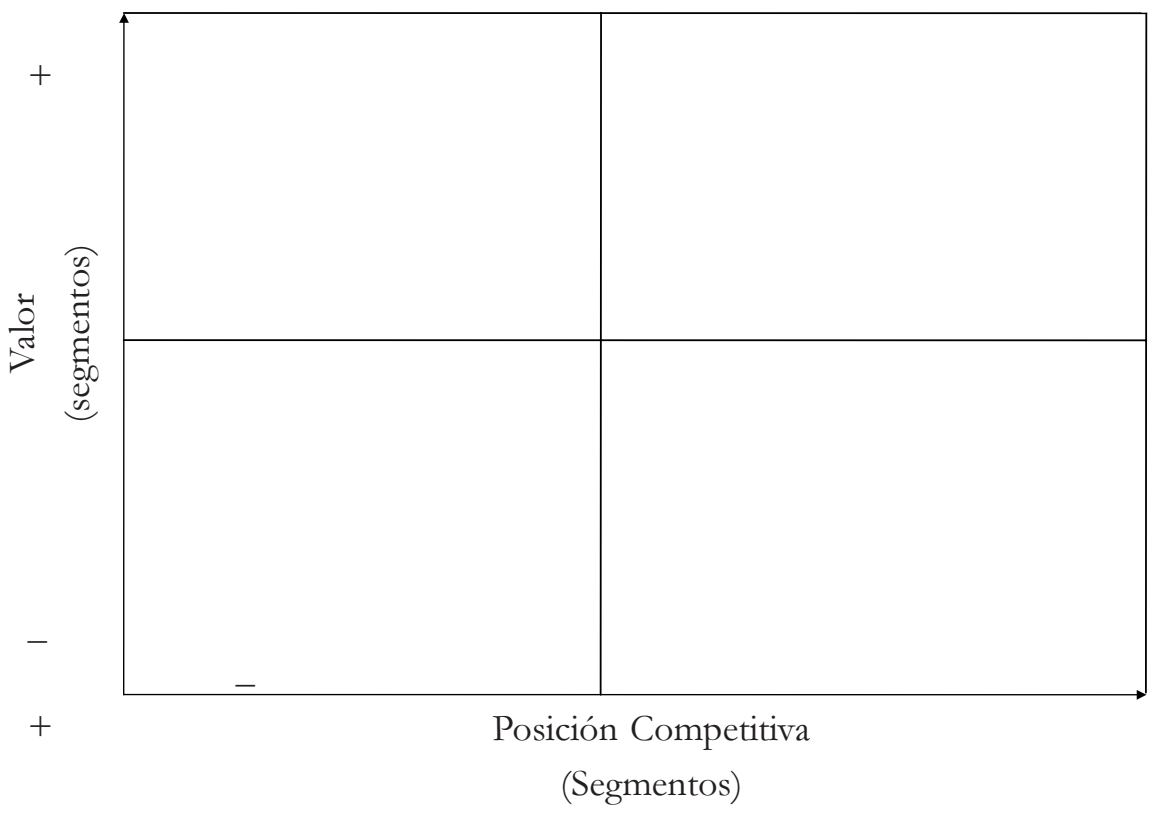


Formato 13

Estrategia de Actuación (Objetivos)

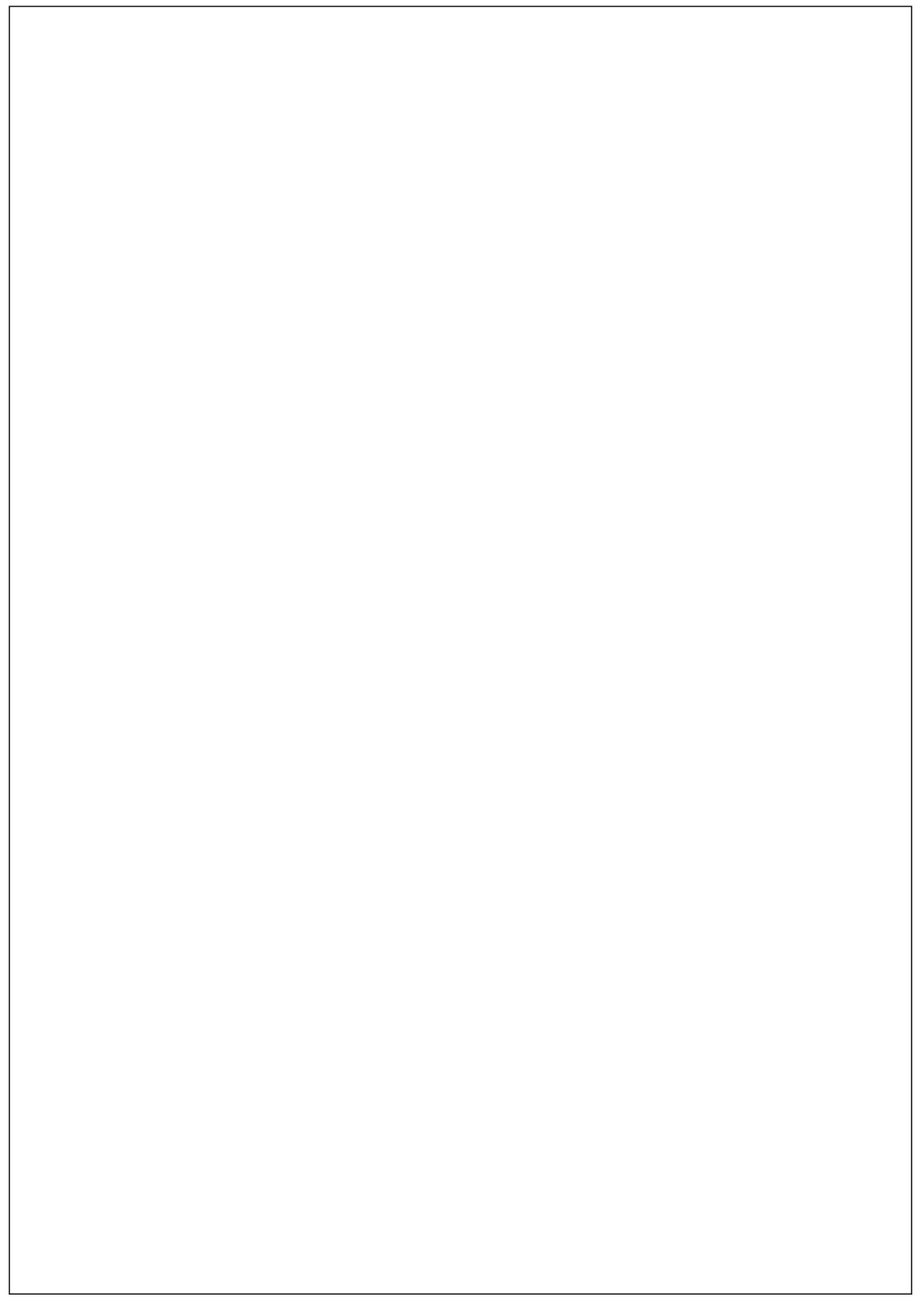




$$
\overline{I I I I}
$$


Formato: $16 \times 23 \mathrm{~cm}$

Tipologia: Garamond

Papel: Pólen Bold $70 \mathrm{~g} / \mathrm{m}^{2}$ (cuerpo del libro) y Supremo $250 \mathrm{~g} / \mathrm{m}^{2}$ (portada)

Fotolitos: Laserfilm (cuerpo del libro)

Engenho e Arte Editoração Ltda. (portada)

Impresión y acabamiento: Imprinta Express Gráfica e Editora Ltda.

Rio de Janeiro, agosto del 2006.

Caso no encuentre nuestros títulos en librerías,

entre en contacto con la EDITORA FIOCRUZ:

Av. Brasil, 4036 - 1ํandar - sala 112 - Manguinhos

21040-361 - Rio de Janeiro - RJ

Tel.: +55 21 3882-9039 e 3882-9041

Telefax: +55 21 3882-9006

e-mail: editora@fiocruz.br

http://www.fiocruz.br/editora 